October 2003 - NREL/SR-520-34822

\title{
High Efficiency Thin Film CdTe and a-Si Based Solar Cells
}

\author{
Final Technical Report \\ 4 March 1998-15 October 2001
}
A.D. Compaan, X. Deng, and R.G. Bohn University of Toledo
Toledo, Ohio

National Renewable Energy Laboratory

1617 Cole Boulevard

Golden, Colorado 80401-3393

NREL is a U.S. Department of Energy Laboratory

Operated by Midwest Research Institute $\bullet$ Battelle $\bullet$ Bechtel

Contract No. DE-AC36-99-G010337 


\title{
High Efficiency Thin Film CdTe and a-Si Based Solar Cells
}

\author{
Final Technical Report \\ 4 March 1998-15 October 2001
}

\author{
A.D. Compaan, X. Deng, and R.G. Bohn \\ University of Toledo \\ Toledo, Ohio
}

NREL Technical Monitor: B. von Roedern

Prepared under Subcontract No. ZAF-8-17619-14

National Renewable Energy Laboratory

1617 Cole Boulevard

Golden, Colorado 80401-3393

NREL is a U.S. Department of Energy Laboratory

Operated by Midwest Research Institute • Battelle • Bechtel

Contract No. DE-AC36-99-G010337 
This publication was reproduced from the best available copy Submitted by the subcontractor and received no editorial review at NREL

\section{NOTICE}

This report was prepared as an account of work sponsored by an agency of the United States government. Neither the United States government nor any agency thereof, nor any of their employees, makes any warranty, express or implied, or assumes any legal liability or responsibility for the accuracy, completeness, or usefulness of any information, apparatus, product, or process disclosed, or represents that its use would not infringe privately owned rights. Reference herein to any specific commercial product, process, or service by trade name, trademark, manufacturer, or otherwise does not necessarily constitute or imply its endorsement, recommendation, or favoring by the United States government or any agency thereof. The views and opinions of authors expressed herein do not necessarily state or reflect those of the United States government or any agency thereof.

Available electronically at http://www.osti.gov/bridge

Available for a processing fee to U.S. Department of Energy and its contractors, in paper, from:

U.S. Department of Energy

Office of Scientific and Technical Information

P.O. Box 62

Oak Ridge, TN 37831-0062

phone: 865.576 .8401

fax: 865.576.5728

email: reports@adonis.osti.gov

Available for sale to the public, in paper, from:

U.S. Department of Commerce

National Technical Information Service

5285 Port Royal Road

Springfield, VA 22161

phone: 800.553 .6847

fax: 703.605.6900

email: orders@ntis.fedworld.gov

online ordering: http://www.ntis.gov/ordering.htm 


\section{SUMMARY}

This is the final report covering approximately 42 months of this subcontract for research on high efficiency CdTe-based thin-film solar cells and on high efficiency a-Si-based thin-film solar cells. Phases I and II have been extensively covered in two Annual Reports. For this Final Report, highlights of the first two Phases will be provided and then detail will be given on the last year and a half of Phase III.

The effort on CdTe-based materials is led by Prof. Compaan and emphasizes the use of sputter deposition of the semiconductor layers in the fabrication of CdS/CdTe cells. The effort on high efficiency a-Si materials is led by Prof. Deng and emphasizes plasma-enhanced chemical vapor deposition for cell fabrication with major efforts on triple-junction devices.

Major accomplishments for the a-Si group during Phase I, Phase II and Phase III are:

Phase I:

- Established a base line for the fabrication of a-Si based solar cells with single, tandem and triple junction structures.

- Achieved the fabrication of a-Si/a-SiGe/a-SiGe triple-junction solar cells with an initial efficiency of $9.7 \%$ during the second quarter, and $10.6 \%$ during the fourth quarter.

- After 1166 hours of light soaking under 1 sun light intensity at $50^{\circ} \mathrm{C}$, these $10.6 \%$ solar cells have stabilized at approximately $9 \%$.

- Fabricated wide bandgap a-Si top cells. The highest $\mathrm{V}_{\mathrm{oc}}$ achieved for our single-junction top cell was $1.02 \mathrm{~V}$. Top cells with high FF (up to 74\%) were fabricated routinely.

- High quality narrow bandgap a-SiGe solar cells with $8.3 \%$ efficiency were fabricated.

- Bandgap graded buffer layers were found to improve the performance $\left(\mathrm{V}_{\mathrm{oc}}\right.$ and $\left.\mathrm{FF}\right)$ of the narrow bandgap a-SiGe bottom cells.

- Studied the sputter deposition of ITO films for the top electrode on a-Si cells and found that a small amount of oxygen partial pressure $\left(\sim 2 \times 10^{-5}\right.$ Torr $)$ was beneficial for growing high quality films from ITO targets.

- Collaborated with various team members including ECD, United Solar, Univ. of North Carolina, UCLA and SUNY-Buffalo.

Phase II:

- Comparatively studied the performance of a-SiGe solar cells and properties of a-SiGe single layer films deposited using a wide range of $\mathrm{H}$ dilution

- Comparatively studied the performance of a-SiGe solar cells and properties of a-SiGe single layer films with different Ge contents

- Fabricated a-Si based solar cells on ultra-thin stainless steel substrate (7.5 micron) and obtained equivalent performance and yield as on the regular SS substrates (127 micron)

- Comparatively studied the performance of a-Si based solar cells on SS substrates and on $\mathrm{SnO}_{2}$ coated glass substrates.

- Studied the performance of p-layers deposited under various deposition conditions for n-i-p type solar cells.

- Performed an analysis for the component cell current matching within a triple-junction solar cell. 
Phase III:

- Achieved triple cells with $12.7 \%$ initial efficiency, which is the highest achieved by any academic group in the world for a-Si/a-SiGe/a-SiGe triple junction solar cells. When measured at NREL, these triple cells show $11.8 \%$ initial total-area efficiency or $12.5 \%$ initial active-area efficiency.

- Conducted light soaking stability test for these UT fabricated triple-junction solar cells and obtained $10.7 \%$ stable cells after 1000 hours of 1 -sun light soaking at 50C.

- Fabricated dozens of triple junction solar cells with improved component cells, with all of the triple cells reaching initial active-area efficiency more than $11 \%$ when measured with UT simulator.

- Studied the dependence of triple cell measurement on light spectrum.

- Modified our multi-chamber PECVD system to convert the load chamber to a deposition chamber for n-layers

- Achieved high performance top cells with $\mathrm{Voc}=1.036 \mathrm{~V}$ and $\mathrm{FF}=72.5 \%$

- Achieved much improved middle cells with $\mathrm{Voc}=0.805 \mathrm{~V}, \mathrm{Jsc}=14.8 \mathrm{~mA} / \mathrm{cm}^{2}$, and $\mathrm{FF}=65.1 \%$, with an initial efficiency of $7.7 \mathrm{~mA} / \mathrm{cm}^{2}$ for cells deposited on SS without BR

- Achieved much improved bottom cells with $\mathrm{Voc}=0.596 \mathrm{~V}, \mathrm{Jsc}=23.3 \mathrm{~mA} / \mathrm{cm}^{2}$ and $\mathrm{FF}=60.2 \%$, with an initial efficiency of $8.4 \%$ for cells deposited on SS with BR

- Improved component cells including top, middle and bottom cells. Performed stability test for these improve component cells.

- Achieved stabilized top cells with 6\% efficiency (0.98V Voc, $9.2 \mathrm{~mA} / \mathrm{cm} 2 \mathrm{Jsc}$ and 67\% FF) for cells on stainless steel without back-reflector

- Achieved stabilized middle cell with $6.4 \%$ stable efficiency when deposited on bare SS and $8.3 \%$ stable efficiency when deposited on SS with back-reflector.

- Achieved stabilized bottom cell with 5.5\% stable efficiency when deposited on bare SS and $7.5 \%$ stable efficiency when deposited on SS with back-reflector; Reduced the degradation of the bottom cell to be around 10\% after 1000 hours of light soaking.

- Constructed a novel hot-wire deposition system, which is used to 1) grow high quality a-Si and a-SiGe alloys at high rates and 2) grow large-grain poly-Si films as the narrow bandgap absorber layer.

- Fabricated a-Si n-i-p solar cells using a novel hot-wire deposition system.

- Studied HW CVD growth of mc-Si and a-Si films at different filament temperature and substrate temperatures; Observe that higher filament temperature and lower substrate temperature favor microcrystalline formation.

- Studied the dependence of growth of $\mu \mathrm{c}-\mathrm{Si}$ and a-Si on the gas flows in HW CVD process; Found that during the initial deposition on quartz substrate, samples with $\mathrm{Si}_{2} \mathrm{H}_{6}$ and $\mathrm{H}_{2}$ from separate inlet (one through filament and one without) show microcrystalline structure while samples with both gases from the same inlet (through the filament or without) show amorphous structure; and 2) During the final stage of deposition (after 30min), all samples show microcrystalline structure.

- Upgraded our PECVD deposition system to include VHF deposition process.

- Fabricated single junction n-i-p solar cells using i-layer deposited with $80 \mathrm{MHz}$ VHF plasma at a deposition rate of $12 \mathrm{~A} / \mathrm{s}$. 
- Deposited middle and bottom a-SiGe cells with the i-layer deposition rate around 10A/s. Fabricated triple-junction a-Si/a-SiGe/a-SiGe solar cells with all i-layers deposited using VHF plasma.

- Calibrated Solar Simulator Intensity; Improved the accuracy of IV measurement by using a stainless steel mask during IV test.

- Reduced the noise and fluctuations in the IV measurements leading to improved reproducibility and accuracy; Reduced the impact of external series resistance for IV measurement using a four-probe source meter

- Studied the effect of sample heating during IV scans

- Designed a new ITO/Grids pattern to reduce grid coverage loss using a two-step lithography for making the ITO and grid patterns

- Used AMPS program to model the roles of p-type hydrogenated microcrystalline silicon (p$\mu \mathrm{c}-\mathrm{Si}: \mathrm{H})$ with a wide bandgap range of 1.5 to $2.0 \mathrm{eV}$

- Analyzed the effects of the energy band offset at the interface between p- $\mu c-S i$ and i-a-Si or a-SiGe on the performances of the solar cells

- Explained the IV curve rollover when there is a mismatch in the Ec at the p-i interface

Major accomplishments for the CdTe group include the following:

Phase I:

- We constructed a second dual magnetron sputter deposition facility that is being used for ZnTe depositions.

- We have optimized reactive sputtering for ZnTe:N films to achieve $10 \Omega$-cm resistivity and $\sim 9 \%$ efficiency cells with a copper-free ZnTe:N/Ni contact. (Now reaching $\sim 5 \Omega-\mathrm{cm}$.)

- We identified Cu-related photoluminescence features and studied their correlation with cell performance including their dependence on temperature and E-fields.

- We studied band-tail absorption in $\mathrm{CdS}_{\mathrm{x}} \mathrm{Te}_{1-\mathrm{x}}$ alloy films at $10 \mathrm{~K}$ and $300 \mathrm{~K}$,

- We collaborated with the National CdTe PV Team on 1) studies of high resistivity tin oxide layers from ITN Energy Systems, 2) fabrication of cells on the HRT layers with 0, 300, \& $800 \mathrm{~nm}$ CdS, and 3) preparation of ZnTe:N-based contacts on First Solar's Vapor Transport Deposited (VTD) CdTe material for stress testing.

- We collaborated with 1) Brooklyn College for ellipsometry studies of $\mathrm{CdS}_{\mathrm{x}} \mathrm{Te}_{1-\mathrm{x}}$ alloy films, and 2) the U. of Buffalo/Brookhaven NSLS for synchrotron x-ray fluorescence studies of interdiffusion in $\mathrm{CdS} / \mathrm{CdTe}$ bilayers.

Phase II:

- We implemented a diode-array spectrograph system and utilized optical emission spectroscopy to help optimize the reactive sputtering of N-doped ZnTe for CdTe back contact structures.

- We identified the photoluminescence signatures of various defect states in CdTe related to $\mathrm{Cd}$ vacancies, $\mathrm{Cu}_{\mathrm{Cd}}$ acceptors, $\mathrm{Cu}-\mathrm{V}_{\mathrm{Cd}}$ complexes and donor-acceptor pairs, and related these states to instabilities in the hole concentration at room temperature.

- In $\mathrm{CdS}$, we showed that $\mathrm{Cu}$ is an important non-radiative center reducing the PL efficiency. 
- We studied band tailing in CdS weakly alloyed with CdTe and CdTe weakly alloyed with CdS.

- We fabricated superstrate ITO/CdS/CdTe cells on Mo substrates with efficiencies above $7.5 \%$.

- We collaborated in studies of Extended X-ray Absorption Fine Structure (EXAFS) of Cu in $\mathrm{CdTe}$ which indicate a $\mathrm{Cu}-\mathrm{Te}$ bond length of $2.62 \mathrm{~A}$ or $6.7 \%$ shorter than the CdTe bond in agreement with calculations of Wei, et al.

- We provided assistance to two groups on laser scribing.

Phase III:

- We have studied bias-dependent junction photoluminescence (PL) in CdTe cells and showed that by applying external bias to reduce the strong electric field at the junction, PL becomes even more sensitive to degradation mechanisms in these polycrystalline films.

- We have begun electroluminescence (EL) studies of CdTe cells showing that the spectra are very similar to that of PL and that EL intensities are also very sensitive to degradation mechanisms since the junction field is suppressed near open circuit and above.

- With diode laser excitation, we showed that PL studies and PL excitation studies could help identify near-band-edge defect states in CdTe and the effect of copper impurities in $\mathrm{CdCl}_{2}$ used for vapor treatments.

- We determined the effect of CdTe thickness on cell performance and stability, showing that cell performance $\left(\mathrm{V}_{\mathrm{OC}}, \mathrm{J}_{\mathrm{SC}}\right.$, and $\left.\mathrm{FF}\right)$ degrades only gradually from $3.0 \mu \mathrm{m}$ to $0.75 \mu \mathrm{m}$ of CdTe and that stability under warm light soak is almost unchanged. We fabricated a $9 \%$ cell with $0.75 \mu \mathrm{m}$ of sputtered CdTe without using a high resistivity buffer layer.

- We lowered the resistivity of reactively sputtered ZnTe:N to $\sim 5 \Omega$-cm partly with the help of optical spectra from the plasma and the identification of $\mathrm{N}_{2}$ ro-vibrational bands.

- We collaborated with IEC for AFM, ellipsometry, and XRD analysis of the ZnTe:N films.

- We used magnetron sputtering to sputter $\mathrm{Ni}_{2.5} \mathrm{P}$ contacts onto CdTe and determined their stability under light soak at $\mathrm{V}_{\mathrm{OC}}$ for up to 285 days.

- We continued studies of substrate structure CdTe cells on molybdenum and stainless steel sheet, using either ITO or $\mathrm{ZnO}: \mathrm{Al}$ for top contacts.

- In two on-going studies, we used ion implantation to help identify impurity features in PL spectra and found evidence that sodium diffusing into CdTe films from soda-lime glass substrates enhances some donor-acceptor pair features in the PL spectra. 


\section{TABLE OF CONTENTS}

$\underline{\text { Page }}$

Summary iii

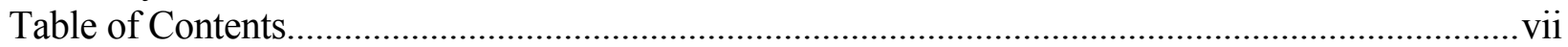

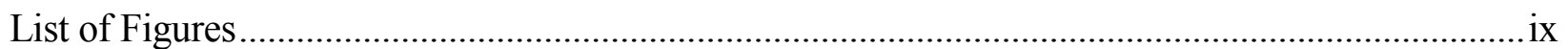

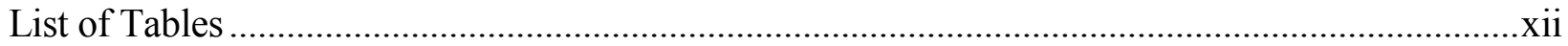

1. Introduction

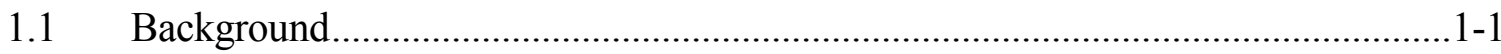

1.2 Technical Approach

1.2.1 Cadmium Telluride-Based Cells..............................................................1-1

1.2.2 Amorphous-Silicon-Based Cells ..............................................................1-1

1.2.3 Characterization Tools ………………...............................................1-2

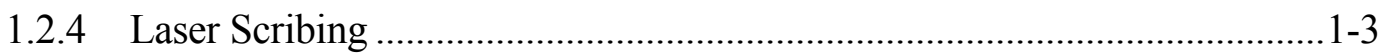

2.0 Amorphous silicon related materials and devices

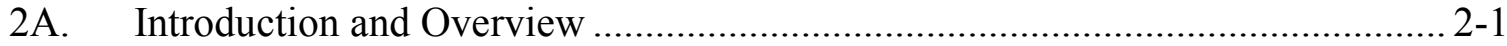

2B. Improved IV measurement and calibration................................................. 2-3

2C. Study of various $\mathrm{p}$-layer deposition conditions for $\mathrm{SS} / \mathrm{n}$-i-p/ITO solar cells ...... 2-7

2D. Optimization of wide-bandgap a-Si top cell ……........................................ 2-10

2E. Optimization of a-SiGe middle and bottom cells .......................................... 2-14

2F. Comparison Study of a-SiGe Solar Cells and Materials Deposited Using Different Hydrogen Dilution........................................................................... 2-16

2G. Comparison study of a-SiGe films and n-i-p devices with different $\mathrm{Ge}$ content in the i-layer ............................................................................ 2-25

2H. Effect of Bandgap Graded Buffer Layer for Narrow Bandgap a-SiGe Cells .... 2-37

2I. Comparison study of a-Si and a-SiGe solar cells on glass and stainless steel... 2-42

2J. Comparison of n-i-p and $\mathrm{p}-\mathrm{I}-\mathrm{n}$ solar cells with the same I-layers...................... 2-43

2K. Stability results of improved component cells................................................ 2-45

2L. Fabrication of high efficiency triple-junction a-Si solar cells .......................... 2-46

2M. Novel hot-wire deposition employing a coiled hot filament ............................. 2-53

2N. VHF deposition of single and triple-junction solar cells .................................. 2-59

2O. Amorphous silicon solar cells deposited on ultra-thin SS substrate .................. 2-61

2P. AMPS Modeling of Nanocrystalline Si p-Layer in a-Si NIP Solar Cells.......... 2-65

2Q. Sputter Deposition of ITO ..................................................................... 2-71

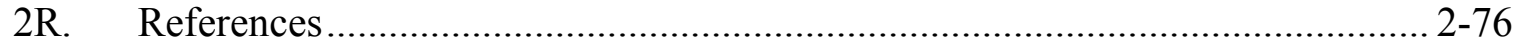

3.0 CdTe-related materials and devices

3. Overview of the CdTe-related accomplishments during Phase III............................3-1

3.1 Bias-dependent junction PL studies of CdTe cells .................................................3-2

3.2 Electroluminescence studies of CdTe cells ............................................................3-7

3.3 Diode laser PL studies of $\mathrm{CdTe}$ and the effect of $\mathrm{CdCl}_{2}$ treatments.......................3-11

3.4 Substrate configuration CdTe cells on molybdenum sheet......................................3-16

3.5 Effect of CdTe thickness on efficiency and stability of CdS/CdTe cells ................3-20

3.6 Nitrogen-doped ZnTe by reactive magnetron sputtering........................................3-26

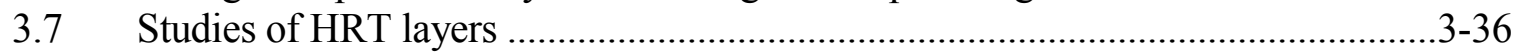

3.8 Effects of $\mathrm{Na}$ on PL from CdTe layers...............................................................3-42

3.9 Preliminary results on PL from ion-implanted CdTe .............................................. 
3.10 Studies of sputtered $\mathrm{Ni}_{\mathrm{x}} \mathrm{P}$ as a Cu-free back contact for $\mathrm{CdTe}$ cells .........................4-46

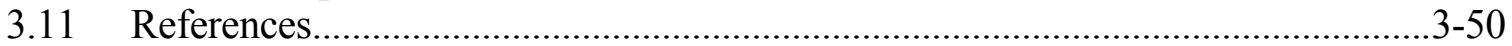

4.0 Publications

4.1 Refereed papers published or in press $(3 / 98-10 / 01) \ldots \ldots \ldots \ldots \ldots \ldots \ldots \ldots \ldots \ldots \ldots \ldots \ldots \ldots \ldots . . .4-1$

4.2 Annual Subcontract Reports..............................................................................4-2

4.3 Annual Contract Summary published in U.S. Dept. of Energy

Photovoltaic Energy Program Contract Summary,

FY 1999 [DOE/GO-102000-0976]

5.0 Project Personnel

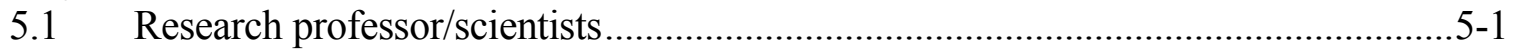

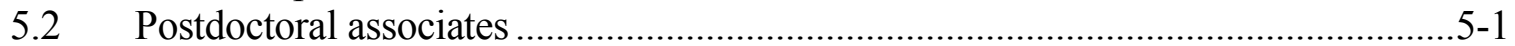

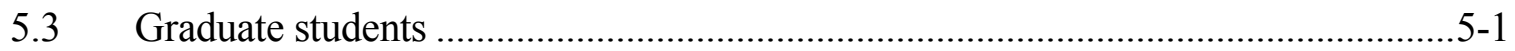

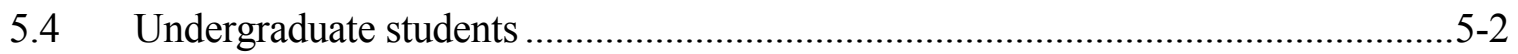

$5.5 \quad$ Technical assistants ..................................................................................... 


\section{LIST OF FIGURES}

Figure 2A-1 Schematics of the single-junction (a) and triple-junction (b) structures of a-Si

solar cell devices fabricated in this program................................................ 2-1

Figure 2A-2 UT's multi-chamber, loaded-locked, PECVD system used for the a-Si solar cell fabrication.

Figure 2B-1

IV curve of a single junction solar cell measured with and without using a Keithley source meter ........................................................................... 2-4

Figure 2B-2 IV curves of a sample GD581 with different incremental voltage steps ............ 2-5

Figure $2 \mathrm{~B}-3$ IV curves near the $\mathrm{V}_{\mathrm{oc}}$ point for a sample measured with different incremental

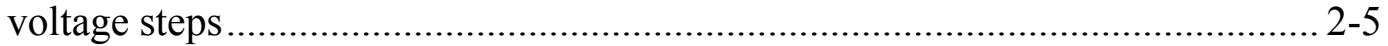

Figure 2B-4 Pattern of ITO and grids with old (a) and new (b) ITO/grids design ................ 2-6

Figure 2C-1 QE curves of $n-i-p$ solar cells with different $p$-layers ....................................... 2-8

Figure 2C-2 QE curves of one sample (GD411) measured under different biases ................. 2-8

Figure 2D-1 SIMS profiles of a p-i-n structure before we install separate deposition chambers for the doped layers............................................................................... 2-10

Figure 2D-2 IV curve of an optimized top cell with $\mathrm{V}_{\mathrm{oc}}=1.035 \mathrm{~V}, \mathrm{~J}_{\mathrm{sc}}=7.97 \mathrm{~mA} / \mathrm{cm}^{2}$ and

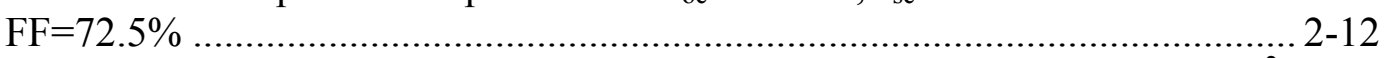

Figure 2E-1 QE curve of a-SiGe bottom cell, showing integrated current of $22.2 \mathrm{~mA} / \mathrm{cm}^{2} .2-15$

Figure 2F-1 Results of $\mathrm{H}$ effusion experiments performed under differential pumping. Total $\mathrm{H}$ content is the area under the curve. Spectra are shifted vertically for clarity ......................................................................................... 2-19

Figure 2F-2 The graph shows the Raman spectra of sample GD424, GD449 and GD450 on 7059 glass.

Figure 2F-3 This figure shows the Raman spectra measured from the surface of the cell samples of GD451 $(\mathrm{R}=180)$ and GD452 $(\mathrm{R}=240)$ on stainless steel substrate.. 2-22

Figure 2G-1 Transmission spectrum of a typical a-SiGe film (GD357) ........................... 2-27

Figure 2G-2 Refractive index as a function of $1 / \lambda^{2}$.................................................... 2-27

Figure 2G-3 Tauc plot, $(\alpha \mathrm{h} v)^{1 / 2}$ vs $\mathrm{h}$ (, used to determine the bandgap $\mathrm{E}_{\mathrm{g}}$........................... 2-28

Figure 2G-4 The bandgap $\mathrm{E}_{\mathrm{g}}$ of a-SiGe films as a function of $\mathrm{GeH}_{4}$ and $\mathrm{Si}_{2} \mathrm{H}_{6}$ gas ratio during deposition ................................................................................ 2-28

Figure 2G-5 Ge content estimated from the bandgap................................................ 2-29

Figure 2G-6 FTIR spectra of a-SiGe films with different Ge content................................. 2-30

Figure 2G-7 FTIR spectra in the $420-850 \mathrm{~cm}^{-1}$ range, showing the wagging mode of $\mathrm{Si}-\mathrm{H}\left(640 \mathrm{~cm}^{-1}\right)$ and $\mathrm{Ge}-\mathrm{H}\left(560 \mathrm{~cm}^{-1}\right)$.

Figure 2G-8 FTIR spectra in the $1800-2200 \mathrm{~cm}^{-1}$ range, showing the stretching mode of $\mathrm{Si}-\mathrm{H}\left(2000 \mathrm{~cm}^{-1}\right), \mathrm{Si}-\mathrm{H}_{2}\left(2100 \mathrm{~cm}^{-1}\right)$ and $\mathrm{Ge}-\mathrm{H}_{2}\left(1975 \mathrm{~cm}^{-1}\right) \ldots \ldots \ldots \ldots \ldots \ldots \ldots \ldots . . . . .2-31$

Figure 2G-9 Photosensitivity of a-SiGe films as a function of a-SiGe bandgap for this series of a-SiGe films.

Figure 2G-10 J-V curve of a representative cell (GD435) among the series, which is similar to the bottom cell in a triple-cell ............................................................. 2-33

Figure 2G-11 Quantum efficiency of a-SiGe solar cells with different Ge content............... 2-34

Figure 2G-12 Current integrated from QE for a-SiGe cells, deposited on bare SS, with different bandgaps

Figure 2G-13 Fill factor before light soaking for a-SiGe devices with different Ge ............. 2-36

Figure 2G-14 Degradation of FF for devices with different Ge...................................... 2-36 
Figure 2H-3 (a) (b) and (c) Schematic layer structure diagram of a-SiGe solar cells with different interfacial buffer layers .................................................................... 2-38

Figure 2H-4 Illuminated J-V characteristics of GD180 and GD209 samples...................... 2-39

Figure 2H-5 Quantum efficiency curves of a-SiGe solar cells. ....................................... 2-39

Figure 2H-6 $\mathrm{I}_{\mathrm{sc}}$ versus $\mathrm{V}_{\mathrm{oc}}$ under various light intensity for samples GD180 (solid circle) and GD209 (open circle) .............................................................................. 2-41

Figure 2J-1 Device structures of (a) n-i-p type cell and (b) p-i-n type cell used in this comparative study ................................................................................... 2-43

Figure 2J-2 IV performance of nip type solar cells with p-layers deposited at different temperatures ............................................................................... 2 2-44

Figure 2J-3 IV curves of pin solar cells with p-layers deposited at different temperatures.. 2-44

Figure 2L-1 IV curve of GD585, showing 12.7\% initial, active-area efficiency................. 2-47

Figure 2L-2 Quantum efficiency curve of 12.7\% cell (GD585) showing the QE for top, middle and bottom cells. The Figure 2L-also shows the short circuit current under UT simulator and AM1.5 spectra ................................................... 2-48

Figure 2L-3 Irradiation spectra of UT Xenon simulator and AM1.5 global........................ 2-49

Figure 2L-4 IV curve of GD585 measured at NREL, showing 11.8\% initial, total-area efficiency................................................................................................ 2-51

Figure 2L-5 IV curve of a triple cell measured after 1000 hours of 1-sun light soaking at 50C, showing 10.7\% stable efficiency ..................................................... 2-52

Figure 2M-1 A schematic of the new HW chamber, showing the gas confining cup, gas flow pattern, the coil filament, rf electrode and some other details................. 2-53

Figure 2M-2 I-V of a-Si solar cell gd508-m, whose i-layer deposited using the new hot-wire chamber at a high deposition rate................................................ 2-55

Figure 2M-3 Raman scattering for the hot-wire films in the range of $400-550 \mathrm{~cm}^{-1} \ldots \ldots \ldots \ldots .2-56$

Figure 2M-4 Raman scattering measured from the front side of the samples ....................2 2-57

Figure 2M-5 Raman scattering measured from the back side through the quartz substrates.. 2-58

Figure $2 \mathrm{~N}-1$ IV curve of a single-junction solar cell with the i-layer deposited at $12 \AA / \mathrm{s}$ using VHF plasma at 80 MHz excitation................................................... 2-59

Figure 2N-2 IV curve of a triple-junction a-Si/a-SiGe/a-SiGe solar cell with all of the i-layers deposited using VHF plasma at high rates........................................ 2-60

Figure 2O-1 J-V curves of two representative a-Si solar cells deposited on 7.5 $\mathrm{m}$ ultra-thin SS substrate and $127 \mu \mathrm{m}$ thick standard SS substrate ................................... 2-63

Figure 2P-1 I-V curves of a-SiGe middle cells with p-layer deposited at different temperatures, $\mathrm{T}_{\mathrm{s}}(\mathrm{p})=70{ }^{\circ} \mathrm{C}$ for GD554 and $\mathrm{T}_{\mathrm{s}}(\mathrm{p})=140{ }^{\circ} \mathrm{C}$ for GD572 ............ 2-68

Figure $2 \mathrm{P}-2 \mathrm{~b}$ The calculated dark and illuminated $\mathrm{J}-\mathrm{V}$ characteristics for mid bandgap cells

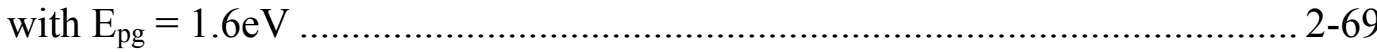

Figure 2P-3 The calculated thermodynamic equilibrium energy diagrams for the mid cell p-i-n structures shown in Figure 2P-2a and 2b. ......................................... 2-69

Figure 2P-4 The simulated light I-V characteristics for mid cells with different $\varphi_{\mathrm{B} 0} \ldots \ldots \ldots . .2-70$

Figure 2Q-1 Thickness of ITO films as a function of the $\mathrm{rf}$ power.................................. 2-73

Figure 2Q-2 Effective sheet resistance $\mathrm{R}^{*}$ as a function of $\mathrm{rf}$ power for various temperature

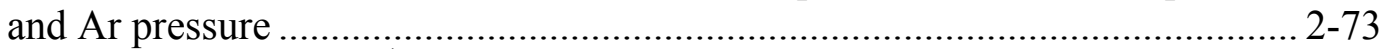

Figure 2Q-3 Effective absorption $\mathrm{A}^{*}$ of ITO films as a function of rf power for various deposition temperature and Ar pressure 
Figure 3-1

Figure 3-2

Figure 3-3

Figure 3-4

Figure 3-5

Figure 3-6

Figure 3-7

Figure 3-8

Figure 3-9

Figure 3-10

Figure 3-11

Figure 3-12

Figure 3-13

Figure 3-14

Figure 3-15

Figure 3-16

Figure 3-17

Figure 3-18

Figure 3-19

Figure 3-20

Figure 3-21

Figure 3-22

Figure 3-23

Figure 3-24

Figure 3-25

Figure 3-26

Figure 3-27

Figure 3-28

Figure 3-29

Figure 3-30

Figure 3-31

Figure 3-32

Figure 3-33

Figure 3-34

Figure 3-35

Figure 3-36

Figure 3-37

Figure 3-38

Figure 3-39

Figure 3-40

Figure 3-41

Figure 3-42

Figure 3-43

Figure 3-44

Figure 3-45

Figure 3-46

Figure 3-47
Total junction PL at room temperature vs. bias voltage $3-2$ Integrated PL signal at room temperature vs. excitation power ....................... 3-3 Sketch of glass-side excitation geometry and the internal electric field.............. 3-4 Spatial dependence of carrier generation ...................................................... 3-5

Fit of bias dependence of the PL signal ................................................... 3-5

E-field according to AMPS-1D ..................................................................... 3-5

Bias PL spectra from unstressed VTD CdS/CdTe junction................................ 3-6

EL and PL spectra obtained from a VTD cell ................................................ 3-7

EL and PL spectra from a magnetron sputtered cell...................................... 3-7

Integrated EL intensity (through triple spectrometer) ................................. 3-8

Square root of electroluminescence vs. current with least squares fit ................ 3-9

Room temperature EL from a magnetron sputtered cell................................ 3-10

Dependence of $1.5 \mathrm{eV}$ PL intensity on excitation energy .............................. 3-12

$10 \mathrm{~K}, 1.581 \mathrm{eV}$ excited PL spectrum of CdTe as grown, and annealed ............. 3-13

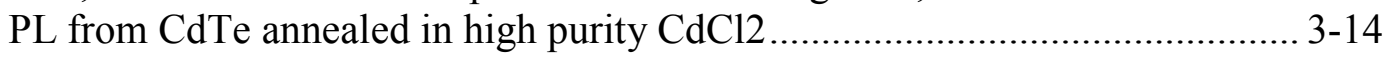

PL from as-grown $\mathrm{CdTe}, \mathrm{CdTe}: \mathrm{Cu}$, and $\mathrm{CdTe}$.......................................... 3-15

The structure of our best substrate solar cell ................................................. 3-17

Comparison of the QE curves of the substrate and superstrate cells ................ 3-18

QE curves of substrate cells with different CdS thicknesses .......................... 3-18

IV curve of a typical substrate cell ............................................................. 3-19

Optical transmission through uncontacted cell structure ............................... 3-21

X-ray diffractogram of cells with different CdTe thicknesses........................ 3-21

QEs for cells with four different CdTe thicknesses ....................................... 3-23

Changes in cell performance vs. CdTe thickness ....................................... 3-24

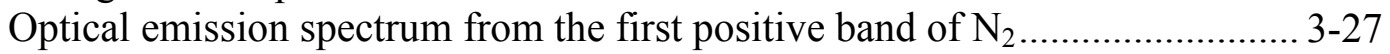

Optical emission spectrum from the second positive band of $\mathrm{N}_{2}$.................. 3-28

Intensities of two Ar and two $\mathrm{N}_{2}$ emission lines vs. distance ......................... 3-28

AFM images of $0.5 \mu \mathrm{m}$ thick films of $\mathrm{ZnTe}$............................................. 3-29

X-ray diffractograms of ZnTe:N films ..................................................... 3-29

Room temperature Raman spectra of films of $\mathrm{ZnTe}: \mathrm{N}$............................... 3-30

Optical transmission of pure ZnTe film and ZnTe:N film............................ 3-31

Resistivity of ZnTe:N films vs. $\mathrm{N}_{2} /\left(\mathrm{Ar}+\mathrm{N}_{2}\right)$ fraction .................................. 3-31

$\mathrm{I}-\mathrm{V}$ at one sun for cells with ZnTe:N/Ni back contact................................. 3-33

Stability for $\mathrm{ZnTe}: \mathrm{N} / \mathrm{Ni}$ and $\mathrm{Cu} / \mathrm{Au}$ contacts under one-sun light soak............ 3-34

Stability for $\mathrm{ZnTe}: \mathrm{N} / \mathrm{Ni}$ and $\mathrm{Cu} / \mathrm{Au}$ contacts under dark heat ........................ 3-34

Efficiency of several cell contacts with different $\mathrm{ZnTe}: \mathrm{N}$ thicknesses ............. 3-35

QE for cells on TEC-8 with CdS thicknesses indicated ................................ 3-36

QE for cells on TEC-8/HRT with CdS thicknesses indicated ......................... 3-36

Dark \& light J-V curves for cells with different CdS thickness \& substrates ... 3-38

Bias-dependent PL from sputtered cells on TEC-8 and TEC-8/HRT............... 3-39

PL from films on BSG sputtered from three different targets ........................ 3-42

PL from films on SLG sputtered from three different targets ........................ 3-42

PL spectra of CdTe films after diffusion of $\mathrm{NaCl}$.......................................... 3-43

PL from crystalline CdTe and CdTe implanted with $\mathrm{Te}^{4+}$ of different doses.... 3-44

PL from Te-implanted CdTe after various annealings ................................. 3-45

$\mathrm{J}-\mathrm{V}$ curves of NiP-contacted cells; light and dark ....................................... 3-47

$\mathrm{J}-\mathrm{V}$ curves at one-sun for $\mathrm{C} / \mathrm{NiP}$ contacts after various stress times ................ 3-49 


\section{LIST OF TABLES}

Table 2B-1 Device performance of a triple cell (GD581-2) measured with different voltage steps, $5 \mathrm{mV}, 10 \mathrm{mV}, 20 \mathrm{mV}$ and $50 \mathrm{mV}$.............................................. 2-6

Table 2C-1 List of p-layer deposited under different conditions and 400nm QE measured under different electrical bias for n-i-p solar cells with these p-layers.

Table 2D-1 The optimization results for top cells deposited on SS or Back-reflector ......... 2-11

Table 2D-2 Performance of top cells deposited in our lab during the past 3 years .............. 2-13

Table 2E-1 Performance of middle and bottom a-SiGe cells deposited under different

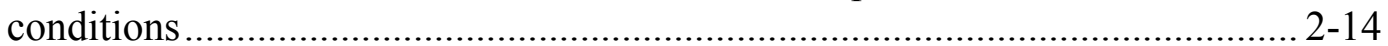

Table 2F-1 Deposition conditions for the single i-layer including process gas flow rates, temperature, radio-frequency power, chamber pressure, and

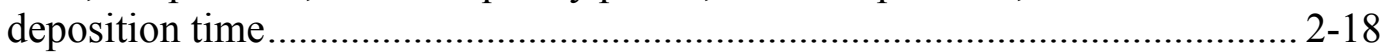

Table 2F-2 Results of measurements on single i-layer films including thickness of film, index of refraction, bandgap, and hydrogen content ................................ 2-18

Table 2F-3 Performance of $n-i-p$ devices made with different $H$ dilution $R$...................... 2-21

Table 2F-4 J-V performance of a-SiGe cells with the a-SiGe i-layer deposited using different grading of H-dilution R....................................................................... 2-23

Table 2G-1 Deposition conditions for a-SiGe films with different Ge contents .................. 2-26

Table 2G-2 Film properties n, d, and Eg for a-SiGe films with different Ge content .......... 2-29

Table 2G-3 Deposition conditions for the i-layers of a-SiGe solar cells ………................... 2-32

Table 2G-4 Performance of a-SiGe devices with different Ge content ............................... 2-34

Table 2H-2 Photovoltaic parameters of solar cells with different buffer layers .................... 2-38

Table 2H-3 a-SiGe solar cell device performance ............................................................. 2-40

Table 2I-1 Comparison of IV performance for a-Si top cell, a-SiGe middle cell and a-SiGe bottom cell deposited on $\mathrm{SnO}_{2}$ coated glass and stainless steel ............ 2-42

Table 2J-1 Summary of IV performance of nip and pin type solar cells with p-layers deposited at different temperatures .................................................................. 2-44

Table 2K-1 IV performance of top, middle and bottom component cells before and after 1000 hours of light soaking under 1 sun intensity at 50C................................ 2-45

Table 2L-1 IV and QE data for the triple-junction solar cells .............................................. 2-46

Table 2L-2 IV data for GD585 measured at UT and NREL ……..................................... 2-50

Table 2L-3 IV data of triple cells degraded under 1 sun light for 1000 hours ..................... 2-52

Table 2M-1 Deposition conditions and Raman results for hot-wire films deposited at different filament temperatures and substrate temperatures .............................. 2-55

Table 2M-2 Deposition conditions and Raman scattering peaks for films deposition in the HW CVD process with different gas flow schemes ................................... 2-57

Table 2O-1 Average I-V performance under AM1.5 illumination and yield information for a-Si solar cells deposited on different thin SS substrates............................. 2-62

Table 2P-1 Parameters used in AMPS modeling ........................................................... 2-66

Table 2P-2 AMPS simulation results for the top cells with different $\mathrm{E}_{\mathrm{gp}}$............................ 2-66

Table 2Q-1 Deposition conditions and quality for ITO films deposited under various sputtering conditions ……............................................................................. 2-72

Table 2Q-2 J-V data of solar cells with ITO deposited from $\operatorname{In}_{2} \mathrm{O}_{3} / \mathrm{SnO}_{2}$ targets having different compositions ................................................................................... 2-74 
Table 3-1 AMPS: General Layer Parameters (Lifetime Model) ..................................... 3-6

Table 3-2 CdTe Thickness in different cells ............................................................. 3-21

Table 3-3 XRD analyses of crystallographic texture and strain.................................... 3-30

Table 3-4 Mobility and carrier concentration of ZnTe:N films ................................ 3-32

Table 3-5 Conductivity activation energies for ZnTe:N films ................................... 3-32

Table 3-6 Average and best cell I-V parameters vs. CdS thickness on TEC-8................ 3-37

Table 3-7 Average and best cell I-V parameters vs. CdS thickness on TEC-8/HRT........ 3-37

Table 3-8 I-V parameters of stressed cells with different CdS thickness ........................ 3-40

Table 3-9 Performance of NiP-contacted cells vs. etch and deposition temperature......... 3-46

Table 3-10 Effect of post-deposition diffusion on NP etched/C/NiP contacts................... 3-47

Table 3-11 Stress data for NP etched, NiP contacts .................................................. 3-48

Table 3-12 Stress data for NP etched, c/NiP contacts .................................................. 3-48 


\section{Introduction}

\subsection{Background}

This annual report covers the third year plus a five-month extension of the current NREL thin-film partnership subcontract with the University of Toledo which supports cell fabrication and related materials studies on two types of thin-film solar cells, CdTe-based and a-Si:H-based.

\subsection{Technical Approach}

\subsubsection{Amorphous-Silicon-Based Cells}

Triple-cell fabrication-One of our focused efforts is to fabricate high efficiency triplejunction a-Si based solar cells. A plasma-enhanced chemical vapor deposition (PECVD) process is used for the deposition of all semiconductor layers. In addition, we have completed the construction of a novel hot-wire deposition system which is accessible from the central load lock together with the two PECVD chambers. Our efforts include the optimization of a-Si and a-SiGe intrinsic layers with improved network ordering, optimization of doped microcrystalline silicon p-layers and amorphous silicon n-layers, optimization of tunnel junctions and interfaces.

Novel processes for high quality narrow-bandgap a-SiGe deposition-Various approaches are used to explore the deposition of narrower-bandgap $(\sim 1.3 \mathrm{eV})$ a-SiGe materials. We have completed the installation of the hot-wire chamber which includes a special design to make a-SiGe alloys with several different gas flow patterns for $\mathrm{Si}_{2} \mathrm{H}_{6}, \mathrm{GeH}_{4}$ and $\mathrm{H}_{2}$ gases.

Non-semiconductor layers - We also optimize the deposition of ITO and other nonsemiconductor layers which are required for the solar cell operation. Interfaces between semiconductor and the non-semiconductor layers, ITO top electrodes and $\mathrm{ZnO}$ back-reflector, are being explored.

\subsubsection{Cadmium Telluride-Based Cells}

Magnetron sputtering-Our CdTe-based effort is focused on the use of rf sputtering for thin film deposition. Much of our effort is designed to exploit the effects of excited state species in the plasma to improve the film growth or lower the growth temperature. The ultimate goal is to fabricate rf sputtered $\mathrm{CdS} / \mathrm{CdTe}$ thin film solar cells with efficiencies exceeding $15 \%$ on sodalime glass. For the $\mathrm{CdS}$ and CdTe deposition, we utilize a specially designed two-gun magnetron sputtering chamber with optical thickness monitors as described previously. A second, similar sputtering chamber is used for deposition of contact structures. In this chamber we presently do reactive sputtering of ZnTe:N. This is one example of utilizing the energy in the sputtering plasma, in this case to dissociate $\mathrm{N}_{2}$ to make atomic $\mathrm{N}$ available for electrically-active incorporation in the film. A third sputtering system is used to extend the range of metals available for contact structures. This dc magnetron sputtering system has been used for the deposition of Ni on top of the ZnTe:N layers.

Pulsed Laser Deposition (PLD) - We have continued to make limited use of PLD as a convenient method for preparation of films with unusual composition. Thus we have prepared additional films of the ternary alloy $\mathrm{CdS}_{\mathrm{x}} \mathrm{Te}_{1-\mathrm{x}}$ and bilayers of $\mathrm{CdS} / \mathrm{CdTe}$ for synchrotron-based experiments with collaborators at the Univ. of Buffalo. 
Post-Deposition Processing - For post-deposition processing of the sputtered films we have now standardized on a vapor $\mathrm{CdCl}_{2}$ treatment and can handle substrate sizes of about threeinch square.

\subsubsection{Characterization Tools}

For characterization of films and cells, we continue to use SEM, EDS, x-ray, Raman, photoluminescence, optical absorption, Hall measurements, C-V, I-V, and QE. We have continued collaborative efforts with Case Western Reserve University for Rutherford Backscattering and XPS measurements, electroluminescence measurements with the University of North Carolina, mobility-lifetime measurements with UCLA, and synchrotron x-ray measurements with the University of Buffalo and Brookhaven National Lab, and ellipsometry with Brooklyn College (CUNY).

\subsubsection{Laser Scribing}

We continue to maintain facilities for making laser scribes on substrates up to $\sim 6$ inch square. Scribing can be done, at either the $1064 \mathrm{~nm}$ or $532 \mathrm{~nm}$ lines, with a cw-lamp-pumped repetitively Q-switched Nd:YAG or a flash-lamp-pumped Nd:YAG. In addition, we can use the $\mathrm{XeCl}$ laser at $308 \mathrm{~nm}$. During the contract period we have used these scribing facilities several times for work on submodules of our sputtered cells and for some collaborative work at the request of other groups. 


\section{A. Introduction and Overview}

Significant progress has been made recently in a-Si photovoltaic research and manufacturing using a triple-junction structure [A1 to A4]. These include the achievement of $15.2 \%$ initial efficiency for small area solar cells [A1], 13\% stable efficiency for small area solar cells [A2], 10.2\% stable efficiency for $1 \mathrm{ft}^{2}$ solar panels [A3] and $8 \%$ stable efficiency for $4 \mathrm{ft}^{2}$ production scale PV modules [A4]. However, to meet the long term efficiency $(>15 \%)$ and cost $\left(<\$ 50 / \mathrm{m}^{2}\right)$ goals [A5], further improvement in the materials and device structure for the high efficiency triple-junction solar cells is still needed.

We focus our study on some long term issues related to high efficiency multiple-junction a-Si based solar cells. During the past three years, one of our emphases was to establish a good baseline for the fabrication of high efficiency a-Si-based single- and triple-junction solar cells.

The device structure for single and triple cells are shown in Figure 2A-1 (a) and (b). These devices were deposited on bare stainless steel (SS) substrates or back-reflector (Ag/ZnO) coated SS substrates. These substrates were provided by Energy Conversion Devices, Inc. (ECD). In these figures, the mc-Si layers are also considered as nanocrystalline Si by many researchers.

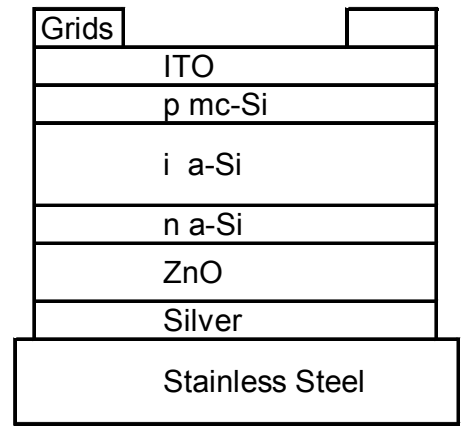

(a)

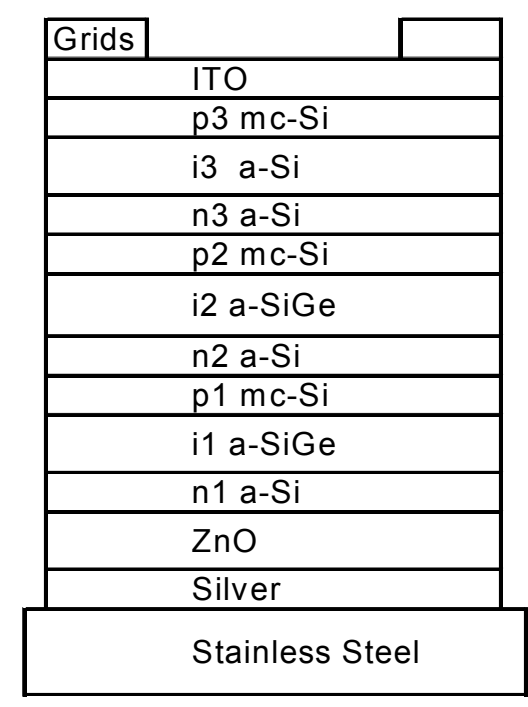

(b)

Figure 2A-1. Schematics of the single-junction (a) and triple-junction (b) structures of a-Si solar cell devices fabricated in this program.

Amorphous silicon based thin film materials required for our solar cell devices are deposited using rf plasma enhanced chemical vapor deposition (PECVD) process using an ultrahigh-vacuum, multi-chamber, load-locked deposition system, as shown in Figure A2. There are three deposition chambers in this system, with one (Chamber 2) designated for growth of a-Si and a-SiGe intrinsic materials, the second (Chamber 1) designated for the growth of p-type microcrystalline silicon ( $\mu \mathrm{c}-\mathrm{Si}$ or mc-Si) layers or a-Si layers, and the third (Chamber 3) designated for the growth of n-type a-Si layers. 
Mixtures of $\mathrm{Si}_{2} \mathrm{H}_{6}\left(\mathrm{Si}_{2} \mathrm{H}_{6}\right.$ and $\left.\mathrm{GeH}_{4}\right)$ and $\mathrm{H}_{2}$ are used for the deposition of a-Si (a-SiGe) materials. Mixtures of $\mathrm{BF}_{3}\left(\mathrm{PH}_{3}\right), \mathrm{SiH}_{4}$ and $\mathrm{H}_{2}$ are used for the deposition of p-type $\mu \mathrm{c}-\mathrm{Si}$ (n-type a-Si) layers to form the a-Si n-i-p junctions. 4"x4" stainless steel foils, $0.13 \mathrm{~mm}$ thick, with and without a textured $\mathrm{Ag} / \mathrm{ZnO}$ back-reflector coating, are used as substrates for the solar cell fabrication.

ITO layers, serving as the top electrodes and anti-reflective coatings, are deposited in an rf sputtering chamber from an $\mathrm{In}_{2} \mathrm{O}_{3} / \mathrm{SnO}_{2}$ target with $90 \% / 10 \%$ composition. In addition, targets with $5 \%$ and $15 \% \mathrm{SnO}_{2}$ composition have also been explored. Aluminum grids are evaporated in vacuum at room temperature to improve the current collection.

Current-Voltage characteristics and quantum efficiency curves are measured at UT to evaluate solar cell performances.

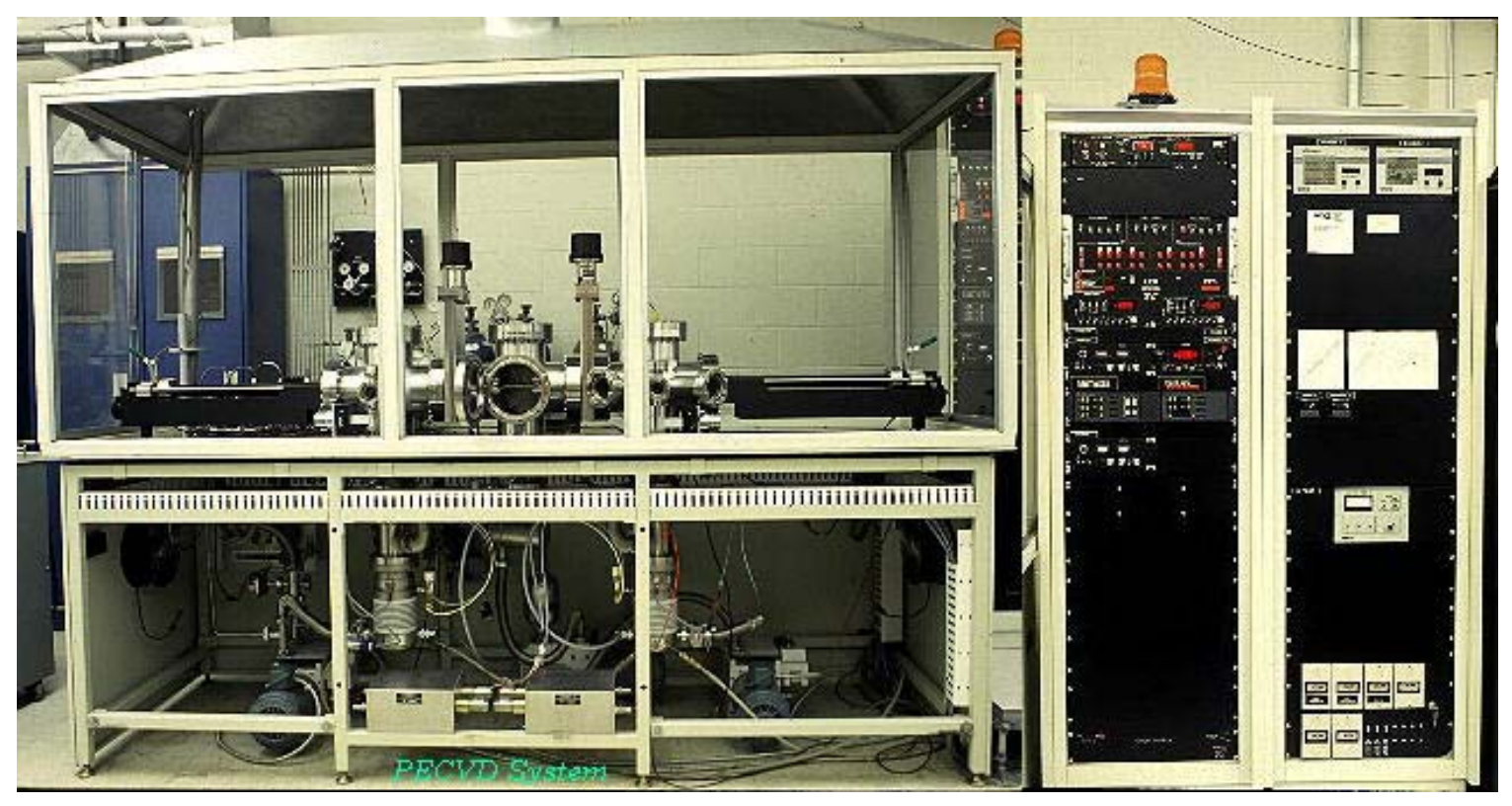

Figure 2A-2 UT's multi-chamber, loaded-locked, PECVD system used for the a-Si solar cell fabrication. 


\section{B. Improved IV measurement and calibration}

In the course of improving solar cell efficiency, it is important to have reliable and reproducible IV measurements. Several actions were taken to improve the measurement reliability and reproducibility, as summarized below.

\section{Calibration of Solar Simulator Intensity}

We used three crystalline silicon light detectors, purchased from UDT Sensors, Inc., and obtained current measurements for all three detectors under the simulator at the United Solar Systems Corp. and again under the simulator at First Solar, LLC. We used the average value obtained from both United Solar and First Solar to adjust the intensity of UT's solar simulator and obtain 1-sun light intensity.

\section{$\underline{\text { Use of a stainless steel mask during IV for accurate } \mathrm{J}_{\mathrm{sc}} \text { measurement }}$}

The size (active area) of our solar cell devices is defined by the size of the ITO front contact. Our ITO films are deposited via an RF sputtering process. Unfortunately, the sputter deposited ITO contacts do not have clearly defined edges although a stainless steel mask is mounted as close as we can during deposition to define the area. The "fuzzy" edge of these ITO contacts leads to uncertainties in the solar cell sizes, hence to the values of short circuit current. For smaller ITO contacts the uncertainty in the area, and hence in the short circuit current, is bigger. Usually, the "fuzzy" ITO contacts lead to an underestimate in the area and therefore an overestimate of the $\mathrm{J}_{\mathrm{sc}}$ and efficiency. Contact area-independent quantum efficiency measurements have sometimes been used to determine the exact short circuit current by integrating the QE with the solar irradiation spectrum. Although the QE measurement is more reproducible, it is not necessarily more accurate than the I-V measurement due to many contributing factors. In order to measure the Jsc more accurately, we adopted a procedure in which we cover the solar cells during the I-V measurements with the same mask that we use for ITO sputtering. In this way, the size of the exposed area is accurately defined. A significant improvement in the consistency and reproducibility was achieved using such a simple procedure.

\section{$\underline{\text { IV measurement with reduced noise }}$}

As for the measurement of IV curves, a simple circuit (home made) with an operational amplifier (Motorola LF353N) is used to collect the signal from the device and feed it to an analog to digital converter (PC Lab card PCL-812PG). The IV measurement was somewhat noisy, particularly when we measured small cells with low currents. Recently, we reduced the noise level and improved the measurement reproducibility by using a newly acquired Keithley Source Meter (model 2400). Figure 2B-1 shows the IV curve of a sample measured with and without using the Keithley Source Meter 2400, which shows much improved IV curves with the source meter. 


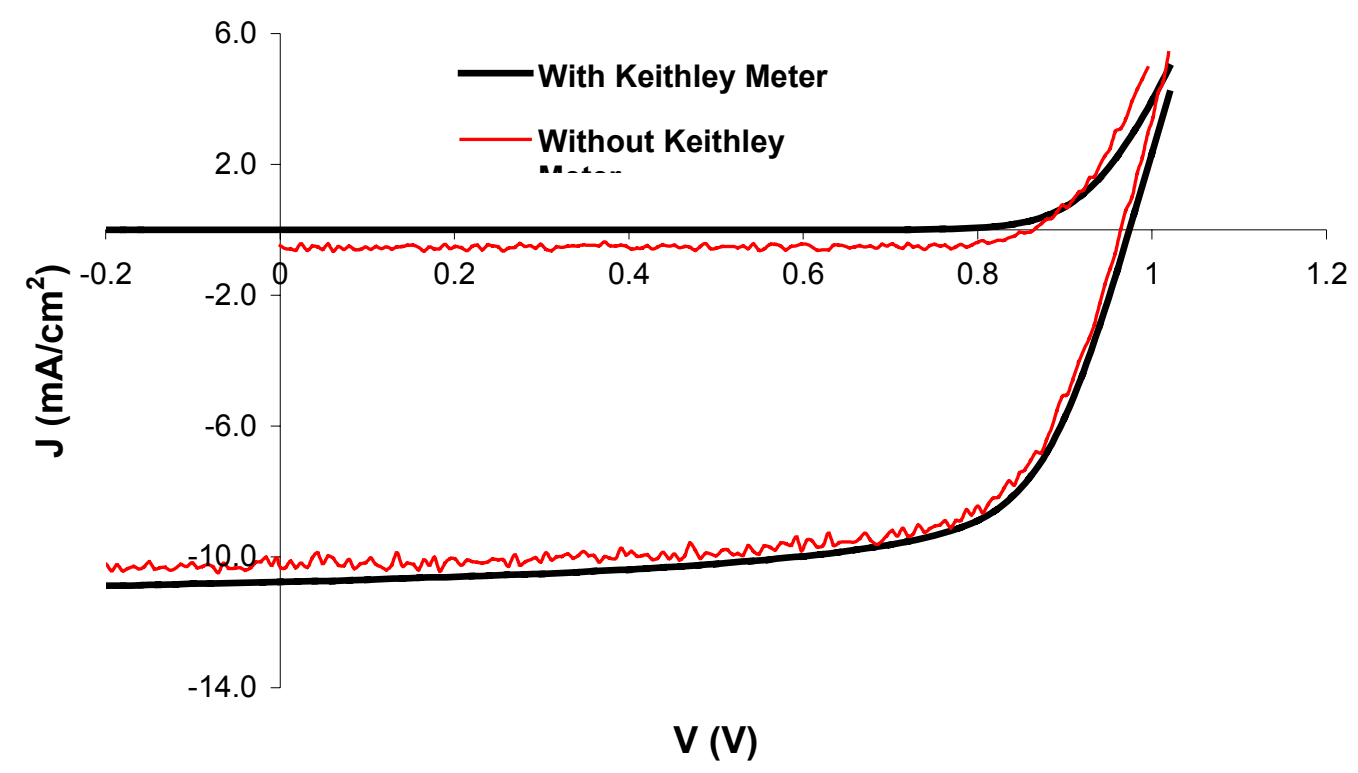

Figure 2B-1 IV curve of a single junction solar cell measured with and without using a Keithley source meter.

$\underline{\text { Four-probe source meter to reduce series resistance }}$

In addition, the Keithley Source Meter 2400 allows us to use four probes for the IV measurement with two probes connected to the cell and two probes connected to the ground. In this way, the series resistance from the external wires is reduced. Sometimes, we measure devices without metal grids by using two probes contacting the ITO. We can obtain the same FF and series resistance $R_{s}$ as cells with metal grids.

\section{$\underline{\text { Effect of sample heating during IV scans }}$}

The improved reproducibility and consistency with the Keithley source meter allows us to examine closely the smaller variations that were buried in the noise before. For example, we found that when we scan the IV with different incremental voltage steps, different cell performance was obtained.

Figure 2B-2 shows the IV curves of a triple cell GD581, measured with different incremental voltage steps. Different IV performances were obtained, as summarized in Table 2B-1. Figure 2B-3 shows the IV curves near the open circuit point, showing clearly the difference with different scanning steps. As we see from Table 2B-1, the IV curve measured with a smaller step shows a lower $\mathrm{V}_{\mathrm{oc}}$, a higher $\mathrm{FF}$ and a lower series resistance. The measurement is very reproducible. Such a change in performance with different voltage increments occurs to all samples.

We determined that the change in cell performance for different voltage steps was due to the temperature change of the sample during measurement. The sample temperature increases when it is placed under the simulator light. In Table 2B-1, we also included the scan time for different 
voltage steps. A 37 second exposure time under the light allows the sample to warm up slightly. When the scan is made in an increasing voltage, from reverse bias to forward bias, the later part of the measurement is taken when the sample temperature is higher. A higher temperature causes the bandgap to shrink, resulting in a reduced $\mathrm{V}_{\mathrm{oc}}$. The upward bending of the IV curve during the voltage scans with smaller increments results in an "artificial" drop in series resistance and increase in FF. Based on this argument, the faster scan is more reliable since the sample is left under the simulator light for only a few seconds. To reduce the dependence of the IV measurement on the scanning time, we also installed a sample mount that has a bigger thermal mass, hence reduce the fluctuation of temperature during the voltage scans.

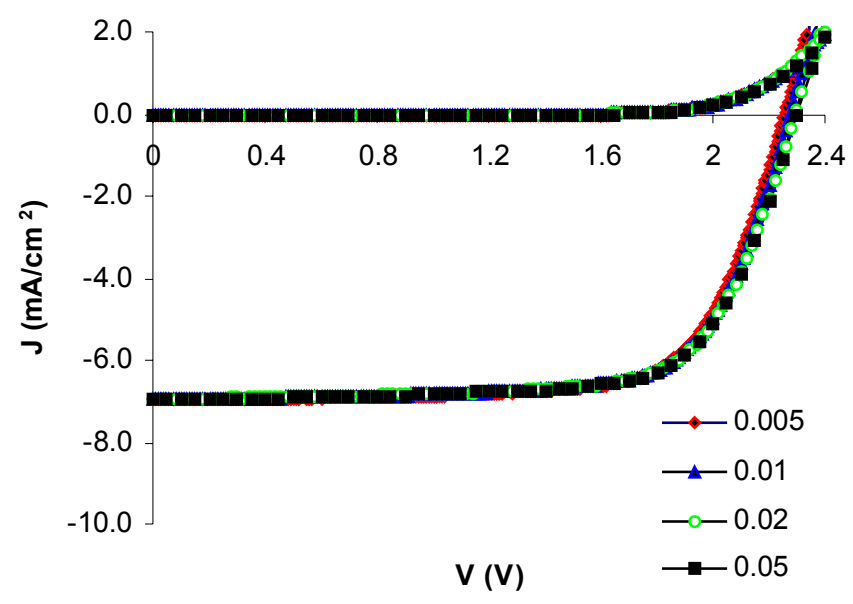

Figure 2B-2 IV curves of a sample GD581 measured with different incremental voltage steps.

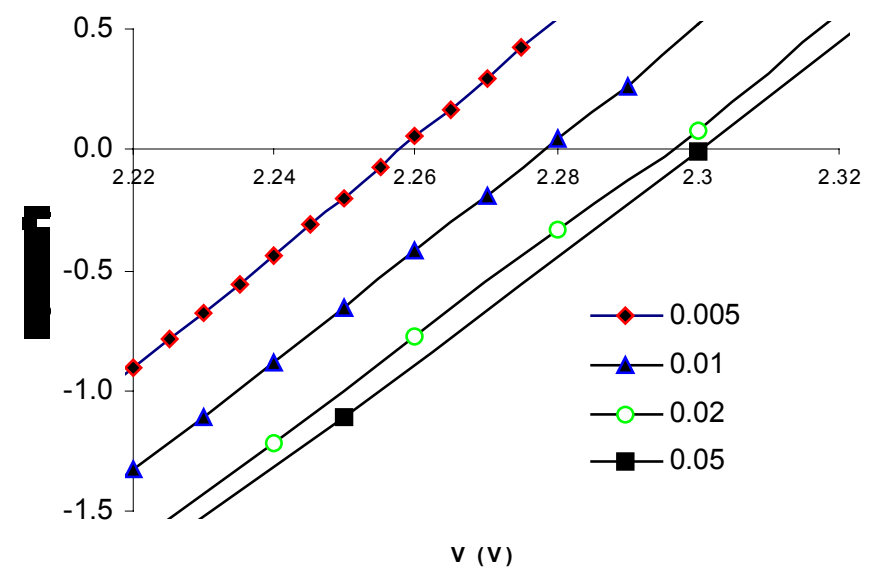

Figure 2B-3 IV curves near the $V_{o c}$ point for a sample measured with different incremental voltage steps. 
Table 2B-1 Device performance of a triple cell (GD581-2) measured with different voltage steps, $5 \mathrm{mV}, 10 \mathrm{mV}, 20 \mathrm{mV}$ and $50 \mathrm{mV}$.

\begin{tabular}{ccccccc}
\hline $\begin{array}{c}\text { Voltage } \\
\text { Step }(\mathrm{V})\end{array}$ & $\begin{array}{c}\mathrm{V}_{\mathrm{oc}} \\
(\mathrm{V})\end{array}$ & $\begin{array}{c}\mathrm{J}_{\mathrm{sc}} \\
\left(\mathrm{mA} / \mathrm{cm}^{2}\right)\end{array}$ & $\begin{array}{c}\mathrm{FF} \\
(\%)\end{array}$ & $\begin{array}{c}\eta \\
(\%)\end{array}$ & $\begin{array}{c}\mathrm{R}_{\mathrm{s}} \\
(\Omega \cdot \mathrm{cm})\end{array}$ & $\begin{array}{c}\text { Time for } \\
\text { scanning }(\mathrm{s})\end{array}$ \\
\hline 0.05 & 2.300 & 6.965 & 70.84 & 11.350 & 60.3 & 4 \\
0.02 & 2.296 & 6.946 & 70.95 & 11.316 & 45.7 & 9 \\
0.01 & 2.278 & 6.970 & 71.09 & 11.286 & 43.0 & 18 \\
0.005 & 2.258 & 6.962 & 71.68 & 11.267 & 41.0 & 37 \\
\hline
\end{tabular}

\section{$\underline{\text { Reducing grid coverage }}$}

The progress of high efficiency solar cell research is usually measured by total-area efficiency rather than the active-area efficiency. In an effort to improve the total-area efficiency, we developed a new grid design for our cells. Figure 2B-4 (a) shows the old design, in which there is a $6-7 \%$ coverage loss due to the metal grids. Figure $2 \mathrm{~B}-4$ (b) shows the new design that only has a $3 \%$ coverage loss. In the new design, there are 6 cells of $1 \mathrm{~cm}^{2}$ size and 21 cells of $0.25 \mathrm{~cm}^{2}$ in size with a sample of 2" by 2". The new design requires a two-step lithography process, one for the ITO layer and one for the metal grids. The Department of Physics and Astronomy at the University of Toledo has an operational clean room facility that includes a mask aligner with sub-micron lithography capability. We designed and acquired two masks for the ITO and metal $(\mathrm{Ag}, \mathrm{Al}$ or $\mathrm{Au}$ ) layers. Figure 2B-4 (b) shows the ITO and grid patterns fabricated in our lab. With this new ITO/grid procedure, the cell size is clearly and accurately defined. With the new mask, we increased the total-area efficiency by $4 \%$ from the previous level.

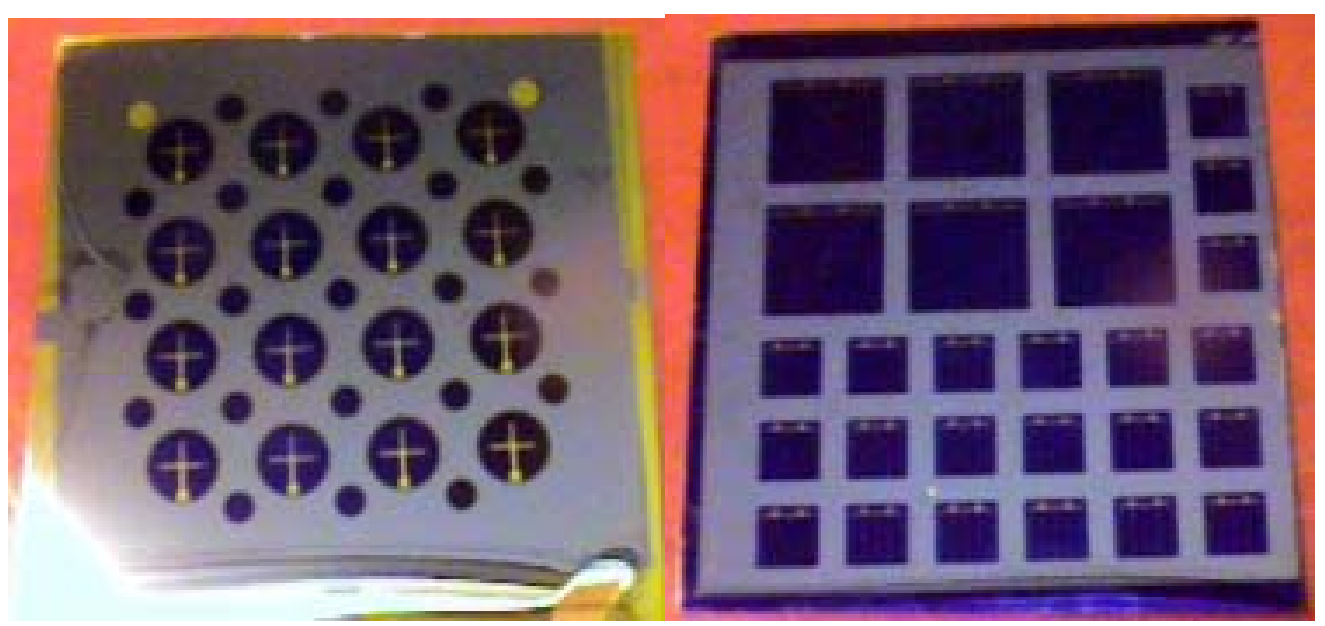

(a) (b)

Figure 2B-4 Pattern of ITO and grids with old (a) and new (b) ITO/grids design. 


\section{C. Study of various p-layer deposition conditions for SS/n-i-p/ITO solar cells}

For a-Si based solar cells, the window p-layer is very critical since it needs to be transparent to let light through to reach the absorber layer and it also needs to create a high builtin potential in the i-layer. A microcrystalline (or, nanocrystalline) p-layer has demonstrated the advantage of being more transparent than the amorphous counterpart. As will be discussed in section $2 \mathrm{P}$, "microcrystalline p-layer" in this report represents $\mu \mathrm{c}-\mathrm{Si}$, nc- $\mathrm{Si}$ or $\mathrm{Si}$ near the transition of a-Si to $\mu \mathrm{c}-\mathrm{Si}$. The exact structure of the thin p-layer that is made with high $\mathrm{H}$ dilution, high RF power and low temperature and provides high Voc in n-i-p type cell has yet to be exactly defined. For simplicity, we still adopt the term "microcrystalline p-layer" for historical reasons.

The microcrystalline p-layer is usually deposited under a high $\mathrm{H}$ dilution and high $\mathrm{RF}$ power. It is important to find the impact of the p-layer deposition conditions such as B doping, temperature and thickness on the solar cell performance.

We deposited p-layers of a-Si n-i-p solar cells under different conditions and compared the performance using quantum efficiency measurements under zero bias, forward bias and reverse bias. We use QE at 400nm to measure the p-layer optical transmission and the ratio of the $\mathrm{QE}$ at $400 \mathrm{~nm}$ measured under $0.7 \mathrm{~V}$ forward bias to that measured under zero bias as an indication of $\mathrm{p}$-layer electrical performance (similar to $\mathrm{FF}$ ).

Figure 2C-1 shows the QE curves for all of the samples measured in dark under zero electrical bias. The sample with $1 / 2$ thickness and the sample deposited at 2 Torr show the highest QE in the blue. Optically, a high QE at $400 \mathrm{~nm}$ indicates a highly transparent p-layer and that more light can reach the i-layer.

Figure 2C-2 shows the QE curve of one typical sample measured under forward $(0.5 \mathrm{~V}$ and $0.7 \mathrm{~V})$ and reverse $(-0.5 \mathrm{~V})$ bias. The $\mathrm{QE}$ under reverse bias is higher than that under no bias since the additional electrical field generated by the reverse bias enhances the collection of the light generated carriers. Under forward bias, the electrical field generated by the $p-n$ junction is weakened by the bias, resulting in a reduced collection. The ratio of the QE measured under forward bias to that under zero bias correlates to the FF of the solar cell devices. The reason that we are using QE rather than a solar simulator is that we could observe the voltage dependent photocurrent which has a major influence on FF for different wavelength of the incident light.

In Table 2C-1, the $\mathrm{QE}$ at $400 \mathrm{~nm}$ and the $\mathrm{QE}$ ratio at $400 \mathrm{~nm}$ are summarized. Compared with the standard p-layer which is deposited at 1 Torr, $70 \mathrm{C}$, we find that

- $\quad$-layer with half the thickness is more transparent but slightly poorer FF.

- p-layer deposited at 2 Torr has the same transparency and has higher FF, probably due to higher microcrystalinity.

- p-layer deposited at temperature higher than standard is less transparent 


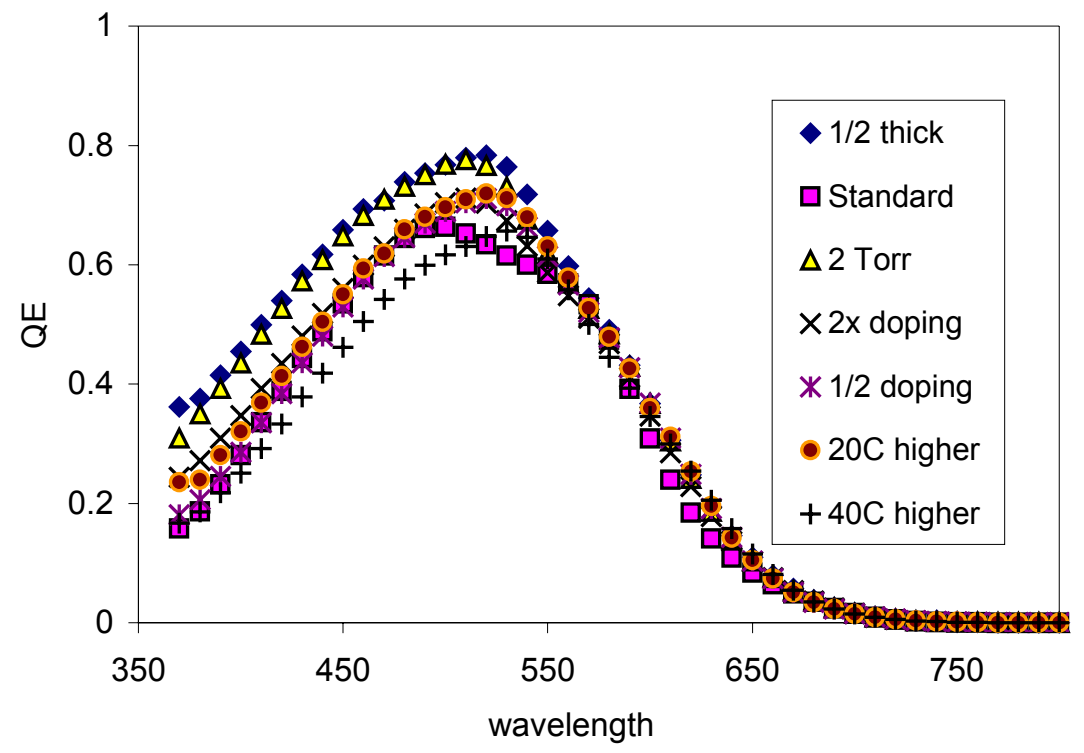

Figure 2C-1. QE curves of n-i-p solar cells with different p-layers.

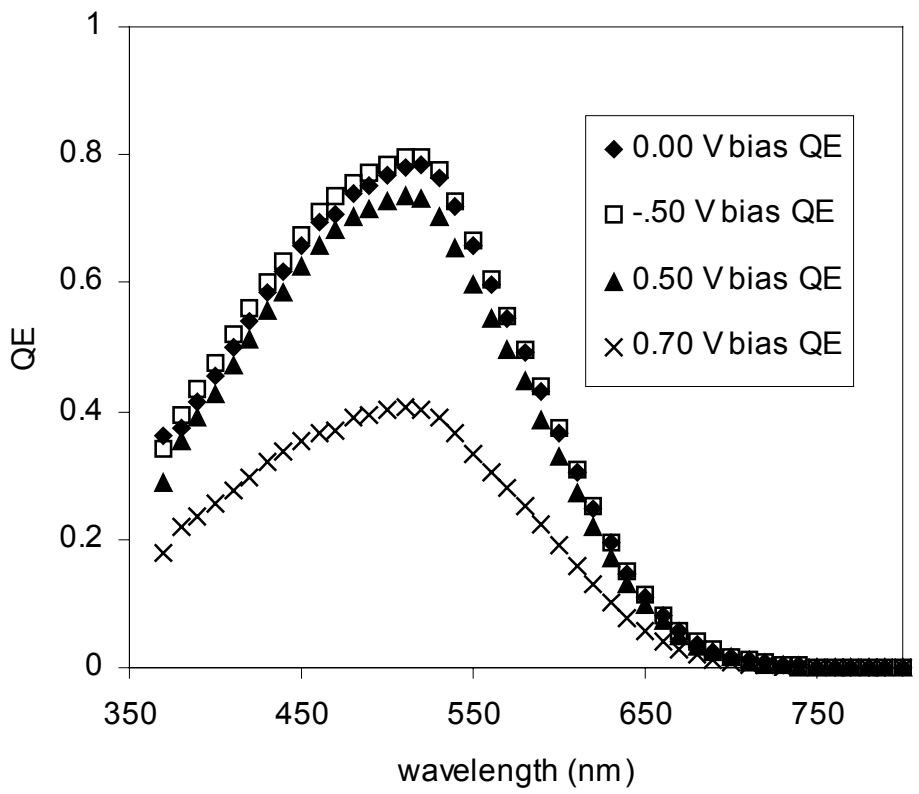

Figure 2C-2. QE curves of one sample (GD411) measured under different biases. 
Table 2C-1. List of p-layer deposited under different conditions and 400nm QE measured under different electrical bias for n-i-p solar cells with these p-layers.

\begin{tabular}{cccccc}
\hline \hline p-layer conditions & Sample \# & QE & $V(0.7) / V(0.0)$ & $V(0.5) / V(0.0)$ & $V(-0.5) / V(0.0)$ \\
& & at 400nm & at 400nm & at 400nm & at 400nm \\
\hline Standard @1Torr 70C & GD412 & 0.28 & 0.58 & 0.85 & 1.06 \\
Std but 1/2 thick & GD411 & 0.45 & 0.56 & 0.94 & 1.04 \\
Std but 2Torr & GD414 & 0.44 & 0.65 & 0.92 & 1.03 \\
Std but 2x doping & GD415 & 0.35 & 0.21 & 0.60 & 1.06 \\
Std but 1/2 doping & GD416 & 0.29 & 0.56 & 0.82 & 1.06 \\
Std but 20C higher & GD417 & 0.32 & 0.57 & 0.84 & 1.08 \\
Std but 40C higher & GD418 & 0.25 & 0.35 & 0.81 & 1.08 \\
\hline \hline
\end{tabular}




\section{D Optimization of wide-bandgap a-Si top cell}

\section{Modification of UT's multi-chamber PECVD system}

At the beginning of this three year program, our solar cell fabrication system had two PECVD chambers: one for the intrinsic layer and the other for both $\mathrm{p}$ and $\mathrm{n}-$ type doped layers. From SIMS analysis (see Figure 2D-1) on a sample deposited earlier (GD196), we observed a cross-contamination of dopants in the doped layers, due to the fact that we deposited p-layer and n-layer in the same chamber (chamber 1). Even though we deposited a pre-coating of the same layer to be deposited in the chamber, we still observed a high background density $\left(\sim 10^{19} \mathrm{~cm}^{-3}\right)$ of phosphorus (boron) in the p-layer (n-layer). There is a need to deposit the $n$ - and p-layer in separate chambers. For this reason, we added high vacuum system, gas tube system and rf power electrode to the load-lock chamber for n-layer deposition, and leave chamber 1 designated for $\mathrm{p}$ layer deposition. Based on the improved performance of our solar cells, we believe that the cross-contamination in the doped layers for the solar cells is much suppressed.

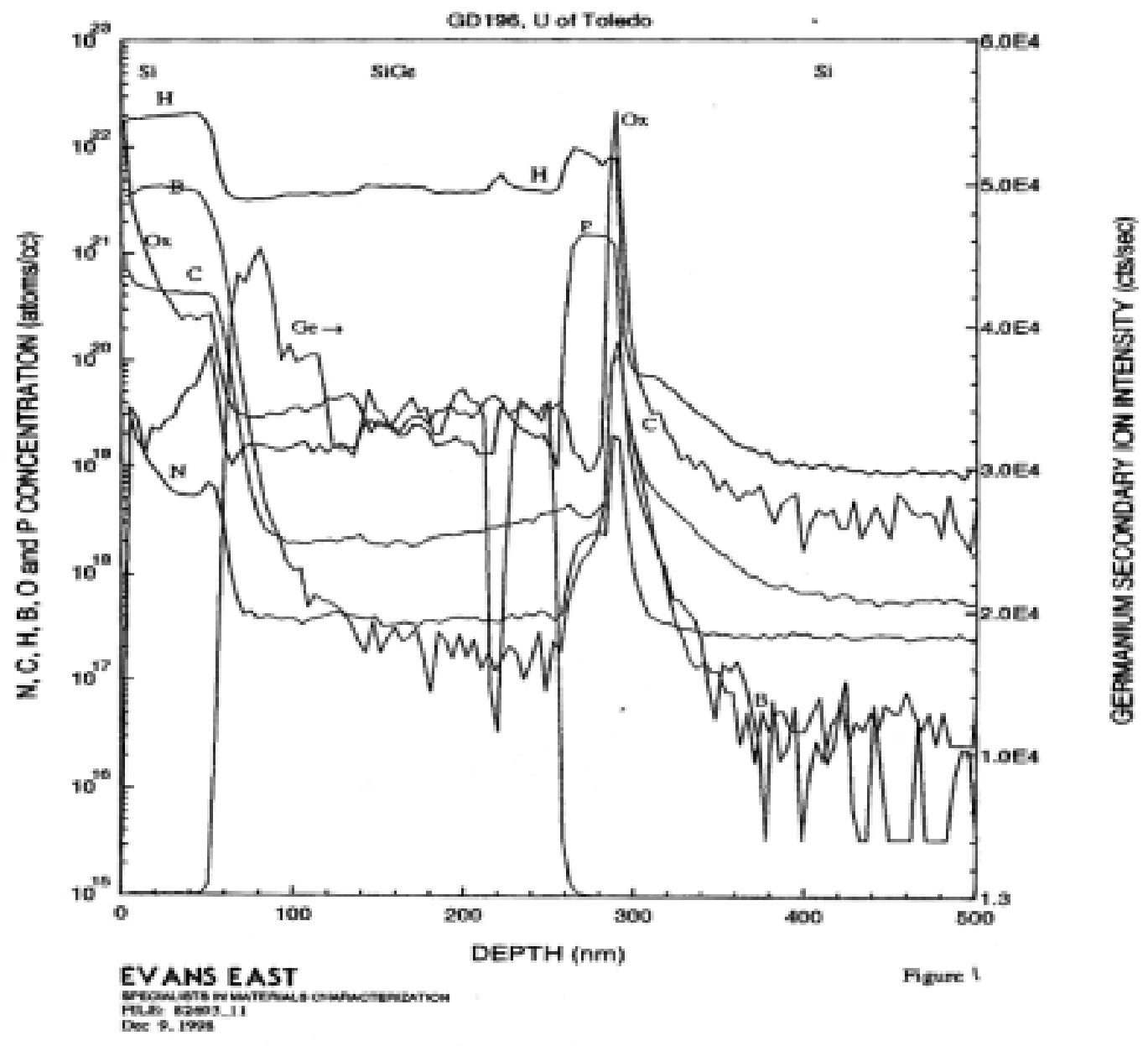

Figure 2D-1 SIMS profiles of a single-junction a-SiGe p-i-n structure before we installed separate deposition chambers for the doped layers 


\section{Further optimization of wide bandgap a-Si top cell}

In the further optimization process for the wide bandgap a-Si top cells, we focused on the deposition of wide bandgap p- $\mu \mathrm{c}-\mathrm{Si}: \mathrm{H}$ and matches between the p- $\mu \mathrm{c}-\mathrm{Si}: \mathrm{H}$ and the i-a-Si. The main results are shown in Table 2D-1. It shows the critical deposition conditions and the PV parameters for eight typical samples, each of which contains 23 small cells of active $0.043 \mathrm{~cm}^{2}$ and 16 relatively larger cells of active $0.25 \mathrm{~cm}^{2}$. Due to some fluctuations of the measured data, the listed $\mathrm{V}_{\mathrm{oc}}, \mathrm{J}_{\mathrm{sc}}$ and $\mathrm{FF}$ are the average values for the best three FF cells in each cell number. To evaluate the impact of the p-layer to the top cell current, we measured the quantum efficiency with particular attention to the blue region. High blue response at $400 \mathrm{~nm}$ would suggest a more transparent p-layer.

We begin our discussion from the previous standard top cell GD531 which has a p-layer deposited at a gas pressure of 1 Torr. We fabricated a series of samples at 1, 1.5 and 2 Torr gas pressures for the p-layer deposition. When we increased the pressure to 2 Torr for depositing $\mathrm{p}$ layer of GD534, the blue QE and $\mathrm{V}_{\text {oc }}$ are increased. This suggests that the p-layer in GD534 has better transparency and wider bandgap compared with that of GD531. It should be noted here that cells in Table 2D-1 show much variation in Jsc since this was measured before we adopt new measurement procedures described in Section 2B.

The second change we made in the optimization was to lower the doping concentration of the p-layer as seen in GD534, GD532, GD533, where the flow of doping gas $\mathrm{BF}_{3}$ is decreased from 2.5 to $1 \mathrm{sccm}$. As a result, the $\mathrm{V}_{\text {oc }}$ and blue $\mathrm{QE}$ tend to go up. This is because excessive $\mathrm{B}$ doping causes the bandgap to shrink. Meanwhile, in order to improve the Ohmic contact at the interface of the p-layer with the ITO film, we introduced a very thin heavily doped layer between the p-layer and the ITO, which results in some increase in FF.

Table 2D-1 The optimization results for top cells deposited on SS or Back-reflector

\begin{tabular}{|c|c|c|c|c|c|c|c|c|c|c|c|}
\hline $\begin{array}{l}\text { Sample } \\
\text { No. }\end{array}$ & $\begin{array}{l}\text { p-pres. } \\
\text { (Torr) }\end{array}$ & $\begin{array}{c}\mathrm{BF}_{3} \\
\text { flow } \\
\text { (sccm) }\end{array}$ & $\begin{array}{c}\text { p-dep } \\
\text { time } \\
\text { (min) }\end{array}$ & $\begin{array}{l}\text { i-H-dilut } \\
\mathrm{H}_{2} / \mathrm{SiH}_{4}\end{array}$ & $\begin{array}{c}\text { i- } \\
\text { power } \\
\text { (W) }\end{array}$ & $\begin{array}{l}\text { Ts } \\
\text { (C) }\end{array}$ & $\underset{\left(\mathrm{mA} / \mathrm{cm}^{2}\right)}{\mathrm{J}_{\mathrm{sc}}}$ & $\begin{array}{l}\mathrm{V}_{\mathrm{oc}} \\
(\mathrm{V})\end{array}$ & $\begin{array}{l}\mathrm{FF} \\
(\%)\end{array}$ & $\begin{array}{l}\mathrm{J}_{\mathrm{sc}} \text { from } \\
\mathrm{QE}(\%)\end{array}$ & $\begin{array}{c}\mathrm{QE} \\
(\mathrm{at} \\
400 \mathrm{~nm})\end{array}$ \\
\hline GD531 & 1 & 2.5 & 2 & 50 & 2 & 200 & 14.8 & 0.943 & 65.739 & 13.1 & 0.31 \\
\hline GD534 & 2 & 2.5 & 2 & 50 & 2 & 200 & 11.7 & 0.953 & 67.9 & 10.9 & 0.61 \\
\hline GD532 & 2 & 1.5 & 2 & 50 & 2 & 200 & 12.1 & 0.977 & 68.5 & 10.3 & 0.53 \\
\hline GD533 & 2 & 1 & 2 & 50 & 2 & 200 & 11.6 & 0.979 & 69.4 & 10.9 & 0.68 \\
\hline GD539 & 2 & 1 & 2 & 100 & 2.5 & 170 & 12.3 & 0.984 & 69.2 & 12.0 & 0.65 \\
\hline GD550* & 2 & 1 & 3 & 100 & 2.5 & 170 & 9.49 & 0.999 & 71.3 & 8.67 & 0.55 \\
\hline GD552* & 2 & 1 & 3 & 100 & 3 & 170 & 9.18 & 1.003 & 67.3 & 8.64 & 0.54 \\
\hline GD553* & 2 & 1 & 3 & 100 & 3.5 & 170 & 8.12 & 1.022 & 72.6 & 7.2 & 0.64 \\
\hline
\end{tabular}

$\left.{ }^{*}\right)$ on SS, without BR

The wide band gap i-a-Si:H layer is obtained at high H-dilution, and low deposition temperature. In the last group of samples GD539, GD550, GD552, GD553 in Table 2D-1, all the intrinsic layers were deposited at a high-H dilution of 100 , which is the flow ratio of hydrogen to 
disilane, and at lower substrate temperature of $170 \mathrm{C}^{\circ}$. As described in our previous reports, these i-layers are of high quality, stable and in amorphous phase before the onset of microcrystalline formation. Therefore solar cells made using these intrinsic layers are expected to have higher $\mathrm{V}_{\text {oc. }}$ Two other fruitful approaches we took in optimizing the top cell were to increase the thickness (deposition time) of the p-layer, by a factor of 1.5 here, and to increase the glow discharge power for i-layer, from $2.5 \mathrm{~W}$ to $3.5 \mathrm{~W}$. It is seen that these further improved $\mathrm{V}_{\text {oc }}$ to around $1.022 \mathrm{~V}$ with FF to $72.6 \%$, and the highest $\mathrm{V}_{\mathrm{oc}}$ is $1.045 \mathrm{~V}$ with $\mathrm{FF}=70.3 \%$ ( not listed in the Table). It is important to adjust the p-layer thickness appropriately. On one hand, one needs a minimal p-layer thickness to suppress the tunneling probability of photo-generated holes from ilayer directly to ITO films, while on the other hand, when the p-layer is too thick, it could lead to a poor blue spectral response and somewhat higher series resistance. As for the rf power used for depositing i-layers, we should avoid the bombardment damage of ions to the growing surface, but we also need plasma etching to some extent to eliminate the energetic defect structures from the growing surface. Another reason that sometime adequate power is needed since there is relatively less contamination in the film when the films are deposited within a shorter time.

The resultant illuminated I-V curve for a further optimized wide-badgap top cell is given in Fig. 2D-2. In Table 2D-2, we show our progress made in the fabrication of high performance top cells deposited on SS without back-reflector.

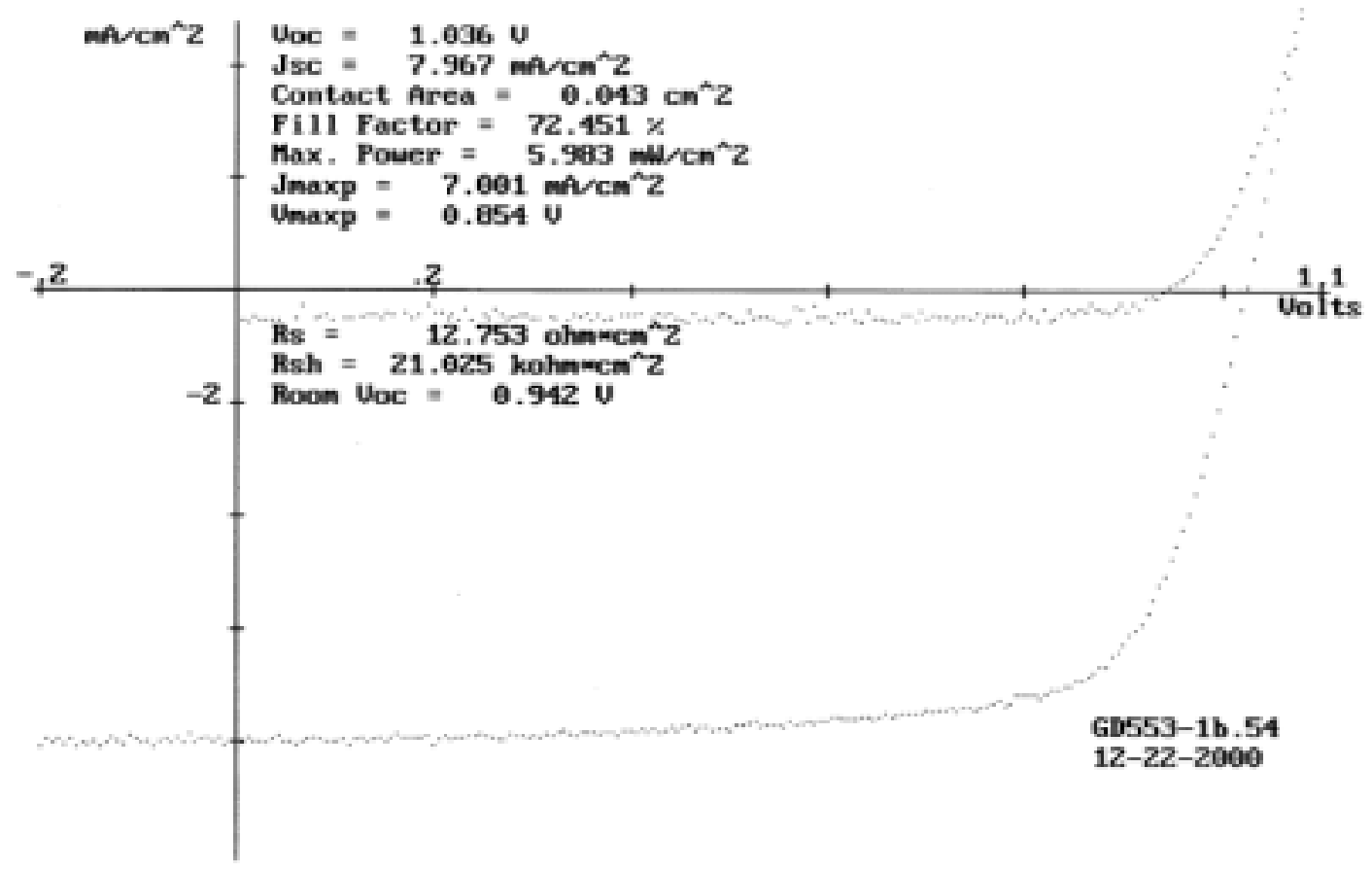

Figure 2D-2 IV curve of an optimized top cell with $\mathrm{Voc}=1.035 \mathrm{~V}, \mathrm{Jsc}=7.97 \mathrm{~mA} / \mathrm{cm} 2$ and $\mathrm{FF}=72.5 \%$. 
Table 2D-2 Performance of top cells deposited in our lab during the past 3 years

$\begin{array}{cccccc}\text { sample No. } & \text { Voc(V) } & \text { Jsc }(\mathrm{mA} / \mathrm{cm} 2) & \text { FF(\%) } & \begin{array}{c}\text { Efficiency } \\ \%)\end{array} & \text { date } \\ \text { GD82 } & 1.019 & 8.574 & 55.1 & 4.8 & \text { Apr. 1998 } \\ \text { GD304 } & 0.980 & 6.641 & 71.067 & 4.6 & \text { Mar. 1999 } \\ \text { GD553 } & 1.036 & 7.967 & 72.451 & 6.0 & \text { Dec. 2000 }\end{array}$




\section{E. Optimization of a-SiGe middle and bottom cells}

During the recent optimization, we focused on the current matching of the component cells and the interface matching between the wide bandgap p-layer with the mid and narrow bandgap i-a-SiGe cells.

The optimization results for the mid and narrow bandgap a-SiGe cells are shown in Table 2E-1. The listed $\mathrm{V}_{\mathrm{oc}}, \mathrm{J}_{\mathrm{sc}}$ and $\mathrm{FF}$ for each cell number are the average values for the best three FF cells. The variation in the deposition conditions are in the substrate temperature $\mathrm{T}_{\mathrm{sp}}$ for the $\mathrm{p}$ layer, and in the $\mathrm{H}$-dilution $\left\{\left(\mathrm{H}_{2} /\left(\mathrm{GeH}_{4}+\mathrm{Si}_{2} \mathrm{H}_{6}\right)\right\}\right.$ and $\mathrm{Ge}$ content for I-layer. For depositing the mid bandgap cells, we changed the ratio of $\mathrm{GeH}_{4} / \mathrm{Si}_{2} \mathrm{H}_{6}$ from 0.24 to 0.37 for the intrinsic a$\mathrm{SiGe}: \mathrm{H}$ layers, and also the substrate temperatures from $70 \mathrm{C}$ to $160 \mathrm{C}$ for the p-layer. The resultant best mid cell (GD572) on stainless steel substrate has the performance of $\mathrm{V}_{\mathrm{oc}}=0.805 \mathrm{~V}$, $\mathrm{FF}=65.1 \%$ and $\mathrm{J}_{\mathrm{sc}}=14.8 \mathrm{~mA} / \mathrm{cm}^{2}$, with the optical bandgap of about $1.65 \mathrm{eV}$, and is ideal for use as the middle cell in a triple-junction cell.

Table 2E-1 Performance of middle and bottom a-SiGe cells deposited under different conditions.

\begin{tabular}{|c|c|c|c|c|c|c|c|c|c|c|}
\hline Sample & $\begin{array}{c}\text { p-layer } \\
\mathrm{T}_{\mathrm{sp}}\end{array}$ & $\begin{array}{c}\text { I-layer } \\
\mathrm{GeH}_{4} / \mathrm{Si}_{2} \mathrm{H}_{6}\end{array}$ & H-dilute & $\mathrm{Eg}(\mathrm{eV})$ & $\begin{array}{c}\text { PV } \\
\text { Voc(V) }\end{array}$ & $\mathrm{FF}$ & $\mathrm{Jsc}\left(\mathrm{mA} / \mathrm{cm}^{2}\right)$ & $\operatorname{Eff}(\%)$ & $\underset{\mathrm{mA} / \mathrm{cm}^{2}}{\mathrm{Jph}}$ & $\operatorname{area}\left(\mathrm{cm}^{2}\right)$ \\
\hline GD554/ss & 70 & 0.36 & 35 & \multirow[t]{4}{*}{1.65} & 0.826 & 63.4 & 12.1 & 6.35 & 10.9 & 0.25 \\
\hline GD557/ss & 120 & 0.36 & 35 & & 0.819 & 64.8 & 13.0 & 6.89 & 11.6 & 0.25 \\
\hline GD572/ss & 140 & 0.36 & 35 & & 0.805 & 65.1 & 14.8 & 7.74 & 13.7 & 0.25 \\
\hline GD568/ss & 160 & 0.36 & 35 & & 0.813 & 63.1 & 15.0 & 7.62 & 14.2 & 0.25 \\
\hline \multicolumn{11}{|l|}{ Bottom cell } \\
\hline GD556/ss & 70 & 0.88 & 16 & 1.45 & 0.605 & 46.3 & 20.8 & 5.84 & -- & 0.25 \\
\hline GD577/BR & 140 & 0.80 & 56 & & 0.606 & 54.1 & 22.6 & 7.41 & 22.2 & 0.25 \\
\hline GD578/BR & 140 & 0.88 & 53 & & 0.596 & 60.2 & 23.3 & 8.37 & 21.2 & 0.25 \\
\hline
\end{tabular}

For depositing the narrow bandgap cells, we changed the substrate temperature from $70 \mathrm{C}$ to $140 \mathrm{C}$ for the p-layer, and the $\mathrm{H}$ dilution ratio from 16 to 56 and the $\mathrm{GeH}_{4} / \mathrm{Si}_{2} \mathrm{H}_{6}$ ratio from 0.8 to 0.88 for intrinsic layer. The best bottom cell seen in Table 3 is GD578 with $\mathrm{V}_{\text {oc }}=0.596 \mathrm{~V}$, $\mathrm{FF}=60.2$ and $\mathrm{J}_{\mathrm{sc}}=23.3 \mathrm{~mA} / \mathrm{cm}^{2}$, which has an i-layer with an optical bandgap of $\sim 1.45 \mathrm{eV}$ and could be used in triple junction cells as the bottom cell. It is worthy to mention that the I-V measurements are carried out under AM1.5, $100 \mathrm{~mW} / \mathrm{cm}^{2}$, newly calibrated, with a cover mask to limit the illuminated area, therefore these data including the $\mathrm{J}_{\mathrm{sc}}$ are reliable. The $\mathrm{J}_{\mathrm{ph}}$ values calculated from integrated $\mathrm{QE}$ are in general agreement with the $\mathrm{J}_{\mathrm{sc}}$ measured in the IV. Figure 2E-1 gives the QE of Sample GD577 as a function of wavelength $(\mathrm{nm})$, from which we deduced the integrated current density of $\sim 22.2 \mathrm{~mA} / \mathrm{cm}^{2}$ which is in a good agreement with the I-V results. Another point which is to be discussed in a later section (section $2 \mathrm{P}$ ) is the significant influence of $\mathrm{T}_{\mathrm{sp}}$ on the photovoltaic parameters of the both middle and bottom cells. 
gd577-2-43 Jph=22.2

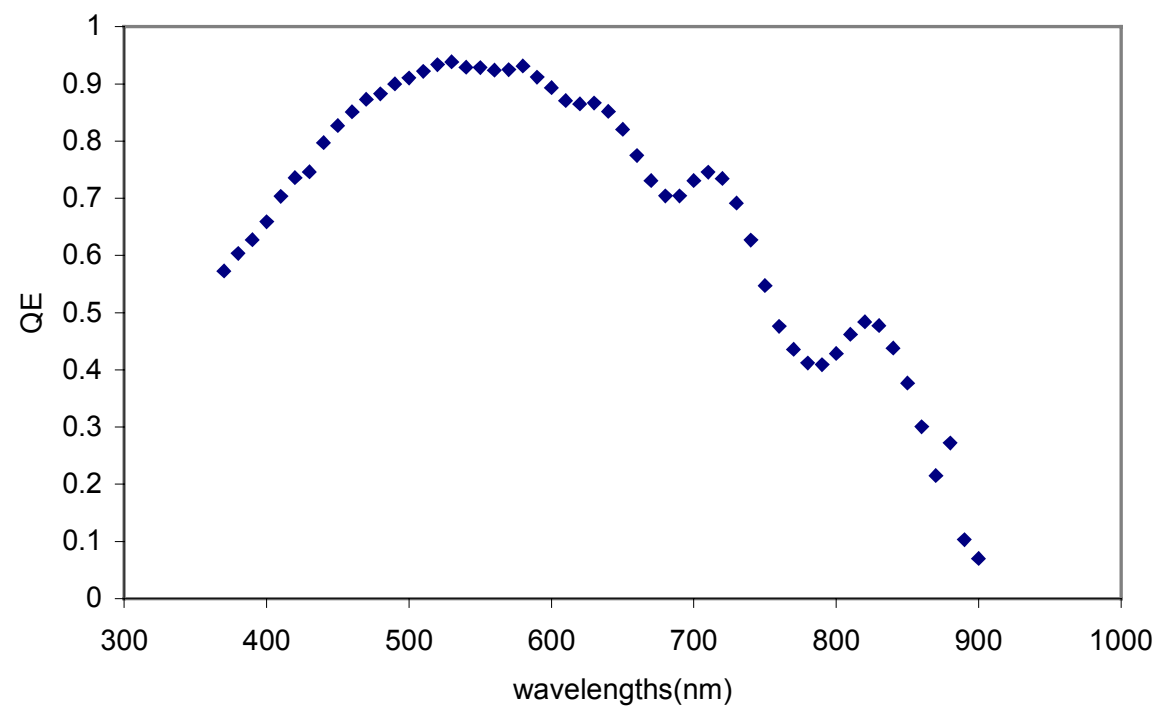

Figure 2E-1 QE curve of an a-SiGe bottom cell, showing integrated current of $22.2 \mathrm{~mA} / \mathrm{cm}^{2}$. 


\section{F. Comparison Study of a-SiGe Solar Cells and Materials Deposited Using Different Hydrogen Dilution}

\section{F.1 SUMMARY}

A-SiGe n-i-p solar cells with i-layer deposited via plasma enhanced chemical vapor deposition (PECVD) with a hydrogen dilution $\mathrm{R}=\left(\mathrm{H}_{2}\right.$ flow $) /\left(\mathrm{GeH}_{4}+\mathrm{Si}_{2} \mathrm{H}_{6}\right.$ flow) values of $1.7,10$, $30,50,120,180$ and 240 were deposited on stainless steel substrates. The average germane to dililane ratio is 0.72 since the bandgap of a-SiGe layer is intentionally graded. This germane to disilane ratio is what we typically use for the i-layer in the bottom cell of our standard triplejunction solar cells. Solar cell current-voltage curves $(\mathrm{J}-\mathrm{V})$ and quantum efficiency $(\mathrm{QE})$ were measured for these devices. Light soaking tests were performed for these devices under 1 sun light intensity at $50{ }^{\circ} \mathrm{C}$. While device with $\mathrm{R}=30$ showed the highest initial efficiency, the device with $\mathrm{R}=120$ exhibit higher stabilized efficiency after 1000 hours of light soaking.

Single-layer a-SiGe films ( $\sim 500 \mathrm{~nm}$ thick) were deposited under the same conditions as the i-layer of these devices on a variety of substrates including 7059 glass, crystalline silicon, and stainless steel for visible-IR transmission spectroscopy, FTIR, Raman scattering and hydrogen effusion studies. It is interesting to note that: 1) with increasing $\mathrm{R}$ the $\mathrm{H}$ content in the a-SiGe films decreases, based on both the IR and $\mathrm{H}$ effusion measurements; 2) while the $\mathrm{H}$ content changes significantly with different $\mathrm{R}$, the change in $\mathrm{E}_{\mathrm{g}}$ is relatively small. This is most likely due to a change in Ge content in the films for different R; 3 ) the phase transition from a-SiGe to $\mu \mathrm{c}-\mathrm{SiGe}$ occurs when the film was deposited on glass with $\mathrm{R}$ around 180 .

\section{F.2 INTRODUCTION}

Although the correlation between amorphous silicon based solar cell device performance and a variety of intrinsic layer (i-layer) material properties have been studied broadly,[F1 - F3] a reliable correlation between i-layer properties and device performance is not yet well established. This is partially due to the different ways used for depositing these materials. $\mathrm{H}$ dilution has been used extensively to improve a-Si based solar cell materials and device quality[F4 - F6]. However, the exact role of $\mathrm{H}$ dilution to the growth of narrow bandgap a-SiGe alloys, in particular the phase transition from amorphous to microcrystalline state of the materials, have not yet been fully understood and deserve further study. Here we describe our recent studies of a-SiGe n-i-p solar cells and films deposited under a wide range of $\mathrm{H}$ dilution. We were particularly interested in the phase transition region and the effect of the different hydrogen dilution on long-term stability of these solar cells.

\section{F.3 EXPERIMENT}

A-SiGe films, approximately $0.5 \mu \mathrm{m}$ thick, were deposited on 7059 glass, c-Si substrates and stainless steel (SS) using a hydrogen dilution ratio $\mathrm{R}$ of 1.7, 10, 30, 50, 120, 180 and 240 by PECVD. Optical measurements were performed for samples on 7059 glass substrates to obtain sample thickness, refractive index and the bandgap. FTIR absorption measurements were taken for samples on $\mathrm{c}-\mathrm{Si}$ substrates to obtain information on the $\mathrm{H}$ content and bonding. In order to analyze the structural properties, Raman scattering spectra were measured for the films on 7059 glass and for cell devices on stainless steel, upon excitation by an argon laser with $488 \mathrm{~nm}$ 
wavelength. H effusion measurements were performed on samples deposited on SS substrates to obtain the total $\mathrm{H}$ content.

Single junction $n-i-p$ solar cells using these a-SiGe materials as the i-layers were deposited on SS substrates without the use of a back-reflector. I-V measurements were taken under a Xe-lamp solar simulator under AM1.5 spectrum. Quantum efficiency (QE) measurements were taken between $420 \mathrm{~nm}$ and $900 \mathrm{~nm}$. Light soaking was performed under onesun light intensity using a metal halide lamp. The intensity is maintained at a level so that a reference Si solar cell generates the same current as it does under a Xe-lamp simulator.

\section{F.4 RESULTS}

\section{F.4.1 Single-layer a-SiGe films}

Table 2F-1 shows the deposition conditions for these a-SiGe films including the flows of $\mathrm{GeH}_{4}, \mathrm{Si}_{2} \mathrm{H}_{6}$ and $\mathrm{H}_{2}$, the substrate temperature, radio frequency power, chamber pressure, and deposition time. The deposition times of our single layer films were adjusted so that the samples would have approximately the same thickness. It is worth noting that Sample GD422 is made using the dilution that is currently used for the bottom cell i-layer and, therefore, serves as a reference point for this set of samples.

Transmission spectra of the single layers were measured using dual beam visible/near-IR spectroscopy. No substrate was used in the reference beam during the measurement. There were clear interference fringes within the measured range allowing us to calculate the refractive index $n$ in the weak absorption region and the thickness $d$ for the samples.[F7] A linear fit to the refractive index $n$ plotted versus $1 / \lambda^{2}$ allows us to extrapolate the $n$ value in the strong absorption region $(\lambda<800 \mathrm{~nm})$. The $n$ values estimated from this extrapolation were then used together with the transmission values in the strong absorption region to obtain absorption coefficient $\alpha$. A linear fitting of the Tauc plot, $(\alpha h v)^{1 / 2}$ vs. hv, gives the material's bandgap $\mathrm{E}_{\mathrm{g}}$.

Using the above procedure, $n, d$, and $E_{g}$ for all of the samples with different R were measured and summarized in Table 2F-2. The deposition rates were obtained from the thicknesses and deposition times. It is found that the deposition rate is reduced by more than one order of magnitude when $\mathrm{R}$ is increased from 1.7 to 240 .

To find out $\mathrm{H}$ content and the bonding configuration, infrared absorption for these films were measured using an FTIR spectroscope. There were two absorption peaks observed near 640 and $2000 \mathrm{~cm}^{-1}$, corresponding to the waging and stretching modes of $\mathrm{Si}-\mathrm{H}$ and $\mathrm{Ge}-\mathrm{H}$ bonding. From the $640 \mathrm{~cm}^{-1}$ peak we calculated the $\mathrm{H}$ content. We find that the $\mathrm{H}$ content decreases with increasing R. Sample GD419 (with $\mathrm{R}=1.7$ ) has the largest amount of $\mathrm{H}$. While there is a pronounced peak near $2100 \mathrm{~cm}^{-1}$ for the low R sample (GD 419), the stretching mode absorption for the high $\mathrm{R}$ sample $(\mathrm{R}=120)$ shows only $2000 \mathrm{~cm}^{-1}$ absorption indicating mostly monohydride bonding. 
Table 2F-1. Deposition conditions for the single i-layer including process gas flow rates, temperature, radio-frequency power, chamber pressure, and deposition time.

\begin{tabular}{|c|c|c|c|c|c|c|c|c|}
\hline Sample & $\mathrm{R}$ & $\mathrm{GeH} 4$ & $\mathrm{Si} 2 \mathrm{H} 6$ & $\mathrm{H} 2$ & Temp & Power & Pressure & Time \\
\hline No. & & $(\mathrm{sccm})$ & $(\mathrm{sccm})$ & $(\mathrm{sccm})$ & $(\mathrm{C})$ & $(\mathrm{W})$ & $($ Torr $)$ & $(\mathrm{min})$ \\
\hline GD419 & 1.7 & 0.72 & 1 & 2.9 & 400 & 3 & 0.6 & 30 \\
\hline GD420 & 10 & 0.72 & 1 & 17.2 & 400 & 3 & 0.6 & 60 \\
\hline GD422 & 30 & 0.72 & 1 & 51.6 & 400 & 3 & 0.6 & 120 \\
\hline GD423 & 50 & 0.72 & 1 & 86.0 & 400 & 3 & 0.6 & 180 \\
\hline GD424 & 120 & 0.72 & 1 & 202 & 400 & 3 & 0.6 & 240 \\
\hline GD449 & 180 & 0.468 & 0.65 & 202 & 400 & 3 & 0.6 & 360 \\
\hline GD450 & 240 & 0.35 & 0.49 & 201 & 400 & 3 & 0.6 & 480 \\
\hline
\end{tabular}

Table 2F-2. Results of measurements on single i-layer films including thickness of film, index of refraction, bandgap, and hydrogen content.

\begin{tabular}{cccccccc}
\hline \hline $\begin{array}{c}\text { Sample } \\
\text { No. }\end{array}$ & $\mathrm{R}$ & $\begin{array}{c}\text { Thickness } \\
(\mathrm{nm})\end{array}$ & $\begin{array}{c}\text { Dep.rate } \\
(\mathrm{nm} / \mathrm{sec})\end{array}$ & $\mathrm{n} @ 600 \mathrm{~nm}$ & $\begin{array}{c}\mathrm{E}_{\mathrm{g}} \\
(\mathrm{eV})\end{array}$ & $\begin{array}{c}\text { [H] from IR } \\
(\text { at.\% })\end{array}$ & $\begin{array}{c}\text { H effusion } \\
\text { relative }\end{array}$ \\
\hline GD419 & 1.7 & 529 & 0.294 & 4.42 & 1.515 & 15.4 & 13.8 \\
GD420 & 10 & 531 & 0.148 & 4.45 & 1.489 & 12.4 & 9.7 \\
GD422 & 30 & 556 & 0.0772 & 4.36 & 1.479 & 10.9 & 13.2 \\
GD423 & 50 & 608 & 0.0563 & 4.29 & 1.482 & 8.6 & 7.9 \\
GD424 & 120 & 410 & 0.0285 & 4.48 & 1.516 & 11.6 & 7.6 \\
GD449 & 180 & 492 & 0.0227 & 4.47 & 1.501 & 5.1 & -- \\
GD450 & 240 & 511 & 0.0177 & 4.53 & 1.482 & 4.7 & -- \\
\hline \hline
\end{tabular}

Figure $2 \mathrm{~F}-1$ shows the $\mathrm{H}$ effusion spectra of these a-SiGe films. The partial pressure of $\mathrm{H}$ is measured during pumping so the $\mathrm{H}$ content is proportional to the integrated area under the curves. A relative value from the integrated area is shown in Table $2 \mathrm{~F}-2$. Again, we see that the $\mathrm{H}$ content decreases with increasing $\mathrm{R}$. It is interesting to note that while $\mathrm{H}$ content is decreased significantly, the bandgap remains approximately the same. This suggests that the Ge contents in the high R samples are likely lower. Another point worthy discussion is the sudden decrease in $\mathrm{H}$ content when $\mathrm{R}$ is increased to 180, implying the occurrence of phase transition from amorphous state to microcrystalline state.

To clarify this structural variation we performed Raman spectroscopy measurements on the three samples with highest dilution. Figure 2F-2 shows the Raman spectra of sample GD424, GD449 and GD450, taken from the front surface of the a-SiGe films on 7059 glass. And for comparison the Raman spectrum of GD450R, taken from the back- side of sample GD450 through the glass substrate, is also shown in the figure. 


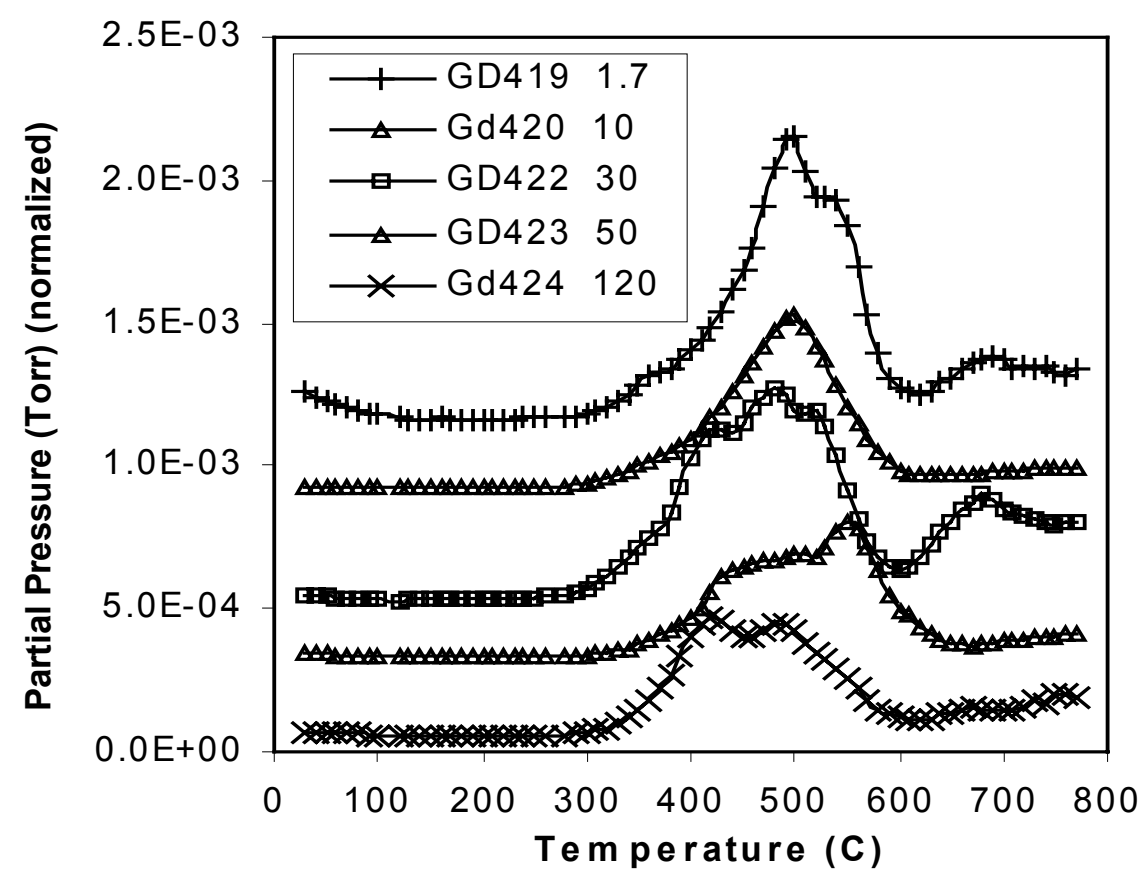

Figure 2F-1. Results of $\mathrm{H}$ effusion experiments performed under differential pumping. Total $\mathrm{H}$ content is the area under the curve.

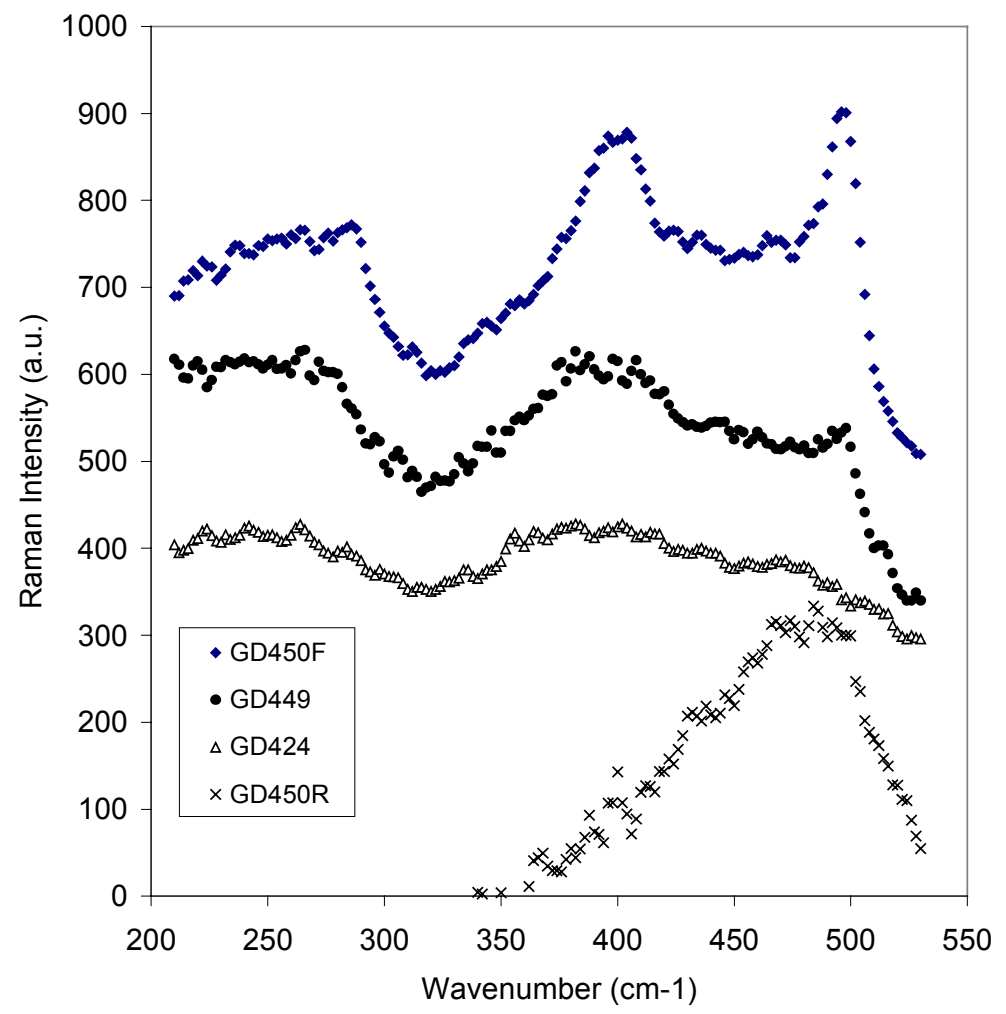

Figure 2F-2 The graph shows the Raman spectra of sample GD424, GD449 and GD450 on 7059 glass. For GD450 we have taken the signals from both sides, the front- and back- side of the sample, denoted as GD450F and GD450R, respectively. 
From these spectra, several Raman characteristic peaks can be seen. For sample GD424 ( $\mathrm{R}=120$ ), two broad peaks were observed at $\sim 390 \mathrm{~cm}^{-1}$ and $\sim 260 \mathrm{~cm}^{-1}$, which may correspond to $\mathrm{Si}-\mathrm{Ge}$ and $\mathrm{Ge}-\mathrm{Ge}$ vibrations in the amorphous network. Compared to the earlier report[F8] on Raman spectra of a-SiGe, these peaks have a red shift of about $10 \mathrm{~cm}^{-1}$, probably due to more $\mathrm{Ge}$ contents in our samples. In addition to the above two peaks, a shoulder at $\sim 470 \mathrm{~cm}^{-1}$ was recognized, which corresponds to the TO phonon of a-Si, while with $10 \mathrm{~cm}^{-1}$ red shift with respect to the normal a-Si TO phonon. This lowered frequency could be due to the presence of the larger mass neighboring Ge atoms in the amorphous network.

As R increases to 240 (GD450), the crystallized SiGe Raman characteristic peaks were observed: the Si-Si TO phonon at $498 \mathrm{~cm}^{-1}$, the Si-Ge vibration at $400 \mathrm{~cm}^{-1}$ and $\mathrm{Ge}-\mathrm{Ge}$ TO phonon at $286 \mathrm{~cm}^{-1}$. This observation is similar to the results reported by Jelenkovic et al[F9], who obtained the three Raman peaks from the SiGe samples deposited by sputtering and crystallized at $550^{\circ} \mathrm{C}$, while our results are based on the microcrystalline SiGe samples prepared only by $\mathrm{H}-$ dilution in PECVD.

For sample GD449 with $\mathrm{R}=180$, we find that it is near the phase transition region from amorphous to microcrystalline state. When $\mathrm{R}$ is increased up to 180 , the $\mathrm{Si}-\mathrm{Si}$ vibration at $498 \mathrm{~cm}^{-1}$ starts to appear in the Raman spectrum, while the Si-Ge vibration at $400 \mathrm{~cm}^{-1}$ keeps nearly unchanged. Similar situation was also observed by Jelenkovic et. al. They found that during annealing crystallization the Si-Si peak first appeared and grew in intensity with annealing time (see their Fig.4). It seems that there are phase segregation phenomena in a-SiGe films and the crystallization begins first from the Si-rich region. Further study is needed to clarify this assumptions.

For the Raman spectrum GD450R, taken from the back-side of GD450 through the glass substrate, only one broad peak can be seen at $480 \mathrm{~cm}^{-1}$, indicating that the film first grown on the glass substrate is still in amorphous state, even though $\mathrm{R}$ is as high as 240. Crystallinity of SiGe films deposited in PECVD process with a high hydrogen dilution depends on the film thickness.

\section{F.4.2 a-SiGe n-i-p Devices}

The a-SiGe films with different $\mathrm{R}$ were used as i-layer for $\mathrm{n}$-i-p solar cells. The device

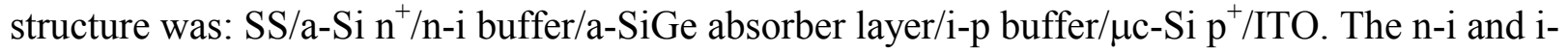
$\mathrm{p}$ buffer layers consisted of a-Si buffer layers next to the doped layer and a-SiGe interface layers with a graded bandgap to reduce bandgap discontinuity. The a-SiGe absorber layer had a graded bandgap such that the bandgap is narrower near the p-side.[F10] Such a graded bandgap is used in the routine fabrication of bottom cells for high efficiency triple-junction solar cells. No backreflector was used for this study since the comparative study would be expected to yield the same results with or without a back-reflector.

For all of these devices, only the i-layer conditions were varied. All other deposition conditions were kept unchanged. In order to fabricate solar cells with i-layer of approximately the same thickness, the i-layer deposition time was adjusted according to the thickness measurement of the single-layer sample. The thickness of the i-layer was measured using a capacitance technique. This thickness includes the thickness of both the a-SiGe absorber layer and the buffer layers. Table 2F-3 shows the solar cell performance of a series of a-SiGe solar cells deposited using different $\mathrm{H}$ dilution, ranging from 1.7 to 240 . The photovoltaic parameters of the cells were measured under a Xenon lamp solar simulator with AM1.5 light. The QE data 
were summarized, using the QE values at $400 \mathrm{~nm}$ and $700 \mathrm{~nm}$. For a-SiGe solar cells deposited on bare SS, the red response was high.

It is seen from the Table that the $\mathrm{J}_{\mathrm{ph}}$ value, obtained by integrating QE curves over AM1.5 spectrum, suggest that the short circuit current is higher for $R=10$ to 120 . The drop in $J_{s c}$ at higher $\mathrm{R}(>120)$ is due to microcrystalline formation. $\mathrm{J}_{\mathrm{sc}}$ values from the $\mathrm{J}-\mathrm{V}$ measurement have slightly larger variation. $\mathrm{J}_{\mathrm{sc}}$ is relatively low for these samples since no back-reflector is used for this study. The FF is highest $(\mathrm{FF}=59.1 \%)$ for $\mathrm{R}=30$, a moderate dilution, which is the condition that we used for the fabrication of the bottom cell of our $11 \%$ triple-junction solar cell. Device GD425 $(\mathrm{R}=30)$ is the same as our standard bottom cells and is used as a reference for this dilution study. The $\mathrm{V}_{\text {oc }}$ increases from $0.64 \mathrm{~V}$ to $0.67 \mathrm{~V}$ with $\mathrm{R}$ up to 120 , before it starts to decrease down to $0.64 \mathrm{~V}$ when $\mathrm{R}$ is further increased to 240, again due to small amount of microcrystalline phase formed at $\mathrm{R}=180$, as expected from the above Raman scattering results taken from high dilution films on glass. Considering the fact that the a-SiGe solar cells are deposited on stainless steel and only 168nm (GD452) thick, the microcrystallinity may not be the same as thick films on glass. Therefore, we performed Raman measurements on the solar cells deposited on SS substrates. Fig. 2F-3 gives the Raman spectra measured from the samples of GD451 and GD452. It is seen that there is a main characteristic peak at $\sim 480 \mathrm{~cm}^{-1}$, indicating that these samples are mostly in amorphous state, and it seems to have a small shoulder at $\sim 500 \mathrm{~cm}^{-1}$, showing the beginning of crystallization. However, due to experimental fluctuation, this shoulder needs to be further verified.

Table 2F-3. Performance of n-i-p devices made with different $\mathrm{H}$ dilution $\mathrm{R}$.

\begin{tabular}{cccccccccccc}
\hline \hline $\begin{array}{c}\text { Device } \\
\text { No. }\end{array}$ & $\begin{array}{c}\mathrm{H} \text { dilution } \\
\mathrm{R}\end{array}$ & $\begin{array}{c}\text { Time } \\
(\mathrm{min})\end{array}$ & $\begin{array}{c}\text { Thickness } \\
(\mathrm{nm})\end{array}$ & $\begin{array}{c}\mathrm{V}_{\mathrm{oc}} \\
(\mathrm{V})\end{array}$ & $\begin{array}{c}\mathrm{J}_{\mathrm{sc}} \\
\left(\mathrm{mA} / \mathrm{cm}^{2}\right)\end{array}$ & $\begin{array}{c}\mathrm{FF} \\
(\%)\end{array}$ & $\begin{array}{c}\mathrm{P}_{\max } \\
(\%)\end{array}$ & $\begin{array}{c}\mathrm{QE} \\
\text { at } 400 \mathrm{~nm}\end{array}$ & $\begin{array}{c}\text { aE } \\
\text { at }\end{array}$ & $\begin{array}{c}\mathrm{J}_{\mathrm{ph}} \\
(\mathrm{QE})\end{array}$ & $\begin{array}{c}\text { Light Degrad. } \\
(\%)\end{array}$ \\
\hline GD429 & 1.7 & 9.5 & 189 & 0.638 & 13.9 & 53.8 & 5.54 & 0.57 & 0.37 & 13.7 & $>21.1$ \\
GD428 & 10 & 19 & 190 & 0.640 & 16.2 & 53.1 & 6.02 & 0.58 & 0.42 & 14.4 & 20.9 \\
GD425 & 30 & 36 & 189 & 0.656 & 15.7 & 59.1 & 6.76 & 0.59 & 0.43 & 14.5 & 21.6 \\
Gd426 & 50 & 50 & 175 & 0.662 & 15.8 & 55.0 & 6.25 & 0.58 & 0.32 & 14.0 & 14.2 \\
GD427 & 120 & 98 & 190 & 0.669 & 14.9 & 54.8 & 6.25 & 0.60 & 0.39 & 14.3 & 11.4 \\
GD451 & 180 & 123 & 176 & 0.656 & 15.8 & 56.0 & 6.65 & 0.64 & 0.27 & 13.6 & -- \\
GD452 & 240 & 158 & 168 & 0.636 & 14.7 & 55.8 & 6.55 & 0.63 & 0.29 & 13.6 & -- \\
\hline \hline
\end{tabular}




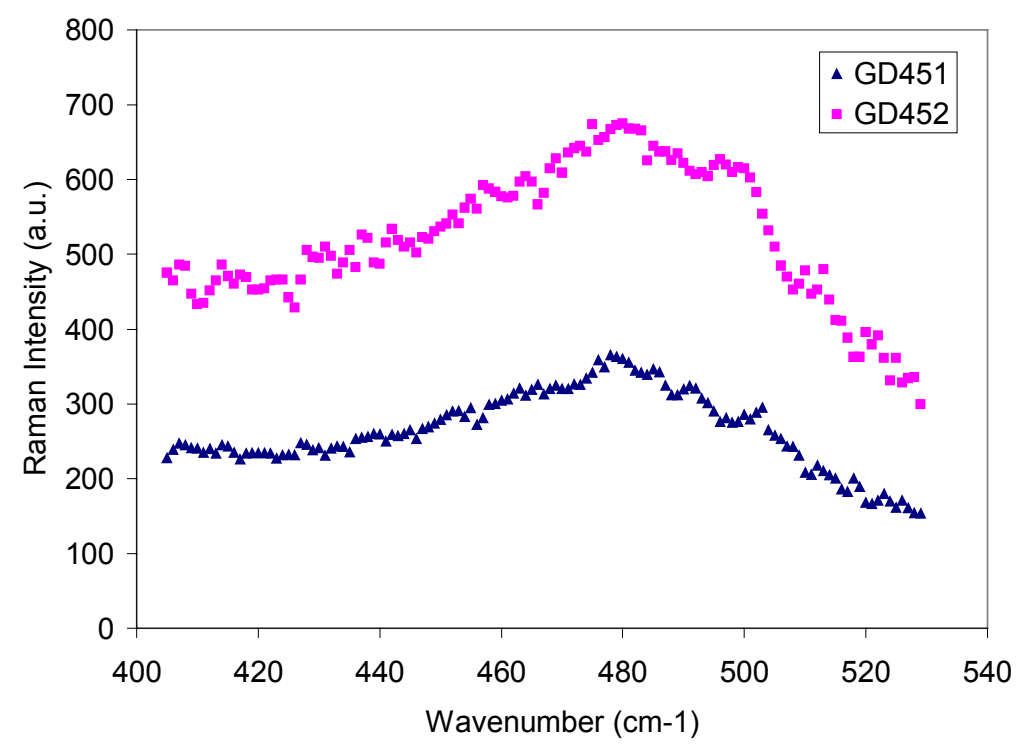

Figure 2F-3 This figure shows the Raman spectra measured from the surface of the cell samples of GD451 $(\mathrm{R}=180)$ and GD452 $(\mathrm{R}=240)$ on stainless steel substrate.

\section{F.4.3 Light Soaking Stability Test}

Light soaking tests for these a-SiGe samples were performed to understand the effect of $\mathrm{R}$ on the device stability. The light soaking was done under a metal halide lamp with one-sun light intensity. This lamp is relatively blue rich and has somewhat less red light compared with AM1.5 global spectrum. Our samples are light soaked under one-sun light intensity. Since an aSiGe bottom cell typically sees only one third of the sun light inside a triple-junction solar cell, this one-sun light intensity is approximately three times more intense than that in the standard testing conditions. However, the relative trend among these samples would likely remain the same. The last column of Table $2 \mathrm{~F}-3$ shows the degradation under one-sun light soaking at $50{ }^{\circ} \mathrm{C}$ for 1000 hours. The degradation for sample GD429 at 1000 hours of soaking is unavailable since all of the test cells were shorted. The 300-hour soaking results shows a degradation of $21.1 \%$, which is expected to be further increased at 1000 hours. It is found that the degradation is reduced with higher $\mathrm{R}$, down from $20.9 \%$ for $\mathrm{R}=10$ to $11.4 \%$ for $\mathrm{R}=120$. Degradation of Samples GD451 and GD452 are not included here since they were fabricated later. From Table 2F-3, one concludes that before light soaking, $\mathrm{R}=30$ (GD425) shows the highest $\mathrm{P}_{\max }$ while after light soaking, $\mathrm{R}=120$ (GD427) shows the highest $\mathrm{P}_{\max }$.

2F.4.4 a-SiGe solar cells with i-layer made with graded $\mathrm{H}$ dilution

We observed that although the films prepared with a higher hydrogen dilution $(R=120)$ have a lower initial efficiency compared to those in our standard cell $(\mathrm{R}=30)$, they are found to be more 
stable and have a higher efficiency after $300 \mathrm{hrs}$ of light soaking. Since the i-layer prepared with a higher hydrogen dilution tend to be microcrystalline-like with increasing thickness, we tried to investigate the effect of hydrogen dilution grading on the performance of these cells. The structure of these cells is: $\mathrm{SS} / \mathrm{a}-\mathrm{Si} \mathrm{n}^{+} / \mathrm{a}-\mathrm{Si}$ (buffer)/a-SiGe absorber layer/a-Si Buffer/ $\mu \mathrm{c}-\mathrm{Si}$ $\mathrm{p}^{+} /$ITO. The a-Si buffer layers and a-SiGe absorber layer were prepared without any germanium grading. The $\mathrm{GeH}_{4}$ to $\mathrm{Si}_{2} \mathrm{H}_{6}$ ratio is 0.72 , the same as the standard bottom cell i-layer. Four devices are explored, with $\mathrm{H}$ dilution $\mathrm{R}, \mathrm{H}_{2} /\left(\mathrm{GeH}_{4}+\mathrm{Si}_{2} \mathrm{H}_{6}\right)$, as in the following: 1) $\mathrm{R}=30$, unchanged, 2) $\mathrm{R}=117$, unchanged, 3) $\mathrm{R}$ changes from 30 to 117 linearly and 4) $\mathrm{R}$ changes from 30 to 117 linearly. The i-layer deposition time is adjusted to obtain the same thickness. For comparison, the cells were prepared on SS substrate with and without back reflector in the same deposition run.

Table 2F-4 J-V performance of a-SiGe cells with the a-SiGe i-layer deposited using different grading of H-dilution $\mathrm{R}$.

\begin{tabular}{|l|c|c|c|c|c|}
\hline Device & $\mathrm{R}$ & Substra. & $\mathrm{V}_{\mathrm{oc}}$ & $\mathrm{J}_{\mathrm{sc}}$ & $\mathrm{FF}$ \\
\hline & & & $\mathrm{V})$ & $\left(\mathrm{mA} / \mathrm{cm}^{2}\right)$ & $(\%)$ \\
\hline GD443 & \multirow{2}{*}{30 to 30} & $\mathrm{SS}$ & 0.660 & 17.4 & 55.3 \\
\cline { 3 - 6 } & & $\mathrm{BR}$ & 0.645 & 19.6 & 56.4 \\
\hline GD446 & 117 to 117 & $\mathrm{SS}$ & 0.674 & 17.1 & 53.5 \\
\cline { 3 - 6 } & & $\mathrm{BR}$ & 0.650 & 20.2 & 53.0 \\
\hline GD444 & \multirow{3}{*}{30 to 117} & $\mathrm{SS}$ & 0.680 & 18.3 & 53.2 \\
\cline { 3 - 6 } & & $\mathrm{BR}$ & 0.658 & 20.3 & 54.9 \\
\hline GD445 & \multirow{2}{*}{117 to 30} & $\mathrm{SS}$ & 0.679 & 17.0 & 56.2 \\
\cline { 3 - 6 } & & $\mathrm{BR}$ & 0.663 & 19.4 & 58.0 \\
\hline
\end{tabular}

$\mathrm{I}-\mathrm{V}$ measurements on this series of samples show that the cells prepared with hydrogen dilution grading $117 \rightarrow 30$ have higher $\mathrm{V}_{\mathrm{oc}}$ and $\mathrm{FF}$, whereas the cells prepared with $\mathrm{R}=117$ through out have lowest $\mathrm{V}_{\mathrm{oc}}, \mathrm{FF}$. The cells prepared with $\mathrm{R}=30$ have the performance which is slightly below the graded $\mathrm{R}(117 \rightarrow 30)$ cells. The $\mathrm{J}_{\mathrm{sc}}$ values for all the samples are nearly the same. Table $2 \mathrm{~F}-4$ lists the average cell performance for these cells. Similar results are also obtained for the cells made on substrate with back reflector, except that the $\mathrm{J}_{\mathrm{sc}}$ value is higher for these cells as compared to the cells made on bare SS. 


\section{F.5 CONCLUSION}

We have deposited a series single-layer films and n-i-p solar cells devices using narrow bandgap $(\sim 1.5 \mathrm{eV})$ a-SiGe materials deposited via PECVD using different $\mathrm{H}$ dilution ranging from $\mathrm{R}=1.7$ to 240 . Samples with higher $\mathrm{R}$ value showed lower amounts of $\mathrm{H}$ incorporated into the film though the bandgap remained approximately the same. This suggests that the Ge content in films deposited with higher $\mathrm{R}$ is likely lower. Measurements of Ge content in these films will be performed to verify this. The results from the devices and films deposited using different $\mathrm{H}$ dilution suggest that a high $\mathrm{H}$ dilution up to 120 could be used to deposit a-SiGe films with improved light stability. Amorphous SiGe devices were prepared with i-layer made using graded $\mathrm{H}$ dilution. Device with i-layer dilution from 117 down to 30 show the highest Voc and FF. 


\section{G. Comparison study of a-SiGe films and n-i-p devices with different Ge content in the i-layer}

\section{G.1 Summary}

In order to improve our understanding of the influence of the germanium content on the optoelectronic properties of amorphous silicon germanium alloy thin films and the performance of the n-i-p solar cells with the corresponding i-layer, we prepared and studied a series of a-SiGe films and n-i-p solar cells with varying $\mathrm{GeH}_{4}$ to $\mathrm{Si}_{2} \mathrm{H}_{6}$ ratio in the process gas from 1.43 to 0 . These silicon germanium alloys are used for making different i-layers in a multi-junction solar cell in order to capture the full range of the solar spectra. These studies help in optimizing the device performance for better efficiency and stability. Establishing such a baseline is necessary for the further improvement of our devices from our present $11 \%$ initial triple cells.

We deposited about $0.7 \mu$ m thick a-SiGe layers with varying $\mathrm{GeH}_{4}$ to $\mathrm{Si}_{2} \mathrm{H}_{6}$ ratio, on Corning 7059 glass, crystalline silicon and stainless steel substrates. We found that as the $\mathrm{GeH}_{4}$ to $\mathrm{Si}_{2} \mathrm{H}_{6}$ ratio in the process gas increases, the band gap $\mathrm{E}_{\mathrm{g}}$ decreases. $\mathrm{E}_{\mathrm{g}}$ is $1.36 \mathrm{eV}$ for a $\mathrm{GeH}_{4}$ to $\mathrm{Si}_{2} \mathrm{H}_{6}$ ratio of 1.43 (highest $\mathrm{GeH}_{4}$ flow) while $\mathrm{E}_{\mathrm{g}}$ is $1.84 \mathrm{eV}$ for a ratio of zero (no $\mathrm{GeH}_{4}$ flow). FTIR measurements show that the total hydrogen content (as determined by the bending mode near $600 \mathrm{~cm}^{-1}$ including the $\mathrm{Ge}-\mathrm{H}$ bending mode) increases with decreasing Ge content. In addition, films with higher Ge content are less photosensitive.

$\mathrm{N}$-i-p solar cells which have i-layers corresponding to these a-SiGe films were fabricated. We observe that $\mathrm{V}_{\text {oc }}$ and $\mathrm{FF}$ increase, whereas $\mathrm{J}_{\mathrm{sc}}$ decreases as the Ge content is lowered. A similar trend is observed in the QE measurements, where the integrated current $\mathrm{J}_{\mathrm{ph}}$ decreases as the Ge content is decreased.

\section{G.2 Introduction}

Amorphous silicon germanium alloys are usually used as the bottom and middle cell ilayers in a high-efficiency triple-junction amorphous silicon alloy based solar cells. By varying the amount of $\mathrm{Ge}$ in the i-layer, the band gap can be varied from $\sim 1.1 \mathrm{eV}$ (in pure a-Ge films) to $\sim 1.8 \mathrm{eV}$ ( pure a-Si films). This allows the capture of the full range of the solar spectra in different layers and thus increases the efficiency of the solar cells. However, the properties of aSiGe alloy films and the performance of a-SiGe solar cells deposited in different laboratories or different manufacturing plants are not necessary the same. Therefore, the Ge contents in the bottom and middle cell i-layer optimal for high-efficiency triple-junction solar cell are likely different in different laboratories. In this work, we study a-SiGe alloy materials and solar cells to establish the choice of a-SiGe alloys optimal for use as the bottom and middle cell i-layers in our laboratory. Such a component cell study is important for further improving our cells with efficiency beyond our present $11 \%$ triple cells.

We have made a-SiGe films with varying amount of Ge and then used these alloys as the i-layers in fabricating single-junction solar cells. Some of these layers are standard i-layers that have been routinely used in the fabrication of our triple junction solar cells, as the bottom, middle and top cell i-layers. To find a-SiGe i-layer that yield higher triple-cell efficiency than our current standard a-SiGe i-layers, we also explored a-SiGe alloy materials with intermediate Ge content between the bottom and middle cells and between the middle and top cells. In addition, we made some cells which have higher Ge content than our regular bottom cell. 


\section{G.3 Experimental Details}

A-SiGe films, approximately $0.7 \mu \mathrm{m}$ thick, are deposited on Corning 7059 glass, c-Si substrates and stainless steel (SS) with varying $\mathrm{GeH}_{4}$ to $\mathrm{Si}_{2} \mathrm{H}_{6}$ ratio. The hydrogen flow is the same as that for our standard cells. For i-layers with the intermediate Ge content, hydrogen and $\mathrm{Si}_{2} \mathrm{H}_{6}$ flows were adjusted accordingly. Table $2 \mathrm{G}-1$ shows the deposition conditions for these aSiGe films, including the flow of $\mathrm{GeH}_{4}, \mathrm{Si}_{2} \mathrm{H}_{6}, \mathrm{H}_{2}$, the substrate temperature, rf power, chamber pressure and deposition time. The deposition times are adjusted so that these samples have approximately the same thickness. It is to be noted that GD357, GD359 and GD361 are deposited under the same conditions as the i-layers in our regular bottom, middle and top cells, except that GD357 has no Ge grading as we have in our bottom cell. These samples serve as the reference points for this set of samples. $\mathrm{N}-\mathrm{i}-\mathrm{p}$ solar cells using these a-SiGe materials as the ilayers are deposited on $\mathrm{SS}$ with and without a $\mathrm{Ag} / \mathrm{ZnO}$ back reflector. $\mathrm{J}-\mathrm{V}$ measurements are taken under a Xenon solar simulator.

Table 2G-1 Deposition conditions for a-SiGe films with different Ge contents.

\begin{tabular}{ccccccccccc}
\hline \hline & $\begin{array}{c}\text { Used in } \\
\text { triple-cell }\end{array}$ & $\begin{array}{c}\mathrm{GeH}_{4} \\
(\mathrm{sccm})\end{array}$ & $\begin{array}{c}\mathrm{Si}_{2} \mathrm{H}_{6} \\
(\mathrm{sccm})\end{array}$ & $\begin{array}{c}\mathrm{H}_{2} \\
(\mathrm{sccm})\end{array}$ & $\begin{array}{c}\mathrm{Temp} \\
(\mathrm{C})\end{array}$ & $\begin{array}{c}\text { Time } \\
(\mathrm{min})\end{array}$ & $\begin{array}{c}\text { Power } \\
(\mathrm{W})\end{array}$ & $\begin{array}{c}\text { Pressure } \\
(\text { Torr })\end{array}$ & $\mathrm{GeH}_{4} / \mathrm{Si}_{2} \mathrm{H}_{6}$ & $\left.\mathrm{H}_{2} / \mathrm{Si}_{2} \mathrm{H}_{6}+\mathrm{GeH}_{4}\right)$ \\
\hline GD431 & & 1.00 & 0.7 & 50 & 400 & 180 & 3 & 0.6 & 1.43 & 32 \\
GD430 & & 0.80 & 0.8 & 50 & 400 & 180 & 3 & 0.6 & 1 & 33 \\
GD357 & bottom & 0.72 & 1 & 50 & 400 & 180 & 3 & 0.6 & 0.72 & 30 \\
GD358 & & 0.63 & 1.25 & 60 & 350 & 180 & 3 & 0.6 & 0.504 & 33 \\
GD359 & middle & 0.54 & 1.5 & 70 & 300 & 180 & 3 & 0.6 & 0.36 & 35 \\
GD360 & & 0.27 & 1.5 & 72.5 & 250 & 240 & 2.25 & 0.6 & 0.18 & 42 \\
GD361 & top & 0 & 1.5 & 75 & 200 & 300 & 2.5 & 0.6 & 0 & 50 \\
\hline \hline
\end{tabular}

\section{G.4 RESULTS AND DISCUSSION}

\section{G.4.1 Single layer amorphous silicon germanium films}

Figure 2G-1 shows the transmission spectrum of a typical sample GD357, which is deposited using the same $\mathrm{GeH}_{4} / \mathrm{Si}_{2} \mathrm{H}_{6}$ ratio as our standard bottom cell i-layer. This transmission spectrum is measured using a dual beam visible/near IR spectroscopy. No substrate is used in the reference beam during the measurements. In the spectrum, there are clear interference fringes within the measured range. The refractive index $\mathrm{n}$ in the weak and medium absorption region and the thickness $d$ for these samples are calculated from the position of these interference fringes and their transmission values. ${ }^{7}$ In Figure $2 \mathrm{G}-2$, the refractive index $n$ as a function of $\left(1 / \lambda^{2}\right)$ is plotted. A linear fitting allows us to extrapolate the $n$ values in the strong absorption region. The $n$-value estimated from this extrapolation is then used together with the transmission values in the strong absorption region to obtain the absorption coefficient $\alpha$. 
Figure $2 \mathrm{G}-3$ is the Tauc plot $(\alpha h v)^{1 / 2}$ vs hv, for the sample in the range 590-750nm ( for GD357). A linear fitting of the plot gives material's bandgap. A fitting with better $R$-squared value could be obtained using a smaller fitting range, which gives a slightly higher $E_{g}$ value. However, as long as the fitting procedure is consistent, the conclusion for this study remains unaffected.

Using the procedure described above, $n, \mathrm{~d}$ and $E_{g}$ for all of the samples with different [Ge] are measured and summarized in Table 2G-2. The deposition rates are obtained from the thickness and deposition times. It is found that the deposition rate is reduced by nearly about $50 \%$ when $\mathrm{GeH}_{4} / \mathrm{Si}_{2} \mathrm{H}_{6}$ ratio decreases from 1.43 to 0 . This is because the films with less $\mathrm{GeH}_{4}$ flow are prepared with higher hydrogen dilution. Figure $2 \mathrm{G}-4$ shows $\mathrm{E}_{\mathrm{g}} \mathrm{vs}_{\mathrm{GeH}} / \mathrm{Si}_{2} \mathrm{H}_{6}$ ratio for these films.

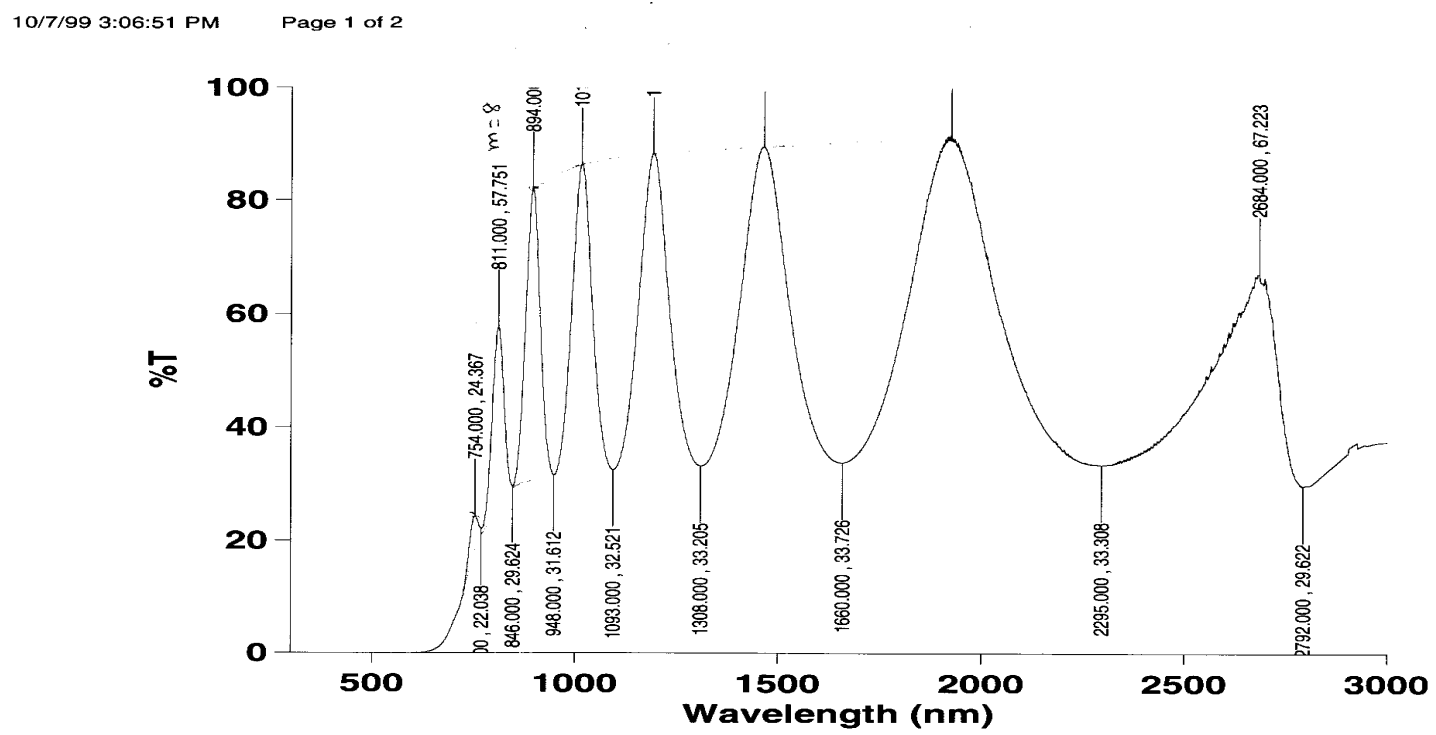

Figure 2G-1. Transmission spectrum of a typical a-SiGe film (GD357).

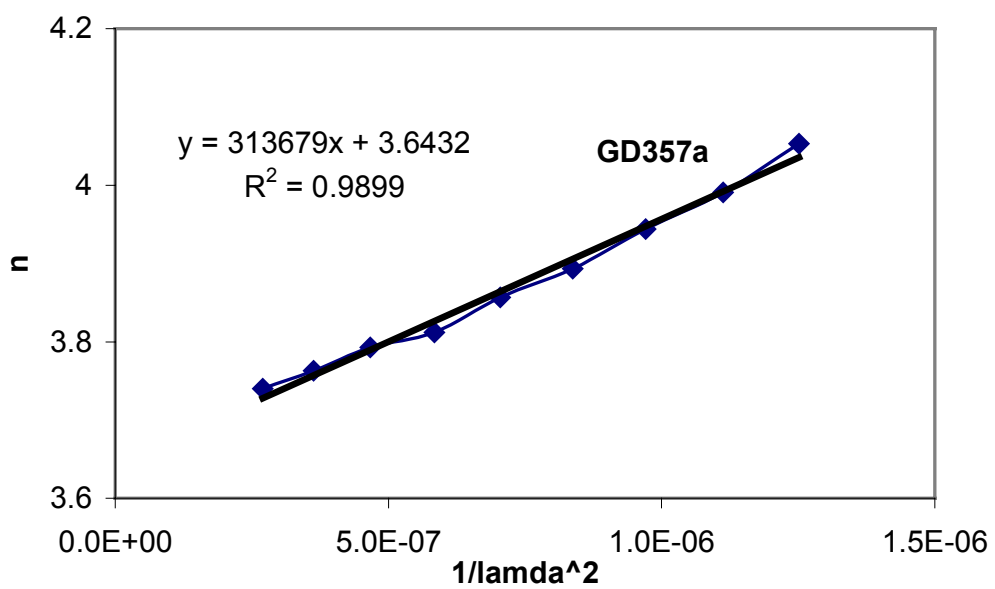

Figure 2G-2. Refractive index as a function of $1 / \lambda^{2}$. 


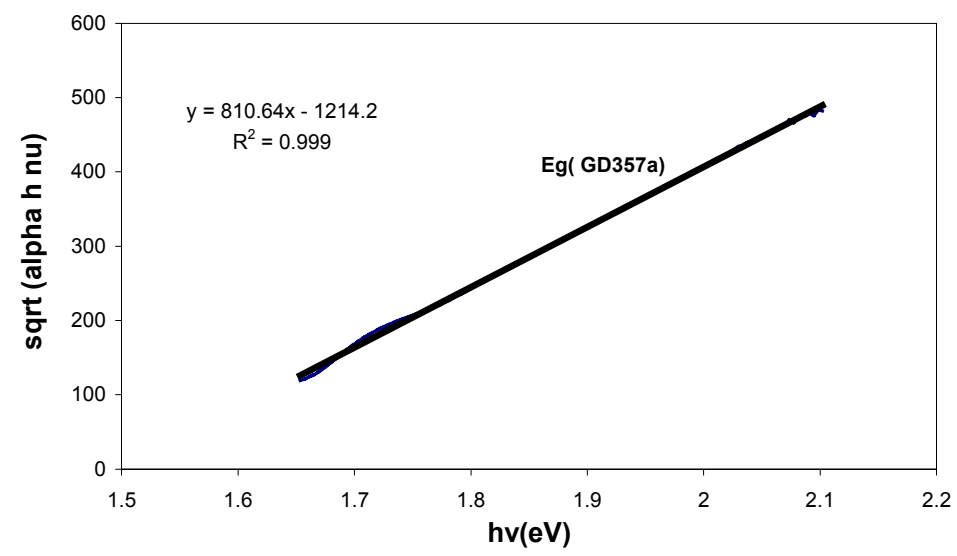

Figure 2G-3. Tauc plot, $(\alpha h v)^{1 / 2}$ vs hv, used to determine the bandgap $\mathrm{E}_{\mathrm{g}}$.

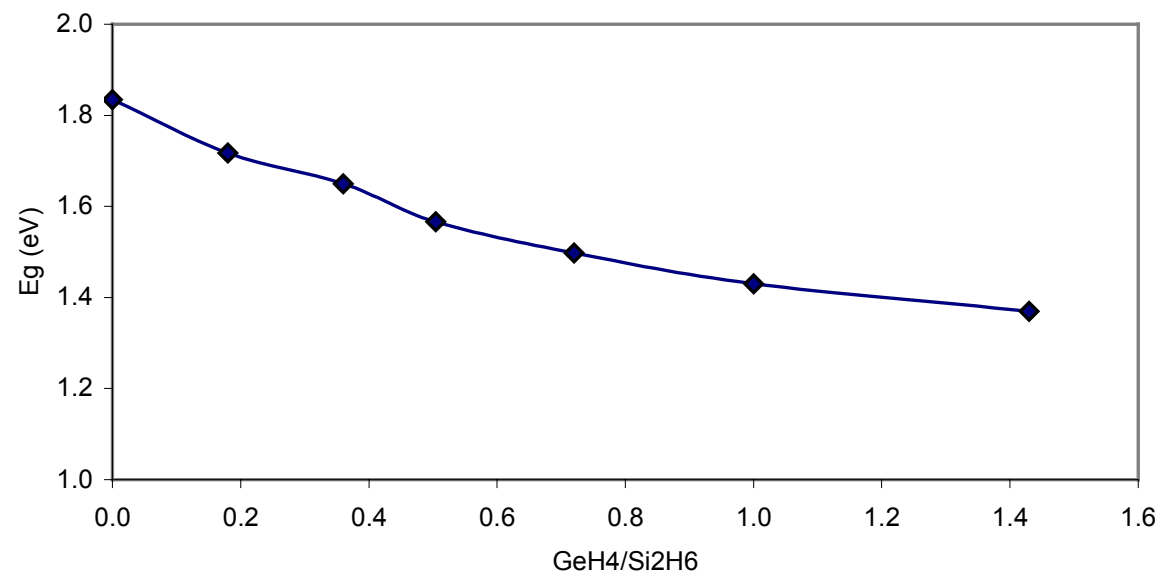

Figure 2G-4. The bandgap $\mathrm{E}_{\mathrm{g}}$ of a-SiGe films as a function of $\mathrm{GeH}_{4}$ and $\mathrm{Si}_{2} \mathrm{H}_{6}$ gas ratio during deposition. 
Table 2G-2. Film properties n, $\mathrm{d}$, and $\mathrm{E}_{\mathrm{g}}$ for a-SiGe films with different Ge content.

\begin{tabular}{lccccccc}
\hline Sample & $\mathrm{GeH}_{4} / \mathrm{Si}_{2} \mathrm{H}_{6}$ & $\begin{array}{c}\mathrm{H} \text { dilution } \\
\mathrm{R}\end{array}$ & $\begin{array}{c}\text { Thickness } \\
(\mathrm{nm})\end{array}$ & $\begin{array}{c}\text { Dep rate } \\
(\mathrm{nm} / \mathrm{sec})\end{array}$ & $\begin{array}{c}\mathrm{E}_{\mathrm{g}} \\
(\mathrm{eV})\end{array}$ & $\begin{array}{c}\mathrm{n} \\
\text { at } 600 \mathrm{~nm}\end{array}$ & $\begin{array}{c}{[\mathrm{H}]} \\
(\text { at. \%) }\end{array}$ \\
\hline $\mathrm{GD} 431$ & 1.43 & 32 & 720 & 0.0666 & 1.37 & 4.81 & 8.6 \\
$\mathrm{GD} 430$ & 1.00 & 33 & 720 & 0.0666 & 1.43 & 4.49 & 7.8 \\
$\mathrm{GD} 357$ & 0.72 & 30 & 772 & 0.0715 & 1.50 & 4.59 & 10.5 \\
$\mathrm{GD} 358$ & 0.50 & 33 & 774 & 0.0716 & 1.57 & 4.62 & 11.9 \\
$\mathrm{GD} 359$ & 0.36 & 35 & 741 & 0.0686 & 1.65 & 4.27 & 15.0 \\
$\mathrm{GD} 360$ & 0.18 & 42 & 774 & 0.0538 & 1.72 & 4.60 & 18.1 \\
$\mathrm{GD} 361$ & 0.00 & 50 & 727 & 0.0404 & 1.84 & 4.06 & 16.5 \\
\hline \hline
\end{tabular}

Following the work of Mckenzie et al. [1991], we try to estimate the amount of Ge in these films. We use $\mathrm{E}_{\mathrm{g}}=1.76-0.78 \mathrm{x}$ for $\mathrm{a}-\mathrm{Si}_{1-\mathrm{x}} \mathrm{Ge}_{\mathrm{x} \text {. }}$ to estimate the $\mathrm{x}$ for samples $\mathrm{Gd} 431, \mathrm{Gd} 430$, GD357, and Gd358. Whereas, the correction for the band gap for pure amorphous silicon film has been done keeping in mind that these films are prepared with higher hydrogen dilution and at lower temperature. The estimated Ge content as a function of $\mathrm{E}_{\mathrm{g}}$ is plotted in Figure 2G-5.

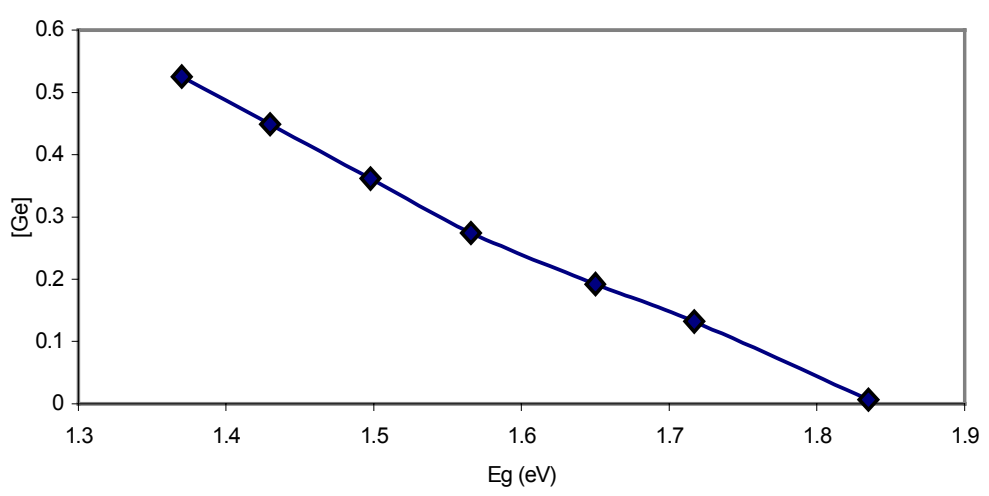

Figure 2G-5. Ge content estimated from the bandgap.

\section{FTIR Measurements}

To find out the $\mathrm{H}$ content and its bonding in our films, infrared absorption for these films is measured using an FTIR spectroscope in the range of $400-4000 \mathrm{~cm}^{-1}$. Figure 2G-6 shows the transmission of these a-SiGe films in the $400-2400 \mathrm{~cm}^{-1}$ range.

The crystalline silicon substrate from the same plot has been used to determine the baseline for these measurements. The curves in Figure 2G-6 are shifted vertically for clarity. There are absorption peaks near 640 and $2000 \mathrm{~cm}^{-1}$, corresponding to the wagging and stretching modes of Si-H (or Ge-H) bonding. In Figure 2G-7, the absorption curves in the range 400$850 \mathrm{~cm}^{-1}$ are plotted to show the $\mathrm{Si}-\mathrm{H}$ and $\mathrm{Ge}-\mathrm{H}$ wagging mode absorption. $\mathrm{H}$ content calculated from the wagging mode absorption is shown in Table 2G-2. Figure 2G-8 shows the smoothened curves of FTIR transmission in the range of $1800-2200 \mathrm{~cm}^{-1}$ to illustrate the features of Si-H and Ge-H stretching modes. 


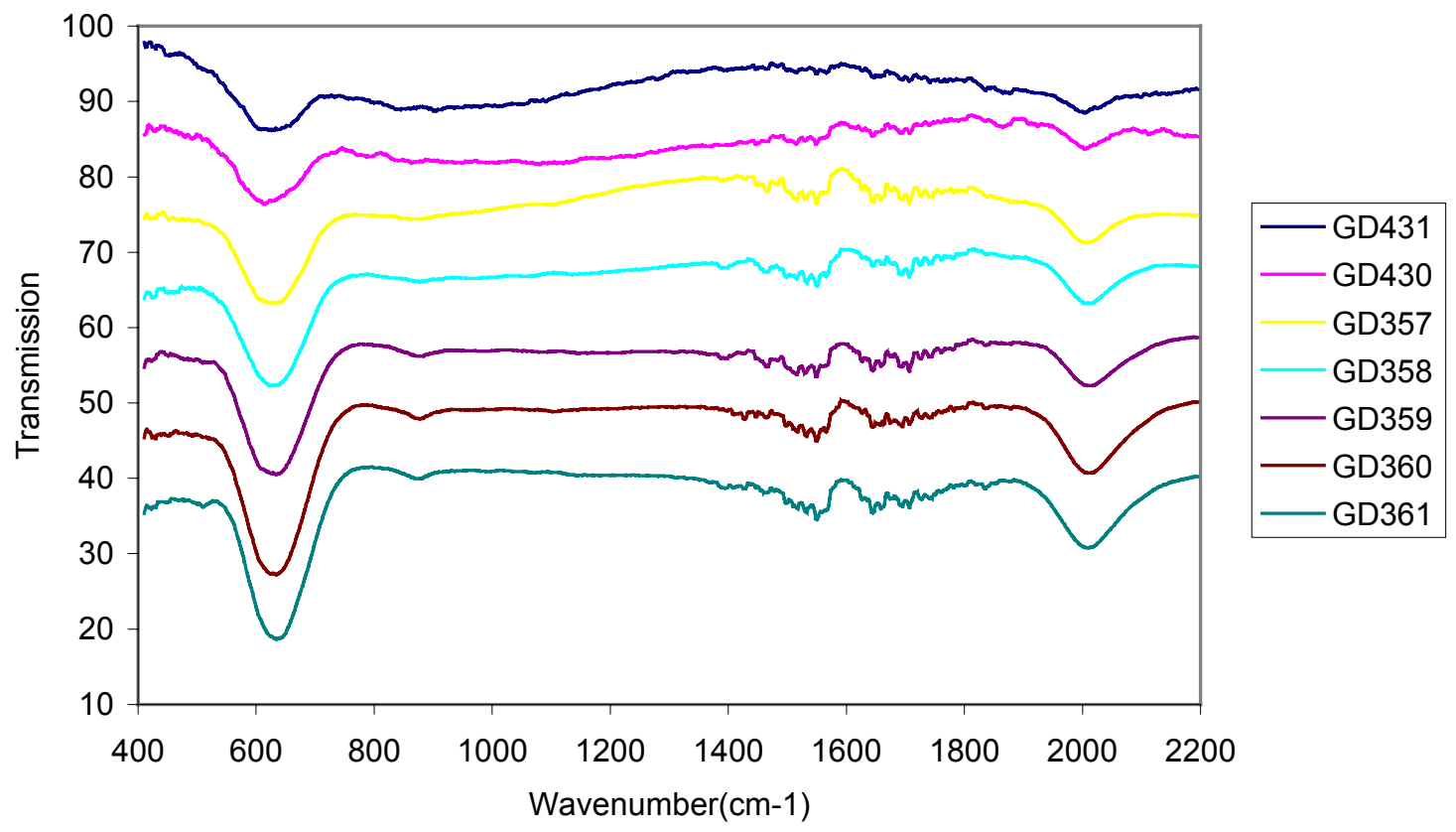

Figure 2G-6. FTIR transmission spectra of a-SiGe films with different Ge content.

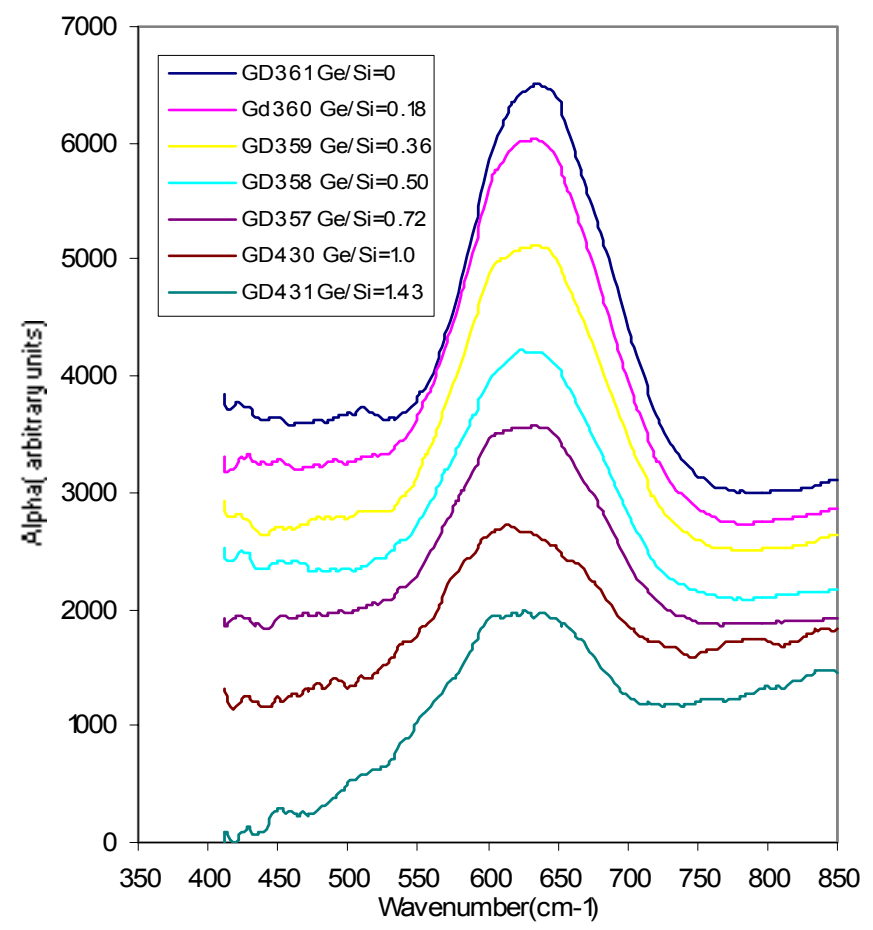

Figure 2G-7. Absorption calculated from FTIR spectra in the $420-850 \mathrm{~cm}^{-1}$ range, showing the wagging mode of $\mathrm{Si}-\mathrm{H}\left(640 \mathrm{~cm}^{-1}\right)$ and $\mathrm{Ge}-\mathrm{H}\left(560 \mathrm{~cm}^{-1}\right)$. 


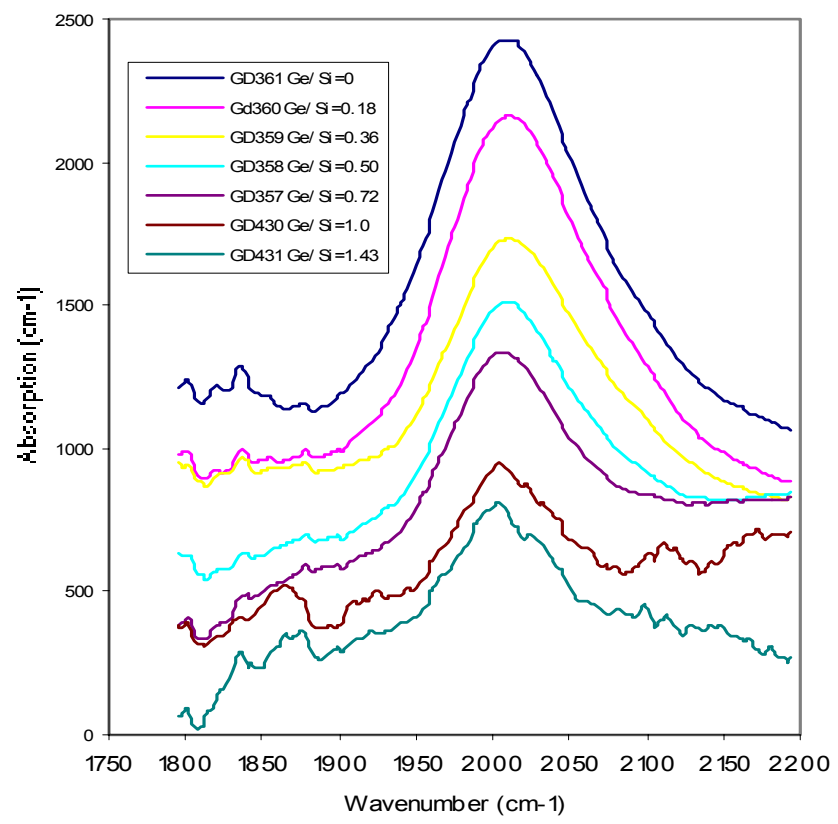

Figure 2G-8. FTIR spectra in the $1800-2200 \mathrm{~cm}^{-1}$ range, showing the stretching mode of Si-H $\left(2000 \mathrm{~cm}^{-1}\right), \mathrm{Si}-\mathrm{H}_{2}\left(2100 \mathrm{~cm}^{-1}\right)$ and $\mathrm{Ge}-\mathrm{H}_{2}\left(1975 \mathrm{~cm}^{-1}\right)$.

Conductivity Measurements

Preliminary dark and photoconductivity measurements on GD357-Gd361 show that the dark conductivity of these films decreases as [Ge] content decrease in these films, however, when [Ge] decreases, these films become more photosensitive, i.e., the photoconductivity to dark conductivity ratio increases upon decreasing [Ge], or in other words, increasing the band gap of these films. Figure 2G-9 Shows the photosensitivity as a function of bandgap for these films under a tungsten lamp. (Intensity less than AM1.5).

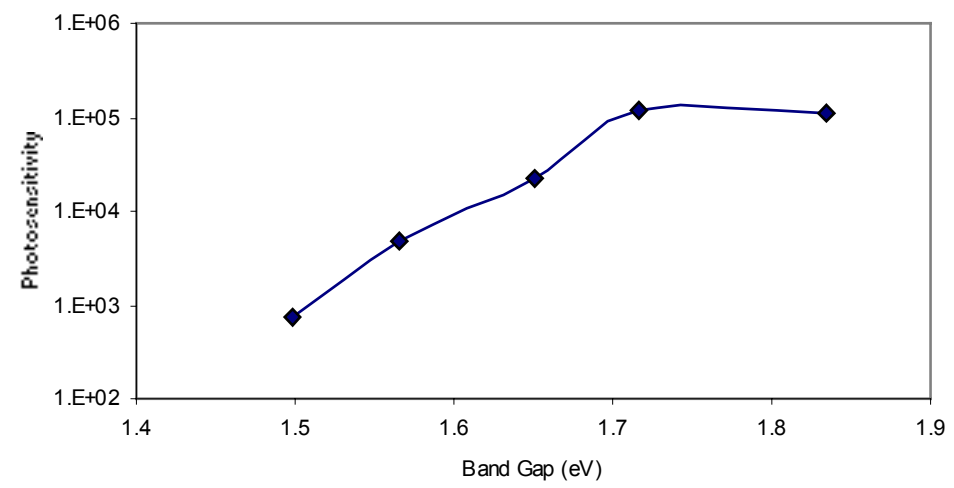

Figure 2G-9. Photosensitivity of a-SiGe films as a function of a-SiGe bandgap for this series of a-SiGe films. 


\section{G.4.2 A-SiGe n-i-p Devices}

These a-SiGe films with varying [Ge] are then used as i-layer for n-i-p solar cells. The device structure is: SS/a-Si n ${ }^{+} / \mathrm{n}-\mathrm{i}$ buffer/a-SiGe absorber layer/i-p buffer/ $\mu \mathrm{c}-\mathrm{Si}^{+} / \mathrm{ITO}$. The $\mathrm{n}-\mathrm{i}$ and i-p buffer layers consist of a-Si buffer layers in between a doped layer and the absorber layer. Unlike our normal cells, these buffer layers did not have any graded bandgap. The Si-Ge absorber layer, also was prepared without any germanium grading to match with the corresponding single layer films.

Table 2G-3 shows the selective i-layer deposition conditions for these a-SiGe solar cells. For all these cells, the $\mathrm{n}^{+}$and $\mathrm{p}^{+}$layers remain the same, whereas the buffer layers were prepared at the absorber layer temperature for the same duration for all the samples. The deposition time for absorber layer for these cells was estimated from the deposition rate of the single layers so that all the samples have the same thickness. However, partially because of the non-uniform deposition on a 4"x 4" substrate and partially because of the fact that the buffer layers were prepared at different temperatures, we find a variation in the thickness of these cells. The thickness of i-layer is measured using capacitance measurement technique and is also included in the table.

Table 2G-3. Deposition conditions for the i-layers of a-SiGe solar cells.

\begin{tabular}{lcccccccc}
\hline \hline & $\begin{array}{c}\text { Used in } \\
\text { triple }\end{array}$ & $\begin{array}{c}\mathrm{GeH}_{4} \\
\mathrm{Sccm}\end{array}$ & $\begin{array}{c}\mathrm{Si}_{2} \mathrm{H}_{6} \\
\text { sccm }\end{array}$ & $\begin{array}{c}\mathrm{H}_{2} \\
\mathrm{Sccm}\end{array}$ & $\begin{array}{c}\text { Time } \\
(\mathrm{min})\end{array}$ & $\begin{array}{c}\text { Thickness } \\
(\mathrm{nm})\end{array}$ & $\mathrm{GeH}_{4} / \mathrm{Si}_{2} \mathrm{H}_{6}$ & $\mathrm{H}$ dilution \\
\hline gd441 & & 1.00 & 0.7 & 50 & 42.0 & 151 & 1.43 & 32 \\
gd442 & & 0.80 & 0.8 & 50 & 42.0 & 184 & 1.00 & 33 \\
gd443 & bottom & 0.72 & 1 & 50 & 39.2 & 171 & 0.72 & 30 \\
gd435 & bottom & 0.72 & 1 & 50 & 37.3 & 153 & 0.72 & 33 \\
gd436 & & 0.63 & 1.25 & 60 & 39.1 & 171 & 0.50 & 33 \\
gd437 & middle & 0.54 & 1.5 & 70 & 40.9 & 209 & 0.36 & 35 \\
gd438 & & 0.27 & 1.5 & 72.5 & 52.1 & 215 & 0.18 & 42 \\
gd439 & top & 0 & 1.5 & 75 & 69.3 & 194 & 0.00 & 50 \\
\hline \hline
\end{tabular}

Figure $2 \mathrm{G}-10$ shows a representative $\mathrm{J}-\mathrm{V}$ curve of a cell in a sample GD435 $\left(\mathrm{GeH}_{4} / \mathrm{Si}_{2} \mathrm{H}_{6}\right.$ $=0.72$, average Ge content in our standard bottom cell with graded Ge) measured under a Xenon lamp solar simulator at an intensity of $100 \mathrm{~mW} / \mathrm{cm}^{2}$. This device shows a $\mathrm{V}_{\text {oc }} 0.674 \mathrm{~V}$, a $\mathrm{J}_{\mathrm{sc}}$ of $18.1 \mathrm{~mA} / \mathrm{cm}^{2}$, a FF of 56.8 and a $\mathrm{P}_{\max }$ of $6.94 \mathrm{~mW} / \mathrm{cm}^{2}$ corresponding to an efficiency of $6.94 \%$. These values are comparable to our standard solar cells with graded buffer layer and absorber layer. The slight decrease in maximum power may be due to the bandgap discontinuity at the interface of these low bandgap cells. For each device fabricated, there are 23 cell of $0.05 \mathrm{~cm}^{2}$ size. Three cells with highest $P_{\max }$ are selected to represent the device performance. The average performance of the three cells is used for sample comparison and process optimization. 


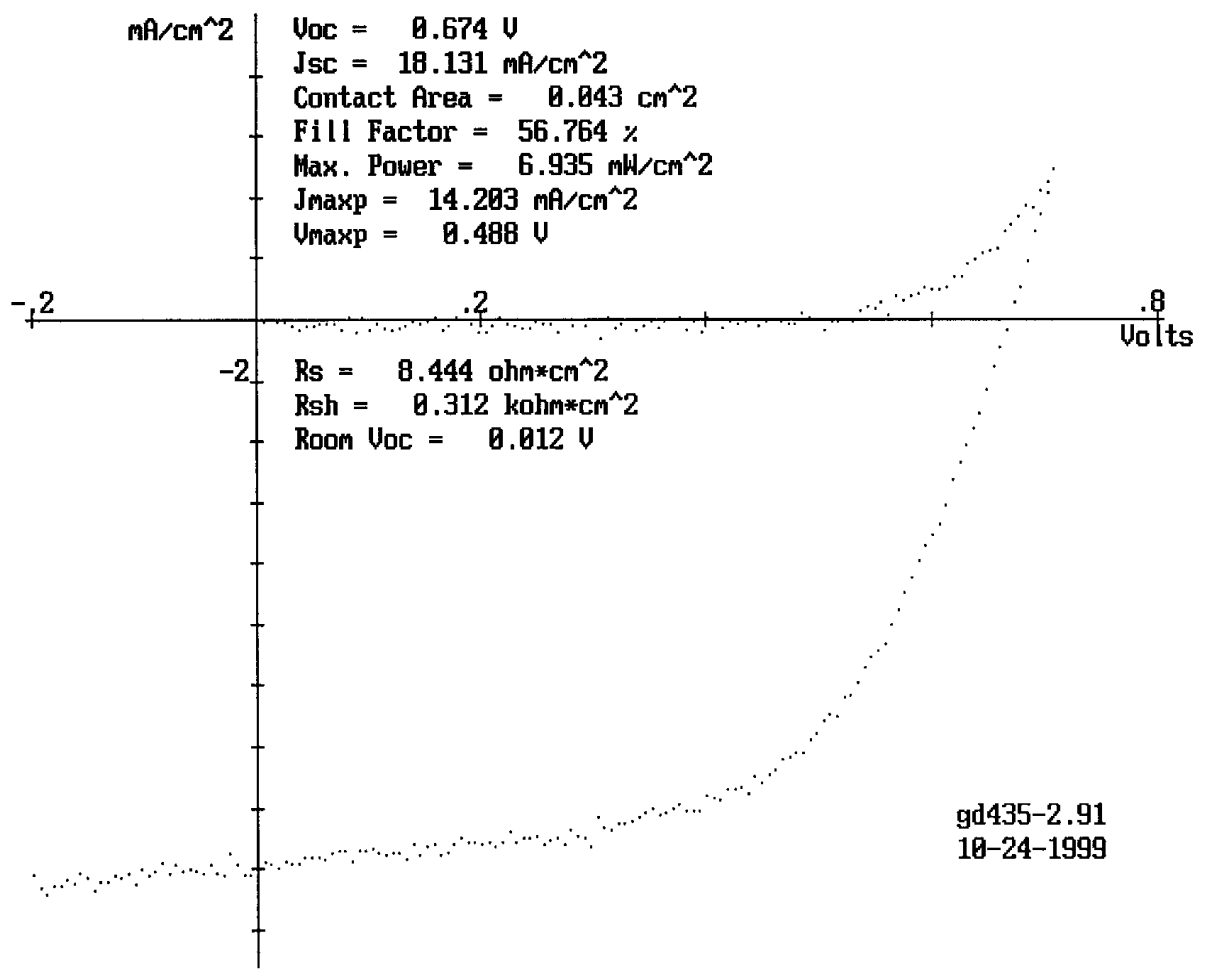

Figure 2G-10. J-V curve of a representative cell (GD435) among the series, which is similar to the bottom cell in a triple-cell. 
In Table 2G-4, we summarize the average performance for all of the a-SiGe devices with different [Ge]. The two samples Gd435 and 443 are prepared using identical conditions at the two extreme ends of the series and their performance show that they are comparable thus a good reproducibility could be established between the different runs using the same preparation conditions. In Table 2G-4, only the average performance for three cells showing highest $\mathrm{P}_{\max }$ for each sample is listed. As we see from the table, the $V_{\mathrm{oc}}$ and $\mathrm{FF}$ increase, whereas $\mathrm{J}_{\mathrm{sc}}$ decrease as $[\mathrm{Ge}]$ content is reduced in these cells.

Table 2G-4. Performance of a-SiGe devices with different Ge content.

\begin{tabular}{|c|c|c|c|c|c|c|c|}
\hline Sample & Cell & $\mathrm{GeH}_{4} / \mathrm{Si}_{2} \mathrm{H}_{6}$ & $\mathrm{~V}_{\mathrm{oc}}$ & $\mathrm{J}_{\mathrm{sc}}$ & $\mathrm{FF}$ & $\mathrm{R}_{\mathrm{s}}$ & $\mathrm{P}_{\max }$ \\
\hline No. & & & $(\mathrm{V})$ & $\left(\mathrm{mA} / \mathrm{cm}^{2}\right)$ & $(\%)$ & $\left(\mathrm{Ohm}^{*} \mathrm{~cm}^{2}\right)$ & $\left(\mathrm{mW} / \mathrm{cm}^{2}\right)$ \\
\hline GD441-2 & & 1.43 & 0.519 & 15.4 & 43.1 & 12.7 & 3.44 \\
\hline GD442-2 & & 1.00 & 0.577 & 16.1 & 50.1 & 9.7 & 4.65 \\
\hline GD443-2 & bottom & 0.72 & 0.660 & 15.3 & 55.3 & 9.9 & 5.58 \\
\hline GD435-2 & bottom & 0.72 & 0.666 & 16.0 & 54.3 & 9.2 & 5.79 \\
\hline GD436-2 & & 0.50 & 0.744 & 13.0 & 63.9 & 8.8 & 6.18 \\
\hline GD437-2 & middle & 0.36 & 0.810 & 14.2 & 61.8 & 9.3 & 7.11 \\
\hline GD437-4 & middle & 0.36 & 0.811 & 14.3 & 60.1 & 10.7 & 6.97 \\
\hline GD438-2 & & 0.18 & 0.849 & 10.5 & 63.1 & 10.7 & 5.63 \\
\hline GD439-2 & top & 0.00 & 0.895 & 8.93 & 69.5 & 10.6 & 5.55 \\
\hline GD439-4 & top & 0.00 & 0.892 & 8.93 & 66.4 & 11.7 & 5.29 \\
\hline
\end{tabular}

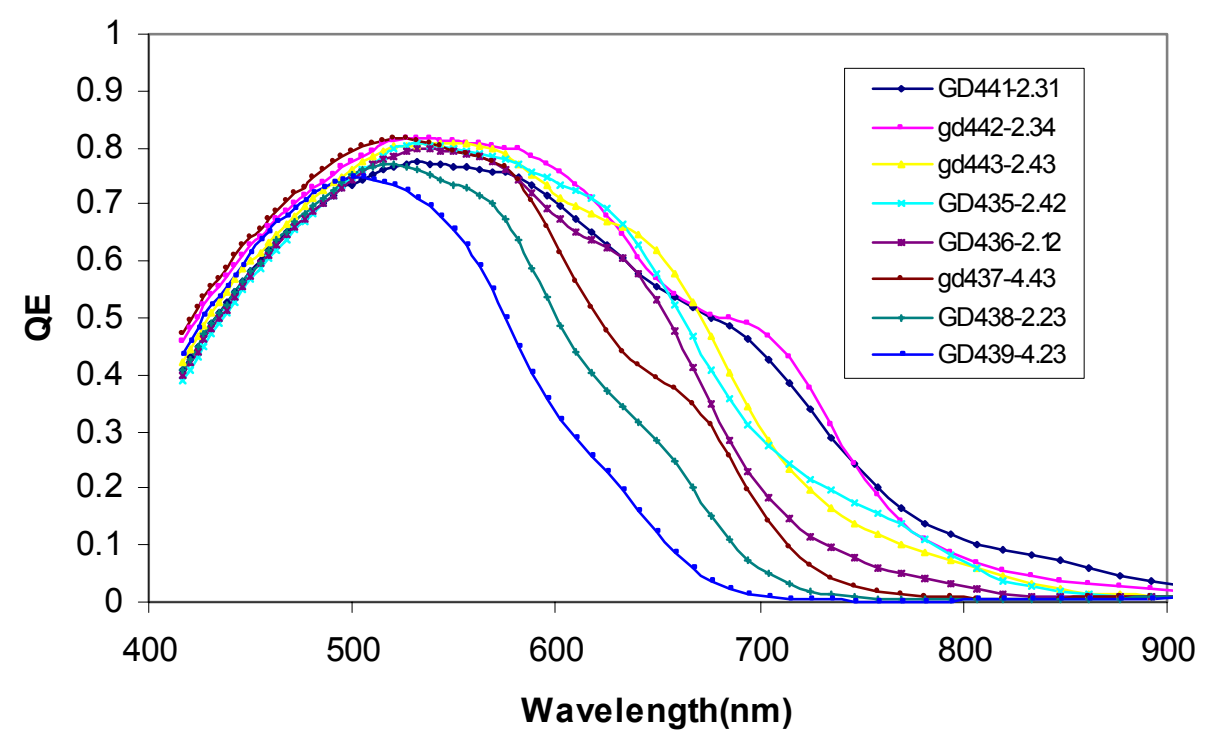

Figure 2G-11. Quantum efficiency of a-SiGe solar cells with different Ge content.

The quantum efficiency for this set of devices with different [Ge] were also measured and shown in Figure 2G-11. The quantum efficiency curves were measured in dark (no bias light) with the monochromatic light beam focussed inside the cell. Therefore, the measurement is independent of the variation in the sample size. For films with higher [Ge], red response is 
higher. A slight variation in the interference fringes of the quantum efficiency curves is due to the variation in the thickness of the film. Figure $2 \mathrm{G}-12$ shows the integrated current density $\mathrm{J}_{\mathrm{ph}}$ as a function of the bandgap of absorber layer in these devices. The $\mathrm{J}_{\mathrm{ph}}$ values are lower than the $\mathrm{J}_{\mathrm{sc}}$ values obtained from J-V curves since 1) $\mathrm{J}_{\mathrm{ph}}$ is integrated with a narrower spectral range (420nm$900 \mathrm{~nm}$ ) for these samples and 2) some light might not be focused inside the $0.05 \mathrm{~cm}^{2}$ cell area during QE measurement. The $\mathrm{J}_{\mathrm{ph}}$ values for the two samples deposited on back-reflector, shown in Figure 2G-11, is not included in Figure 2G-12.

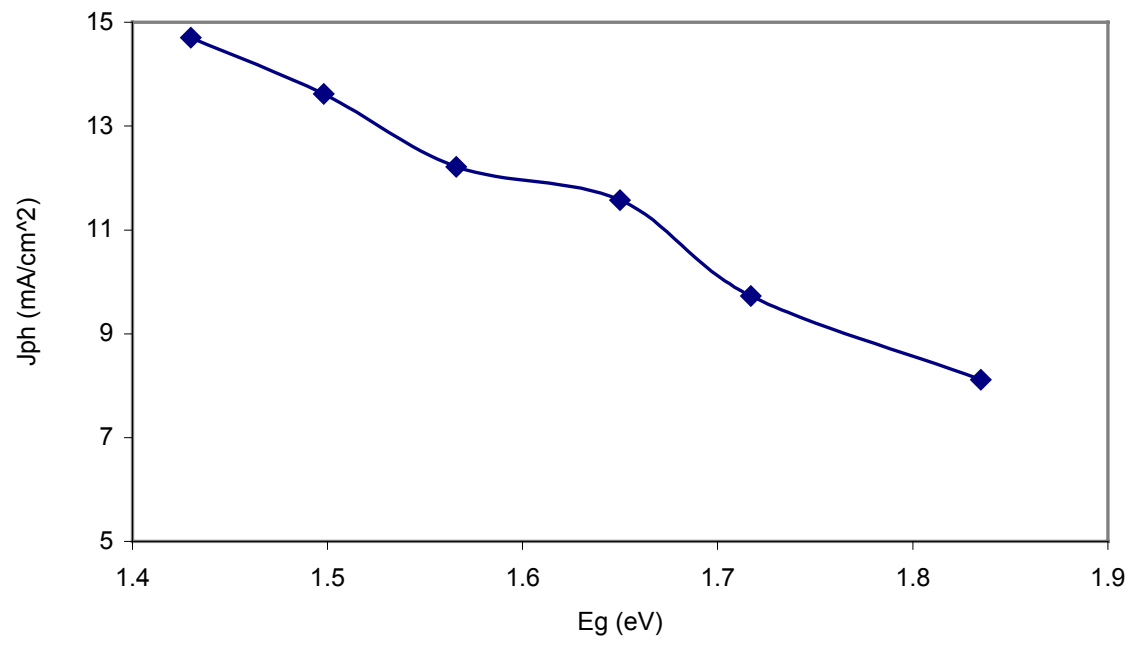

Figure 2G-12. Current integrated from QE for a-SiGe cells, deposited on bare SS, with different bandgaps.

\section{G.4.3 Light soaking stability study}

Light degradation study has been performed for these a-SiGe solar cells with different $\mathrm{Ge}$ contents. These devices were put under One-sun light at around $50{ }^{\circ} \mathrm{C}$ for 1000 hours. While all $\mathrm{V}_{\mathrm{oc}}, \mathrm{J}_{\mathrm{sc}}$ and $\mathrm{FF}$ degrade after 1000 hours of light soaking, we present in Figure 2G-13 and 2G-12 the degradation of FF as a function of the Ge content. Figure 2G-13 shows the FF before light soaking for different samples while Figure $2 \mathrm{G}-14$ shows the percentage drop in FF. We found that devices with small amount of Ge degrades the most, while device with more Ge in the film degrades less, after 1000 hours of light soaking. One should note that the degradation is performed under 1 sun light while a bottom a-SiGe cell usually sees one third of one sun light inside a triple cell.

It is somewhat surprising to note that among this set of devices, pure a-Si device without Ge has lower light degradation than a-SiGe with small amount of Ge. Further study needs to be performed to confirm this and to quantitatively describe the change of light degradation near this level of Ge alloying. 


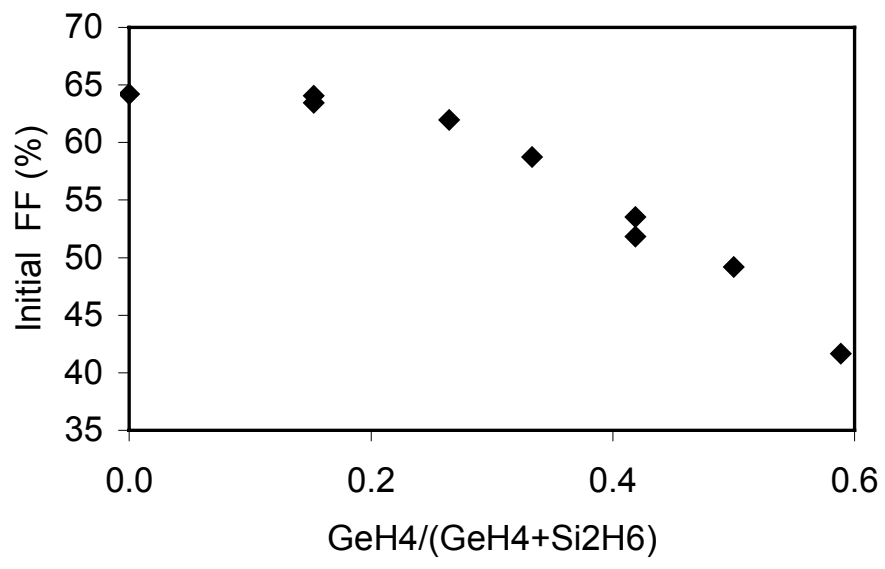

Figure 2G-13. Fill factor before light soaking for a-SiGe devices with different Ge.

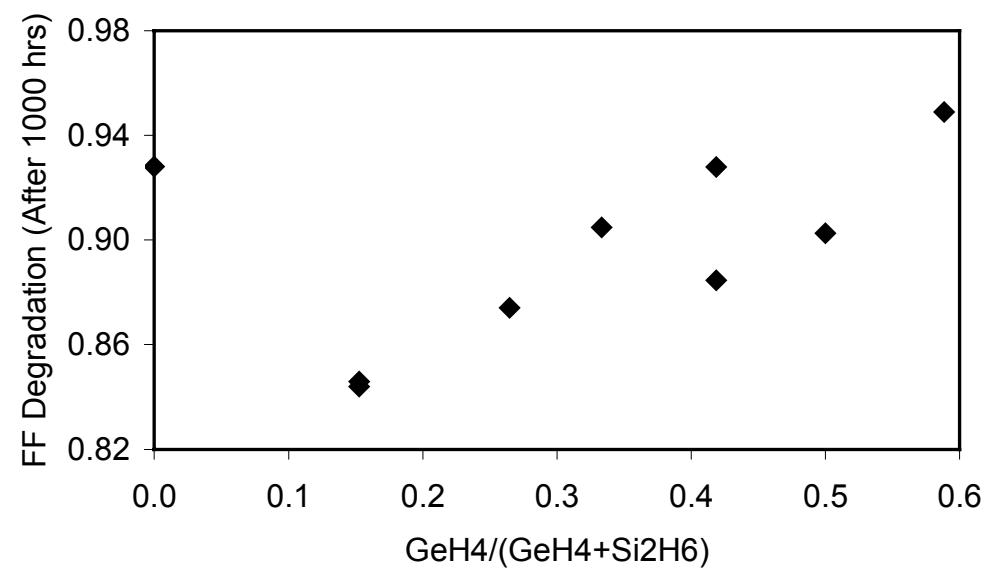

Figure 2G-14. Degradation of FF for devices with different Ge. 


\section{H. Effect of Bandgap Graded Buffer Layer for Narrow Bandgap a-SiGe Cells}

Narrow bandgap (NBG) a-SiGe materials and solar cell devices have been studied extensively for their use in the spectrum splitting, multiple-junction a-Si based solar cells [H1 H4]. To achieve high conversion efficiency solar cells, an a-SiGe absorber layer is usually sandwiched between two thin a-Si buffer layers which are in direct contact with the p- and ndoped layers $[\mathrm{H} 3-\mathrm{H} 5]$. These a-Si buffer layers were found to enhance the performance of aSiGe solar cells. However, even with these a-Si buffer layers, there is still an abrupt discontinuity in the bandgap at the interfaces between these buffer layers and the a-SiGe absorber layer. We investigated the effect of inserting additional a-SiGe interface layers between these a-Si buffer layers and the a-SiGe absorber layer. We found that such additional interface layers increased solar cell $\mathrm{V}_{\mathrm{oc}}$ and $\mathrm{FF}$ sizably, most likely due to the reduction or elimination of the abrupt bandgap discontinuity between the a-SiGe absorber layer and the a-Si buffer layers [H5].

In this section, we report our study on the insertion of additional a-SiGe interface layers (with less Ge compared with the absorber) which reduces the bandgap offset.

The a-SiGe and a-Si materials used in this study were deposited using UT's PECVD system. A gas mixture of $\mathrm{GeH}_{4}, \mathrm{Si}_{2} \mathrm{H}_{6}$ and $\mathrm{H}_{2}$ were used for the a-SiGe deposition and $\mathrm{Si}_{2} \mathrm{H}_{6}$ and $\mathrm{H}_{2}$ for a-Si deposition. The deposition conditions included a substrate temperature range of 300$400{ }^{\circ} \mathrm{C}$, a chamber pressure of 0.5-0.6 Torr and an rf power of 2.5-3.0 W for the a-SiGe and a-Si layer depositions. Different $\mathrm{GeH}_{4}$ to $\mathrm{Si}_{2} \mathrm{H}_{6}$ ratios were used to achieve different bandgaps for a$\mathrm{SiGe}$ material. Graded bandgaps for the a-SiGe absorber layer and the a-SiGe buffer layers were achieved by adjusting $\mathrm{GeH}_{4}$ flows during growth. The $\mathrm{GeH}_{4} / \mathrm{Si}_{2} \mathrm{H}_{6}$ gas flow ratio for the a-SiGe absorber layers studied here was 0.68. All of the intrinsic absorber and buffer layers were deposited in Chamber 2.

The device structure used in this study was: $\mathrm{SS} / \mathrm{Ag} / \mathrm{ZnO} / \mathrm{n}(\mathrm{a}-\mathrm{Si}) / \mathrm{b}(\mathrm{a}-\mathrm{Si}) / \mathrm{i}(\mathrm{NBG}$ a$\mathrm{SiGe}) / \mathrm{b}(\mathrm{a}-\mathrm{Si}) / \mathrm{p}(\mu \mathrm{c}-\mathrm{Si}) / \mathrm{ITO}$ for the standard device and $\mathrm{SS} / \mathrm{Ag} / \mathrm{ZnO} / \mathrm{n}(\mathrm{a}-\mathrm{Si}) / \mathrm{b}(\mathrm{a}-\mathrm{Si}) / \mathrm{b}(\mathrm{a}-$ $\mathrm{SiGe}) / \mathrm{i}(\mathrm{NBG}$ a-SiGe$) / \mathrm{b}(\mathrm{a}-\mathrm{SiGe}) / \mathrm{b}(\mathrm{a}-\mathrm{Si}) / \mathrm{p}(\mu \mathrm{c}-\mathrm{Si}) / \mathrm{ITO}$ for the new devices under study, where $\mathrm{b}(\mathrm{a}-\mathrm{Si})$ and $\mathrm{b}(\mathrm{a}-\mathrm{SiGe})$ are thin $\mathrm{a}-\mathrm{Si}$ and a-SiGe buffer and interface layers, respectively.

Figure $2 \mathrm{H}-3$ shows the structure of the various devices used in this study. Figure $2 \mathrm{H}-3$ (a) is a schematic of the structure for standard a-SiGe devices, showing two a-Si buffer layers on both sides of a-SiGe absorber layer. Figure $2 \mathrm{H}-3$ (b) and (c) show the schematics of the device structures with the additionally inserted a-SiGe interface layers having a fixed Ge content (Figure 2H-3(b)) and with interface layers having a graded bandgap (Fig.3.4.3(c)).

Table $2 \mathrm{H}-2$ lists the photovoltaic parameters of the open circuit voltage $\mathrm{V}_{\text {oc }}$, short circuit current density $\mathrm{J}_{\mathrm{sc}}$, fill factor FF and the maximum power output $\mathrm{P}_{\max }$ of a-SiGe solar cells with different interfacial buffers. The $\mathrm{J}_{\mathrm{sc}}$ values listed in this table are likely to be overestimated since these $J_{\mathrm{sc}}$ values were measured under an ELH lamp which is richer in the red. However, the relative trend is the same. GD180 is a standard a-SiGe device (Fig.3.4.3a) and GD202 contains a-SiGe buffer layers with a fixed Ge content inserted between the a-Si buffers and a-SiGe i-layer at both the n- and p-interfaces (See Figure 2H-3b), while GD203 and GD209 have Ge-content graded buffer layers at both interfaces (See Figure $2 \mathrm{H}-3 \mathrm{c}$ ). It is clearly seen that the $\mathrm{V}_{\mathrm{oc}}$ and FF have been increased due to the introduction of the additional a-SiGe interfacial layers and the improvements are approximately in the range of $2-5 \%$ for $\mathrm{V}_{\text {oc }}$ and $5-10 \%$ for $\mathrm{FF}$. The $\mathrm{V}_{\text {oc }}$ and FF enhancement was higher for graded buffer layers. For this reason, the J-V characteristics of GD180 and GD209 are compared in Figure 2H-4, and the results of these two devices are discussed further in the following. 
Figure 2H-5 shows the QE curves for a-SiGe cells without (GD180) and with (GD203 and GD209) bandgap graded interfacial layers. The spectral responses of these devices are approximately the same in the red region. The small variation in the red could also be due to the variation in the back-reflector. The difference in the blue region of the QE curve mostly resulted from the variation in the transmission of ITO films.

Table 2H-2 Photovoltaic parameters of solar cells with different buffer layers

\begin{tabular}{|l|l|l|l|l|}
\hline Samples & $\begin{array}{l}\mathrm{V}_{\mathrm{oc}} \\
(\mathrm{V})\end{array}$ & $\begin{array}{l}\mathrm{J}_{\mathrm{sc}} \\
\left(\mathrm{mA} / \mathrm{cm}^{2}\right)\end{array}$ & FF & $\begin{array}{l}\mathrm{P}_{\max } \\
\left(\mathrm{mW} / \mathrm{cm}^{2}\right)\end{array}$ \\
\hline $\begin{array}{l}\text { GD180 } \\
\text { Standard }\end{array}$ & 0.647 & 23.5 & 0.506 & 7.7 \\
\hline $\begin{array}{l}\text { GD202 } \\
\text { w/ a-SiGe buffer }\end{array}$ & 0.662 & 21.6 & 0.534 & 7.6 \\
\hline $\begin{array}{l}\text { GD203 } \\
\text { w/ graded a-SiGe buffer }\end{array}$ & 0.680 & 23.4 & 0.536 & 8.5 \\
\hline $\begin{array}{l}\text { GD209 } \\
\text { w/ graded a-SiGe buffer }\end{array}$ & 0.675 & 24.3 & 0.559 & 9.2 \\
\hline
\end{tabular}

\begin{tabular}{|l|}
\hline \\
\hline ITO \\
\hline$p \quad m a-S i$ \\
\hline buffer a-Si $\quad \mathrm{Eg}=1.8 \mathrm{eV}$ \\
\hline absorber a-SiGe Eg=1.5 eV \\
\hline buffer a-Si $\mathrm{Eg}=1.8 \mathrm{eV}$ \\
\hline $\mathrm{n} \mathrm{a-Si}$ \\
\hline ZnO \\
\hline Silver \\
\hline Stainless Steel \\
\hline
\end{tabular}

(a)

\begin{tabular}{|l|}
\hline ITO \\
\hline $\mathrm{p} \quad \mathrm{mc}-\mathrm{Si}$ \\
\hline buffer a-Si $\mathrm{Eg}=1.8 \mathrm{eV}$ \\
\hline buffer a-SiGe $\mathrm{Eg}=1.65 \mathrm{eV}$ \\
\hline \\
absorber a-SiGe Eg=1.5 eV \\
\hline buffer a-SiGe Eg=1.65 eV \\
\hline buffer a-Si $\mathrm{Eg}=1.8 \mathrm{eV}$ \\
\hline $\mathrm{n}$ a-Si \\
\hline ZnO \\
\hline Silver \\
\hline Stainless Steel \\
\hline
\end{tabular}

(b)

\begin{tabular}{|l|}
\hline \\
\hline ITO \\
\hline p $\quad \mathrm{mc}-\mathrm{Si}$ \\
\hline buffer a-Si $\mathrm{Eg}=1.8 \mathrm{eV}$ \\
\hline buffer a-SiGe $\mathrm{Eg}=1.5$ to $1.8 \mathrm{eV}$ \\
\hline \\
absorber a-SiGe $\mathrm{Eg}=1.5 \mathrm{eV}$ \\
\hline buffer a-SiGe $\mathrm{Eg}=1.8$ to $1.5 \mathrm{eV}$ \\
\hline buffer a-Si $\mathrm{Eg}=1.8 \mathrm{eV}$ \\
\hline $\mathrm{n}$ a-Si \\
\hline ZnO \\
\hline Silver \\
\hline Stainless Steel \\
\hline
\end{tabular}

(c)

Figure 2H-3 Schematic layer structure diagram of a-SiGe solar cells with different interfacial buffer layers. (a) standard ungraded a-Si buffer; b) ungraded a-SiGe buffer; and c) graded a-SiGe buffer. 


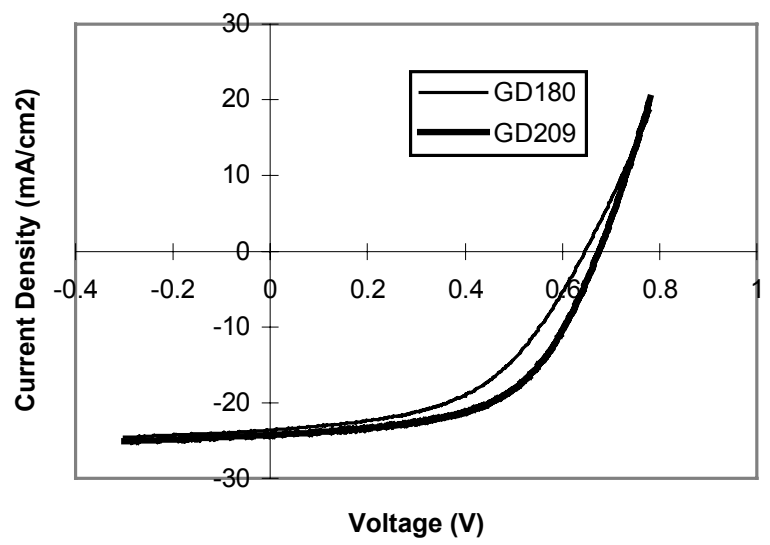

Figure 2H-4 Illuminated J-V characteristics of GD180 and GD209 samples

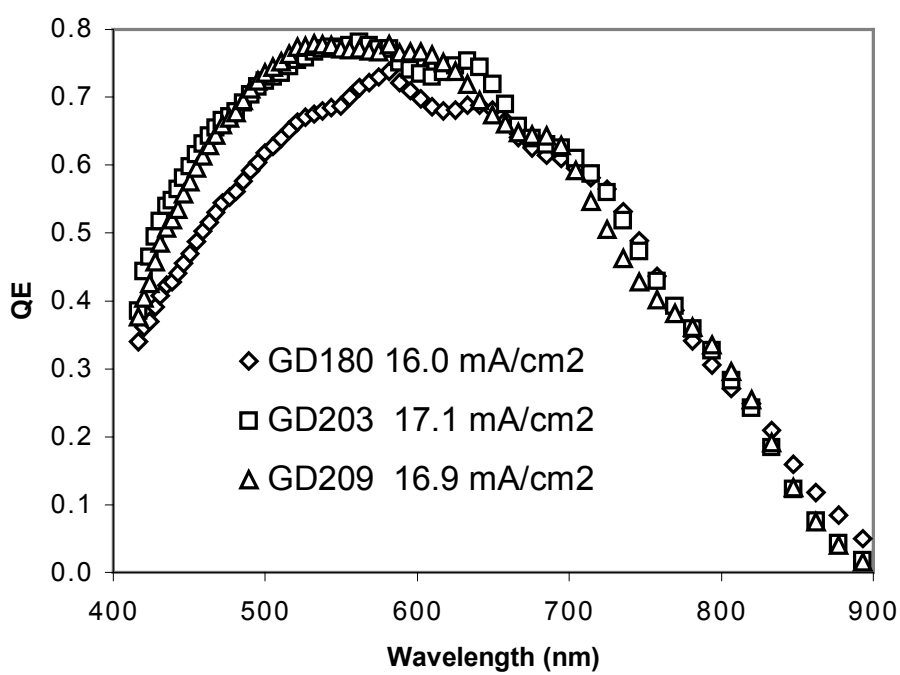

Figure 2H-5 Quantum efficiency curves of a-SiGe solar cells. GD180 is standard solar cell, while GD203 and GD209 are cells with bandgap graded a-SiGe buffers.

We calculated the current density values, $\mathrm{J}_{\mathrm{ph}}$, by integrating the quantum efficiency curves over AM1.5 Global spectrum, as an independent check of the short circuit current values. The obtained $\mathrm{J}_{\mathrm{ph}}$ and the relative $\mathrm{P}_{\max }$ calculated from these $\mathrm{J}_{\mathrm{ph}}$ values are summarized in Table $2 \mathrm{H}-3$. The $\mathrm{J}_{\mathrm{ph}}$ value in Table $2 \mathrm{H}-3$ and the $\mathrm{J}_{\mathrm{sc}}$ values in Table $2 \mathrm{H}-2$ are quite different. This is because $\mathrm{J}_{\mathrm{sc}}$ values in Table $2 \mathrm{H}-2$ were measured using an ELH lamp. On the relative scale, we find that the short circuit currents of standard a-SiGe sample (GD180) and the a-SiGe samples with graded buffer layers (GD203 and GD209) are approximately the same within the experimental variation. The enhancement in $\mathrm{V}_{\mathrm{oc}}$ and $\mathrm{FF}$ result in a net increase in device $\mathrm{P}_{\max }$. 
Table 2H-3 a-SiGe solar cell device performance

\begin{tabular}{|c|c|c|c|c|c|}
\hline Sample & $\begin{array}{c}\mathrm{J}_{\mathrm{ph}} \\
\left(\mathrm{mA} / \mathrm{cm}^{2}\right)\end{array}$ & $\begin{array}{c}\mathrm{QE} \\
@ 800 \mathrm{~nm}\end{array}$ & $\begin{array}{c}\mathrm{V}_{\text {oc }} \\
(\mathrm{V})\end{array}$ & $\mathrm{FF}$ & $\begin{array}{c}\text { Relative } \mathrm{P}_{\max } \\
\left(\mathrm{mW} / \mathrm{cm}^{2}\right)\end{array}$ \\
\hline GD180 & 16.6 & 0.288 & 0.647 & 0.51 & 5.5 \\
\hline GD203 & 17.7 & 0.305 & 0.680 & 0.54 & 6.5 \\
\hline GD209 & 17.5 & 0.315 & 0.675 & 0.56 & 6.6 \\
\hline
\end{tabular}

The influences on the performances of the solar cells from the recombination processes taking place at both interfaces between the intrinsic a-SiGe layer and doped layers could also be observed from the ideality factor (n) of the p-i-n devices. The improved J-V performance in the cells with bandgap graded a-SiGe interfacial layers are reflected also in the improvement of the ideality factor and the reduction in the reverse saturation current density $\left(\mathrm{J}_{0}\right)$ of these devices.

It is well known that the $\mathrm{J}-\mathrm{V}$ characteristics of $\mathrm{p}-\mathrm{i}-\mathrm{n}$ a-Si solar cells under illumination can be approximately described by using transport equation of an ideal p-n junction [H6]:

$$
\mathrm{J}_{\mathrm{ph}}=\mathrm{J}_{\mathrm{o}}\left[\exp \left(\mathrm{q}\left(\mathrm{V}-\mathrm{J}_{\mathrm{ph}} \mathrm{R}_{\mathrm{s}}\right) / \mathrm{nkT}\right)-1\right]-\mathrm{J}_{\mathrm{sc}}
$$

where $\mathrm{n}$ is the ideality factor of the device under illumination, $\mathrm{J}_{\mathrm{ph}}$ represents the photocurrent density, $\left(V-J_{p h} R_{s}\right)$, in which $J_{p h}$ could have negative value, represents the voltage at the junction of an ideal diode. The effect of the equivalent series resistance $R_{s}$ is included in the equation, while the equivalent shunt resistance $\mathrm{R}_{\mathrm{sh}}$ is not taken into account. In order to obtain $\mathrm{n}$ factor directly from experimental measurement, one could use the dependence of $V_{o c}$ on $J_{s c}$ under varying light intensities,

$$
\mathrm{V}_{\mathrm{oc}}=(\mathrm{nkT} / \mathrm{q})\left(\ln \left(\mathrm{J}_{\mathrm{sc}} / \mathrm{J}_{\mathrm{o}}+1\right)\right)
$$

where the effect of $R_{s}$ is avoided, hence $n$ factor can be determined from the slope of the $V_{\text {oc }}$ versus $\ln \left(\mathrm{J}_{\mathrm{sc}}\right)$. Figure $2 \mathrm{H}-6$ shows the experimental data of $\mathrm{J}_{\mathrm{sc}}\left(\mathrm{V}_{\mathrm{oc}}\right)$ measured under various light intensities for samples GD180, with the standard structure of a-SiGe bottom cell, and GD209, with a graded a-SiGe buffer layer at both interfaces. It is seen that there is a nearly linear relationship between $\ln \left(\mathrm{J}_{\mathrm{sc}}\right)$ and $\mathrm{V}_{\mathrm{oc}}$ with R-squared values of 0.9975 and 0.9998 for the two samples studied, consistent with the expectation of Eq. (2). From the slopes of these two lines we deduced the quality factor $\mathrm{n}$ to be 2.02 and 1.77, for the samples without (GD180) and with (GD209) graded a-SiGe interfacial layers at the $\mathrm{p}$-i and i-n junction between the a-Si buffer layer and a-SiGe intrinsic layer, respectively. The reverse saturation current density, obtained from these fittings, were $8.3 \times 10^{-8} \mathrm{~A} / \mathrm{cm}^{2}$ and $7.2 \times 10^{-9} \mathrm{~A} / \mathrm{cm}^{2}$ for GD180 and GD209, respectively. The reductions in the $n$ and $J_{0}$ values indicate an improvement in the $p$-n junction quality and a decrease in the recombination rate of extra minority carriers, as a result of these additional interfacial layers.

In summary, we explored the effect of additional a-SiGe interface layers between narrow bandgap a-SiGe absorber layer and the a-Si buffer layers. The reduction and elimination in the bandgap offset at these interfaces result in sizable increases in device $V_{\text {oc }}$ and $F F$, although the $J_{s c}$ was somewhat unchanged. 


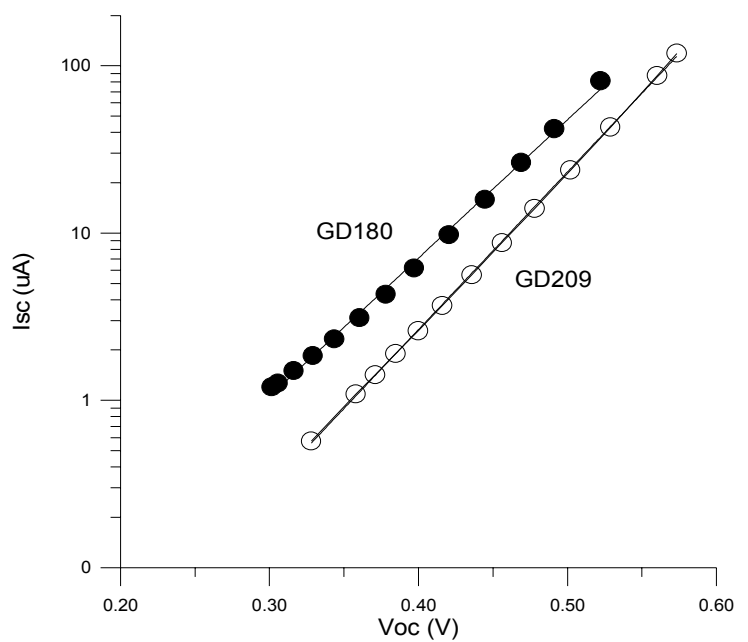

Figure 2H-6 $I_{\mathrm{sc}}$ versus $\mathrm{V}_{\mathrm{oc}}$ under various light intensity for samples GD180 (solid circle) and GD209 (open circle) 


\section{I. Comparison study of a-Si and a-SiGe solar cells on glass and stainless steel}

There are primarily two types of a-Si based solar cells being studied. One is n-i-p based solar cells deposited on stainless steel or Kapton substrates and the other is p-i-n based superstrate solar cells deposited on TCO coated glass. If is often found that these two types of solar cells do not perform the same, mainly due to two reasons: 1) that the growth of a-Si based materials depend sensitively on the substrates used, and 2) that the deposition sequence is opposite. To compare the difference between these two types of cells, we deposit n-i-p solar cells in the same deposition run on both $\mathrm{SnO}_{2}$ coated glass and stainless steel substrates with and without $\mathrm{Ag} / \mathrm{ZnO}$ back-reflector. Table 2I-1 shows the performance of top, middle and bottom component cells deposited on different substrates. Both have n-i-p substrate type configuration, even for the device on glass. All measurements were taken with the light entering from the pside.

We find that the $\mathrm{V}_{\mathrm{oc}}$ and FF of n-i-p solar cells deposited on SS is somewhat higher than those on $\mathrm{SnO}_{2}$ coated glass. We think that the small loss in $\mathrm{V}_{\text {oc }}$ may be from the interface between the n-layer and $\mathrm{SnO}_{2}$ and the lowering of FF for the cells on glass is likely due to the resistance loss of $\mathrm{SnO}_{2}$. The current of the cells on glass is close to the SS cells with backreflector and much higher than the cells on bare SS. This is likely due to the efficient light trapping by the textured $\mathrm{SnO}_{2}$ layer.

Table 2I-1. Comparison of IV performance for a-Si top cell, a-SiGe middle cell and a-SiGe bottom cell deposited on $\mathrm{SnO}_{2}$ coated glass and stainless steel.

\begin{tabular}{|c|c|c|c|c|c|c|}
\hline $\begin{array}{c}\text { Sample } \\
\text { No. }\end{array}$ & Cell & Substrate & $\begin{array}{l}\mathrm{V}_{\mathrm{oc}} \\
(\mathrm{V})\end{array}$ & $\begin{array}{c}\mathrm{J}_{\mathrm{sc}} \\
\left(\mathrm{mA} / \mathrm{cm}^{2}\right)\end{array}$ & $\begin{array}{l}\mathrm{FF} \\
(\%)\end{array}$ & $\begin{array}{l}\text { Eff } \\
(\%)\end{array}$ \\
\hline GD459 & Top & Glass $/ \mathrm{SnO}_{2}$ & 0.86 & 8.6 & 59 & 4.3 \\
\hline GD460 & Middle & Glass/SnO 2 & 0.79 & 14.8 & 55 & 6.4 \\
\hline GD461 & Bottom & Glass $/ \mathrm{SnO}_{2}$ & 0.60 & 16.6 & 44 & 4.4 \\
\hline GD485 & Top & Glass $/ \mathrm{SnO}_{2}$ & 0.89 & 9.8 & 62 & 5.4 \\
\hline GD485 & Top & SS & 0.90 & 7.4 & 62 & 4.1 \\
\hline GD486 & Middle & Glass $/ \mathrm{SnO}_{2}$ & 0.80 & 14.9 & 58 & 6.9 \\
\hline GD486 & Middle & SS & 0.81 & 13.2 & 61 & 6.5 \\
\hline GD488 & Bottom & Glass/SnO 2 & 0.59 & 16.7 & 45 & 4.4 \\
\hline GD488 & Bottom & $\mathrm{SS} / \mathrm{Ag} / \mathrm{ZnO}$ & 0.66 & 20.5 & 54 & 7.3 \\
\hline
\end{tabular}




\section{J. Comparison of n-i-p and p-i-n solar cells with the same i-layers}

The device performance of nip and pin type cells could be quite different even though all of the layers were deposited under exactly the same conditions. This is because the growth of thin a-Si based layers depends sensitively on the surface the material is deposited. Also, it is generally desirable to deposit the initial layers at high temperature and last layers at low temperature to avoid out diffusion of $\mathrm{H}$ from the initial layers during the deposition of subsequent layers.

To understand the influence of the different device structure, we performed a comparative study of a-Si solar cells with two different types of cell structures: 1) SS/n-i-p/ITO and 2) SS/p-i$\mathrm{n} / \mathrm{ITO}$, schematic of which are shown in Figure 2J-1 (a) and (b).

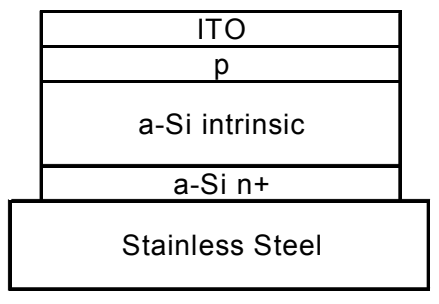

(a)

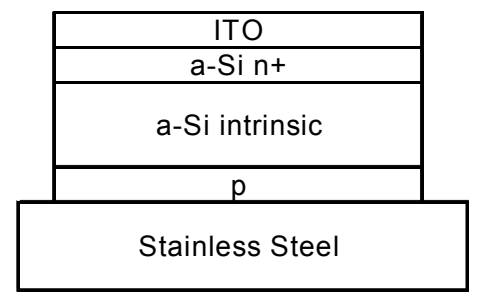

(b)

Figure 2J-1 Device structures of (a) n-i-p type cell and (b) p-i-n type cell used in this comparative study.

In this study, we maintained the deposition conditions of the $\mathrm{n}$ and i-layers to be the same for all samples. The p-layer deposition temperature was varied in both types of structures. Figure 2J-2 shows the IV curve for two nip type cells with p-layer temperature of $300 \mathrm{C}$ (GD273) and $100 \mathrm{C}$ (GD279). It is observed that the device with a low-Ts deposited p-layer shows much higher Voc, Jsc and FF than sample with high-Ts deposited p-layer. It appears that the high-Ts deposited player is amorphous and not near the amorphous-crystalline transition region, although this is somewhat counter-intuitive. Figure 2J-3 shows the IV curve for two pin type cell with p-layer temperatures of $70 \mathrm{C}$ (GD270) and $300 \mathrm{C}$ (GD271). The Voc and FF are similar between these two samples. However, the FF of the device with low-Ts deposited p-layer is much lower. It is likely that there is a severe mismatch in the valance band edge at the p-i interface for GD270. Table 2J-1 summaries the IV data for these four devices.

In summary, device performance could be very different between nip and pin structures. For $\mathrm{SS} / \mathrm{n}$-i-p/ITO structure, low temperature is more desirable for $\mathrm{p}$-layer deposition, while for SS/p$\mathrm{i}$-n/ITO structure, high temperature is more desirable for p-layer deposition. 


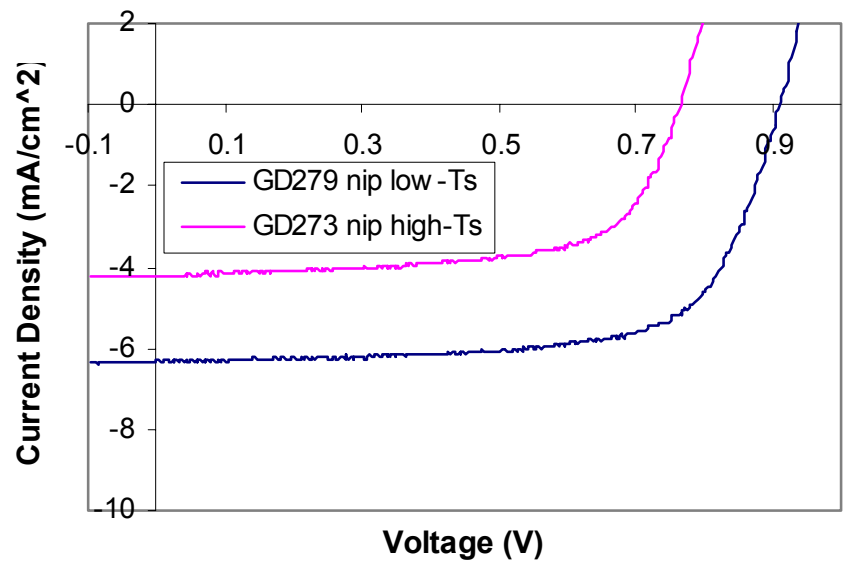

Figure 2J-2 IV performance of nip type solar cells with p-layers deposited at different temperatures.

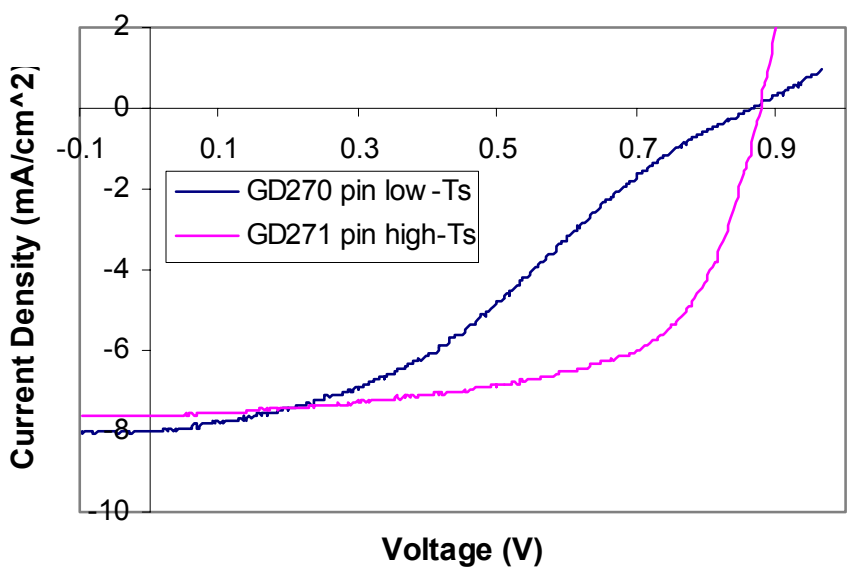

Figure 2J-3 IV curves of pin type solar cells with p-layers deposited at different temperatures.

Table 2J-1 Summary of IV performance of nip and pin type solar cells with p-layers deposited at different temperatures.

\begin{tabular}{|c|c|c|c|c|c|c|c|}
\hline Sample & $\begin{array}{c}\text { Device } \\
\text { Structure }\end{array}$ & $\begin{array}{c}\mathbf{p}-l a y e r \\
\mathbf{T e m p}\left({ }^{\circ} \mathbf{C}\right)\end{array}$ & $\begin{array}{c}\mathbf{V}_{\text {oc }} \\
(\mathbf{V})\end{array}$ & $\begin{array}{c}\mathbf{J}_{\mathbf{s c}} \\
\left(\mathbf{m A} / \mathbf{c m}^{2}\right)\end{array}$ & $\begin{array}{c}\mathbf{R}_{\mathbf{s}} \\
\left(\mathbf{\Omega} \cdot \mathbf{c m}^{2}\right)\end{array}$ & $\begin{array}{c}\mathbf{F F} \\
(\mathbf{\%})\end{array}$ & $\begin{array}{c}\mathbf{P}_{\mathbf{m a x}} \\
\left(\mathbf{m W} / \mathbf{c m}^{2}\right)\end{array}$ \\
\hline GD279 & SS/nip/ITO & 100 & 0.911 & 6.4 & 15.1 & 69.1 & 4.0 \\
\hline GD273 & SS/nip/ITO & 300 & 0.765 & 4.2 & 17.9 & 66.4 & 2.1 \\
\hline GD270 & SS/pin/ITO & 70 & 0.867 & 8.0 & 124 & 36.0 & 2.5 \\
\hline GD271 & SS/pin/ITO & 300 & 0.878 & 7.6 & 12.6 & 63.5 & 4.2 \\
\hline
\end{tabular}




\section{K. Stability results of improved component cells}

We carried out stability test for improved component cells. Table $2 \mathrm{~K}-1$ shows the initial IV performance as well as stabilized IV performance after 1000 hours of one-sun light soaking at $50 \mathrm{C}$.

Table 2K-1 IV performance of top, middle and bottom component cells before and after 1000 hours of light soaking under 1 sun intensity at 50C.

\begin{tabular}{|c|c|c|c|c|c|c|c|c|}
\hline $\begin{array}{c}\text { Cell } \\
\text { Number }\end{array}$ & $\begin{array}{l}\text { Cell } \\
\text { Type }\end{array}$ & $\overline{\text { Subs }}$ & & $\begin{array}{l}\text { Voc } \\
\text { (V) }\end{array}$ & $\begin{array}{c}\mathbf{J s c} \\
\left(\mathrm{mA} / \mathrm{cm}^{2}\right)\end{array}$ & $\begin{array}{c}\text { FF } \\
(\%)\end{array}$ & $\begin{array}{c}\eta \\
(\%)\end{array}$ & $\begin{array}{c}\text { Degradation } \\
(\%)\end{array}$ \\
\hline \multirow{2}{*}{ Gd550-1 } & \multirow[t]{2}{*}{ Top } & \multirow[t]{2}{*}{ SS } & $\begin{array}{l}\text { Initial } \\
\end{array}$ & 1.00 & 9.49 & 71.61 & 6.77 & \\
\hline & & & Stable & 0.98 & 9.20 & 66.66 & 6.01 & 11.23 \\
\hline \multirow{2}{*}{ Gd553-1 } & \multirow[t]{2}{*}{ Top } & \multirow[t]{2}{*}{ SS } & Initial & 1.00 & 8.82 & 71.77 & 6.34 & \\
\hline & & & Stable & 0.97 & 8.52 & 65.81 & 5.42 & 14.51 \\
\hline \multirow{2}{*}{ Gd568-1 } & \multirow[t]{2}{*}{ Middle } & \multirow[t]{2}{*}{ SS } & Initial & 0.81 & 15.43 & 63.11 & 7.91 & \\
\hline & & & Stable & 0.78 & 15.40 & 52.54 & 6.30 & 20.35 \\
\hline \multirow{2}{*}{ Gd572-1 } & \multirow[t]{2}{*}{ Middle } & \multirow[t]{2}{*}{ SS } & Initial & 0.81 & 15.22 & 65.09 & 7.97 & \\
\hline & & & Stable & 0.78 & 14.73 & 55.25 & 6.35 & 20.32 \\
\hline \multirow{2}{*}{ Gd572-2 } & \multirow[t]{2}{*}{ Middle } & \multirow[t]{2}{*}{ BR } & Initial & 0.80 & 18.95 & 65.51 & 9.97 & \\
\hline & & & Stable & 0.78 & 19.63 & 54.14 & 8.29 & 16.85 \\
\hline \multirow{2}{*}{ Gd575-1 } & \multirow[t]{2}{*}{ Bottom } & \multirow[t]{2}{*}{ SS } & Initial & 0.64 & 17.28 & 55.87 & 6.18 & \\
\hline & & & Stable & 0.63 & 16.54 & 51.16 & 5.31 & 14.08 \\
\hline \multirow{2}{*}{ Gd575-2 } & \multirow[t]{2}{*}{ Bottom } & \multirow[t]{2}{*}{ BR } & Initial & 0.62 & 22.85 & 60.96 & 8.57 & \\
\hline & & & Stable & 0.62 & 22.94 & 52.44 & 7.41 & 13.54 \\
\hline \multirow{2}{*}{ Gd578-1 } & \multirow[t]{2}{*}{ Bottom } & \multirow[t]{2}{*}{ SS } & Initial & 0.61 & 20.14 & 54.85 & 6.78 & \\
\hline & & & Stable & 0.59 & 19.08 & 48.34 & 5.48 & 19.18 \\
\hline \multirow{2}{*}{ Gd600-2 } & \multirow[t]{2}{*}{ Bottom } & \multirow[t]{2}{*}{ BR } & Initial & 0.59 & 23.02 & 60.69 & 8.21 & \\
\hline & & & Stable & 0.59 & 23.27 & 54.85 & 7.49 & 8.77 \\
\hline
\end{tabular}

From the table, we observe that for these improved component cells, degradations are $\sim 11 \%$ for top cell on SS, $20 \%$ for middle cell on SS, $17 \%$ for middle cell on back-reflector BR, $14-19 \%$ for bottom cell on SS, and 9-13\% for bottom cell on BR. GD575-2 and GD600-2 show desirable stable performance $(7.5 \%)$ for use as the bottom cell in a triple cell. 


\section{L. Fabrication of high efficiency triple-junction a-Si solar cells}

\section{$\underline{\text { Recent triple cell depositions }}$}

We incorporated the improved component cells into our triple cell fabrication. During this reporting period, we have fabricated a number of triple junction solar cells. Table 2L-1 shows the IV and QE performance for the triple-junction solar cells fabricated during this period. These devices were fabricated on backreflector coated stainless steel substrate under similar conditions (with small adjustment in i-layers' thicknesses, Ge content, etc) during the course of about two weeks. The short circuit current listed under QE is calculated from quantum efficiency integrated with the spectral irradiation from UT's solar simulator as well as AM1.5 spectrum. From Table 2L-1, we see that all of these triple cells show efficiency around $11-12.7 \%$.

Table 2L-1 IV and QE data for the triple-junction solar cells. The short circuit currents are calculated from QE using the radiation spectrum of UT's solar simulator and AM1.5 global spectrum.

\begin{tabular}{|c|c|c|c|c|c|c|c|c|c|c|c|c|c|}
\hline \multirow{2}{*}{$\begin{array}{l}\text { Cell } \\
\text { No. }\end{array}$} & \multirow{2}{*}{$\begin{array}{l}\mathrm{V}_{\mathrm{oc}} \\
(\mathrm{V})\end{array}$} & \multirow{2}{*}{$\begin{array}{c}\mathrm{J}_{\mathrm{sc}} \\
\left(\mathrm{mA} / \mathrm{cm}^{2}\right)\end{array}$} & \multirow{2}{*}{$\begin{array}{l}\mathrm{FF} \\
(\%)\end{array}$} & \multirow{2}{*}{$\begin{array}{c}\mathrm{R}_{\mathrm{s}} \\
(\Omega \mathrm{cm})\end{array}$} & \multirow{2}{*}{$\begin{array}{c}\eta \\
(\%)\end{array}$} & \multicolumn{4}{|c|}{$\mathrm{J}_{\mathrm{ph}}$ from UT-Simul } & \multicolumn{4}{|c|}{ Jph from AM1.5GL } \\
\hline & & & & & & $p$ & Mid & Bottom & Total & Top & $\begin{array}{l}\text { Middl } \\
\mathrm{e}\end{array}$ & Bott & Tot \\
\hline GD581-1 & 2.293 & 7.47 & 68.12 & 62.2 & 11.67 & & & & & & & & \\
\hline GD581-2 & 2.290 & 7.78 & 69.00 & 55.0 & 12.30 & 6.53 & 8.08 & 7.48 & 22.10 & 6.24 & 7.63 & 8.52 & 22.40 \\
\hline GD581-3 & 2.306 & 7.70 & 69.02 & 56.0 & 12.25 & 60 & 8.03 & 28 & & .30 & 7.57 & 29 & 22.20 \\
\hline GD582-1 & 2.251 & 7.88 & 65.93 & 52.3 & 11.69 & 7.08 & 8.10 & & & 6.77 & 7.67 & 9.31 & 22.20 \\
\hline GD582-2 & 2.255 & 8.10 & 64.18 & 52.8 & 11.72 & & & & & & & & \\
\hline GD584-1 & 2.209 & 7.89 & 68.09 & 38.6 & 11.87 & 6.82 & 7.97 & 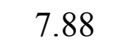 & & 6.52 & 7.52 & 9.37 & 23.41 \\
\hline GD584-2 & 2.283 & 7.39 & 67.04 & 59.0 & 11.31 & & & & & & & & \\
\hline GD584-3 & 2.291 & 7.71 & 65.74 & 61.0 & 11.61 & & & & & & & & \\
\hline GD585-3 & 2.293 & 8.34 & 66.50 & 53.4 & 12.71 & 7.19 & 7.98 & 7.34 & $22=$ & 6.87 & 7.54 & 8.62 & 23.03 \\
\hline GD585-2 & 2.237 & 7.36 & 70.17 & 39.1 & 11.5 & 6.63 & 7.92 & 7.81 & & 6.33 & 7.47 & .10 & 22.91 \\
\hline GD586-1 & 2.261 & 7.68 & 69.57 & 45.7 & 12.08 & 6.51 & 7.92 & 7.65 & & 6.22 & 7.47 & 8.88 & 22.57 \\
\hline GD586-2 & 2.261 & 7.68 & 69.57 & 45.7 & 12.08 & 79 & 7.71 & 6 & 7 & 49 & 7.27 & .04 & 2.81 \\
\hline GD593-2 & 2.215 & 7.54 & 66.25 & 47.0 & 11.0 & 6.71 & 7.87 & 7. & & 6.42 & 7.42 & 8.52 & 22.36 \\
\hline GD593-3 & 2.237 & 7 & 66.31 & 44.4 & 11.4 & 6.86 & 8.03 & 7.44 & & 6.55 & 7.56 & 8.72 & 22.84 \\
\hline GD593-4 & 2.238 & 8.04 & 63.18 & 56.2 & 11.36 & & & & & & & & \\
\hline GD594-1 & 2.217 & 7.76 & 64.90 & 48.2 & 11.17 & 6.85 & 7.92 & & & & 7.46 & 49 & 22.51 \\
\hline GD594-2 & 2.270 & 7.69 & 65.18 & 48.8 & 11.37 & 7.29 & 7.82 & 7.24 & 22 & 6.98 & 7.37 & 8.57 & 22.92 \\
\hline GD596-1 & 2.276 & 7.58 & 68.08 & 39.4 & 11.75 & 6.69 & 8.00 & 7.18 & & 6.39 & 7.53 & .57 & 22.29 \\
\hline GD596-2 & 2.275 & 7.55 & 68.65 & 38.6 & 11.79 & 6.54 & 7.72 & 6.95 & 22 & 6.26 & 7.28 & 11 & 21.64 \\
\hline GD609-2 & 2.184 & & 68.72 & 35.1 & 12.01 & 6.80 & 6.87 & & & 6.50 & 6.41 & 10.82 & 23.74 \\
\hline GD609-3 & 2.201 & 8.01 & 65.48 & 48.1 & 11.55 & 6.91 & 6.81 & 9.05 & 7 & 6.61 & 6.36 & 10.65 & 23.62 \\
\hline GD610-1 & 2.234 & 7.99 & 63.40 & 52.8 & 11.32 & 6.90 & 7.44 & 7.65 & 21.99 & 6.60 & 6.98 & 9.08 & 22.66 \\
\hline GD611-1 & 2.261 & 7.63 & 65.27 & 48.0 & 11.26 & 7.12 & 7.66 & 7.07 & 21.84 & 6.81 & 7.24 & 8.50 & 22.55 \\
\hline GD612-1 & 2.187 & 7.56 & 63.28 & 47.4 & 10.46 & 6.93 & 5.80 & 6.87 & 19.60 & 6.63 & 5.55 & 8.37 & 20.54 \\
\hline GD613-1 & 2.244 & 8.08 & 67.56 & 45.6 & 12.24 & 6.81 & 7.77 & 8.37 & 22.95 & 6.51 & 7.31 & 10.04 & 23.86 \\
\hline GD613-3 & 2.254 & 7.31 & 67.20 & 54.4 & 11.06 & 6.27 & 7.57 & 9.91 & 21.75 & 5.98 & 7.13 & 9.45 & 22.55 \\
\hline GD613-4 & 2.254 & 8.1 & 66.32 & 44.1 & 12.14 & 6.96 & 6.80 & 7.96 & 21.73 & 6.65 & 6.64 & 9.40 & 22.47 \\
\hline GD614-1 & 2.233 & 8.26 & 64.75 & 51.8 & 11.94 & 6.84 & 8.08 & 7.49 & 22.41 & 6.54 & 7.63 & 9.00 & 23.18 \\
\hline
\end{tabular}




\section{$\underline{12.7 \% \text { triple cell }}$}

The significant improvement in the component cells allowed us to achieve the fabrication of triple-junction a-Si/a-SiGe/a-SiGe cells with $12.7 \%$ initial efficiency. Figure $2 \mathrm{~L}-1$ shows the IV curve of the $12.7 \%$ triple-junction solar cell, GD585. It is worth noting that the IV measurement was made at UT under UT's solar simulator through a stainless steel mask with an opening of $0.25 \mathrm{~cm}^{2}$ (excluding the shadow coverage by the contacting probes). Therefore, it is unlikely the active area of the cell is underestimated. The performance for the triple cell is $\mathrm{V}_{\mathrm{oc}}=2.293 \mathrm{~V}$, $\mathrm{J}_{\mathrm{sc}}=8.335 \mathrm{~mA} / \mathrm{cm}^{2}, \mathrm{FF}=66.50 \%$ and the initial efficiency is $12.71 \%$. The cell also has a low series resistance of $53.4 \mathrm{Ohm} * \mathrm{~cm}^{2}$.

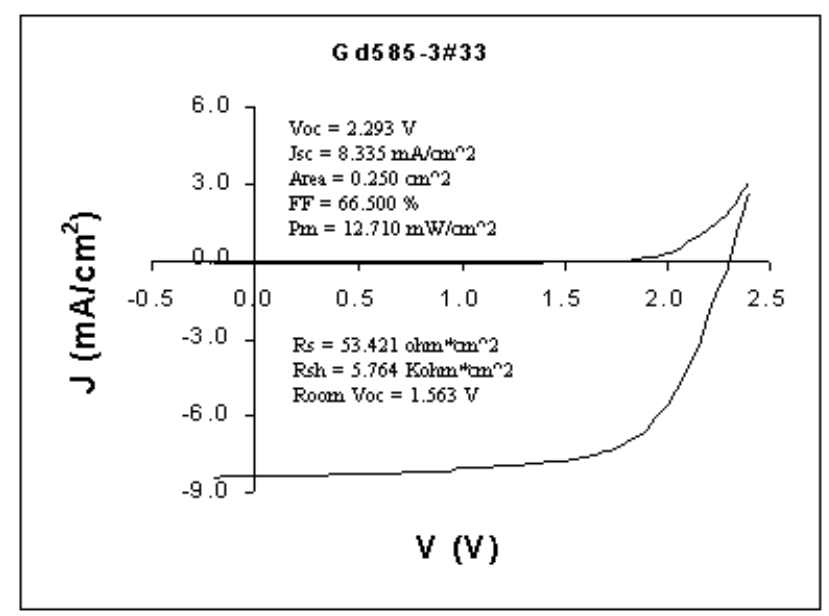

Figure 2L-1 IV curve of GD585, showing 12.7\% initial, active-area efficiency.

Figure 2L-2 shows the quantum efficiency curves of the component cells in this triple cell. At the top of Figure 2L-2, we show the calculated short circuit current of the component cells under both UT simulator and the AM1.5 global spectrum. Unfortunately, since the Xenon lamp solar spectrum does not match exactly the spectrum of AM1.5 global, different short circuit currents were obtained when calculated using different spectrums. With UT's simulator spectrum, we obtain short circuit currents of $7.19,7.98$, and $7.34 \mathrm{~mA} / \mathrm{cm}^{2}$ for the top, middle, and bottom component cells respectively. The sum of the three currents is $22.51 \mathrm{~mA} / \mathrm{cm}^{2}$. It should also be pointed out that the top cell current was calculated with wavelength longer than $370 \mathrm{~nm}$. Therefore, the actual current should be larger than $7.19 \mathrm{~mA} / \mathrm{cm}^{2}$, by about $0.3 \mathrm{~mA} / \mathrm{cm}^{2}$ according to our estimate. When calculated using AM1.5 global spectrum, we obtain short circuit currents of $6.87,7.54$ and $8.62 \mathrm{~mA} / \mathrm{cm}^{2}$ for the top, middle and bottom cells respectively, with a total of $23.03 \mathrm{~mA} / \mathrm{cm}^{2}$. Again, the top cell is likely to be underestimated by about $0.3 \mathrm{~mA} / \mathrm{cm}^{2}$. 


\section{UT QE GD585-3\#34 1/27/01}

Under AM1.5GL Top=6.87, Middle=7.54, Bottom=8..62, Total $=23.03 \mathrm{~mA} / \mathrm{cm} 2$

Under UT-lamp Top=7.19, Middle=7.98, Bottom=7.34, Total $=22.51 \mathrm{~mA} / \mathrm{cm} 2$

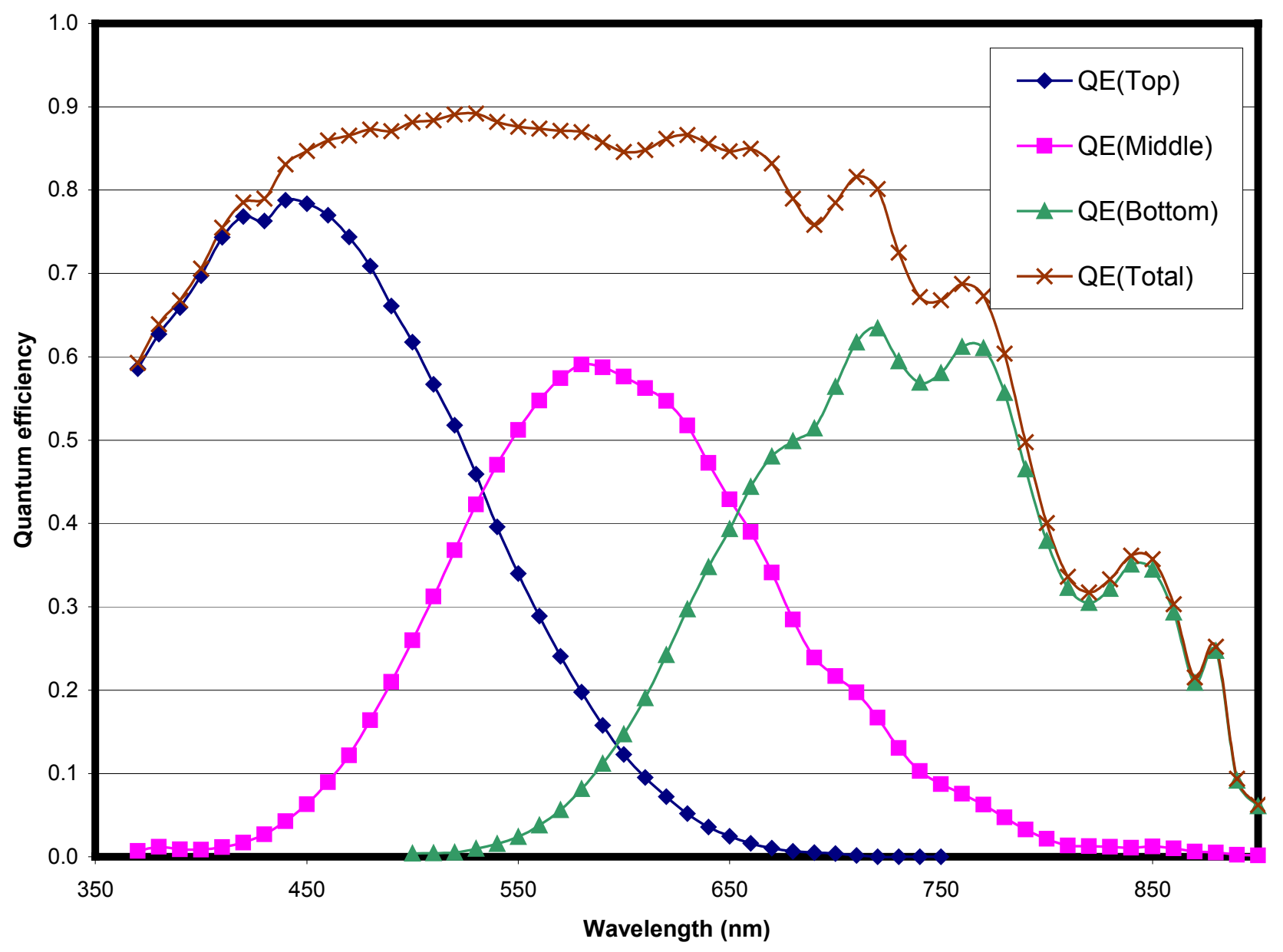

Figure 2L-2 Quantum efficiency curve of $12.7 \%$ cell (GD585) showing the QE for top, middle and bottom cells. The Figure 2L-also shows the short circuit current under UT simulator and AM1.5 spectra.

The difference in the component cell current from these two spectra is due to the difference between UT's solar simulator spectrum and AM1.5 global spectrum. As shown in Figure 2L-3, UT's solar simulator lacks in the red part of the solar spectrum compared with AM1.5 global spectrum. It is therefore not surprising to see different component cell current values when calculated using different spectrum.

It should be noted that the QE measurements of these triple cells are extremely reproducible. Repeated measurements on the same cell usually lead to a difference much less than $1 \%$. We have noticed that the lowest component cell current $(7.19+0.3) \mathrm{mA} / \mathrm{cm}^{2}$ is smaller than the $\mathrm{J}_{\mathrm{sc}}$ measured from IV $\left(8.335 \mathrm{~mA} / \mathrm{cm}^{2}\right)$. We are still in the process to find out the possible reasons for the discrepancy. Although the QE measurement is usually more reproducible, we have no reason to suspect the current from IV measurements to be any less accurate, particularly when the IV measurement was made with a stainless steel mask. 


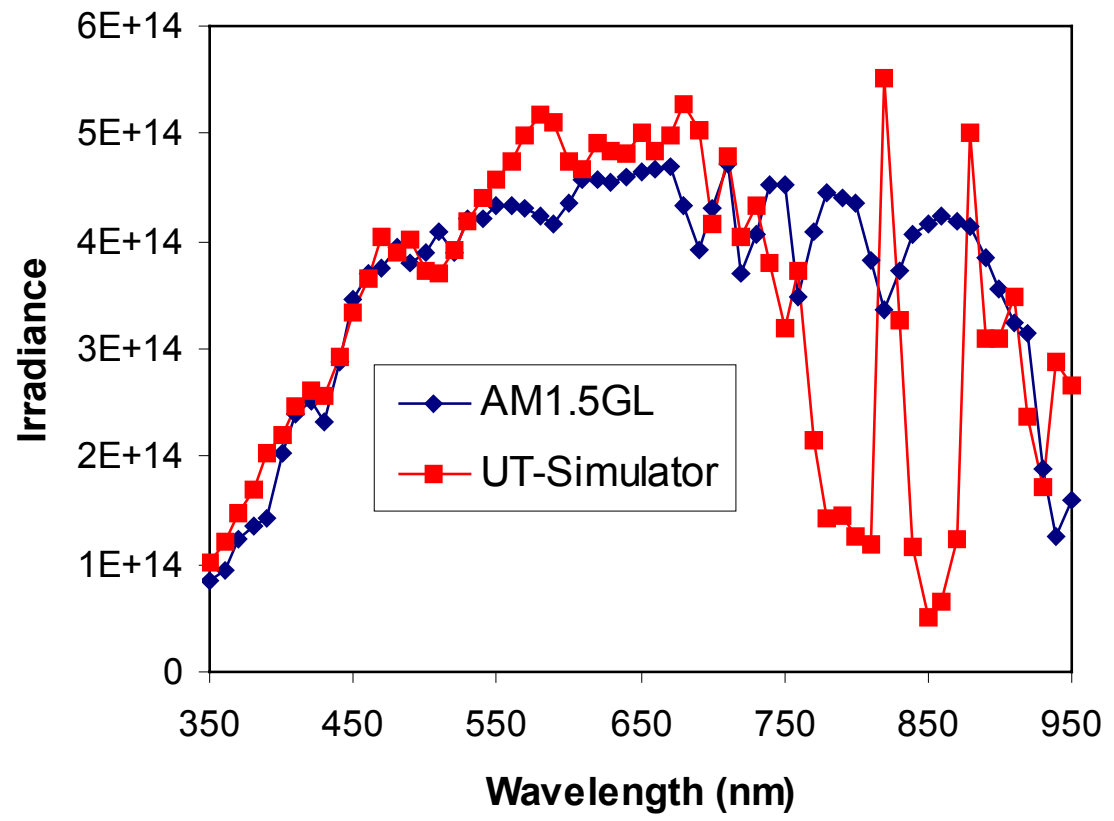

Figure 2L-3 Irradiation spectra of UT Xenon simulator and AM1.5 global. 


\section{Independent measurements at NREL}

Some triple-cells fabricated at UT were sent to NREL for independent measurements. Table 2L2 shows the measurement for GD585 measured at NREL and UT. Comparing the measurements on the same cells, we find that UT's measurement and NREL measurements show excellent agreement.

Table 2L-2 IV data for GD585 measured at UT and NREL.

\begin{tabular}{ccccccccc}
\hline Cell\# & $\mathrm{V}_{\text {oc }}$ & $\mathrm{l}_{\mathrm{sc}}$ & $\mathrm{FF}$ & $\begin{array}{c}\text { Active } \\
\text { area } \\
\left(\mathrm{cm}^{2}\right)\end{array}$ & $\begin{array}{c}\text { Active- } \\
\text { area } \eta \\
(\%)\end{array}$ & $\begin{array}{c}\text { Total } \\
\text { area } \\
\left(\mathrm{cm}^{2}\right)\end{array}$ & $\begin{array}{c}\text { Total- } \\
\text { area } \eta \\
(\%)\end{array}$ & $\begin{array}{c}\text { Measurement } \\
\text { Lab }\end{array}$ \\
\hline \hline UT585-3\#33 & 2.293 & 2.09 & 66.5 & 0.25 & 12.71 & & & UT \\
UT585-3\#22 & 2.286 & 2.045 & 66.34 & 0.25 & 12.41 & & & UT \\
UT 585-3\#33 & 2.323 & 2.06 & 67.2 & 0.256 & 12.55 & 0.272 & 11.81 & NREL \\
UT 585-3\#22 & 2.319 & 2.03 & 66.1 & 0.255 & 12.41 & 0.271 & 11.68 & NREL \\
\hline
\end{tabular}

Note:

1) UT IV curves were measured through a SS mask with a $0.265 \mathrm{~cm}^{2}$ hole, using a fourprobe IV technique, on samples before metal grids were applied. The shadow area from the probes is estimated to be $0.015 \mathrm{~cm}^{2}$.

2) Efficiencies from NREL-measured IVs were calculated using NREL-measured total cell areas.

3) Matching of component cells were optimized such that the efficiency would be highest under UT-simulator, which is slightly lacking of red light compared with AM1.5 global spectrum. 


\section{University of Toledo a-Si/a-Si:Ge/a-Si:Ge Cell}

Device ID: GD585-3\#33

Jun 6, 2001 08:47

Reporting Spectrum: AM1.5 Global
Device Temperature: $25.0 \pm 1.0^{\circ} \mathrm{C}$

Device Area: $0.272 \mathrm{~cm}^{2}$

Irradiance: $1000.0 \mathrm{~W} / \mathrm{m}^{2}$

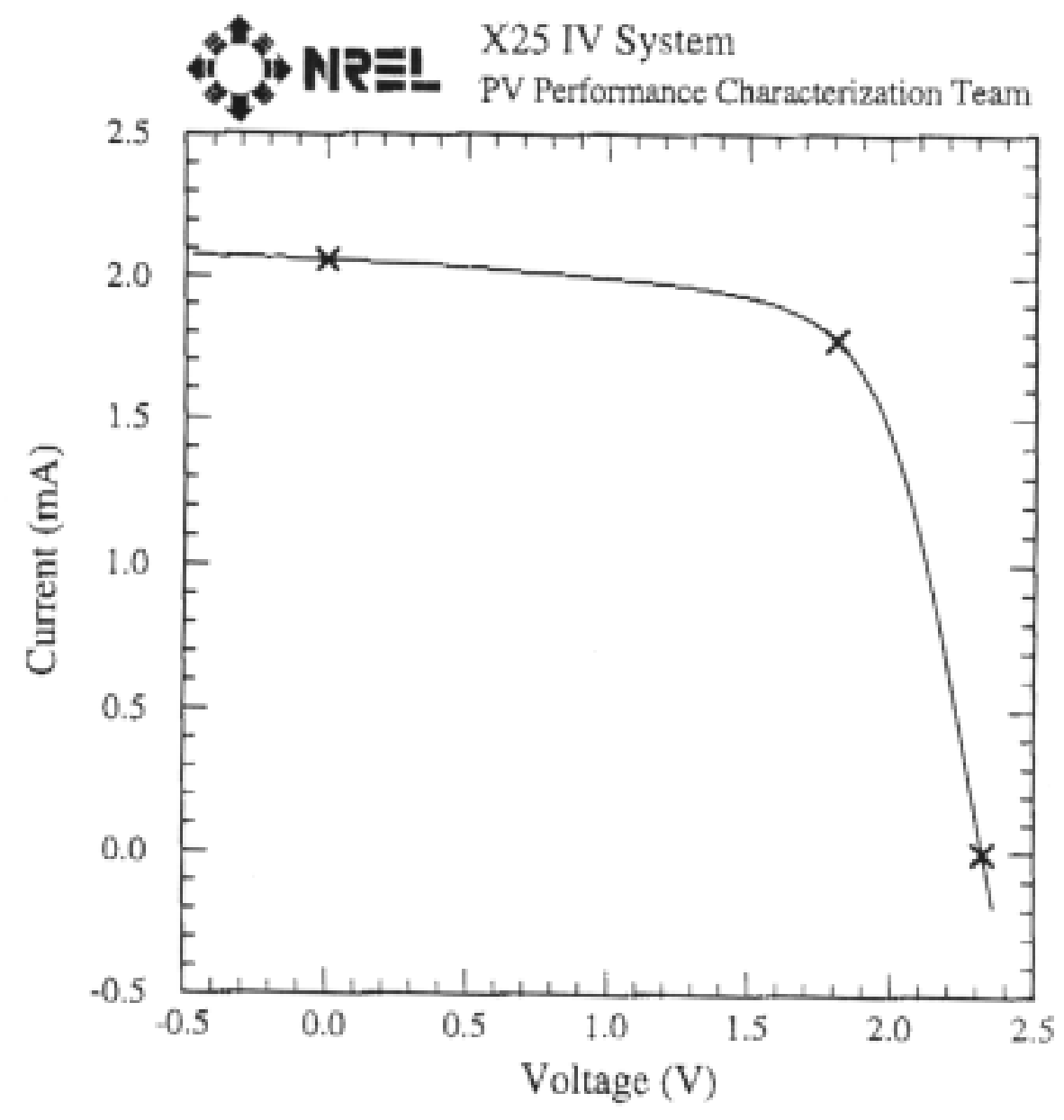

$\mathrm{V}_{\mathrm{oc}}=2.3234 \mathrm{~V}$

$\mathrm{I}_{\mathrm{sc}}=2.0591 \mathrm{~mA}$

$\mathrm{J}_{\mathrm{sc}}=7.5645 \mathrm{~mA} / \mathrm{cm}^{2}$

Fill Factor $=67.17 \%$

$$
\begin{aligned}
& I_{\max }=1.7793 \mathrm{~mA} \\
& \mathrm{~V}_{\max }=1.8061 \mathrm{~V} \\
& P_{\max }=3.2137 \mathrm{~mW} \\
& \text { Efficiency }=11.8 \%
\end{aligned}
$$

Figure 2L-4 IV curve of GD585 measured at NREL, showing $11.8 \%$ initial, total-area efficiency. 


\section{Light Stability Test of triple cells}

We have conducted light soaking stability tests for these UT fabricated triple-junction solar cells. Table 2L-3 shows the IV data of selected triple cells before and after 1000 hours of one-sun light soaking at $50 \mathrm{C}$.

Table 2L-3 IV data of triple cells degraded under 1 sun light for 1000 hours.

\begin{tabular}{|c|c|c|c|c|c|c|}
\hline Cell Number & & $\begin{array}{l}\text { Voc } \\
\text { (V) }\end{array}$ & $\begin{array}{c}\text { Jsc } \\
\left(\mathbf{m A} / \mathbf{c m}^{2}\right)\end{array}$ & $\begin{array}{c}\text { FF } \\
(\%)\end{array}$ & $\begin{array}{c}\eta \\
(\%)\end{array}$ & $\begin{array}{c}\text { Degradation } \\
(\%)\end{array}$ \\
\hline \multirow{2}{*}{ Gd581-1 } & Initial & 2.29 & 7.71 & 67.78 & 11.99 & \\
\hline & Stable & 2.26 & 7.47 & 63.09 & 10.65 & 11.18 \\
\hline \multirow{2}{*}{ Gd582-1 } & Initial & 2.25 & 8.05 & 65.69 & 11.89 & \\
\hline & Stable & 2.21 & 7.97 & 59.95 & 10.54 & 11.35 \\
\hline \multirow{2}{*}{ Gd584-1 } & Initial & 2.21 & 8.06 & 67.89 & 12.12 & \\
\hline & Stable & 2.23 & 7.74 & 62.14 & 10.74 & 11.41 \\
\hline \multirow{2}{*}{ Gd585-2 } & Initial & 2.26 & 7.85 & 68.68 & 12.17 & \\
\hline & Stable & 2.24 & 7.76 & 61.47 & 10.70 & 12.08 \\
\hline \multirow{2}{*}{ Gd586-2 } & Initial & 2.29 & 7.53 & 68.95 & 11.90 & \\
\hline & Stable & 2.26 & 7.54 & 62.39 & 10.61 & 10.84 \\
\hline \multirow{2}{*}{ Gd593-2 } & Initial & 2.22 & 7.67 & 66.61 & 11.34 & \\
\hline & Stable & 2.21 & 7.64 & 60.43 & 10.20 & 10.05 \\
\hline \multirow{2}{*}{ Gd594-2 } & Initial & 2.26 & 7.77 & 64.68 & 11.33 & \\
\hline & Stable & 2.21 & 7.99 & 57.71 & 10.20 & 9.97 \\
\hline \multirow{2}{*}{ Gd596-2 } & Initial & 2.28 & 7.49 & 68.78 & 11.73 & \\
\hline & Stable & 2.23 & 7.52 & 61.21 & 10.26 & 12.50 \\
\hline
\end{tabular}

As we see from Table 2L-3, all of these triple cells have a 1000 hour-degradation within 10$12.5 \%$. All these cells show stable active-area efficiency above $10 \%$ with the highest stable efficiency (active area) after 1000 hours light soaking at 10.7\%, for GD584. Figure 2L-5 shows the IV curve of a triple cell after 1000 hours of light soaking, showing $10.7 \%$ stable efficiency. The achievement of $10.7 \%$ efficiency is a significant improvement from our previously fabricated triple junction solar cells.

\section{G d5 84-1c \#12}

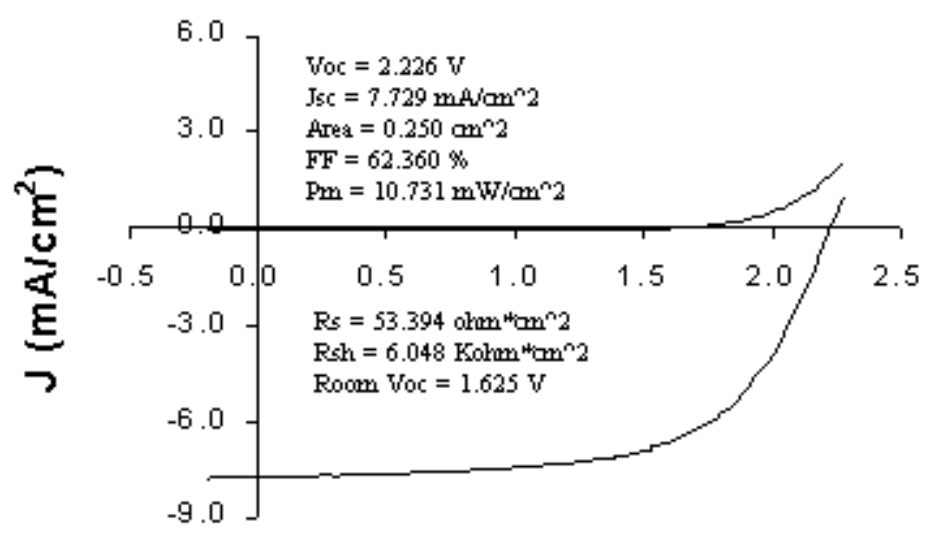

\section{$V(V)$}

Figure 2L-5 IV curve of a triple cell measured after 1000 hours of 1-sun light soaking at 50C, showing $10.7 \%$ stable efficiency. 


\section{M. Novel hot-wire deposition employing a coiled hot filament}

\section{Construction of a novel hot-wire deposition system employing a coiled hot filament}

During this program period, we have completed the installation of a non-conventional hot-wire cell CVD chamber in our ultrahigh-vacuum, multichamber, load-locked PECVD system. This novel hot-wire CVD process is used for the deposition of 1) high quality a-Si and a-SiGe materials at high deposition rates, and 2) large grain size poly-Si films for the narrow bandgap absorber layer.

Figure 2M-1 is a schematic of the chamber showing the gas flow pattern. Such a new design allows us a high degree of controllability of reactive species near the surface, needed for the growth of high-quality poly-Si at high rate. In this new design, a gas-confining cup is used to guide the flow of gases. There are three gas inlets.

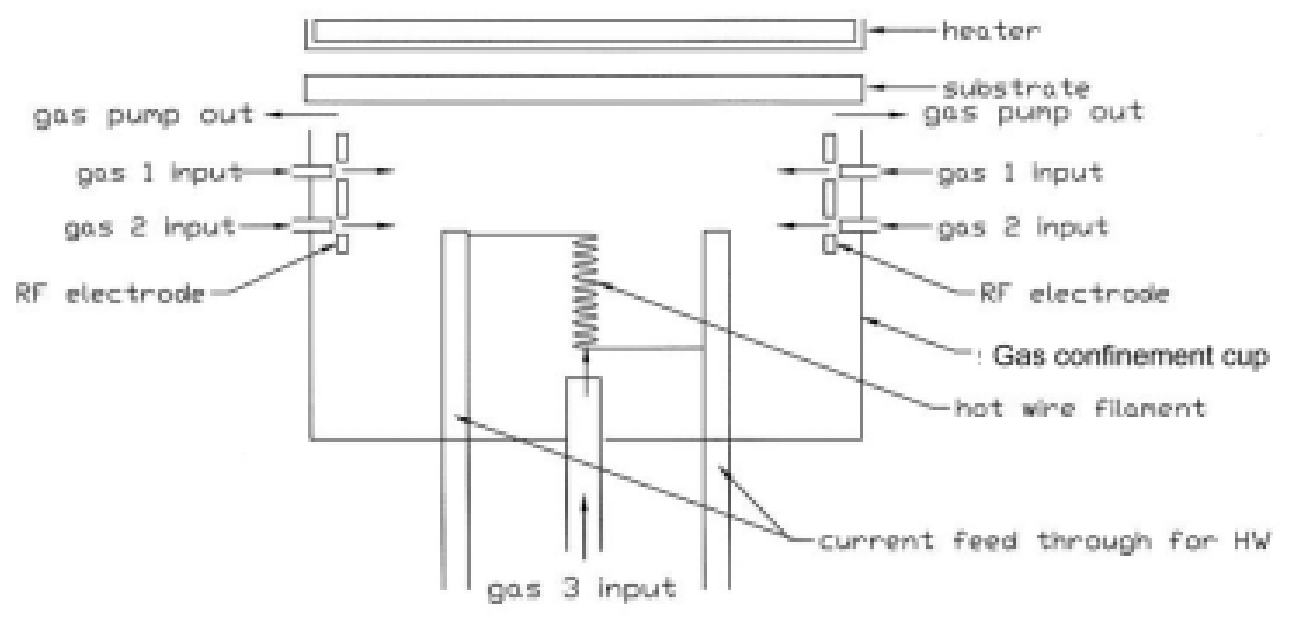

Figure 2M-1 A schematic of the new HW chamber, showing the gas confining cup, gas flow pattern, the coil filament, rf electrode and some other details.

In one approach, we flow the active gases, $\mathrm{SiH}_{4}\left(\right.$ or $\left.\mathrm{GeH}_{4}, \mathrm{Si}_{2} \mathrm{H}_{6}\right)$ and $\mathrm{H}_{2}$ through inlet 3. These gases pass through the heated filament placed next to the inlet tube numerous times, resulting in a maximized dissociation. In another approach, $\mathrm{H}_{2}$ gas is introduced from the bottom gas inlet 3 . It passes the filament coil and gets dissociated. A high concentration of atomic hydrogen flows up from the filaments toward the substrates. $\mathrm{Si}_{2} \mathrm{H}_{6}$ gas, or $\mathrm{SiH}_{4}$ gas, is injected into the chamber through the series of holes circularly distributed on the cup near the substrate. A shutter (not shown) is used to protect the substrate during non-deposition times. The filament coil is mounted inside the cup on two posts. The position of the filament can be adjusted relative to the substrate to control the flux of atomic $\mathrm{H}$ and $\mathrm{SiH}_{3}$ onto the growth surface. A resistive heater is used to heat the substrate. The heater is connected to the top chamber flange through a bellow. After the substrates are loaded, we lower the bellow so that the heater and the substrates are in direct contact. 
As shown in the Figure 2M-1, a circular rf electrode (shaped like a circular ribbon) was installed near the top of the cup, below the substrate but higher than the filament. On the rf electrode plate, there are two series of holes, lined up with the holes on the cup, to allow $\mathrm{GeH}_{4}$ and $\mathrm{Si}_{2} \mathrm{H}_{6}$ injected into the cup from the gas inlet 1 and inlet 2 . This electrode gives us the additional capability of employing a plasma-assisted HW CVD process. This electrode can be particularly useful for $\mathrm{H}$ plasma surface treatments before and after thin film deposition. Gas lines for process gases, $\mathrm{GeH}_{4}, \mathrm{Si}_{2} \mathrm{H}_{6}$ and $\mathrm{H}_{2}$, will be connected in such a way that each gas can flow into the cup from any of the three gas inlets. We will have the flexibility to 1) inject $\mathrm{GeH}_{4}$, $\mathrm{Si}_{2} \mathrm{H}_{6}$ together with the $\mathrm{H}_{2}$ at Inlet 3,2) inject additional $\mathrm{H}_{2}$ from Inlet 1 to cover the surface with more molecular $\mathrm{H}_{2}, 3$ ) inject $\mathrm{H}_{2}$ from Inlet 1 and $\mathrm{Si}_{2} \mathrm{H}_{6}$ from Inlet 3 and run the VHF deposition using a conventional approach, or 4) do any combinations of the above. In Figure $2 \mathrm{M}-1$, the outer chamber (main vacuum chamber) is left out for clarity.

This new HW deposition chamber is integrated into our existing three-chamber PECVD system (GSI system), routinely used for the fabrication of high-efficiency triple-junction solar cells. The substrate can be transferred through gate valves between the HW chamber and the other three deposition chambers without air break, allowing us to fabricate high-efficiency solar cell devices using the layers deposited in the HW chamber.

Our HW chamber is non-conventional and unique because it 1) has a gas confining cup to keep the deposition area clean; 2) has multiple gas inlets allowing maximum control of the radical concentrations near the growth surface; 3) has a coiled filament next to one of the inlets, allowing maximum decomposition of the selected gas inject from this particular inlet; 4) has a $\mathrm{RF} / \mathrm{VHF}$ electrode inside the cup allowing sequential and/or simultaneous excitation of growth radicals during deposition; 5) has a shutter placed very close to the substrate, providing maximum protection during the transient times; 6) is dedicated only for i-layer growth and no doped layers will be deposited in the same chamber to avoid cross contamination; and 7) is integrated in a multiple-chamber triple-junction solar cell fabrication system through a load-lock, allowing airbreak-free sample transfer between the intrinsic and doped layers.

\section{a-Si n-i-p solar cells deposited using novel hot-wire CVD using a coiled filament design}

In this Quarter, we have now fabricated our initial a-Si n-i-p devices using this new deposition system. The structure of the device is $\mathrm{SS} / \mathrm{BR} / \mathrm{n}-\mathrm{i}-\mathrm{p} / \mathrm{ITO}$. Figure $2 \mathrm{M}-2$ shows the I-V performance of such an initial single-junction a-Si solar cell $(\eta=\mathbf{7 \%})$ with the i-layer deposited using the new hot-wire chamber at a high deposition rate.

HW CVD growth of $\mu \mathrm{c}-\mathrm{Si}$ and a-Si films at different filament temperature and substrate temperatures

We explored systematically the dependence of a-Si and $\mu \mathrm{c}-\mathrm{Si}$ films on the filament temperature and substrate temperature on various substrates including Si wafer, quartz, 7059 glass, and stainless steel. Table $2 \mathrm{M}-1$ shows the deposition conditions for a set of films deposit in the filament temperature range of $2000 \mathrm{C}$ to $2400 \mathrm{C}$. It should be pointed out here that the temperature of the filament was estimated from the current flowing through the tungsten filament, according to a standard calibration (provided by Harv Mahan). The other deposition conditions are $\mathrm{Si}_{2} \mathrm{H}_{6}: 3 \mathrm{sccm}, \mathrm{H}_{2}: 3 \mathrm{sccm}$, and pressure: $20 \mathrm{mTorr}$. 


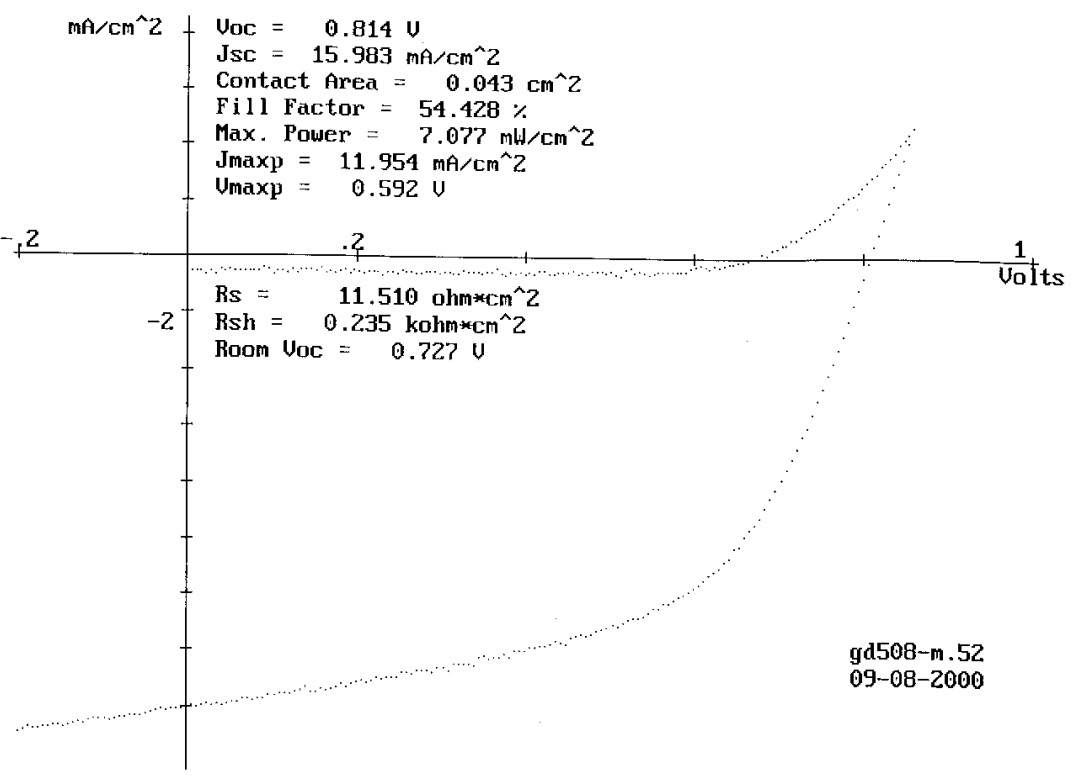

Figure 2M-2. I-V of a-Si solar cell gd508-m, whose i-layer deposited using the new hot-wire chamber at a high deposition rate

Table 2M-1 Deposition conditions and Raman results for hot-wire films deposited at different filament temperatures and substrate temperatures. The deposition rates are approximately the same, partially because the deposition is made under low-flow conditions.

\begin{tabular}{llllll}
\hline $\begin{array}{l}\text { Sample } \\
\text { No. }\end{array}$ & $\begin{array}{l}\mathrm{T}_{\text {fil }} \\
(\mathrm{K})\end{array}$ & $\begin{array}{l}\mathrm{T}_{\text {sub }} \\
(\mathrm{C})\end{array}$ & $\begin{array}{l}\text { Dep.Rate } \\
(\mathrm{A} / \mathrm{s})\end{array}$ & $\begin{array}{l}\text { Raman }\left(\mathrm{cm}^{-1}\right) \\
\text { main peak }\end{array}$ & $\begin{array}{l}\text { Raman }\left(\mathrm{cm}^{-1}\right) \\
2^{\text {nd }} \text { peak-shoulder }\end{array}$ \\
\hline HW29 & 2400 & 150 & 5.4 & 520 & 501 \\
HW28 & 2400 & 225 & 5.5 & 520 & 501 \\
HW27 & 2400 & 300 & 5.6 & 478 & 500 \\
\hline HW31 & 2200 & 150 & 5.0 & 520 & 500 \\
HW30 & 2200 & 225 & 5.9 & 520 & none \\
HW26 & 2200 & 300 & 5.6 & 477 & none \\
\hline HW24 & 2000 & 150 & 0.5 & too thin & \\
HW23 & 2000 & 225 & 0.7 & 476 & too thin \\
HW25 & 2000 & 300 & $?$ & &
\end{tabular}




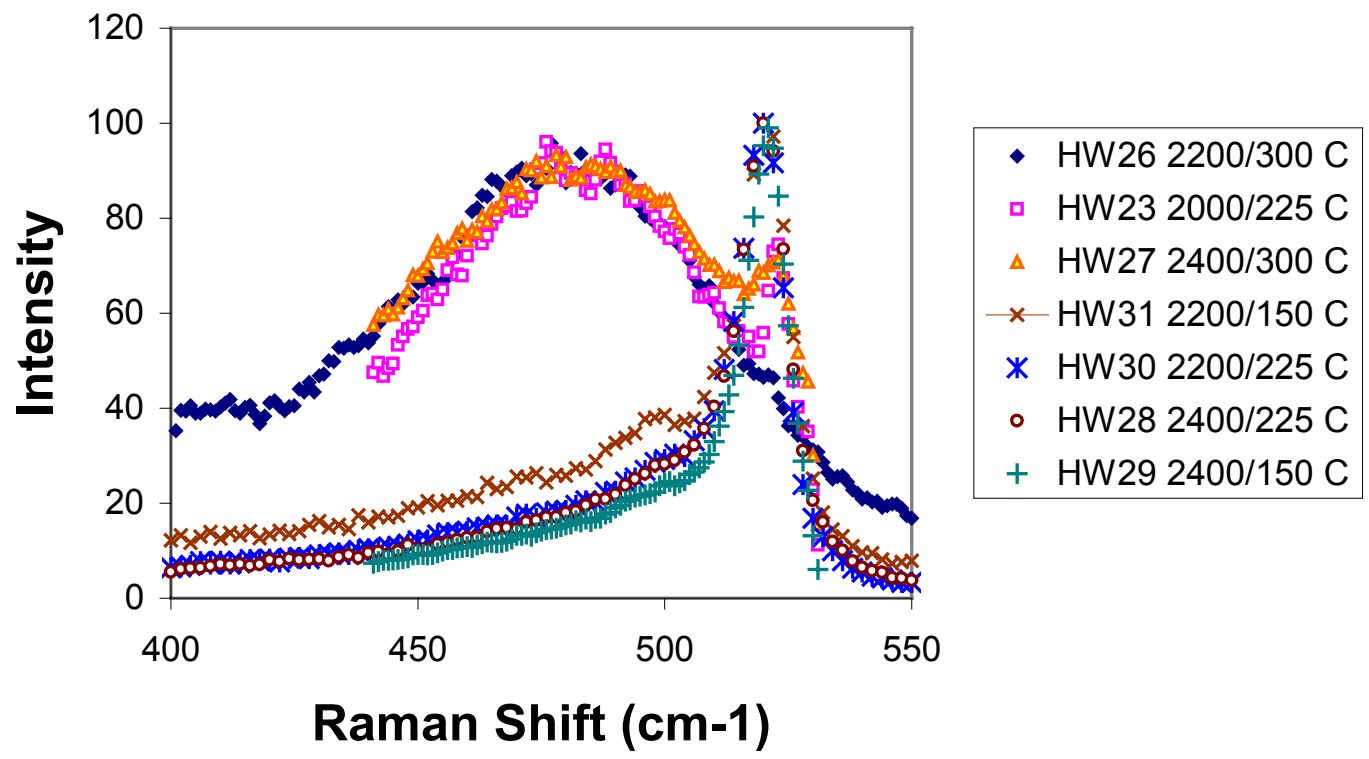

Figure 2M-3 Raman scattering for the hot-wire films in the range of $400-550 \mathrm{~cm}^{-1}$.

From Figure 2M-3, we observe that higher filament temperature and lower substrate temperature favor microcrystalline formation. Furthermore, we find that beside the peaks at 477 and $520 \mathrm{~cm}^{-1}$, there is a distinct peak at $500 \mathrm{~cm}^{-1}$, suggesting material with intermediate-range order.

\section{Dependence of growth of $\mu \mathrm{c}-\mathrm{Si}$ and a-Si on the gas flows in HW CVD process}

As shown in Figure 2M-10, process gases can be injected into the chamber through any or all of these three gas inlets. We studied the growth of a-Si and $\mu \mathrm{c}-\mathrm{Si}$ by flowing gases into the chamber from the Bottom Inlet (gas inlet 3 in Figure 2M-10) through the filament coil and Top Inlet (gas inlet 1 in Figure 2M-10) near the substrate. Table 2M-2 shows the flow schemes for four samples HW28, HW37, HW38 and HW39, deposited on a variety of substrates. Other deposition conditions are $\mathrm{Si}_{2} \mathrm{H}_{6}: 3 \mathrm{sccm}, \mathrm{H}_{2}: 3 \mathrm{sccm}$, pressure: $20 \mathrm{mTorr}, \mathrm{T}_{\mathrm{fil}}=2400 \mathrm{C}, \mathrm{T}_{\mathrm{sub}}=225 \mathrm{C}$, and Time: $30 \mathrm{~min}$. To study the microcrystallinity of these films with deposition time, Raman scattering was measured on the films deposited on quartz substrates on the front side (Figure 2M-4) as well as the back side through the substrate (Figure 2M-5). 'Raman peak-Back surface' indicates the Raman scattering measured from the side through quartz substrate, i.e. the film deposited on the substrate during the initial stage of the deposition, while 'Raman peak-Front surface' indicates the Raman scattering measured from the front surface, i.e. the film deposited during the final stage of deposition. The Raman spectra shown in Figure 2M-4 and Figure 2M-5 are summarized in Table 2M-2.

From Figure 2M-4, Figure 2M-5 and Table 2M-2, we conclude that 1) During the initial deposition on a quartz substrate, samples with $\mathrm{Si}_{2} \mathrm{H}_{6}$ and $\mathrm{H}_{2}$ from separate inlets (one through filament and one above) show microcrystalline structure while samples with both gases from the same inlet (through the filament or above) show amorphous structure and 2) During the final stage of deposition (after 30min), all samples show microcrystalline structure. This agrees with the suggestion from the "deposition phase diagram" of Collins, et al. 
Since Sample HW38 $\left(\mathrm{Si}_{2} \mathrm{H}_{6}\right.$ through filament, $\mathrm{H}_{2}$ above) was most unexpected. It was repeated (HW46, not shown) and the same result was observed. We have also made a set of four samples at a higher pressure $50 \mathrm{~m}$ Torr while other conditions were kept the same. For all four samples, the initial deposition show amorphous and the final stage of deposition show microcrystalline. The difference due to the different gas flows disappears at a higher deposition pressure.

Table 2M-2 Deposition conditions and Raman scattering peaks for films deposition in the HW CVD process with different gas flow schemes.

\begin{tabular}{llllllc}
\hline Sample & $\mathrm{Si}_{2} \mathrm{H}_{6}$ flow & $\mathrm{H}_{2}$ flow & $\begin{array}{r}\text { Front } \\
\text { Raman peak } \\
\left(\mathrm{cm}^{-1}\right)\end{array}$ & $\begin{array}{l}\text { Surface } \\
\text { Structure }\end{array}$ & $\begin{array}{r}\text { Back } \\
\text { Raman peak } \\
\left(\mathrm{cm}^{-1}\right)\end{array}$ & $\begin{array}{l}\text { surface } \\
\text { Structure }\end{array}$ \\
\hline HW28 & Bottom Inlet & Bottom Inlet & 519,499 & $\mu \mathrm{c}-\mathrm{Si}$ & 489 & $\mathrm{a}-\mathrm{Si}$ \\
HW37 & Bottom Inlet & Top Inlet & 520,499 & $\mu \mathrm{c}-\mathrm{Si}$ & 519,496 & $\mu \mathrm{c}-\mathrm{Si}$ \\
HW38 & Top Inlet & Bottom Inlet & 520,499 & $\mu \mathrm{c}-\mathrm{Si}$ & 519,497 & $\mu \mathrm{c}-\mathrm{Si}$ \\
HW39 & Top Inlet & Top Inlet & 518,499 & $\mu \mathrm{c}-\mathrm{Si}$ & 489 & $\mathrm{a}-\mathrm{Si}$ \\
\hline
\end{tabular}

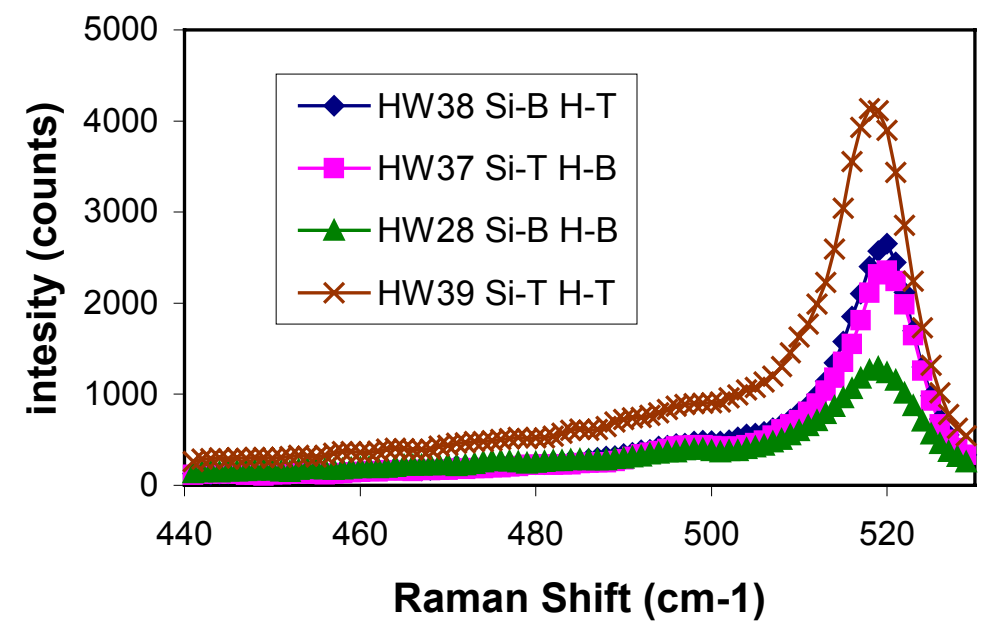

Figure 2M-4 Raman scattering measured from the front side of the samples. 


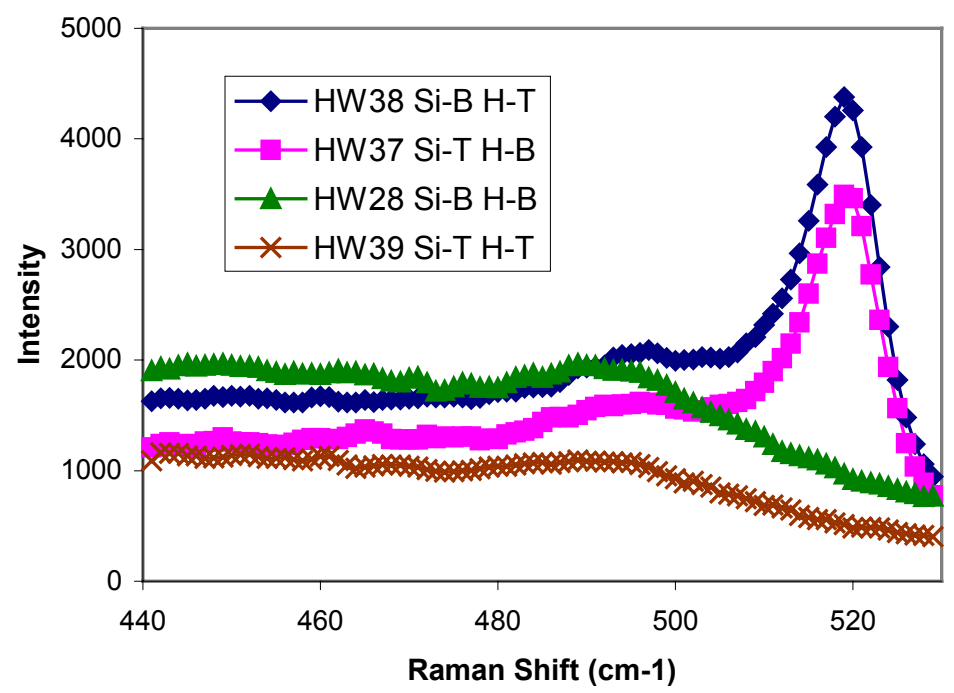

Figure 2M-5 Raman scattering measured from the back side through the quartz substrates. 


\section{N. VHF deposition of single and triple-junction solar cells}

We recently upgraded our PECVD deposition system to include VHF deposition process. The goal is to gain a deeper understanding of the deposition process near the transition from amorphous to microcrystalline and the plasma chemistry for growing a-Si based thin films at high rates. The VHF deposition power source includes an RSG-100B signal generator and an ENI 3100LA VHF power amplifier. A homemade matching box is used. At this moment, we could tune the system to deliver $90 \mathrm{MHz}$ power into the deposition chamber. The VHF power source is currently connected to the i-layer deposition chamber. It could also be connected to the doped layer deposition chamber since all three chambers ( $\mathrm{n}, \mathrm{i}$ and $\mathrm{p}$ ) are similar. With an improved matching box, we would be able to increase the frequency up to $120 \mathrm{MHz}$, which would allow us to study the effect of high frequency plasma excitation with a wider frequency range.

Preliminary films and devices have been made using the VHF plasma at a frequency of $80 \mathrm{MHz}$. A single junction n-i-p solar cell was fabricated using i-layer deposited with $80 \mathrm{MHz}$ VHF plasma at a deposition rate of $12 \AA /$ s. Figure $2 \mathrm{~N}-1$ shows the IV curve for such a device (GD607). The doped layers for this device were made using $13.56 \mathrm{MHz}$ RF glow discharge. The $\mathrm{V}_{\mathrm{oc}}, \mathrm{J}_{\mathrm{sc}}, \mathrm{FF}$ and efficiency for this preliminary device are $0.900 \mathrm{~V}, 11.8 \mathrm{~mA} / \mathrm{cm}^{2}, 61 \%$ and $6.5 \%$ respectively.

With such a VHF deposition process, we also deposited middle and bottom a-SiGe cells with the i-layer deposition rate around $10 \AA / \mathrm{s}$. A triple-junction a-Si/a-SiGe/a-SiGe solar cell was made (GD616) with all i-layers deposited using VHF plasma. Figure 2N-2 shows an IV curve for such a VHF triple cell deposited at high rate. It shows a $\mathrm{V}_{\text {oc }}$ of $2.159 \mathrm{~V}$ and $\mathrm{FF}$ of $64.6 \%$. However, the $\mathrm{J}_{\mathrm{sc}}$ is low due to a severe mismatch among the currents of the component cells. Further study is underway in this area.

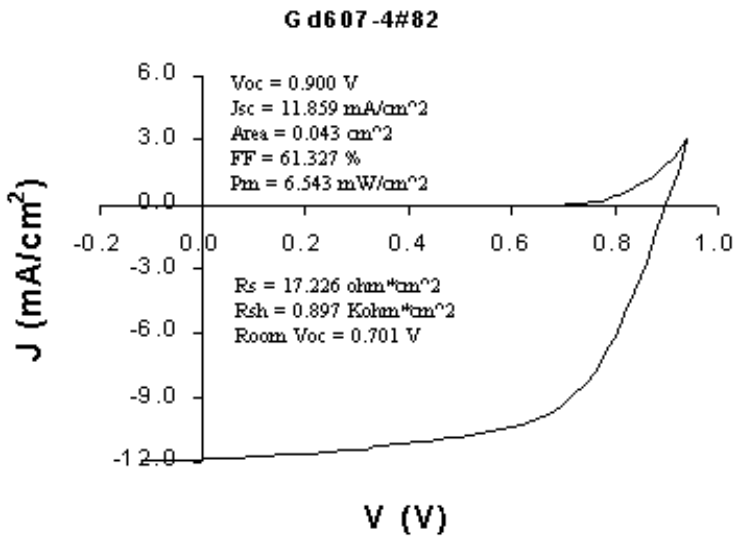

Figure 2N-1 IV curve of a single-junction solar cell with the i-layer deposited at $12 \AA / \mathrm{s}$ using VHF plasma at $80 \mathrm{MHz}$ excitation. 


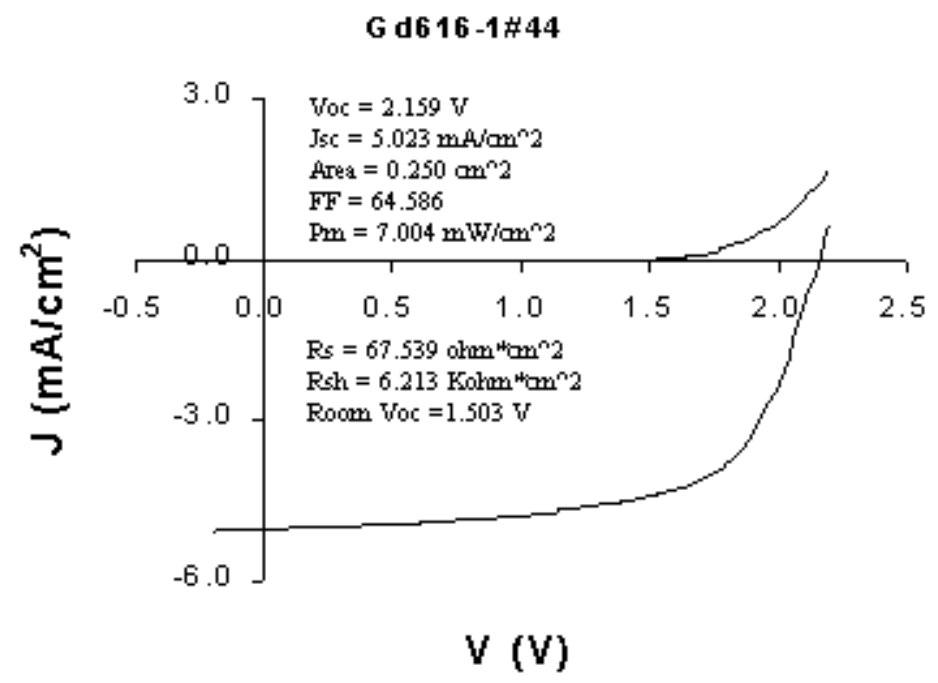

Figure 2N-2 IV curve of a triple-junction a-Si/a-SiGe/a-SiGe solar cell with all of the i-layers deposited using VHF plasma at high rates. 


\section{Amorphous silicon solar cells deposited on ultra-thin SS substrate}

\subsection{Summary}

To significantly reduce the solar cell weight and increase its specific power for space application, we deposited a-Si thin film solar cells on ultra-thin stainless steel (SS) substrates of $15 \mu \mathrm{m}, 12.5 \mu \mathrm{m}$ and $7.5 \mu \mathrm{m}$ thick and compared the results with those on standard 5 mil. $(127 \mu \mathrm{m})$ thick SS substrates that we use on a regular basis. To handle these ultra thin SS foils throughout the device fabrication process, we used a carrier method by attaching the ultra-thin SS foils on thicker $127 \mu \mathrm{m}$ SS substrates. We obtained ultra-lightweight solar cells that have similar performance as solar cells on regular $127 \mu \mathrm{m}$ substrates, with a $\mathrm{V}_{\text {oc }}$ of $0.887 \mathrm{~V}$, a $\mathrm{J}_{\text {sc }}$ of 10.8 $\mathrm{mA} / \mathrm{cm}^{2}$, a FF of $68 \%$ and an efficiency of $6.5 \%$ for cells without back-reflector. These $6.5 \%$ efficient, rollable solar cells deposited on $7.5 \mu \mathrm{m}$ thick SS substrates exhibit a specific power of $1.08 \mathrm{~kW} / \mathrm{kg}$, significant for space power applications and terrestrial applications such as portable electronics batteries.

\section{O.2 Introduction}

Thin film amorphous silicon (a-Si) based solar cells have become attractive alternatives for space power applications due to their low-cost processing and light weight[O2 - O3] as well as their tolerance under high radiation.[O4] The weight advantage of a-Si solar cells comes from their low thickness and high absorption constant. However, this weight advantage can only be realized if the substrate on which the solar cells are deposited is also reduced in weight. Several studies have been made in depositing a-Si based solar cells on lightweight substrates. Early in 1988, Hanak et al at Sovonics reported the achievement of $250 \mathrm{~W} / \mathrm{kg}$ solar arrays using a-Si deposited on lightweight flexible substrates. ${ }^{10}$ More recently, Guha et al at United Solar reported $12 \%$ total-area efficiency under AM0 illumination for a-Si solar cells. Similar efficiency was obtained for cells deposited on 0.5 mil thick SS and 2-mil thick Kapton substrates.[O5]

We performed a study to deposit a-Si solar cells on ultra-thin stainless steel (SS) substrates (down to $7.5 \mu \mathrm{m}$ ) for space power applications. We also report our recent results on the fabrication of a-Si based thin film solar cells on these SS substrates. These thin SS substrates are extremely light weight. In addition, it does not degrade at high temperature, allowing us wider parameter space during the thin film deposition and solar cell fabrication process. Different types of ultra-thin SS substrates are explored and summarized here.

\section{O.3 Experimental}

Single-junction a-Si n-i-p solar cells are fabricated in this study using an ultrahigh vacuum, multi-chamber, load-locked PECVD system. The device structure used in this study is $\mathrm{SS} / \mathrm{a}-\mathrm{Si} \mathrm{n}^{+} / \mathrm{a}-\mathrm{Si} \mathrm{i} / \mu \mathrm{c}-\mathrm{Si} \mathrm{p}^{+} / \mathrm{ITO}$. No current-enhancing back-reflector is used since relative comparison is more emphasized here. Evaluation of the solar cells include solar cell I-V measurement, quantum efficiency measurement and also an estimate of fabrication yield by counting the number of cells functional within a 2"x2" sample.

Three different types of thin SS substrates are explored. These substrates, purchased from Goodfellow Corporation, include:

1) $15-\mu \mathrm{m}$ thick AISI304 SS foil, as rolled, 
2) $12.5-\mu \mathrm{m}$ thick AISI $321 \mathrm{SS}$ foil, hard; and

3) $7.5-\mu \mathrm{m}$ thick AISI316 SS foil, as rolled.

Stainless steel substrates, $127 \mu \mathrm{m}$ thick (5.00 mil.), obtained from ECD, are used for comparison in this study. For a fair comparison, various substrates are put in the same deposition run during the solar cell fabrication. A carrier method is used for handling these thin SS foils during fabrication. In this method, the ultra-thin SS foils are attached to (by wrapping around) thick $(127 \mu \mathrm{m}) \mathrm{SS}$ carrier throughout the fabrication process.

\section{$2 \mathrm{O} .4$ Results}

Table 2O-1 shows the J-V performance of the three most recent deposition runs for a-Si single-junction solar cells deposited on different substrates. All three runs were made using identical deposition conditions for $\mathrm{n}, \mathrm{i}, \mathrm{p}$ and ITO layers. These deposition conditions are the same as those used for the top cell in 11\% triple-junction solar cells [O6-O7] except the i-layer thickness, which is around $200 \mathrm{~nm}$ in this study. Four pieces of 2"x2" substrates, mostly of different types, are loaded in each run for comparison. 23 cells (or 39 cells) are processed in each 2"x2" sample. By counting the number of cells functionally alive (with FF>60\%), we obtained information regarding the dependence of process yield on the use of different substrates. The I-V performance listed in Table 2O-1 is the average performance of the three cells with highest FF in the sample. The uncertainties in $\mathrm{V}_{\mathrm{oc}}, \mathrm{J}_{\mathrm{sc}}$ and FF values are approximately $1 \%, 10 \%$ and $2 \%$, respectively. The relatively larger uncertainty in $\mathrm{J}_{\mathrm{sc}}$ is due to the small size of the solar cells $(0.05$ $\mathrm{cm}^{2}$ ). The $J_{\mathrm{sc}}$ values for these solar cells with $200 \mathrm{~nm}$ thick i-layers are relatively low due to the lack of a current-enhancing back-reflector.

Table 20-1. Average I-V performance under AM1.5 illumination and yield information for a-Si solar cells deposited on different thin SS substrates.

\begin{tabular}{|c|c|c|c|c|c|c|c|}
\hline Device & Substrate & \multicolumn{5}{|c|}{ Average } & \multicolumn{2}{|c|}{ I-V performance } & \multicolumn{2}{|c|}{ Yield } \\
\hline & $\begin{array}{c}\text { Thickness } \\
(\mu \mathrm{m})\end{array}$ & $\begin{array}{c}\mathrm{V}_{\mathrm{oc}} \\
(\mathrm{V})\end{array}$ & $\begin{array}{c}\mathrm{J}_{\mathrm{sc}} \\
\left(\mathrm{mA} / \mathrm{cm}^{2}\right)\end{array}$ & $\begin{array}{c}\mathrm{FF} \\
(\%)\end{array}$ & $\begin{array}{c}\text { Pmax } \\
(\%)\end{array}$ & $\begin{array}{c}\text { Cells } \\
\text { alive }\end{array}$ & $\begin{array}{c}\text { Total } \\
\text { cells }\end{array}$ \\
\hline GD479-1 & 7.5 & 0.906 & 10.0 & 66.0 & 6.0 & 5 & 23 \\
GD479-2 & 127 & 0.891 & 10.8 & 68.9 & 6.7 & 22 & 23 \\
GD479-3 & 15 & 0.889 & 11.0 & 63.1 & 6.2 & 12 & 23 \\
\hline GD480-1 & 7.5 & 0.887 & 10.8 & 68.0 & 6.5 & 12 & 23 \\
GD480-2 & 127 & 0.889 & 10.9 & 69.0 & 6.7 & 7 & 23 \\
GD480-3 & 15 & 0.892 & 10.7 & 62.6 & 6.0 & 5 & 23 \\
GD480-4 & 127 & 0.864 & 10.0 & 65.0 & 5.6 & 7 & 39 \\
\hline GD481-1 & 7.5 & 0.885 & 10.7 & 66.1 & 6.3 & 11 & 39 \\
GD481-2 & 15 & 0.895 & 10.3 & 64.3 & 5.9 & 3 & 39 \\
GD481-3 & 12.5 & 0.886 & 10.9 & 64.1 & 6.2 & 10 & 39 \\
GD481-4 & 127 & 0.889 & 11.4 & 66.4 & 6.7 & 21 & 39 \\
\hline
\end{tabular}




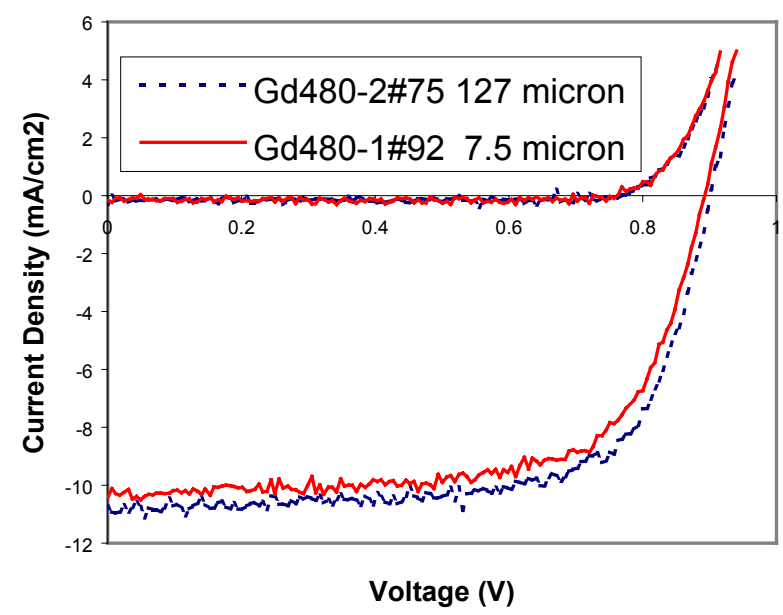

\begin{tabular}{|c|c|c|}
\hline Cell & $\begin{array}{c}\text { GD480- } \\
\mathbf{2 \# 7 5}\end{array}$ & $\begin{array}{c}\text { GD480- } \\
\mathbf{1 \# 9 2}\end{array}$ \\
\hline Substrate & $127 \boldsymbol{\mu m}$ & $7.5 \mu \mathrm{m}$ \\
\hline $\mathrm{V}_{\text {oc }}(\mathrm{V})$ & 0.901 & 0.893 \\
\hline $\mathrm{J}_{\text {sc }}\left(\mathrm{mA} / \mathrm{cm}^{2}\right)$ & 10.7 & 10.4 \\
\hline $\mathrm{FF}(\%)$ & 70.4 & 68.7 \\
\hline Efficiency $(\%)$ & 6.81 & 6.39 \\
\hline
\end{tabular}

Figure 20-1. J-V curves of two representative a-Si solar cells deposited on $7.5 \mu \mathrm{m}$ ultra-thin SS substrate and $127 \mu \mathrm{m}$ thick standard SS substrate, showing very similar performance under AM1.5 illumination.

As we see from Table 2O-1 and Figure 2O-1, the solar cell performances for devices on different substrates are similar. Samples deposited on $127 \mu \mathrm{m}$ thick substrates generally show slightly higher FF than samples on other substrates in the same run, leading to the highest efficiency. Comparing the thinner substrates, samples on $7.5 \mu \mathrm{m}$ thick substrates outperform those on 15 and $12.5 \mu \mathrm{m}$ substrates, especially in the FF. Figure 2O-1 shows the J-V curves of one typical cell in each of a $127 \mu \mathrm{m}$ sample (GD480-2) and a $7.5 \mu \mathrm{m}$ sample (GD480-1). Both samples show very similar performance within statistical variation.

The fabrication yield, number of cells alive divided by the total number of cells processed, for these samples show that $127 \mu \mathrm{m}$ thick substrate lead to slightly higher yield. And the cells on the three-types of thin SS substrates show similar yield within statistical fluctuation.

To find out the cause for the dependence of the process yield on the substrate, we examined the different types of substrates using SEM. The SEM graphs show that both the 7.5 $\mu \mathrm{m}$ and $127 \mu \mathrm{m}$ substrates are smoother while $12.5 \mu \mathrm{m}$ substrates show more roughness or cracks. The $15 \mu \mathrm{m}$ substrates appear to be somewhere in between. This may to some extent shed some light on the yield results. We therefore suggest that the use of as-rolled substrates is more appropriate for solar cell fabrication than the use of hardened SS substrates.

Table 2O-1 shows only our most recent three runs. The six runs prior to these three runs show very similar results and are therefore omitted for inclusion in Table 2O-1. Although the variation in $\mathrm{J}_{\mathrm{sc}}$ for different types of cells is within measurement uncertainty at this moment, the data in Table 2O-1 appear to indicate that $127 \mu$ m substrate provides a higher $\mathrm{J}_{\mathrm{sc}}$ than the thin $\mathrm{SS}$ substrates. We believe that the difference, if any, would vanish after back-reflector layers, such as $\mathrm{Ag} / \mathrm{ZnO}$ layers, are deposited on top of the surface. We plan to put $\mathrm{Ag} / \mathrm{ZnO}$ back-reflector and fabricate high-efficiency triple-junction solar cells on these ultra-thin SS substrates.

Taking the total thickness for the n, i, p and ITO layers to be $300 \mathrm{~nm}$ and that for the SS substrate to be $7.5 \mu \mathrm{m}$, the specific power for a $6.5 \%$ efficient solar cell (GD480-1) becomes $1.08 \mathrm{~kW}$ per kilogram. Such a specific power can be further increased after we fabricate on these 
thin SS substrates triple-junction a-Si/a-SiGe/a-SiGe solar cells with around $11 \%$ efficiency, which have already been fabricated in our laboratory on $127 \mu \mathrm{m}$ thick substrates.[O1, O6] This high specific power is very important for space power application since it significantly reduces launching cost. In addition, a-Si based solar cells deposited on thin SS substrates can be easily rolled up thus reduce the cost associated with launching volume.

\section{O.5 Conclusion}

Amorphous silicon solar cells have been successfully fabricated on ultra-thin SS substrates with down to $7.5 \mu \mathrm{m}$ in thickness. Using a carrier method throughout the fabrication process, we obtained ultra-lightweight solar cells that have similar performance as solar cells on regular $127 \mu \mathrm{m}$ substrates, with a $\mathrm{V}_{\mathrm{oc}}$ of $0.887 \mathrm{~V}$, a $\mathrm{J}_{\mathrm{sc}}$ of $10.8 \mathrm{~mA} / \mathrm{cm}^{2}$, a FF of $68 \%$ and an efficiency of $6.5 \%$ under AM1.5 illumination for cells deposited on bare SS without the use of a back-reflector. It should be noted here that the efficiency value under AM0 illumination should be approximately 20\% lower than the efficiency measured under AM1.5 illumination. The solar cell efficiency could be further improved when a back-reflector is used and when a triplejunction solar cell is fabricated on these substrates. The solar cell yield, although slightly lower than those on thicker SS substrates, is however very promising. These $6.5 \%$ efficient solar cells deposited on $7.5 \mu \mathrm{m}$ thick SS substrates exhibit a specific power of $1.08 \mathrm{~kW} / \mathrm{kg}$, significant for space power application. We have studied the use of various types of SS substrates. The results we obtained so far appear to suggest that the as-rolled AISI316 SS foil is most suitable for the fabrication of a-Si based solar cells for space application. 


\title{
2P. AMPS Modeling of Nanocrystalline Si p-Layer in a-Si NIP Solar Cells
}

\author{
2P.1 Summary
}

We report numerical simulations for the impact of a wide bandgap p-type hydrogenated nanocrystalline silicon (nc-Si:H) on the performance of a-Si based component solar cells, using Analysis of Microelectronic and Photonic Structures (AMPS) computer model developed at Penn State University. The effects of band offset and potential barrier formed at the interfaces of p-layer with i-layer and ITO front contact were also investigated. The simulated results show that 1) with increasing bandgap of p-nc-Si:H $\left(E_{g p}\right)$, the $V_{\text {oc }}$ increases beyond $1 \mathrm{~V}$, then decreases, due to the band offset at the $\mathrm{p} / \mathrm{i}$ interface, which also leads to an anomalous illuminated I-V characteristics with a bending close to the open circuit point; and 2) the front contact barrier plays a similar role to hinder the hole collection and may cause the illuminated I-V curve to bend seriously.

\section{P.2 Introduction}

In order to provide guidance for the optimization of triple-junction amorphous silicon based solar cell fabrication, we carried out numerical simulations using AMPS model developed at Penn State University [P1]. The modeling is geared toward understanding of 1) the impact of the wide bandgap p- $\mu \mathrm{c}-\mathrm{Si}: \mathrm{H}$ layer on $\mathrm{V}_{\text {oc }}$ for the top cells, and 2) the influence of band offsets between $\mathrm{p}$ $\mu \mathrm{c}-\mathrm{Si}: \mathrm{H}$ and $\mathrm{i}-\mathrm{a}-\mathrm{SiGe}$ on the illuminated $\mathrm{I}-\mathrm{V}$ characteristics for the middle and bottom component cells of a triple-junction a-Si solar cell

\section{P.3 Modeling and results}

It is well known that proper selection of the basic parameters of the material concerned is very important for modeling research. In this study, the chosen parameters for AMPS modeling, as listed in Table 2P-1, include: the basic energy band parameters of the bandgap $\mathrm{E}_{\mathrm{g}}$, effective densities of states $\mathrm{N}_{\mathrm{c}}$ and $\mathrm{N}_{\mathrm{v}}$ for the conduction band and valence band, and the electron affinity $\chi_{\mathrm{e}}$; the parameters describing the defect densities of the characteristic energy $\mathrm{E}_{\mathrm{o}}$ of the Urbach band tail, the Gaussian defect density $\mathrm{N}_{\text {gap }}$ in the mid gap; the acceptor concentration $\mathrm{N}_{\mathrm{A}}$ for the p-layer and the mobility $\mu_{\mathrm{e}}$ and $\mu_{\mathrm{h}}$ for electrons and holes.

For i-layer of the top cells, we chose $\mathrm{E}_{\mathrm{g}}=1.84 \mathrm{eV}$, as measured and reported in our previous work [P2]. We chose $\mathrm{N}_{\mathrm{c}}$ and $\mathrm{N}_{\mathrm{v}}$ to be the same as that of crystalline silicon. For the p-layer, we assumed two kinds of them: p-type hydrogenated microcrystalline silicon ( $\mathrm{p}-\mu \mathrm{c}-\mathrm{Si}: \mathrm{H})$ and $\mathrm{p}$-type hydrogenated nanocrystalline silicon (p-nc-Si:H). The former is thought to be simply composed of microcrystallites, and the volume fraction of the interface phase between the microcrystallites could be ignored. However the latter is thought to consist of nanometer-sized crystallites embedded in wide bandgap interface phase, having in fact a two phase structure. We do not yet have enough information on either phase, so we tentatively differ them by different Urbach band tail $\mathrm{E}_{\mathrm{o}}$ and mobility $\mu$. For the pure $\mathrm{p}-\mu \mathrm{c}-\mathrm{Si}: \mathrm{H}$, we assumed $\mathrm{E}_{\mathrm{o}}=0.01 \mathrm{eV}$ and $0.02 \mathrm{eV}$ for conduction band and valence band, respective, and $\mu=5$ and $0.5 \mathrm{~cm}^{2} / \mathrm{s} \cdot \mathrm{V}$ for electrons and holes, respectively. For the p-nc-Si:H, the Urbach band tails become larger with $\mathrm{E}_{\mathrm{o}}=0.06$ and $0.1 \mathrm{eV}$ 
for conduction and valence bands, respectively, and the carrier mobilities decrease to $\mu=2$ and $0.2 \mathrm{~cm}^{2} / \mathrm{s} \cdot \mathrm{V}$ for electrons and holes, respectively.

As for the electron affinity $\chi_{\mathrm{e}}$, we assumed it to be equal to that of c-Si. This means that the band offsets at $\mathrm{p} / \mathrm{i}$ interface mostly occur at the valence band edge. Another sensitive parameter for the simulation is the barrier height $\phi_{\mathrm{B} 0}$ at the front ITO/p-layer interface, which should be dependent on both the work function difference and the interface states. In order to demonstrate the influences of the p-layer bandgap $\mathrm{E}_{\mathrm{gp}}$ on the performances of solar cells, we first chose $\phi_{\mathrm{B} 0}=$ $1.28 \mathrm{eV}$, as an example, to pin the $\mathrm{E}_{\mathrm{F}}$ at somewhere below $\mathrm{E}_{\mathrm{c}}$ by an interfacial layer.

The simulated photovoltaic parameters of $\mathrm{V}_{\text {oc }}$ and FF, obtained from AMPS, are shown in Table $2 \mathrm{P}-2$ as a function of the p-layer bandgap $\mathrm{E}_{\mathrm{gp}}$ varying from 1.5 to $2.0 \mathrm{eV}$. As we can see, for the p-nc-Si:H, $\mathrm{V}_{\text {oc }}$ increases from $0.805 \mathrm{~V}$ to $1.026 \mathrm{~V}$ with increasing $\mathrm{E}_{\mathrm{gp}}$ from 1.5 to $1.8 \mathrm{~V}$, then decreases with further increasing $\mathrm{E}_{\mathrm{gp}}$. The reason for the decline of $\mathrm{V}_{\mathrm{oc}}$ is because the valenceband offset at the $\mathrm{p} / \mathrm{i}$ interface forms a barrier for photogenerated holes drifting across the $\mathrm{p} / \mathrm{i}$ interface to the $\mathrm{p}$-layer. For the pure $\mu \mathrm{c}-\mathrm{Si}$ p-layer, the dependence of $\mathrm{V}_{\mathrm{oc}}$ on $\mathrm{E}_{\mathrm{gp}}$ is similar to the case of $\mathrm{p}-\mathrm{nc}-\mathrm{Si}: \mathrm{H}$, except that rather higher $\mathrm{V}_{\text {oc }}(1.155 \mathrm{~V})$ could be reached, which, as of today, has not yet been achieved experimentally. It is noticed that the calculated results are very sensitive to the choice of $\mathrm{E}_{0}$, for instance, when $\mathrm{E}_{0}$ is decreased by a slight $0.01 \mathrm{eV}$ from the case of the p-nc-Si:H, it will lead to $\mathrm{V}_{\text {oc }}=1.054 \mathrm{~V}$ and $\mathrm{FF}=0.757$, which are close to what we have observed in our top cells.

Table 2P-1 Parameters used in AMPS modeling

\begin{tabular}{|c|c|c|c|c|c|c|c|c|}
\hline Layer & $\begin{array}{l}E_{g} \\
(e V)\end{array}$ & $\begin{array}{l}\mathrm{N}_{\mathrm{c}} \\
\left(\mathrm{cm}^{-3}\right)\end{array}$ & $\begin{array}{l}\mathrm{N}_{\mathrm{v}} \\
\left(\mathrm{cm}^{-3}\right)\end{array}$ & $\begin{array}{l}\mathrm{E}_{0}(\mathrm{C} / \mathrm{V}) \\
(\mathrm{eV})\end{array}$ & $\begin{array}{l}\mathrm{N}_{\mathrm{A}} \\
\left(\mathrm{cm}^{-3}\right)\end{array}$ & $\begin{array}{l}\mathrm{N}_{\text {gap }} \\
\left(\mathrm{cm}^{-3}\right)\end{array}$ & $\begin{array}{l}\mu_{\mathrm{e}} / \mu_{\mathrm{h}} \\
\left(\mathrm{cm}^{2} / \mathrm{V} \cdot \mathrm{s}\right)\end{array}$ & $\begin{array}{l}\chi_{\mathrm{e}} \\
(\mathrm{eV})\end{array}$ \\
\hline i-layer & 1.84 & $2.8 \mathrm{E}+19$ & $1.04 \mathrm{E}+19$ & $0.03 / 0.05$ & & $5.00 \mathrm{E}+15$ & $5 / 0.5$ & 4.05 \\
\hline 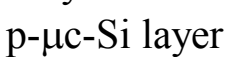 & $1.5^{*}$ & $2.8 \mathrm{E}+19$ & $1.04 \mathrm{E}+19$ & $0.01 / 0.02$ & $1.04 \mathrm{E}+19$ & $1.04 \mathrm{E}+18$ & $5 / 0.5$ & 4.05 \\
\hline p-nc-Si layer & $1.5^{*}$ & $2.8 \mathrm{E}+19$ & $1.04 \mathrm{E}+19$ & $0.06 / 0.1$ & $1.04 \mathrm{E}+19$ & $1.04 \mathrm{E}+18$ & $2 / 0.2$ & 4.05 \\
\hline
\end{tabular}

* denotes the variable for this study

Table 2P-2 AMPS simulation results for the top cells with different $\mathrm{E}_{\mathrm{gp}}$

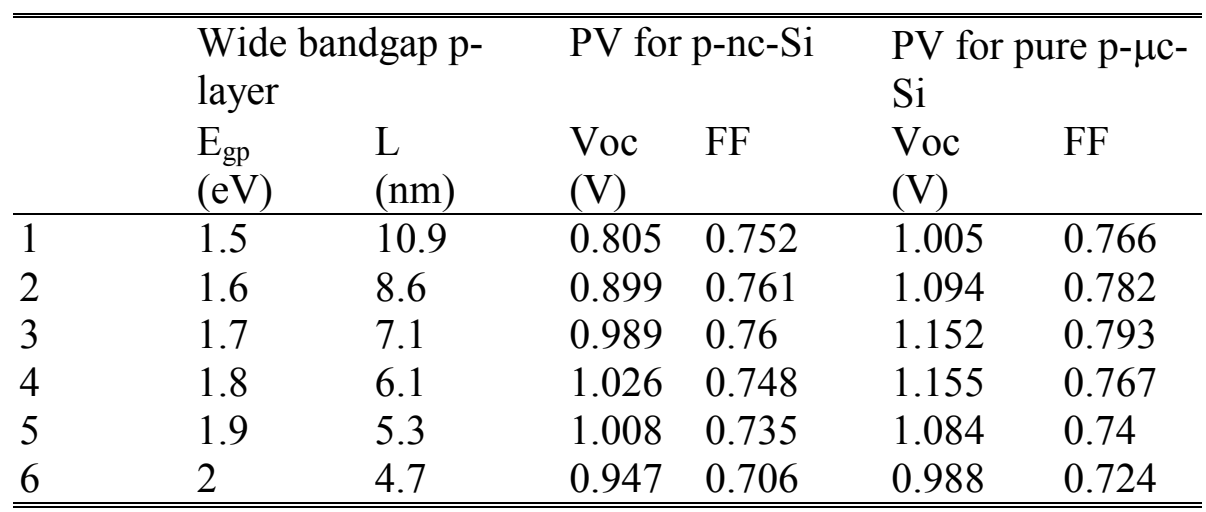




\section{P.4 Quantum confinement effects and p-nc-Si:H}

There are usually two ways of achieving wide bandgap p- $\mu \mathrm{c}-\mathrm{Si}: \mathrm{H}$, either by alloying, e.g. $\mathrm{SiC}_{\mathrm{x}}$, $\mathrm{SiN}_{\mathrm{x}}$, or by decreasing the size of Si clusters to a nanometer range. In our case the $\mathrm{H}$ content inside the Si microcrystalltes is believed to be small, so any cause for larger bandgap of $\mathrm{p}-\mu \mathrm{c}-$ $\mathrm{Si}: \mathrm{H}$ could be mainly due to the quantum size confinement effects, rather than the alloy effects. It was reported that the effective bandgap widening $\Delta \mathrm{Eg}$ of Si clusters is proportional to $1 / \mathrm{L}^{\Upsilon}$, where $\mathrm{L}$ is the size of $\mathrm{Si}$ clusters and $\Upsilon=1$ to 2 depending on the theoretical models used. For example, for the effective mass approach [P3], $\Upsilon=2$ and for the density-function approach [P4], $\Upsilon=1$. Based on the density-function approach, we estimated the sizes of Si clusters in the range of 10.9 to $4.7 \mathrm{~nm}$ for the $\mathrm{p}-\mu \mathrm{c}-\mathrm{Si}: \mathrm{H}$ or $\mathrm{p}-\mathrm{nc}-\mathrm{Si}: \mathrm{H}$ with $\mathrm{E}_{\mathrm{gp}}=1.5$ to $2.0 \mathrm{e} \mathrm{V}$, as also listed in Table $2 \mathrm{P}-2$.

However, these theoretical calculations were performed only for isolated nanocrystals, which could be approximately applied to Si clusters embedded in a dielectric matrix (e.g., $\mathrm{SiO}_{\mathrm{x}}, \mathrm{SiN}_{\mathrm{x}}$ ), forming relatively deep quantum-dot system. In our case, the dielectric matrix could be only the wide bandgap $\mathrm{SiH}_{\mathrm{x}}$ complex, surrounding the Si clusters and forming an interface phase.

Therefore, the wide bandgap p-layer is actually a two-phase structure of nc-Si and $\mathrm{SiH}_{\mathrm{x}}$, and the volume fraction of the interface phase could not be ignored. As an example, we consider a player composed of Si crystallites of $7 \mathrm{~nm}$. The volume fraction of the interface phase in this case should be in the range of $\sim 0.33$ to 0.52 , if the thickness of the interface phase is in the range of $\sim 1$ to $2 \mathrm{~nm}$, the minimum value needed for isolating the clusters. Therefore, for the wide bandgap p-layer we used the term "p-nc-Si:H", instead of p- $\mu c-S i: H$, as it comprises nanometer-sized Si crystallites and the surrounded $\mathrm{SiH}_{\mathrm{x}}$ interface matrix.

Experimentally, the deposition conditions for p-nc-Si:H mainly employ a high H-dilution, a high rf power and a low substrate temperature, likely leading to the formation of crystalline phase with nanometer-sized grains (nano-crystalline phase) and surrounding $\mathrm{SiH}_{\mathrm{x}}$ interface matrix (amorphous phase). It was also reported that using well deposited $\mu \mathrm{c}-\mathrm{Si}: \mathrm{H}$ with high volume fraction of microcrystallinity as the p-layer one obtains a lower $\mathrm{V}_{\mathrm{oc}}$ [P5]. This is because the mobility gap of $\mathrm{p}-\mu \mathrm{c}-\mathrm{Si}: \mathrm{H}$ could be limited to around $1.12 \mathrm{eV}$, i.e., the bandgap of single crystal Si.

\section{P.5 Band offset at $\mathrm{p} / \mathrm{i}$ interface}

We mentioned above that the decrease of $\mathrm{V}_{\text {oc }}$ with further increasing $\mathrm{E}_{\mathrm{gp}}$ (see Table 2P-2) is due to the band discontinuity at the $\mathrm{p} / \mathrm{i}$ interface occurring at the valence band edge. This occurs when we assume that $\chi_{\mathrm{e}}=4.05 \mathrm{eV}$, which is equal to the value of c-Si, no matter how the $\mathrm{p}$ - and i-layer changes. The influences of the band discontinuity on the cell performance should be more serious when we use the wide bandgap p-nc-Si:H layer for the mid and narrow bandgap a-SiGe cells. Figure 2P-1 shows the I-V characteristics of two mid-gap a-SiGe solar cells deposited under similar conditions except the $\mathrm{p}$-nc-Si layer, lower substrate temperature $\mathrm{T}_{\mathrm{s}}$ for GD554 and higher $\mathrm{T}_{\mathrm{s}}$ for GD572. The low $\mathrm{T}_{\mathrm{s}}$ for GD554 probably leads to smaller size for the crystallites and wider bandgap due to quantum confinement. From Figure 2P-1 one can see that GD554 not only has low FF but also an anomalous illuminated I-V curve, with a bending close to the open circuit point. It should be noted here that the same low-temperature deposited player, used in GD554, is ideal for wide bandgap (1.8 eV) a-Si:H top cell that has $\mathrm{V}_{\text {oc }}$ of $1.04 \mathrm{~V}$ and FF of $73 \%$ without any bending in I-V curve near the open circuit point. 

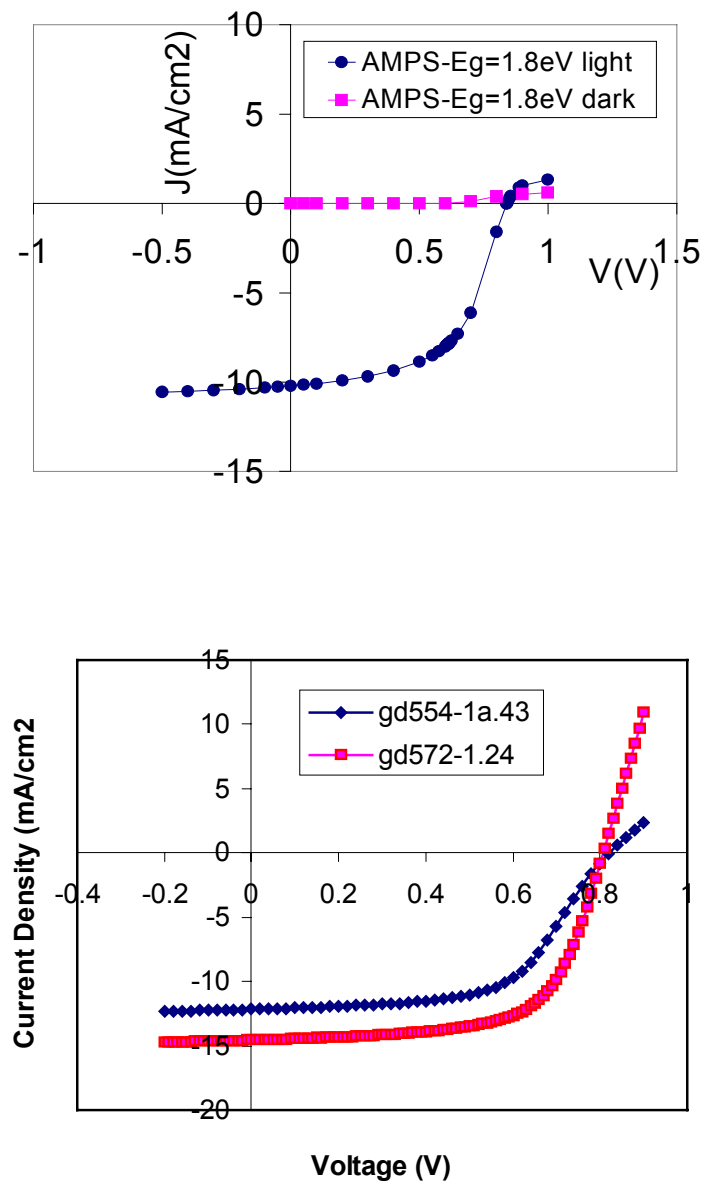

Figure 2P-1. I-V curves of a-SiGe middle cells with p-layer deposited at different temperatures, $\mathrm{T}_{\mathrm{s}}(\mathrm{p})=70{ }^{\circ} \mathrm{C}$ for GD554 and $\mathrm{T}_{\mathrm{s}}(\mathrm{p})=140{ }^{\circ} \mathrm{C}$ for GD572.

In order to better understand this issue we also carried out numerical simulations for mid bandgap a-SiGe cells $(\mathrm{Eg}=1.6 \mathrm{eV})$ using AMPS model. The variable in the calculation is also the bandgap $\mathrm{E}_{\mathrm{gp}}$ of the p-layer, while keeping $\chi_{\mathrm{e}}$ unchanged $(4.05 \mathrm{eV})$. The simulated results are shown in Figure $2 \mathrm{P}-2 \mathrm{a}\left(\mathrm{E}_{\mathrm{gp}}=1.8 \mathrm{eV}\right)$ and $2 \mathrm{~b}\left(\mathrm{E}_{\mathrm{gp}}=1.6 \mathrm{eV}\right)$. It can be seen from Figure 2P-2a that there is an anomalous rollover behavior in the IV characteristics at forward bias close to the $\mathrm{V}_{\text {oc }}$, similar to the experimental observation on that of GD554. But when the p-layer bandgap $\mathrm{E}_{\mathrm{gp}}$ is decreased down to $1.6 \mathrm{eV}$, the same value as that of the intrinsic layer, the rollover behavior in the IV characteristics disappears, and the FF increases, as shown in Figure 2P-2b.

The underlying reason responsible for this phenomenon could be more clearly seen from their band diagrams under thermodynamic equilibrium, as illustrated in Figure 2P-3. The EF, Eca (Ecb) and Eva (Evb) denote the Fermi level, conduction band edge and valence band edge, respectively. For the p-nc-Si:H layer of $1.8 \mathrm{eV}$, the band offset of $0.2 \mathrm{eV}$ in the valence band edge at the $\mathrm{p} / \mathrm{i}$ interface induces a barrier at the $\mathrm{p} / \mathrm{i}$ interface for the photogenerated holes to get collected to the p-layer. Especially when the built-in potential is much weakened when the forward bias is near $\mathrm{V}_{\mathrm{oc}}$, the hindered action of the extra barrier on the hole drifting across the interface will be more significant, leading to the rollover behavior in the I-V characteristics. 
Figure 2P-2a The calculated dark and illuminated J-V characteristics for mid bandgap cells with $\mathrm{E}_{\mathrm{pg}}=1.8 \mathrm{eV}$

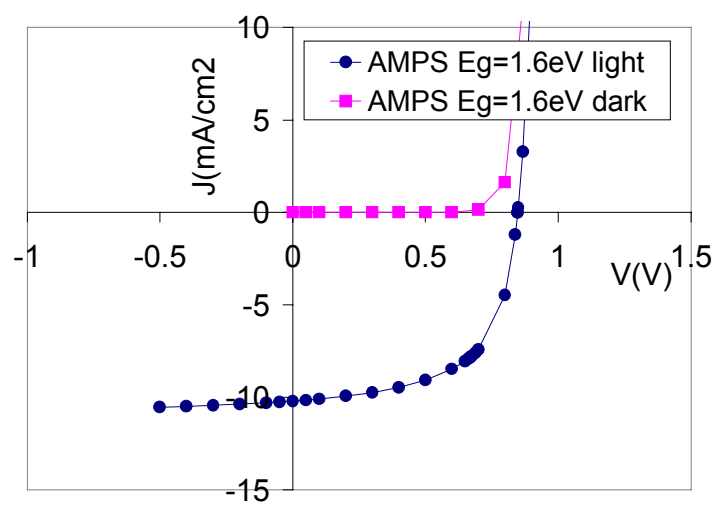

Figure 2P-2b The calculated dark and illuminated J-V characteristics for mid bandgap cells with $\mathrm{E}_{\mathrm{pg}}=1.6 \mathrm{eV}$.

Following this thought, we decreased experimentally the bandgap of the p-layer by using a higher substrate temperature that presumably leads to larger nc-Si particle size and less quantum-confinement induced increase of bandgap. The increase in the p-layer temperature resulted in much improved performances of the mid and narrow bandgap solar cells, as shown in Figure 2P-1 for device GD572. This result also suggests that the major band edge discontinuity occurs at the valence band.

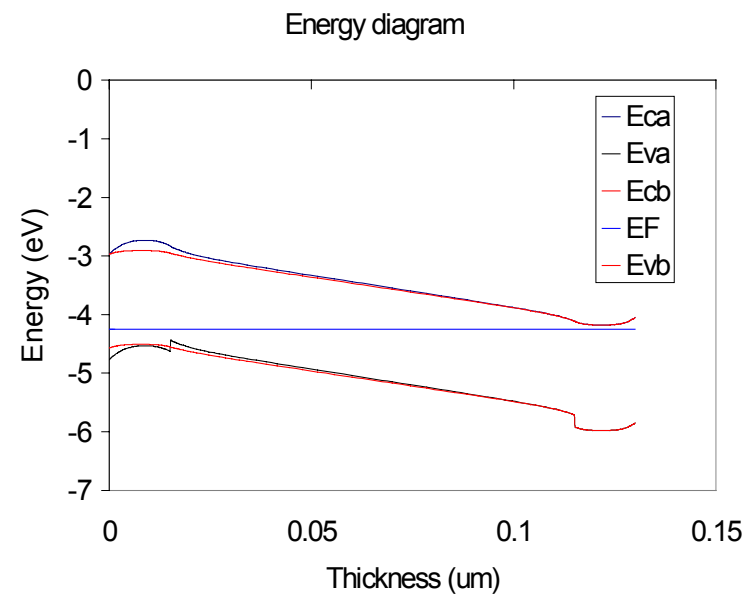

Figure 2P-3 The calculated thermodynamic equilibrium energy diagrams for the mid cell p-i-n structures shown in Figure 2P-2a and $2 \mathrm{~b}$. The p-layer is on the left hand side. 
The above discussion on the band offset at $\mathrm{p} / \mathrm{i}$ interface is based on a fixed barrier height $\phi_{\mathrm{B} 0}=$ $1.28 \mathrm{eV}$ at the front ITO/p-layer interface. Now we address the influences of $\phi_{\mathrm{B} 0}$ on the photovoltaic performances of e.g. mid bandgap a-SiGe cells $\left(\mathrm{E}_{\mathrm{g}}=1.6 \mathrm{eV}\right)$ under the condition of zero band offset at the $\mathrm{p} / \mathrm{i}$ interface $\left(\mathrm{E}_{\mathrm{pg}}=1.6 \mathrm{eV}\right)$.

The results of numerical simulations using AMPS model are given in Figure 2P-4, showing the calculated light I-V characteristics under AM1.5 as a function of $\phi_{\mathrm{B} 0}$.

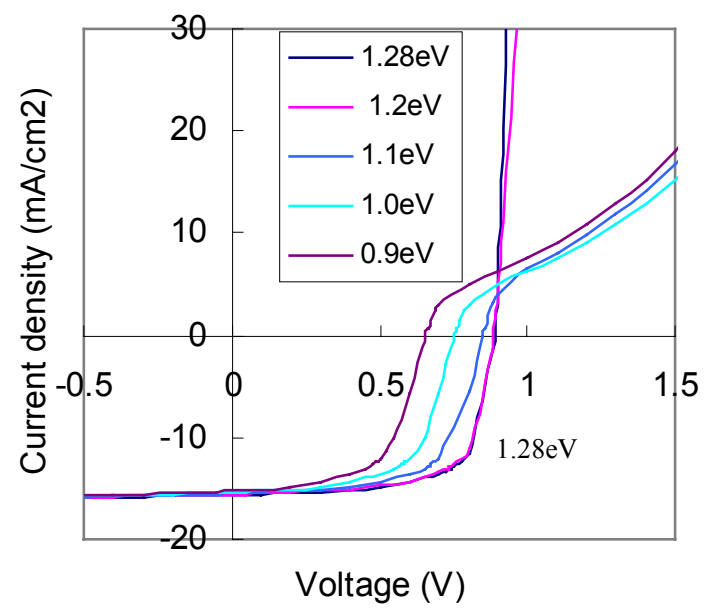

Figure 2P-4 The simulated light I-V characteristics for mid cells with different $\phi_{\mathrm{B} 0}$.

It is seen that with the barrier height $\phi_{\mathrm{B} 0}$ decreases to $1.1 \mathrm{eV}$ or less, the photovoltaic parameters become obviously worse. Furthermore, an anomalous rollover behavior appears on the corresponding illuminated I-V curves. This is because in the case of $\phi_{\mathrm{B} 0}<1.1 \mathrm{eV}$, a hole potential barrier larger than $\sim 0.2 \mathrm{eV}$ is formed at the ITO/p-layer interface, which may block the collection of the photogenerated holes. Of course if this potential barrier for holes coexists with the valence-band offset at the p-interface, its influence on cell performances is more serious.

\section{P.7 Conclusion}

We have carried out AMPS modeling for the impacts of the bandgap of p-nc-Si:H and its interfaces with both the i-layer and ITO front contact on the performances of a-Si based component solar cells. The simulated results show that 1) with increasing $\mathrm{E}_{\mathrm{gp}}$ from 1.5 to $2.0 \mathrm{~V}$, the $\mathrm{V}_{\text {oc }}$ increases first beyond $1 \mathrm{~V}$, then decreases; 2) the reason for the $\mathrm{V}_{\text {oc }}$ decrease may be due to the valence-band offset at the $\mathrm{p} / \mathrm{i}$ interface, which also leads to an anomalous rollover behavior in the illuminated I-V characteristics near the open circuit point; 3 ) the front contact barrier at $\mathrm{p} / \mathrm{ITO}$ interface plays a similar role to hinder the hole collection and may cause the illuminated I$\mathrm{V}$ curve to bend more seriously. 


\section{Q. Sputter Deposition of ITO}

Indium tin oxide (ITO) films used for a-Si solar cells have been deposited using evaporation and sputtering [Q1 - Q4]]. We have studied ITO sputter deposition for use in a-Si ni-p solar cells. The ITO films were deposited using RF sputtering from a 2" sputter gun in a vacuum chamber backed by a turbo molecular pump. The sputter sources used in this study were $\mathrm{In}_{2} \mathrm{O}_{3} / \mathrm{SnO}_{2}$ targets having a $\mathrm{In}_{2} \mathrm{O}_{3}$ content of 95,90 and $85 \%$, respectively. In searching for the optimal ITO film properties, we have investigated a broad deposition parameter space including RF sputtering power, substrate temperature, and Ar pressure. The ITO films were deposited either on glass substrates for resistivity and transmission measurements, or on a-Si n-i-p solar cells for $\mathrm{J}-\mathrm{V}$ and quantum efficiency measurements.

Table 2Q-1 lists the various sputter deposition conditions for a series of ITO films deposited in $30 \mathrm{~min}$. In this table, the film thickness, $\mathrm{d}$, was calculated from the interference fringes in the optical transmission. $\mathrm{R}_{\mathrm{sh}}$ is the sheet resistance of the film, measured using a four point probe. $\mathrm{T}$ is the transmission around $550 \mathrm{~nm}$, calculated using $\mathrm{T}=\left(\mathrm{T}_{\max } \bullet \mathrm{T}_{\min }\right)^{1 / 2}$, where $\mathrm{T}_{\max }$ and $\mathrm{T}_{\min }$ are the transmission maximum and minimum in the UV/Visible transmission spectroscopy. Since the desirable ITO thickness in an a-Si solar cell is around $65 \mathrm{~nm}$ to achieve antireflection, we calculated an effective sheet resistance $\left(\mathrm{R}^{*}\right)$ for a film which would have been $65 \mathrm{~nm}$ thick using

$$
R^{*}=R_{s h} \cdot \frac{d}{65 n m}
$$

In addition, we calculate the absorption coefficient, $\alpha$, of ITO films using

$$
T=\frac{\left(1-R_{1}\right)\left(1-R_{2}\right) \exp (-\alpha \cdot d)}{1-R_{1} R_{2} \exp (-2 \alpha \cdot d)}
$$

where $R_{1}$ and $R_{2}$ are the reflectances at the interfaces with air and glass, respectively, with $\mathrm{R}=\left\{\left(\mathrm{n}_{1}-\mathrm{n}_{2}\right) /\left(\mathrm{n}_{1}+\mathrm{n}_{2}\right)\right\}^{2}$. Refractive indices of 1 and 1.5 are used for air and the glass substrates. Since the refractive index for ITO varies with wavelength near $550 \mathrm{~nm}$, we used 2.1 as the ITO refractive index in our calculation of $\mathrm{R}_{1}$ and $\mathrm{R}_{2}$. From Eq.4, we obtained the absorption coefficient and then used it to calculate an effective absorption loss ( $\left.\mathrm{A}^{*}\right)$ for an ITO film that would have been $65 \mathrm{~nm}$ thick using

$$
A^{*}=1-\exp (-\alpha \cdot 65 n m)
$$

The values of $\mathrm{R}^{*}$ and $\mathrm{A}^{*}$ therefore reflect the film performance of the ITO layers.

Figure 2Q-1 shows the dependence of the film thickness on RF power. The film thickness increases linearly with the increased RF power, independent of temperature and pressure within the selected ranges. Figure $2 \mathrm{Q}-2$ shows $\mathrm{R}^{*}$ as a function of RF power at various temperatures and chamber pressures. To limit the ITO electrical loss to less than $1 \%$ at the maximum power point of a triple-junction a-Si solar cell, we need an ITO sheet resistance of less than $\sim 80 \Omega / \square$, or the resistivity $(\rho)$ to be lower than $\sim 5 \times 10^{-4} \Omega \bullet \mathrm{cm}$ for a $65 \mathrm{~nm}$ thick ITO film. 
Table 2Q-1 Deposition conditions and quality for ITO films deposited under various sputtering conditions using target with $90 \% \mathrm{In}_{2} \mathrm{O}_{3} / \mathrm{SnO}_{2}$.

\begin{tabular}{|c|c|c|c|c|c|c|c|c|}
\hline $\begin{array}{c}\text { Sample } \\
\text { No. } \\
\end{array}$ & $\begin{array}{l}\text { RF } \\
(\mathbf{W}) \\
\end{array}$ & $\begin{array}{c}\text { Temp } \\
\text { (C) }\end{array}$ & $\begin{array}{c}P \\
(\mathrm{mT}) \\
\end{array}$ & $\begin{array}{c}d \\
(\mathrm{~nm}) \\
\end{array}$ & $\begin{array}{c}\text { Rsh } \\
(\mathrm{Ohm}) \\
\end{array}$ & $\begin{array}{c}T \\
(\%) \\
\end{array}$ & $\begin{array}{c}R * \\
(\mathrm{Ohm}) \\
\end{array}$ & $\begin{array}{l}A * \\
(\%) \\
\end{array}$ \\
\hline ITO-37 & 30 & 225 & 8 & 454 & $1.5 \mathrm{E}+01$ & 83.3 & $1.1 \mathrm{E}+02$ & 0.47 \\
\hline ITO-25 & 40 & 225 & 8 & 620 & $5.9 \mathrm{E}+00$ & 80.2 & $5.7 \mathrm{E}+01$ & 0.75 \\
\hline ITO-34 & 50 & 225 & 8 & 779 & $5.0 \mathrm{E}+00$ & 80.2 & $5.9 \mathrm{E}+01$ & 0.60 \\
\hline ITO-50 & 10 & 150 & 6 & 171 & $1.9 \mathrm{E}+02$ & 80.0 & $5.1 \mathrm{E}+02$ & 2.77 \\
\hline ITO-49 & 20 & 150 & 6 & 327 & $.2 \mathrm{E}+01$ & 81.9 & $2.1 \mathrm{E}+02$ & 1.00 \\
\hline ITO-47 & 30 & 150 & 6 & 449 & $2.4 \mathrm{E}+01$ & 81.0 & $1.7 \mathrm{E}+02$ & 0.89 \\
\hline ITO-48 & 40 & 150 & 6 & 601 & $1.5 \mathrm{E}+01$ & 79.6 & $1.4 \mathrm{E}+02$ & 0.85 \\
\hline-55 & 50 & 150 & 6 & 771 & $1.1 \mathrm{E}+01$ & 79.7 & $1.3 \mathrm{E}+02$ & 0.65 \\
\hline ITO-66 & 60 & 150 & 6 & 916 & $2.4 \mathrm{E}+01$ & 79.2 & $3.4 \mathrm{E}+02$ & 0.60 \\
\hline ITO-5 1 & 10 & 175 & 6 & 176 & $2.2 \mathrm{E}+02$ & 80.0 & $6.1 \mathrm{E}+02$ & 2.70 \\
\hline ITO-53 & 30 & 175 & 6 & 460 & $1.8 \mathrm{E}+01$ & 80.8 & $1.2 \mathrm{E}+02$ & 0.90 \\
\hline ITO-67 & 50 & 175 & 6 & 785 & $2.3 \mathrm{E}+01$ & 76.6 & $2.8 \mathrm{E}+02$ & 0.97 \\
\hline ITO-68 & 30 & 200 & 6 & 452 & $3.1 \mathrm{E}+01$ & 79.9 & $2.2 \mathrm{E}+02$ & 1.08 \\
\hline 59 & 40 & 200 & 6 & 589 & $E+01$ & 81.1 & $1.2 \mathrm{E}+02$ & 0.66 \\
\hline ITO-7 1 & 50 & 200 & 6 & 761 & $1.1 \mathrm{E}+01$ & 80.1 & $1.3 \mathrm{E}+02$ & 0.62 \\
\hline ITO-72 & 30 & 225 & 6 & 459 & $1.8 \mathrm{E}+01$ & 81.0 & $1.3 \mathrm{E}+02$ & 0.87 \\
\hline ITO-73 & 40 & 225 & 6 & 547 & $8.8 \mathrm{E}+00$ & 80.5 & $7.4 \mathrm{E}+01$ & 0.80 \\
\hline ITO-65 & 20 & 250 & 6 & 288 & $2.1 \mathrm{E}+01$ & 80.8 & $9.5 \mathrm{E}+01$ & 1.44 \\
\hline ITO-75 & 30 & 250 & 6 & 378 & $8.7 \mathrm{E}+00$ & 82.8 & $5.1 \mathrm{E}+01$ & 0.67 \\
\hline ITO-78 & 40 & 250 & 6 & 500 & $1.1 \mathrm{E}+01$ & 80.2 & $9.8 \mathrm{E}+01$ & 0.79 \\
\hline ITO-79 & 50 & 250 & 6 & 760 & $9.6 \mathrm{E}+00$ & 79.4 & $1.1 \mathrm{E}+02$ & 0.70 \\
\hline ITO-16 & 30 & 200 & 18 & 387 & $1.4 \mathrm{E}+03$ & 84.0 & $8.1 \mathrm{E}+03$ & 0.41 \\
\hline ITO-20 & 20 & 225 & 18 & 266 & $1.4 \mathrm{E}+04$ & 83.9 & $5.7 \mathrm{E}+04$ & 0.63 \\
\hline ITO-24 & 30 & 225 & 18 & 386 & $7.0 \mathrm{E}+03$ & 85.1 & $4.1 \mathrm{E}+04$ & 0.19 \\
\hline ITO-19 & 40 & 225 & 18 & 606 & $1.3 \mathrm{E}+02$ & 83.8 & $1.2 \mathrm{E}+03$ & 0.29 \\
\hline ITO-23 & 50 & 225 & 18 & 741 & $1.0 \mathrm{E}+02$ & 82.8 & $1.2 \mathrm{E}+03$ & 0.34 \\
\hline ITO-14 & 30 & 250 & 18 & 940 & $8.9 \mathrm{E}+02$ & 85.0 & $1.3 \mathrm{E}+04$ & 0.09 \\
\hline ITO-15 & 30 & 250 & 18 & 320 & $1.5 \mathrm{E}+03$ & 85.0 & $1.1 \mathrm{E}+04$ & 0.26 \\
\hline
\end{tabular}




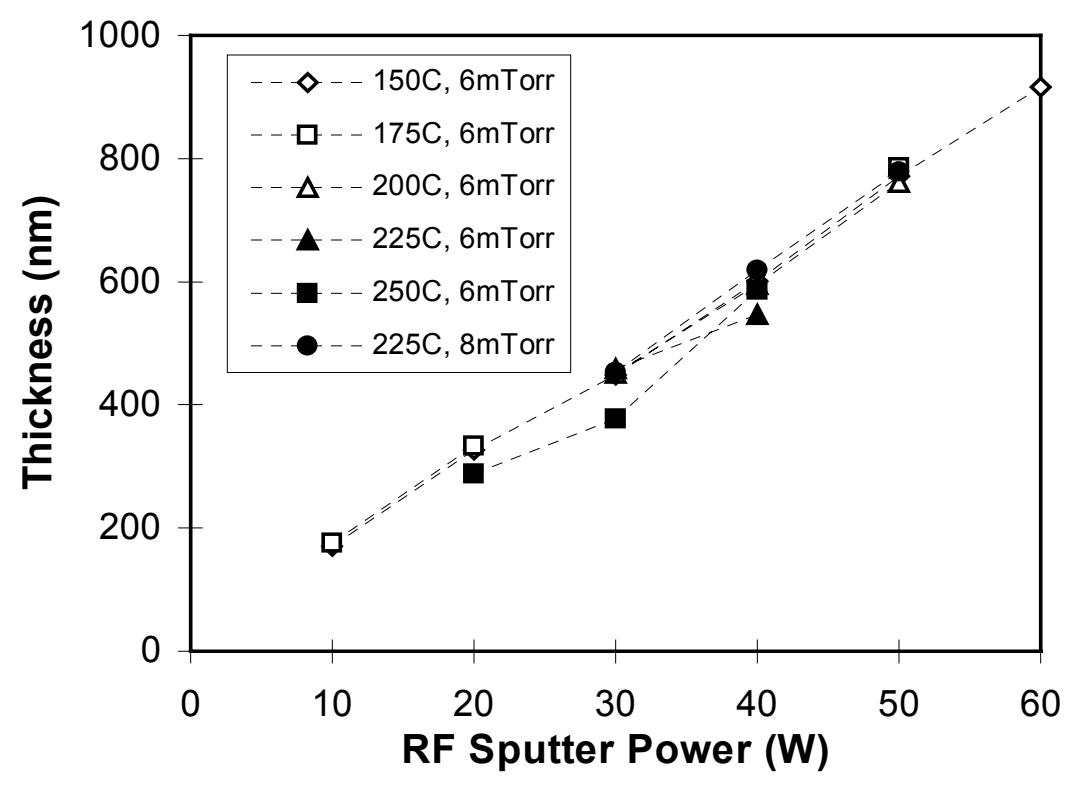

Figure 2Q-1 Thickness of ITO films as a function of the rf power.

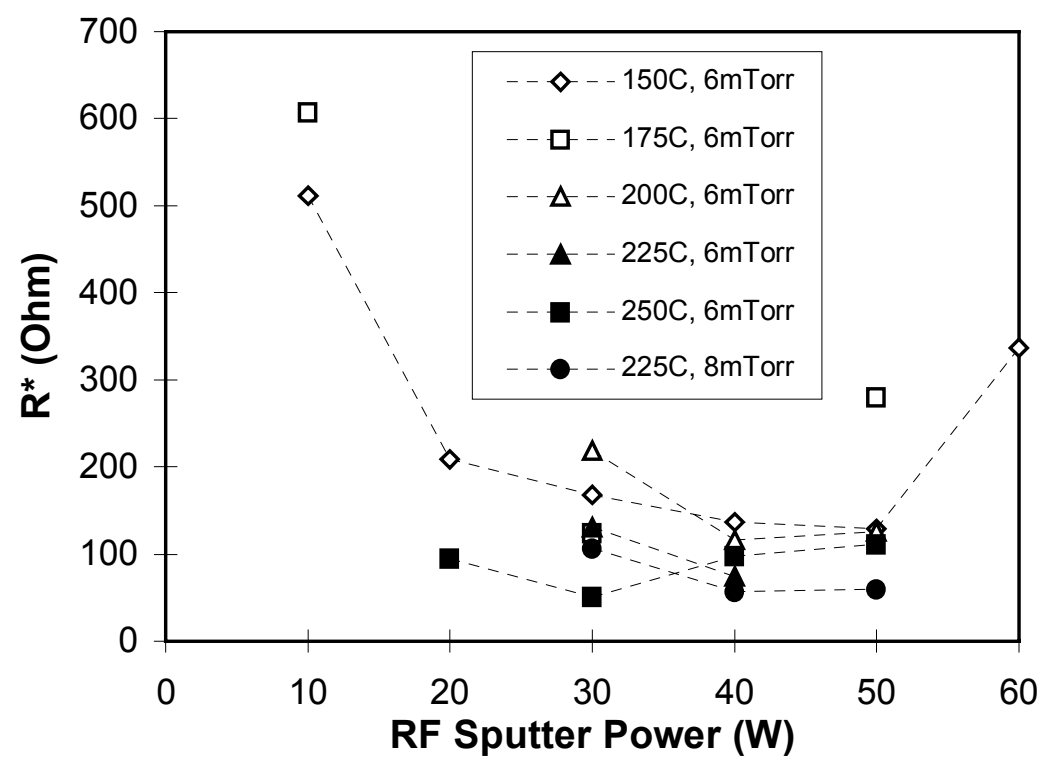

Figure 2Q-2 Effective sheet resistance $\mathrm{R}^{*}$ as a function of $\mathrm{rf}$ power for various temperature and Ar pressure.

From Figure 2Q-2, we observe that only those ITO films deposited at or above $225{ }^{\circ} \mathrm{C}$ and with RF power around $30-50 \mathrm{~W}$ could meet $\rho \leq 5 \times 10^{-4} \Omega \bullet \mathrm{cm}$ requirements. At temperatures lower than $200{ }^{\circ} \mathrm{C}$, the resistivity is too high.

Figure 2Q-3 shows the effective absorption $\mathrm{A}^{*}$ for different RF power under various temperatures and pressure conditions. Again, to have the absorption loss lower than $1 \%$, we will need to have a minimum sputtering power of around $30 \mathrm{~W}$. 


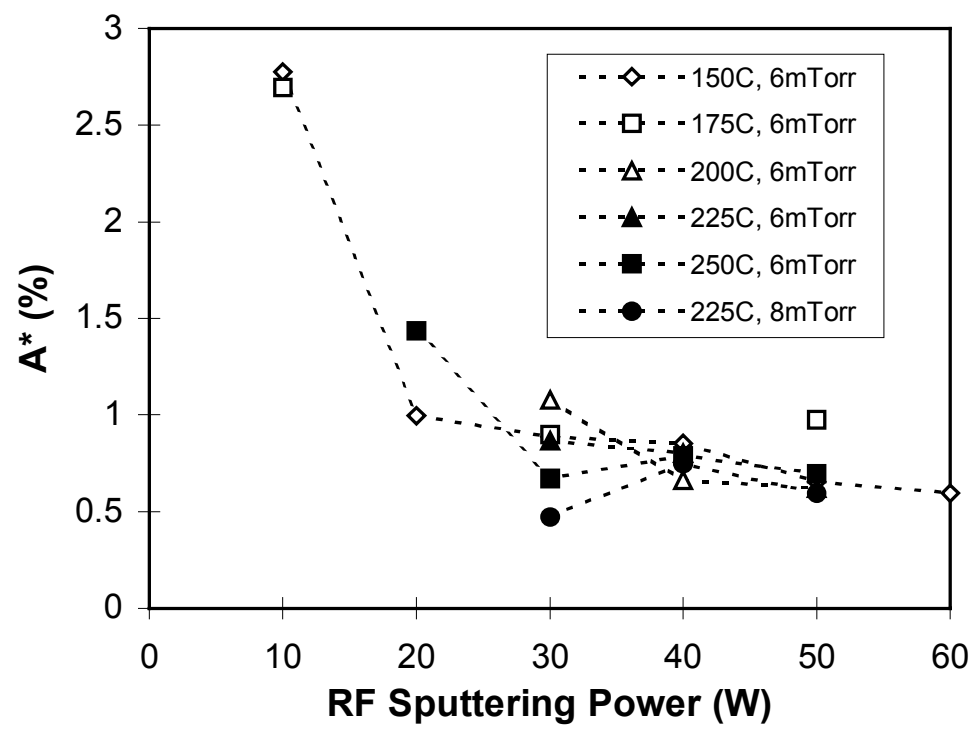

Figure 2Q-3 Effective absorption A* of ITO films as a function of $\mathrm{rf}$ power for various deposition temperature and $\mathrm{Ar}$ pressure.

Among all the deposited ITO films, those made under conditions of RF power within 30$50 \mathrm{~W}$, temperature within $225-250{ }^{\circ} \mathrm{C}$ and pressure around 6-8 mTorr demonstrate the optimal film properties: $\mathrm{R}^{*}=50 \Omega$ and $\mathrm{A}^{*}<1 \%$. This range of conditions was then used as a starting point for the study of ITO films on substrate-type a-Si solar cells in which an ITO film intimately contacts a $\mu \mathrm{c}-\mathrm{Si}$ p-layer.

We deposited approximately $65-75 \mathrm{~nm}$ thick ITO films on a-SiGe solar cells prepared on bare stainless steel without the use of a back-reflector. The reason a-SiGe is used rather than a-Si is because performance of a-SiGe cell depends more on the performance of ITO due to its greater current. Three different sputtering targets having different $\mathrm{In}_{2} \mathrm{O}_{3}$ and $\mathrm{SnO}_{2}$ concentrations were used. In Table 2Q-2, we list the device data for three a-SiGe solar cells with their ITO layers deposited using different targets. Again, the 90/10 target provides the highest $\mathrm{FF}$ and $\mathrm{J}_{\mathrm{sc}}$ among the three samples, suggesting that the $90 \% / 10 \% \mathrm{In}_{2} \mathrm{O}_{3} / \mathrm{SnO}_{2}$ target might be more desirable for use in a-Si based substrate-type solar cells. We would like to point out that these preliminary results were obtained from limited samples and show large fluctuations. Further study is needed to draw a general conclusion.

Table 2Q-2 J-V data of solar cells with ITO deposited from $\operatorname{In}_{2} \mathrm{O}_{3} / \mathrm{SnO}_{2}$ targets having different compositions.

\begin{tabular}{lllllll}
\hline $\begin{array}{l}\text { Sputter Target } \\
\mathrm{In}_{2} \mathrm{O}_{3} \% / \mathrm{SnO}_{2} \%\end{array}$ & $\begin{array}{l}\mathrm{V}_{\text {oc }} \\
(\mathrm{V})\end{array}$ & $\begin{array}{l}\mathrm{J}_{\mathrm{sc}} \\
\left(\mathrm{mA} / \mathrm{cm}^{2}\right)\end{array}$ & $\mathrm{FF}$ & $\begin{array}{l}\mathrm{R}_{\mathrm{s}} \\
\left(\Omega \bullet \mathrm{cm}^{2}\right)\end{array}$ & $\begin{array}{l}\mathrm{P}_{\max } \\
\left(\mathrm{mW} / \mathrm{cm}^{2}\right)\end{array}$ & $\begin{array}{l}\mathrm{J}_{\text {ph }} \text { from QE } \\
\left(\mathrm{mA} / \mathrm{cm}^{2}\right)\end{array}$ \\
\hline $95 / 5$ & 0.71 & 11.8 & 0.46 & 28 & 3.9 & 11.6 \\
$90 / 10$ & 0.69 & 13.5 & 0.55 & 22 & 4.3 & 12.2 \\
$85 / 15$ & 0.65 & 10.5 & 0.41 & 35 & 2.8 & 10.6 \\
\hline
\end{tabular}


In summary, good quality ITO films were sputter-deposited for use as the top electrodes of substrate-type a-Si based solar cells. The ITO films, deposited at elevated temperature (225$\left.250{ }^{\circ} \mathrm{C}\right)$ and low pressure ( $\left.~ 8 \mathrm{mTorr}\right)$ with an RF power of $30-50 \mathrm{~W}$ in a $2 "$ sputter gun, exhibit an effective sheet resistivity of approximately $50 \Omega$ and absorption loss of less than $1 \%$. 


\section{R. References:}

[A1] J. Yang, A. Banerjee, S. Sugiyama, and S. Guha, Proc. of 2nd world Conference on Photovoltaic Solar Energy Conversion, Vienna, Austria, 6-10 July 1998.

[A2] J. Yang, A. Banerjee, and S. Guha, in Proc. of NREL/SNL Photovoltaic Program Review Meeting, Nov. 18-22, 1996, Lakewood, CO.

[A3] S. Guha, J. Yang, A. Banerjee, T. Glatfelter, K. Hoffman, S. R. Ovshinsky, M. Izu, H. C. Ovshinsky, and X. Deng, MRS Proc. 336, 645, (1994).

[A4] M. Izu, X. Deng, A. Krisko, K. Whelan, R. Young, H. C. Ovshinsky, K. L. Narasimhan, and S. R. Ovshinsky, 23rd IEEE PVSC, 919 (1993).

[A5] E. A. DeMeo, Proc. of 10th EC Photovoltaic Solar Energy Conf., 1991, p1269.

[F1]. L. Yang, L. Chen, and A. Catalano, MRS Proc. 219, 259 (1991).

[F2]. J. Yang, X. Xu and S. Guha, MRS Proc. 336, 687 (1994).

[F3]. M. Shima et. al, MRS Proc. 507, 145 (1998).

[F4]. S. Guha, K.L. Narasimhan, and S.M. Pietruszko, J. Appl. Phys. 52, 859 (1981).

[F5]. K. Tanaka and A. Matsuda, MRS Proc. 70, 245 (1986).

[F6]. J. Yang and S. Guha, MRS Proc. 557, 239 (1999).

[F7]. R. Swanepoel, J. Phys. E: Sci. Instrum. 16, pp. 1214-1222 (1983)

[F8]. Y. Chou and S. Lee, J. Appl. Phys. 83, 4111 (1998)

[F9]. E.V. Jelenkovic, K.Y.Tong, Z. Son, C.L. Mak, and W.Y. Cheung, J. Vac. Sci. Tech. A15, 2836 (1997)

[F10]. J. Yang et al, MRS Proc. 149, 435 (1989)

[F11] X. Deng, X. B. Liao, S. Han, H. Povolny, P. Agarwal, Solar Energy Mat. \& Solar Cells, 62, 89 (2000)

[F12]. J. Hanak, L. Walter, D. Dobias and H. Flasisher, "Deployable aerospace PV array based on amorphous silicon alloys", Space Photovoltaic Research and Technology 1988, NASA Confference Publication 3030, April 1988.

[F13]. G. Landis, S. Bailey and D. Flood, "Advances in thin-film solar cells for lightweight space photovoltaic power", Space Power, Vol. 8. 31 (1989); available as NASA Technical Memo. TM-102017, 1989.

[F14]. J. Woodyard and G. Landis, "Radiation resistance of thin film solar cells", Solar Cells, Vol.31, 297 (1991).

[F15]. S. Guha et al., "Amorphous silicon alloy solar cells for space applications", $2^{\text {nd }}$ World Conference on Photovoltaic Solar Energy Conversion, vol.3, 3609 (1998).

[F16]. X. Deng, "Study of triple-junction a-Si alloy solar cells", in AIP Conf. Proc. 462, 297 (1998).

[H1] See. Review by Y.S. Tsuo and W. Luft, Appl. Phys. Comm, 10, 71 (1990) and references there in.

[H2] S. Guha, J.S. Payson, S.C. Agarwal and S.R. Ovshinsky, J. Non-Cryst. Solids 97-98, 1455 (1988).

[H3] J. Yang, R. Ross, T. Glatfelter, R. Mohr and S. Guha, MRS Poc. 149, 435 (1989).

[H4] A. Banerjee, X. Xu, J. Yang and S. Guha, MRS Proc. Vol. 377, 675 (1995). 
[H5] X.B. Liao, J. Walker and X. Deng, MRS Symposium, April 1999.

[H6] S.M. Sze , Physics of Semiconductor Devices, $2^{\text {nd }}$ Edition, John Wiley \& Sons, New York, 1981.

[H7] J. Yang, A. Banerjee, and S. Guha, Appl. Phys. Lett., 70, 2975 (1997).

[H8] T. J. Coutts, N. M. Pearsall, and L. Tarricone, J. of Vac. Sci. \& Tech., B, 2, 140 (1984).

[H9] S.S. Hegedus, W.A. Buchanan, E. Eser, J.E. Phillips, and W.N. Shafarman, AIP Conference Proceedings, Vol 394, 547 (1997).

[H10] X. Deng, G. Miller, G., R. Wang, L. Xu, and A.D. Compaan, 2nd world Conference on Photovoltaic Solar Energy Conversion, Vienna, Austria, 6-10 July 1998

[P1] For AMPS, see http://www.psu.edu/dept/AMPS/.

[P2] P. Agarwal, H. Povolny, S. Han and X. Deng, "Study of a-SiGe:H Films and n-i-p Devices used in High Efficiency Triple Junction Solar Cells", J. of Non-Cryst. Solids, 2002 pp. 1213-1218.

[P3] Q. Ye, R. Tsu and E.H. Nicollian, "Resonant tunneling via microcrystalline Si quantum confinement", Phys. Rev. B 44, 1991, pp. 1806-1811.

[P4] B. Delley and E.F. Steigmeier, "Quantum confinement in Si nanocrystals", Phys. Rev. B 47, 1997, pp. 1397-1400.

[P5] D J.K.Rath, C.H.M. van der Werl , F.A.Rubinelli and R.E.I.Schropp, "Development of aSi based p-i-n solar cell in a superstrate structure with p-microcrystalline $\mathrm{Si}$ as window layer", $25^{\text {th }}$ IEEE PVSC, 1996, pp. 1101-1105.

[Q1] J. Yang, A. Banerjee, and S. Guha, Appl. Phys. Lett., 70, 2975 (1997).

[Q2] T. J. Coutts, N. M. Pearsall, and L. Tarricone, J. of Vac. Sci. \& Tech., B, 2, 140 (1984).

[Q3] S.S. Hegedus, W.A. Buchanan, E. Eser, J.E. Phillips, and W.N. Shafarman, AIP Conference Proceedings, Vol 394, 547 (1997).

[Q4] X. Deng, G. Miller, G., R. Wang, L. Xu, and A.D. Compaan, 2nd world Conference on Photovoltaic Solar Energy Conversion, Vienna, Austria, 6-10 July 1998 


\subsection{CdTe-related materials and devices}

\section{Overview of the CdTe-related accomplishments during Phase III}

\section{Deposition and cell structure issues}

We have focused on the magnetron sputtering process for both $\mathrm{CdS}$ and CdTe and have made improvements in the reproducibility and yield of our cell fabrication process that incorporates a vapor $\mathrm{CdCl}_{2}$ treatment. We have demonstrated that our small grain, sputtered cells can be fabricated with as-deposited CdTe thickness of 0.75 to $1.0 \mu \mathrm{m}$ achieving efficiencies above 9\%. Remarkably these thin cells show little difference in stability, compared with $2.3 \mu \mathrm{m}$ CdTe cells, during light soak at $\sim 55^{\circ} \mathrm{C}$. (See Section 3.5.) Our studies of high resistivity

HRT-coated substrates or of stannate-based substrates, we have not achieved further improvements and have been unable to address systematically how these HRT layers affect stability issues in our small-grain magnetron-sputtered cells.

We have continued to improve the conductivity of the reactively sputtered $\mathrm{ZnTe}: \mathrm{N}$ films and are able to prepare 9-10\% cells from VTD CdTe using ZnTe:N/nickel back contacts without the use of any intentional copper. These cells show much improved stability over cells with our standard contacts. (See Section 3.6.) In addition, we have studied sputtered $\mathrm{Ni}_{\mathrm{x}} \mathrm{P}$ as an alternative back contact. (See Section 3.10.)

During Phases II and III, we had some success in fabricating CdTe/CdS cells in the substrate configuration on Mo foil substrates. This effort was not planned in the original statement of work, but provides a powerful method to access the junction and to study window/emitter-layer issues. For example, the CdS is applied on top of fully developed grains of CdTe, and the junction is more accessible for high resolution optical and electrical studies. Interdiffusion of CdS and CdTe appears to be more easily controlled. (See Section 3.4.)

\section{Characterization and stress testing aspects}

Strong emphasis continues to be placed on materials and cell characterization through the use of photoluminescence, including bias-dependent PL and diode-laser-excited PL, (See Sections 3.1 and 3.3.) Hall measurements, Rutherford backscattering, Raman scattering, and optical absorption. The bias-dependent PL has led us to establish electroluminescence as another powerful technique to investigate the junction properties. (See Section 3.2.) We find that biasPL and EL are much more sensitive to device degradation than is the device J-V curve.

Using PL we have been able to identify the effect of sodium, diffusing in from soda-lime glass substrates or from intentional surface diffusion, on enhancing the donor-acceptor pair spectra. (See Section 3.8.) Ion implantation appears to be a good technique for introducing controlled densities of impurities and we have identified the anneal temperatures needed for removing the implantation-induced damage and restoring the PL. (See Section 3.9.)

\section{Laser patterning efforts}

We continue to maintain the capability for laser scribing and have provided occasional laser patterning services to the thin-film PV community. 


\subsection{Bias-dependent junction PL studies of CdTe cells}

At the CdTe National Team meeting in January, 2001,[1] we reported on preliminary measurements of junction photoluminescence studies at room temperature as a function of voltage bias across the cell junction. These studies have been done both on magnetron sputtered cells and on cells for which the CdTe was vapor-transport-deposited (VTD) at First Solar, LLC. Helpful discussions have been held with V. Karpov and J. Christiansen of First Solar and we acknowledge their help in this work and in the interpretation of the results.

Changing the bias across the cell while under photoexcitation, can yield changes in the PL intensity exceeding $10^{4}$. Furthermore this bias-dependent PL appears to be quite sensitive to light-soak-stress-induced changes in many cells.

Here we provide further details on the characteristics of this bias-dependent PL and some interpretation of the physical mechanisms for this dependence. We believe that bias-dependent PL can be a powerful tool to further characterize the device parameters and to understand the mechanisms of enhanced nonradiative carrier recombination in degraded devices.

Fig. 3-1 below provides an example of the changes in PL signal with external bias across the cell. These data were obtained at room temperature with $4 \mathrm{~mW}$ of excitation at $752 \mathrm{~nm}$ focused to be equivalent to approximately 20 suns. PL data from our spectrograph/CCD system were integrated from approximately 1.45 to $1.6 \mathrm{eV}$. Data from an as-fabricated cell are shown as well as data from the same cell after stressing for 28 days at open circuit under one-sun illumination at $\sim 65^{\circ} \mathrm{C}$. A remarkable feature in Fig. 3-1 is that PL in the large forward bias region is extremely sensitive to light-soak-induced degradation: an observed change by almost an order of magnitude typically corresponds to just a several percent change in the device efficiency. We plan to correlate these changes more quantitively in our future work.

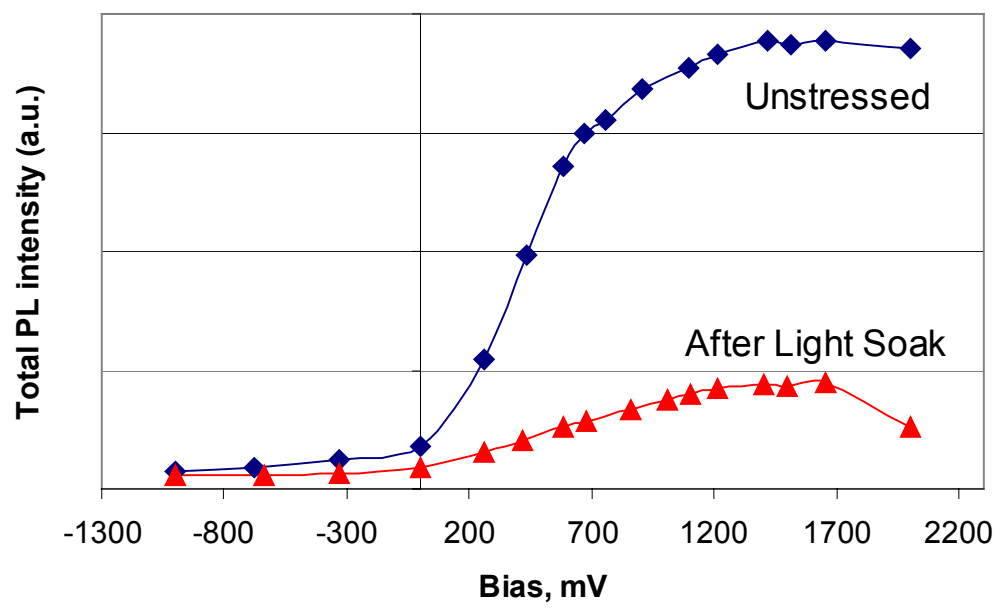

Fig. 3-1. Total junction PL at $300 \mathrm{~K}$ vs. bias voltage for an as-deposited VTD cell and the same cell after 28 days of light soak at open circuit under one sun illumination and $65^{\circ} \mathrm{C}$. Excitation at $752 \mathrm{~nm}, 20$ suns equivalent.

Additional information on the mechanisms which give rise to the bias dependence is obtained from the power dependence of the PL signal under two different static bias conditions. Fig. 3-2 shows that under open circuit, which is the condition most likely to be used in a PL experiment when no attention is paid to the bias effects, the PL intensity increases rapidly with excitation 
power. Here the focal spot size was about $0.025 \mathrm{~cm}^{2}$ so that $10 \mathrm{~mW}$ corresponds to approximately $4.0 \mathrm{~W} / \mathrm{cm}^{2}$ or 40 suns. Note that at $1 \mathrm{~mW}$ the PL intensity difference between open circuit (OC) and short circuit (SC) conditions is much smaller than for higher powers.

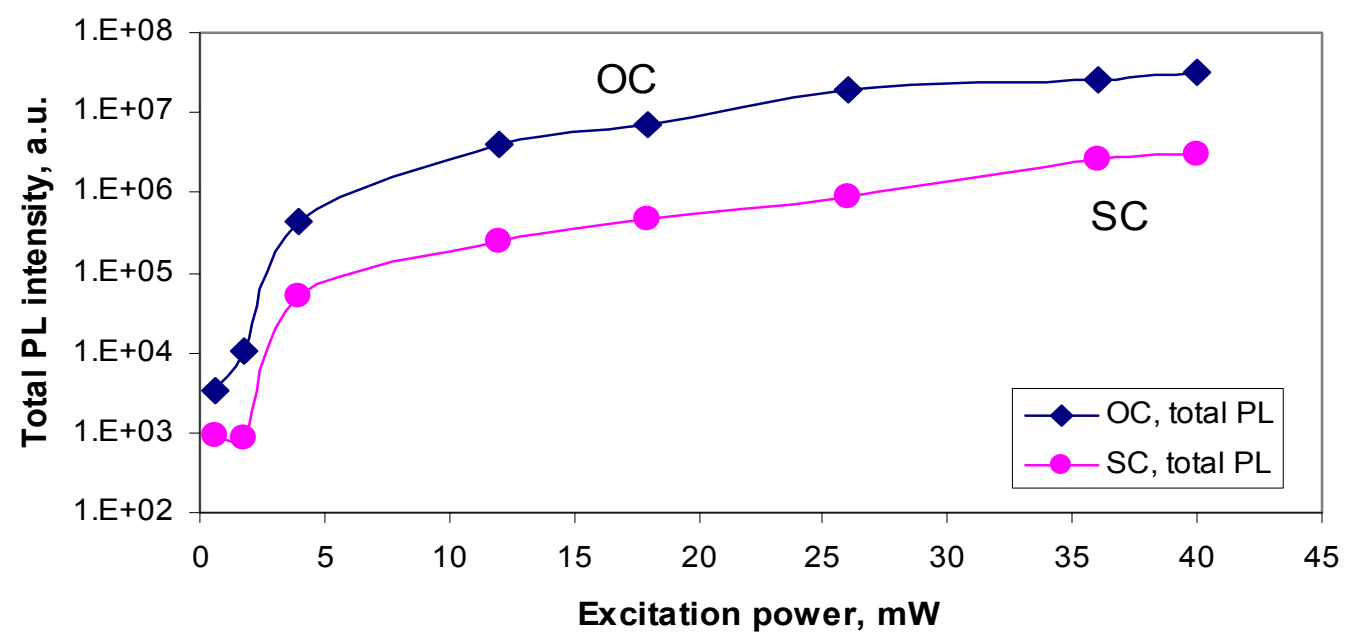

Fig. 3-2 Integrated PL signal at room temperature vs. excitation power at $752 \mathrm{~nm}$ with cell held at open circuit (OC) or at short circuit (SC) conditions.

Essential features of the bias dependence can be understood from the relationship between external bias and internal fields near the junction. Figure 3-3 sketches the observation geometry with the laser excitation beam entering the junction from the glass side with a penetration depth at $752 \mathrm{~nm}$ of about $0.3 \mu \mathrm{m}$. The internal electric field, E, is sketched for three conditions under the assumption of constant acceptor density in the CdTe (and Te-rich CdSTe alloy) and constant, although somewhat higher, donor density in the CdS (and S-rich CdSTe alloy). In reverse bias, the maximum field increases as well as the depletion width. In forward bias the maximum field and depletion width decrease. For illustrative purposes, if we assume for the CdTe an acceptor density of

$$
\mathrm{N}_{\mathrm{a}}=1 \times 10^{15} \mathrm{~cm}^{-3}
$$

then in the approximation of an abrupt, one-sided junction, the maximum electric field in the dark in thermal equilibrium will be given by

$$
\mathrm{E}_{\mathrm{m}}=\left(2 \Psi_{\mathrm{o}} \mathrm{eN} \mathrm{N}_{\mathrm{a}} / \kappa \varepsilon_{\mathrm{o}}\right)^{1 / 2} \approx 15,000 \mathrm{~V} / \mathrm{cm},
$$

where $\Psi_{\mathrm{o}}(\sim 1 \mathrm{eV})$ is the built-in potential and $\kappa=10$ is the static dielectric constant for CdTe. [In the following, we use parameters for CdTe, such as electron mobility and lifetime, suggested by Fahrenbruch and Sites in the January 2000 Colorado State Univ. contract report.][2]

If we further assume that the electron mobility in this p-CdTe is

$$
\mu_{\mathrm{e}}=500 \mathrm{~cm}^{2} / \mathrm{V}-\mathrm{s} \text {, }
$$

then the peak drift velocity will be

$$
\mathrm{v}_{\mathrm{d}}=\mu_{\mathrm{e}} \mathrm{E}_{\mathrm{m}} \approx 8 \times 10^{6} \mathrm{~cm} / \mathrm{s} .
$$

Since carrier generation occurs roughly over the $0.3 \mu \mathrm{m}$ light absorption depth, the order of magnitude for the electron sweep-out time from this depth will be

$$
\Delta \mathrm{t} \cong 4 \times 10^{-12} \mathrm{sec} \text {. }
$$

A typical lifetime for minority carriers in CdTe is $\tau \cong 5 \times 10^{-10} \mathrm{sec}$. Thus the carrier sweep-out effect at zero applied bias and low photo-injection can easily account for a decrease in PL signal 


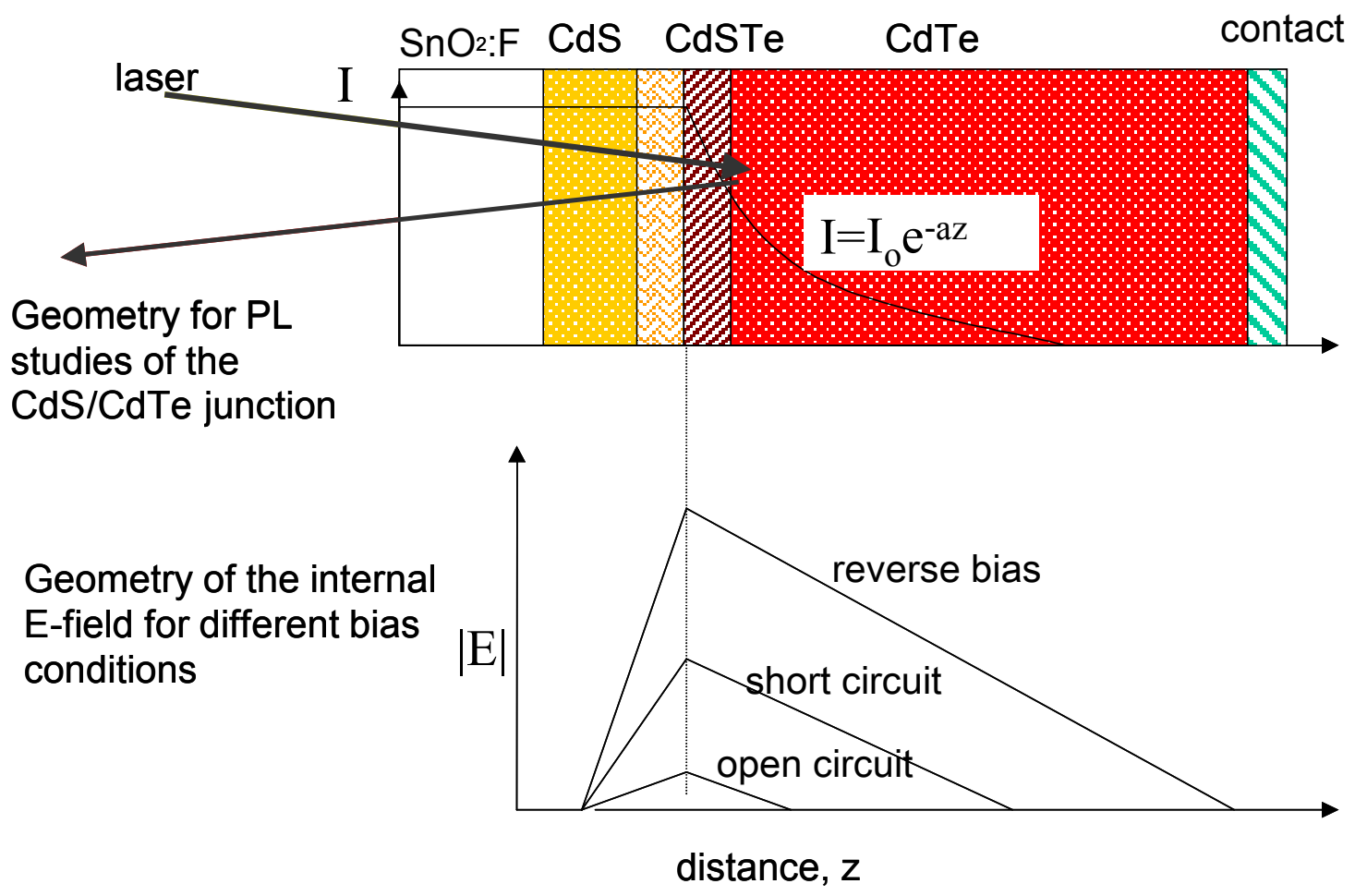

Fig. 3-3. Sketch of glass-side excitation geometry and the internal electric field near $\mathrm{CdTe/CdS}$ junction under three different bias conditions.

by two orders of magnitude. At high injection levels, under open circuit conditions, the carrier generation can easily lead to open circuit voltage and nearly flat-band $(E=0)$ conditions. This will produce a large increase in PL signal as carriers are then limited only by diffusion.

The observed room temperature PL, in the energy range studied with our spectrometer/CCD, arises from electron-hole recombination in band-to-band transitions and through donor-acceptor pair transitions The strong E-field of the depletion region will suppress the PL by the E-field induced drift of the electrons and holes (carrier sweep-out). The larger the field, the lower will be the steady-state minority carrier density in the CdTe. This process is sketched from the point of view of pulsed excitation in Fig. 3-4.

Radiative recombination of the electron hole pairs (photoluminescence) requires the presence of both carrier types in the same region of space. The fraction of carriers which radiate before separation will be inversely proportional to the drift lengths of electrons, $1_{\mathrm{e}}$, and holes, $1_{\mathrm{h}}$. Thus, the PL signal is expected to be given by

$$
\mathrm{I}_{\mathrm{PL}} \sim\left(\mathrm{l}_{\mathrm{e}} \bullet \mathrm{l}_{\mathrm{h}}\right)^{-1} \sim \mathrm{E}^{-2} \sim\left(\mathrm{V}_{\mathrm{OC}}-\mathrm{V}_{\mathrm{appl}}\right)^{-1}
$$

where we have used the drift lengths as $1_{\mathrm{e}, \mathrm{h}}=\mathrm{E} \mu_{\mathrm{e}, \mathrm{h}} \tau_{\mathrm{e}, \mathrm{h}}$ and taken the internal electric field to be zero at $\mathrm{V}_{\mathrm{OC}}$ so that $\mathrm{E} \sim\left(\mathrm{V}_{\mathrm{OC}}-\mathrm{V}_{\mathrm{appl}}\right)^{1 / 2}$. In this model, using one adjustable parameter, the fit to the data are given in Fig. 3-5. The model appears to describe the basic physics of the bias dependence, at least until the field becomes weak and carrier diffusion terms need to be applied. 


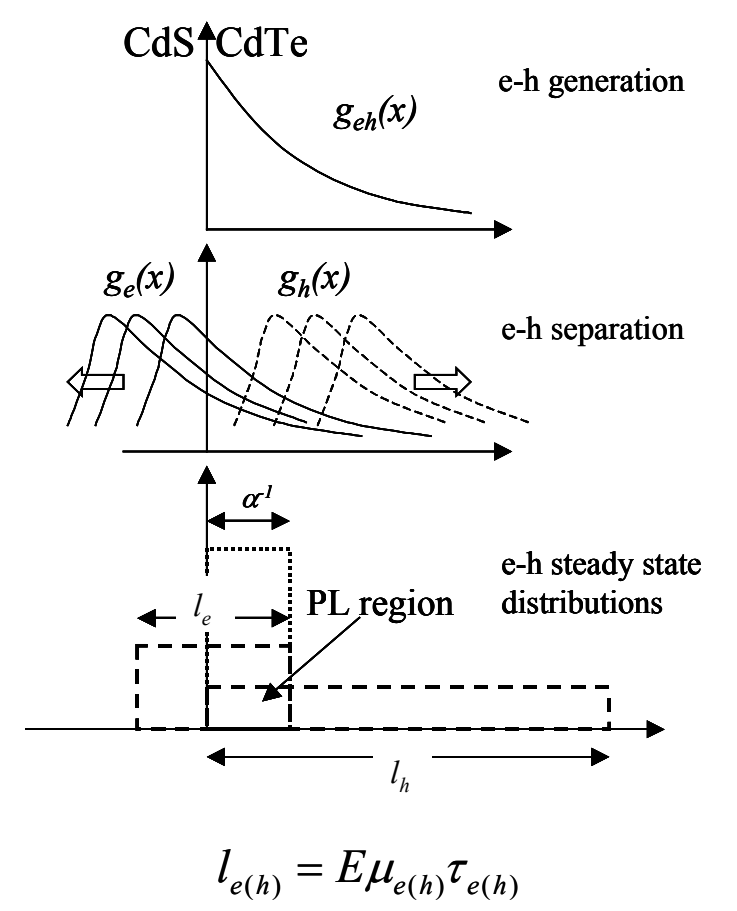

Fig. 3-4. Spatial dependence of carrier generation, $g_{\text {eh }}$, with absorption length, $\alpha^{-1}$, electron and hole distributions with drift in Efield, and the overlap region which produces the PL.

AMPS 1D simulation [3] of the electric field in the junction region is shown in Fig. 3-6. The CdS/CdTe heterojunction is at $\mathrm{x}=0.5 \mu \mathrm{m}$ with $\mathrm{x}>0.5 \mu \mathrm{m}$ being the $\mathrm{CdTe}$ region. The modeling was done with typical values of the materials parameters for CdTe. For Fig. 3-6 the donor density in CdS was the same as the acceptor density in CdTe $(p=$ $1 \times 10^{15} \mathrm{~cm}^{-3}$ ). The assumed materials parameters are given in Table 3-1. It is generally thought that $\mathrm{CdS}$ is more heavily doped but since no carriers are collected nor PL received from the CdS the field profile there is not important. The modeling shows that the maximum junction field decreases from about $11 \mathrm{kV} / \mathrm{cm}$ at zero bias to $\sim 6$ $\mathrm{kV} / \mathrm{cm}$ at $+0.5 \mathrm{~V}$ to near zero at $\mathrm{V}_{\mathrm{OC}}$ and reverses sign but remains small for forward biases. This behavior corresponds closely to the predicted behavior in which carrier sweep-out controls the PL intensity from the junction region.

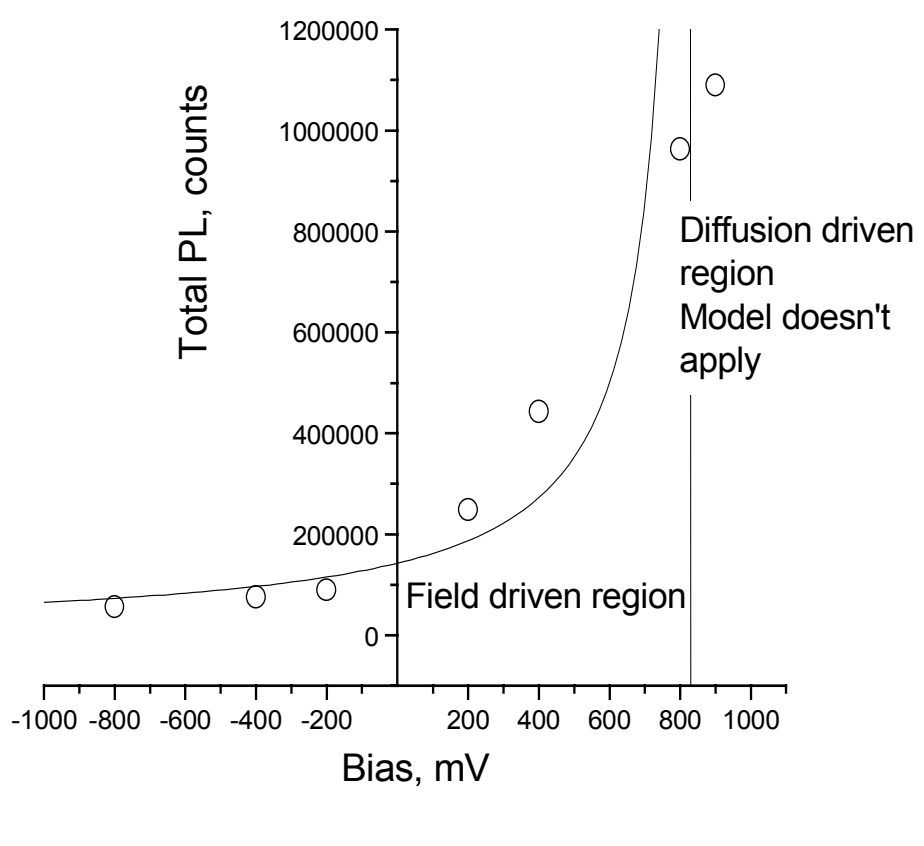

Fig. 3-5 Fit of bias dependence of the PL signal to the function, I $\sim\left(\mathrm{V}_{\mathrm{OC}}-\mathrm{V}_{\text {appl }}\right)^{-1}$ as predicted from Eq. 3.1.1, $V_{\text {oc }}=820 \mathrm{mV}$.

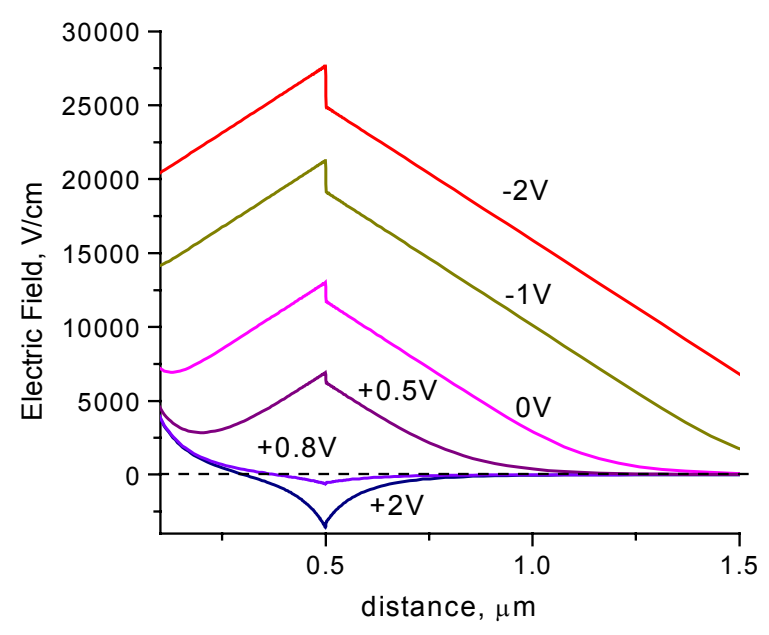

Fig. 3-6. E-field according to AMPS-1D. 
Table 3-1: $\quad$ AMPS: General Layer Parameters (Lifetime Model)[2,3]

\begin{tabular}{|l|l|l|}
\hline & \multicolumn{1}{|c|}{ CdS } & \multicolumn{1}{c|}{ CdTe } \\
\hline epsilon & $9.0 \quad 10.0$ \\
\hline mu-n & $350.0 \mathrm{~cm}^{\wedge} 2 / \mathrm{V}-\mathrm{sec}$ & $500.0 \mathrm{~cm}^{\wedge} 2 / \mathrm{V}-\mathrm{sec}$ \\
\hline $\mathrm{mu}-\mathrm{p}$ & $50.0 \quad \mathrm{~cm}^{\wedge} 2 / \mathrm{V}-\mathrm{sec}$ & $50.0 \quad \mathrm{~cm}^{\wedge} 2 / \mathrm{V}-\mathrm{sec}$ \\
\hline $\mathrm{Na}$ & $1.0 \mathrm{e}+014 \quad 1 / \mathrm{cm}^{\wedge} 3$ & $1.0 \mathrm{E}+015 \quad 1 / \mathrm{cm}^{\wedge} 3$ \\
\hline $\mathrm{Nd}$ & $1.0 \mathrm{E}+015 \quad 1 / \mathrm{cm}^{\wedge} 3$ & 0.0 \\
\hline $\mathrm{Eg}$ & $2.40 \mathrm{eV}$ & $1.50 \mathrm{eV}$ \\
\hline $\mathrm{Nc}$ & $1.8 \mathrm{E}+0191 / \mathrm{cm}^{\wedge} 3$ \\
\hline $\mathrm{Nv}$ & $2.4 \mathrm{E}+018 \quad 1 / \mathrm{cm}^{\wedge} 3$ & $2.8 \mathrm{E}+019 \quad 1 / \mathrm{cm}^{\wedge} 3$ \\
\hline $\mathrm{chi}$ & $4.50 \mathrm{eV}$ & $1.04 \mathrm{E}+0191 / \mathrm{cm}^{\wedge} 3$ \\
\hline tau & $1.0 \mathrm{e}-10 \mathrm{~s}($ holes$)$ & $5.0 \mathrm{e}-10 \mathrm{~s}(\mathrm{electrons})$ \\
\hline
\end{tabular}

The spectrum of the PL observed under external bias appears to quite unaffected by the bias. That is, the internal electric field in the junction region has strong effects on the radiative recombination probability but does not influence the relative intensities of the various features of the spectrum. Although we have done some measurements of bias PL in the cryostat at 10K, most measurements were done at room temperature. An example is given in Fig. 3-7. The two overlapping bands arise from pure CdTe (centered at $\sim 1.51 \mathrm{eV}$ ) and from the alloyed region with about $5 \% \mathrm{~S}$ (band centered at $\sim 1.48 \mathrm{eV}$ ).

These spectral features are also observed in the electroluminescence spectra discussed in the next section. Note that the relative intensity of the two bands depends on the processing. The sputtered cells exhibit higher intensity in the $1.48 \mathrm{eV}$ band. (See Figs. 3-8 and 3-9 below.)

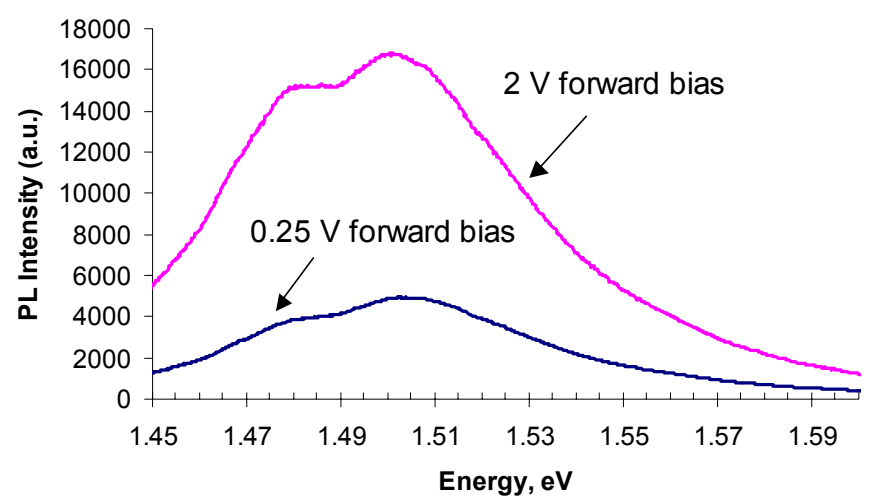

Fig. 3-7. Bias PL spectra from unstressed VTD CdS/CdTe junction at two different voltages. The data are from the same cell as for Fig. 3-1. 


\subsection{Electroluminescence studies of CdTe cells}

The bias-dependent PL studies involve the simultaneous application of an excitation light source and the bias field. However in a simpler mode, it is possible to obtain light emission without a light excitation source during the application of an applied field, or electroluminescence (EL). The UK group of Potter et al.[4] reported EL in a CdTe photovoltaic device at $10 \mathrm{~K}$ and suggested its possibilities as an analytical tool, although we are not aware of additional studies by this group. We have studied the properties of this EL vs. bias for two types of CdTe cells and also the sensitivity of the EL to stress-induced changes in the junction or back contact properties. In fact, we find considerable sensitivity to stress.

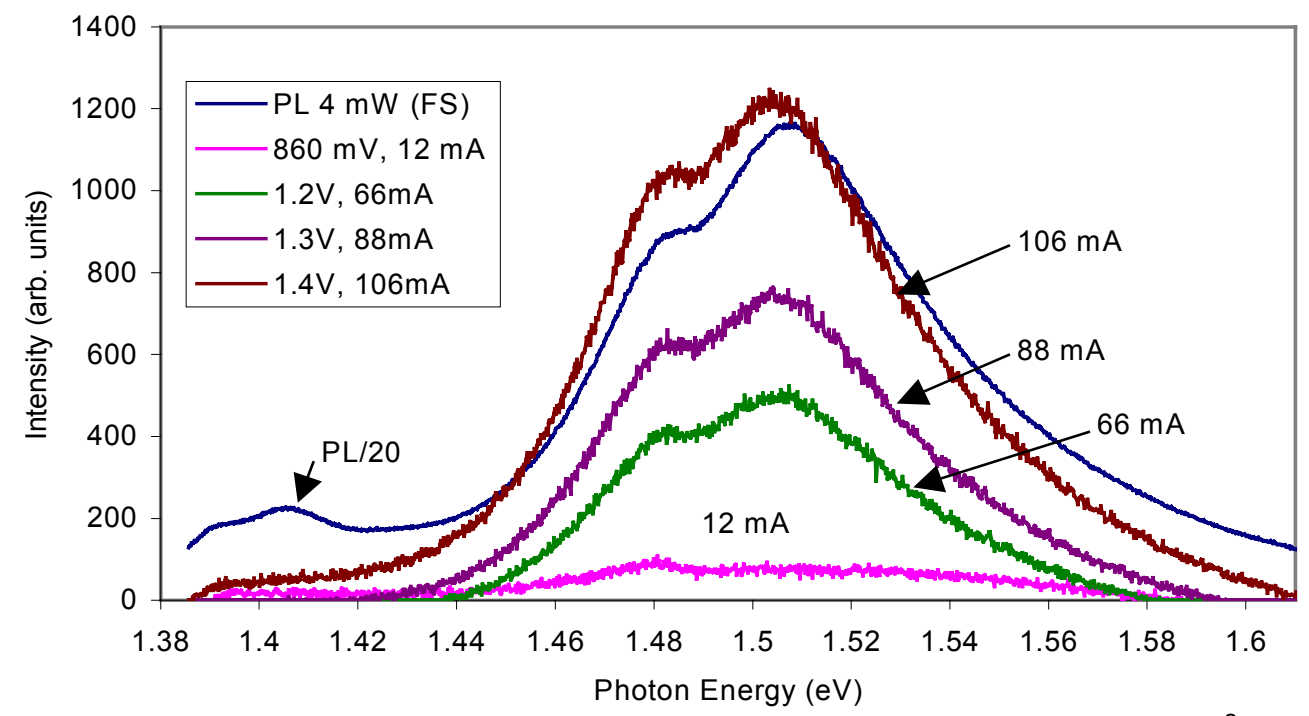

Fig. 3-8. EL and PL (divided by 20) spectra obtained at $300 \mathrm{~K}$ from a $1.1 \mathrm{~cm}^{2}$ First Solar VTD cell for several injection currents as shown. (CdTe band gap $=1.50 \mathrm{eV}$.)

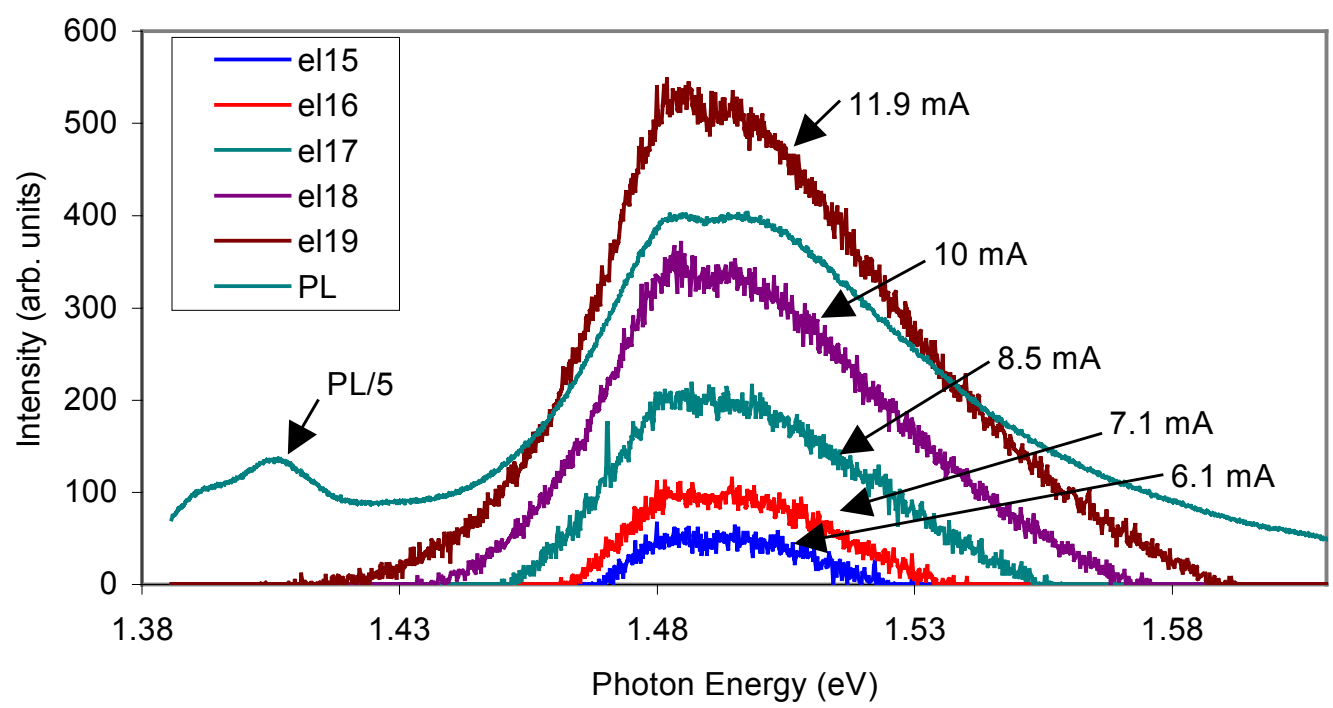

Fig. 3-9. EL and PL (divided by 5) spectra at $300 \mathrm{~K}$ from a $0.12 \mathrm{~cm}^{2}$ magnetron sputtered cell for several injection currents. Bias voltages and injection currents are: el15:1.5V, 6.1mA; el16: 1.61V, 7.1mA; el17: 1.75V, 8.5mA; el18: 1.9V, 10mA; el19: 2.0V, $11.9 \mathrm{~mA}$. 
The EL spectra obtained from vapor transport deposited (VTD) and magnetron sputtered cells are given, respectively, in Figs 3-8 and 3-9 together with comparison PL spectra.

The spectra were taken with the samples at room temperature. The PL was generated with $40 \mathrm{~mW}$ of excitation at $752 \mathrm{~nm}$ through the glass $/ \mathrm{SnO}_{2}: \mathrm{F} / \mathrm{CdS}$. In both cases the signal was imaged into a triple spectrometer with a CCD detector. Both the EL and PL spectra typically were integrated for $40 \mathrm{sec}$. For PL, the laser was focused with a cylindrical lens to a line approximately $5 \mathrm{~mm} \times 0.1 \mathrm{~mm}$. The PL emission was then imaged into the $1 \mathrm{~cm} \times 0.5 \mathrm{~mm}$ spectrometer slit with a magnification of about six. The EL spectra were imaged with similar magnification. However, the emission area was the entire solar cell contact, that is $\sim 1 \mathrm{~cm}^{2}$ for the VTD cell and $0.12 \mathrm{~cm}^{2}$ for the sputtered cell, so that the spectrometer received EL from only about $0.1 \%$ and $3 \%$, respectively, of the two cells. Cells were measured at $300 \mathrm{~K}$.

The basic features of the PL and EL spectra are very similar. The two overlapping peaks arise from pure CdTe $(1.51 \mathrm{eV})$, and from $\mathrm{CdS}_{\mathrm{x}} \mathrm{Te}_{1-\mathrm{x}}$ layers with $\mathrm{x} \sim 0.06(1.48 \mathrm{eV})$, near the junction. The alloyed layer arises from interdiffusion probably mainly during growth in the VTD case and during $\mathrm{CdCl}_{2}$ treatment in the sputtered case. At this point it is not clear whether the difference in relative peak heights for the two types of cells reflect a different alloy layer thickness or differences in PL and EL efficiencies from the two layers. In the wings of the spectra, the PL is stronger in the above-band-gap region from 1.57 to $1.6 \mathrm{eV}$ and in the region of deep-level defects near $1.41 \mathrm{eV}$. These differences are not yet fully understood. Note that the EL signal is not observed in these spectra until the bias is near open circuit $(\sim 0.8 \mathrm{~V})$.

We expect that the EL signal, to first approximation, should be proportional to the product of electron and hole densities in the same region of space. Each of these injected carrier densities will be proportional to the injection current. Thus the EL signal is expected to be proportional to the square of the current. In Fig. 3-10 we have plotted the square root of the EL signal vs. the injection current. The EL signal is roughly proportional to the square of the current but clearly also depends on the back contact structure and perhaps also on the different (VTD or sputtering) techniques used for the absorber deposition.

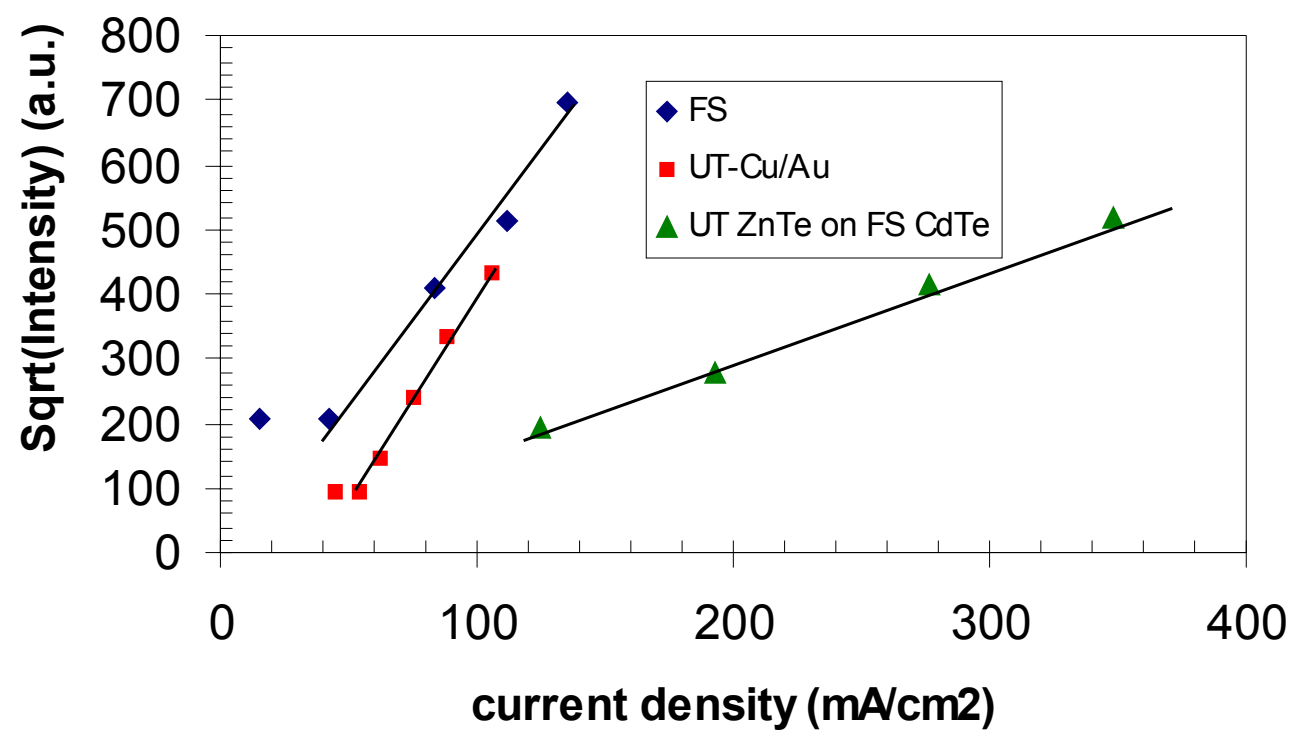

Fig. 3-10. Integrated EL intensity (through triple spectrometer) for cells with three types of contact structures. Cells were at room temperature. 
For more detailed measurements of the dependence on injection current, we have placed the cells directly in front of a photomultiplier photocathode and recorded the spectrally integrated light signal as detected by the PMT. This allows the signal to be tracked to much lower injected current densities. Fig. 3-11 shows the square root of the integrated intensity vs. current for a $1.1 \mathrm{~cm}^{2}$ cell. The inset indicates the (dark) current-voltage curve for this cell. Note that significant EL intensity is observed for driving bias voltages above $\sim 0.6 \mathrm{~V}$. For the current density range up to about $2.3 \mathrm{~A} / \mathrm{cm}^{2}$ the EL intensity is proportional to the square of the current density. (The deviation observed at low currents is due to the dark count from the PMT.)

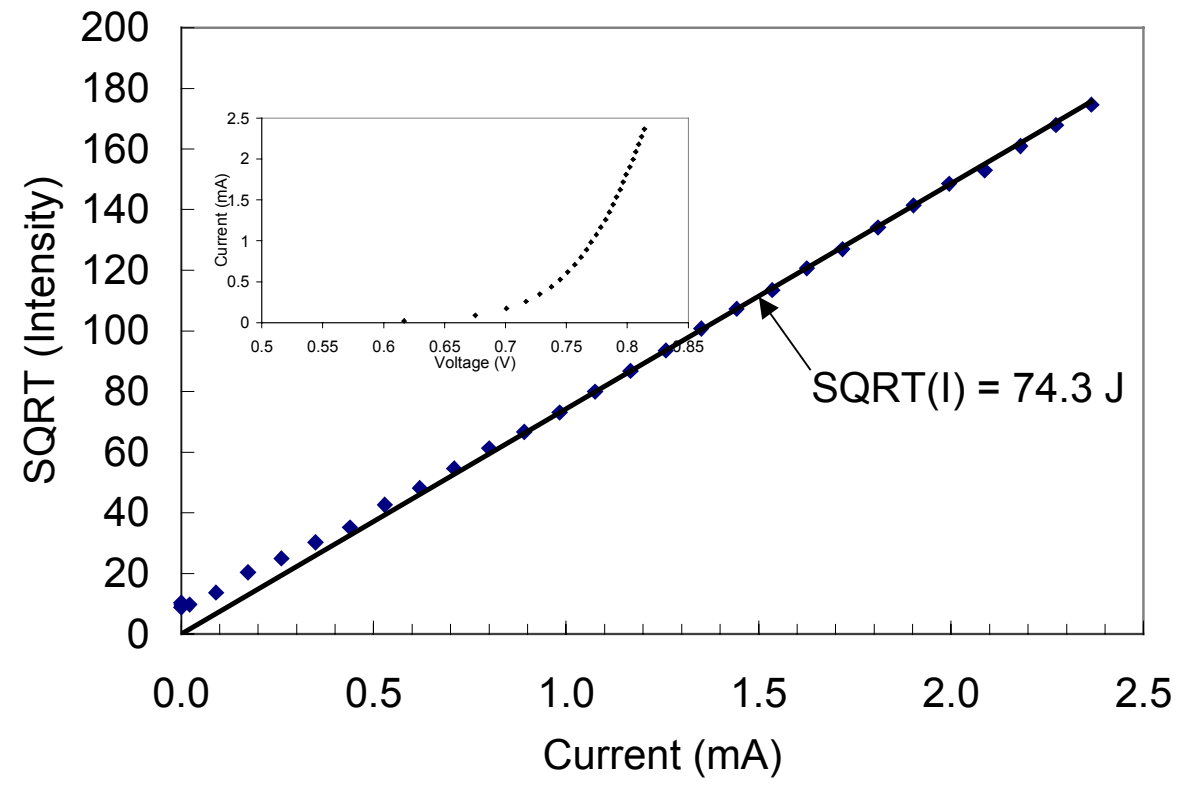

Fig. 3-11. Square root of electroluminescence vs. current with least squares fit. Inset shows the corresponding current-voltage relationship. Cell area $=1.1 \mathrm{~cm}^{2}$.

Light soaking of the cells produces substantial changes in the slope of the EL signal vs. current. This behavior, shown in Fig. 3-12, is consistent with our observations of bias-dependent photoluminescence in which the PL signal near open circuit and forward bias voltages is much more sensitive to stress-induced changes in the cell, than for PL studied under short circuit conditions for which the junction field greatly suppresses the radiative electron-hole recombination. Since the EL signals in Fig. 3-12 were obtained with the cell directly in front of the photomultiplier, the relative intensities are quite accurate. The EL from the stressed cell dropped to about $30 \%$ of the unstressed cell although the change in the cell efficiency was less than $10 \%$.

We are presently studying a broader range of cells and relating these phenomena to the changes in the I-V characteristics with light soak. We expect that EL as well as bias-dependent PL will develop as a very useful diagnostic of stress-dependent changes in CdTe solar cells. 


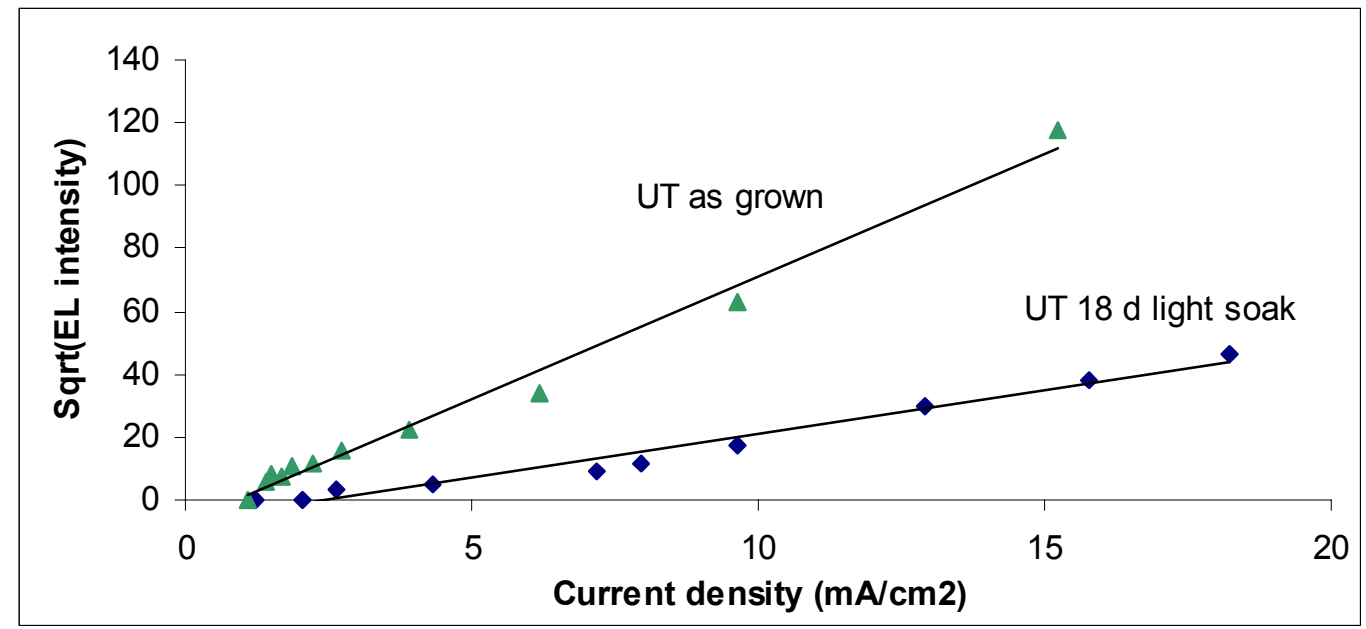

Fig. 3-12. Room temperature EL from a magnetron sputtered cell before and after 18 days of continuous light soaking at open circuit and $65 \mathrm{C}$. 


\subsection{Diode laser photoluminescence studies of $\mathrm{CdTe}$ and the effect of $\mathrm{CdCl}_{2}$ treatments}

In this section we summarize results which appeared in two papers in the MRS spring meeting. In this work Kent Price and Diana Shvydka used our $\mathrm{Kr}$ ion laser at $752 \mathrm{~nm}$ and a diode laser continuously tuned in the range from 770 to $790 \mathrm{~nm}$ to study single crystal CdTe at 10K. The first paper, by Diana Shvydka, A.D. Compaan and K.J. Price, was titled "Absorption and photoluminescence studies of lightly alloyed $\mathrm{CdTe}(\mathrm{S})$ and $\mathrm{CdS}(\mathrm{Te})$ "; $[5]$ the second paper, by Kent Price was titled "Effect of $\mathrm{CdCl}_{2}$ treatment on the interior of CdTe crystals."[6] The paper by Price utilized the deep penetration of the diode laser at $1.581 \mathrm{eV}$ to study the CdTe well below the surface and deep into the grains and found that the PL spectra depend on the purity of the $\mathrm{CdCl}_{2}$ used to perform the chloride anneal treatment. Among other data, the paper of Shvydka, et al, generated a PL excitation spectrum which helps to identify the origin of the 1.55 $\mathrm{eV}$ donor-acceptor pair peak.

Introduction--It is generally accepted that the $\mathrm{CdCl}_{2}$ process promotes grain boundary growth and passivation, and facilitates interdiffusion of $\mathrm{S}$ and $\mathrm{Te}$ near the $\mathrm{CdTe} / \mathrm{CdS}$ junction [710]. Recently, evidence has been presented suggesting that $\mathrm{CdCl}_{2}$ treatment affects doping and carrier barrier height at the grain boundaries $[11,12]$ and results in the incorporation of $\mathrm{Cu}$ into the CdTe layer [13]. The above effects are not fully understood, and it is not known how they work in tandem to improve solar cell performance. One of the reasons for the incomplete understanding is the complicated nature of polycrystalline materials as compared to their single crystal counterparts due to the presence of grain boundary effects. In order to better understand the role of $\mathrm{CdCl}_{2}$ treatment on CdTe, we have performed photoluminescence (PL) and electrical measurements on single crystal $\mathrm{CdTe}$ that has been annealed in $\mathrm{CdCl}_{2}$ vapor under conditions similar to those used in the fabrication of polycrystalline $\mathrm{CdTe} / \mathrm{CdS}$ solar cells. This allows us to determine the effects of $\mathrm{CdCl}_{2}$ on the bulk of the $\mathrm{CdTe}$ in the absence of grain boundaries.

Below-band-gap excitation allowed us to observe changes in photoluminescence spectra of the samples under investigation at $10 \mathrm{~K}$, concentrating primarily on a PL feature at about 1.55 $\mathrm{eV}$, established in the literature as a Cd vacancy state for CdTe. The inset of Figure 3-13 shows a typical PL spectrum of CdTe crystal excited with diode laser tuned to $1.587 \mathrm{eV}$. For all three samples we observed gradual change in $\sim 1.55$ peak intensity with excitation energy change. The dependence of PL intensity on excitation energy for three CdTe single crystal samples is shown on Figure 3-13. From this graph we were able to determine a resonant energy equal to $\sim 1.585$ $\mathrm{eV}$, which produced the highest PL signal in the range of interest. This allows us to infer a shallow donor state at $1.61-1.585 \cong 0.025 \mathrm{eV} \cong 25 \mathrm{meV}$ below the conduction band at $1.61 \mathrm{eV}$. In p-type CdTe this state, normally ionized, could be directly pumped from the valence band. Those donors paired with an acceptor at the appropriate distance could produce D-A pair (DAP) luminescence at the observed $1.545 \mathrm{eV}$.

We show below that the $1.545 \mathrm{eV}$ emission, known to be related to a cadmium vacancy $\left(\mathrm{V}_{\mathrm{Cd}}\right)$ center,[14] is not eliminated by high-purity $\mathrm{CdCl}_{2}$ treatment despite the presence of excess $\mathrm{Cd}$ from the $\mathrm{CdCl}_{2}$. When the $\mathrm{CdCl}_{2}$ used is of low purity, the $1.545 \mathrm{eV}$ emission disappears, and an additional emission at $1.555 \mathrm{eV}$ appears that is known to be related to $\mathrm{Cu}$. We believe that this $\mathrm{Cu}$ originates from the low-purity $\mathrm{CdCl}_{2}$ which is specified as having $2 \mathrm{ppm} \mathrm{Cu}$, in contrast with the high purity $\mathrm{CdCl}_{2}$ which has less than $1 \mathrm{ppm}$. We also show that both high and low purity $\mathrm{CdCl}_{2}$ treatment creates a $1.45 \mathrm{eV}$ donor-acceptor-pair (DAP) transition in the crystal that is likely related to $\mathrm{Cl}$ and $\mathrm{Cu}$ (possibly residual $\mathrm{Cu}$ in $\mathrm{CdTe}$ ). In addition, $\mathrm{CdCl}_{2}$ treatment affects 
the electrical properties of the crystal, reducing the bulk resistivity by nearly two orders of magnitude. These results demonstrate that $\mathrm{CdCl}_{2}$ treatment affects the bulk properties of $\mathrm{CdTe}$ crystals. Therefore, it is likely that the effect of $\mathrm{CdCl}_{2}$ treatment includes the creation of states and doping in the interior of the CdTe grains in polycrystalline CdTe solar cells.

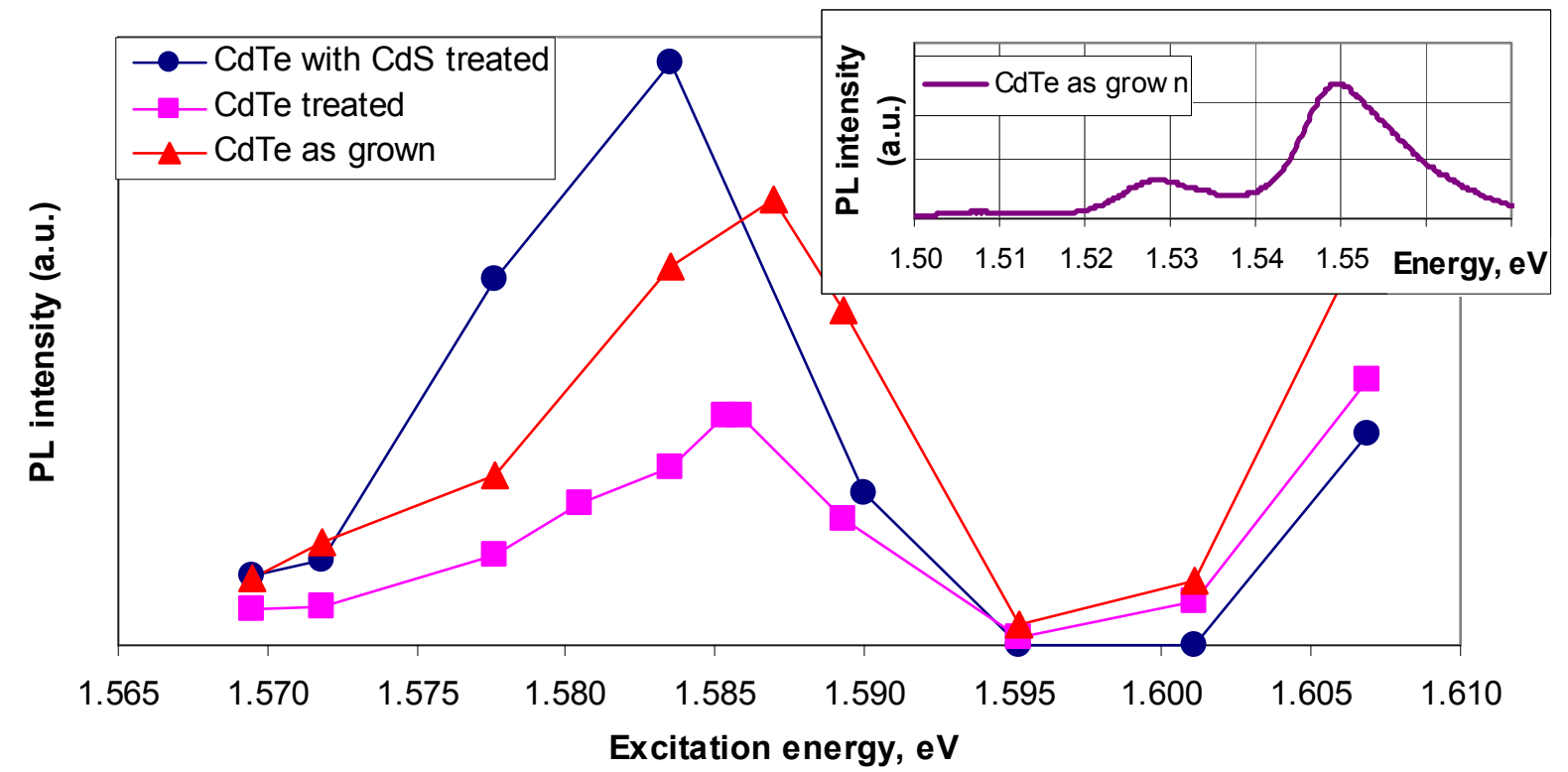

Figure 3-13. Dependence of $1.545 \mathrm{eV} \mathrm{PL}$ intensity on excitation energy for three CdTe single crystal samples: as grown, $\mathrm{CdCl}_{2}$ treated, and $\mathrm{CdCl}_{2}$ treated with $\mathrm{CdS}$. The inset shows a typical PL spectrum for CdTe crystal excited with diode laser tuned to $1.587 \mathrm{eV}$ at $10 \mathrm{~K}$.

Experimental--CdTe crystals were obtained from Keystone Crystal. Crystals were $6 \mathrm{~N}$ purity double-side polished and oriented along $<111>$. Two sources of $\mathrm{CdCl}_{2}$ powder were used. Powder of $99.998 \%$ purity ("high purity") was obtained from Alfa Aesar, and powder of $99.7 \%$ purity ("low purity") was obtained from Fisher. According to the manufacturer's analysis, the high purity $\mathrm{CdCl}_{2}$ contains less than $1 \mathrm{ppm} \mathrm{Cu}$, and the low purity $\mathrm{CdCl}_{2}$ contains approximately $2 \mathrm{ppm} \mathrm{Cu}$. $\mathrm{CdCl}_{2}$ annealing was done by placing the crystal in a pyrex tube with $\mathrm{CdCl}_{2}$ powder, then evacuating and sealing the tube. The tube was then placed in a furnace at $387 \mathrm{C}$ for one hour. Additional samples were annealed in our high-purity vapor $\mathrm{CdCl}_{2}$ treatment system at 387 $\mathrm{C}$ for 1 hour. In this system, used in the fabrication of $\mathrm{CdS} / \mathrm{CdTe}$ polycrystalline solar cells, the sample is placed approximately $1 \mathrm{~mm}$ above a glass plate covered with $\mathrm{CdCl}_{2}$ powder, covered in an unsealed graphite crucible, and heated with lamps in a dry air atmosphere. Three types of control samples were used: an as-grown CdTe crystal, a CdTe crystal annealed in a sealed tube with $\mathrm{Cd}$ powder at $387 \mathrm{C}$ for 1 hour, and a CdTe:Cu crystal prepared by evaporating $10 \mathrm{~nm}$ of elemental $\mathrm{Cu}$ on the crystal and diffusing for 1 hour at $200 \mathrm{C}$ in air. One CdTe crystal was $\mathrm{CdCl}_{2}$-treated after depositing a thin layer of $\mathrm{CdS}$ on top of it. The purpose of the last annealing schedule was to try incorporate small amounts of $\mathrm{S}$ into $\mathrm{CdTe}$, simulating interdiffusion. An asgrown CdTe sample was used for the reference.

Photoluminescence measurements were performed at $10 \mathrm{~K}$ using a power density of approximately $200 \mathrm{~mW} / \mathrm{cm}^{2}$ (2 suns) from a diode laser tuned to $1.581 \mathrm{eV}$. Note that this energy is below the CdTe bandgap of $1.61 \mathrm{eV}$ at $10 \mathrm{~K}$. Using below-gap excitation increases the penetration depth of the probing beam, allowing the study of sub-surface states. From absorption 
experiments we estimate the penetration depth for $1.581 \mathrm{eV}$ light to be between 10 and 100 microns. Emission was recorded using a triple-grating spectrometer and CCD detector. Samples for electrical measurements were annealed in the manner described above, then covered on each face with $0.113 \mathrm{~cm}^{2}$ contacts of $25 \mathrm{~nm}$ of thermally evaporated $\mathrm{Cu}$. Electrical measurements were performed in the dark with a picoammeter.

High Purity $\mathrm{CdCl}_{2} 1.5$ - $1.58 \mathrm{eV} \mathrm{PL--PL} \mathrm{spectra} \mathrm{from} \mathrm{CdTe} \mathrm{as-grown,} \mathrm{and} \mathrm{evacuated-}$ tube-annealed in high-purity $\mathrm{CdCl}_{2}$ are shown in Figure 3-14 for the region $1.4-1.58 \mathrm{eV}$. The energy axis extends to $1.61 \mathrm{eV}$ to indicate the $10 \mathrm{~K}$ band gap energy of CdTe. The emission from the vapor- $\mathrm{CdCl}_{2}$-in-air-treated sample is identical to that of the tube-annealed sample and is not shown. The dominant feature in both samples is the $1.550 \mathrm{eV}$ emission with phonon replicas 21 and $42 \mathrm{meV}$ lower. This feature is known to be a DAP transition involving a $\mathrm{Cd}$ vacancy $\left(\mathrm{V}_{\mathrm{Cd}}\right)$ acceptor [9 and references therein].

Interestingly, the $1.550 \mathrm{eV}$ cadmium vacancy feature is still prominent after annealing in $\mathrm{CdCl}_{2}$. This feature is quenched entirely in samples annealed in the presence of Cd vapor at 387 $\mathrm{C}$, shown in Figure 3-15. Therefore the presence of $\mathrm{Cl}$ somehow prevents the filling of the cadmium vacancies. Recently, Wei [15] has proposed on theoretical grounds that $\mathrm{CdCl}_{2}$ treatment results in the formation of $\mathrm{V}_{\mathrm{Cd}}-\mathrm{Cl}_{\mathrm{Te}}$ defect complexes. The formation of these complexes could explain why the $\mathrm{V}_{\mathrm{Cd}}$ PL emission remains after that $\mathrm{CdCl}_{2}$ treatment, but is quenched after annealing in $\mathrm{Cd}$ vapor.

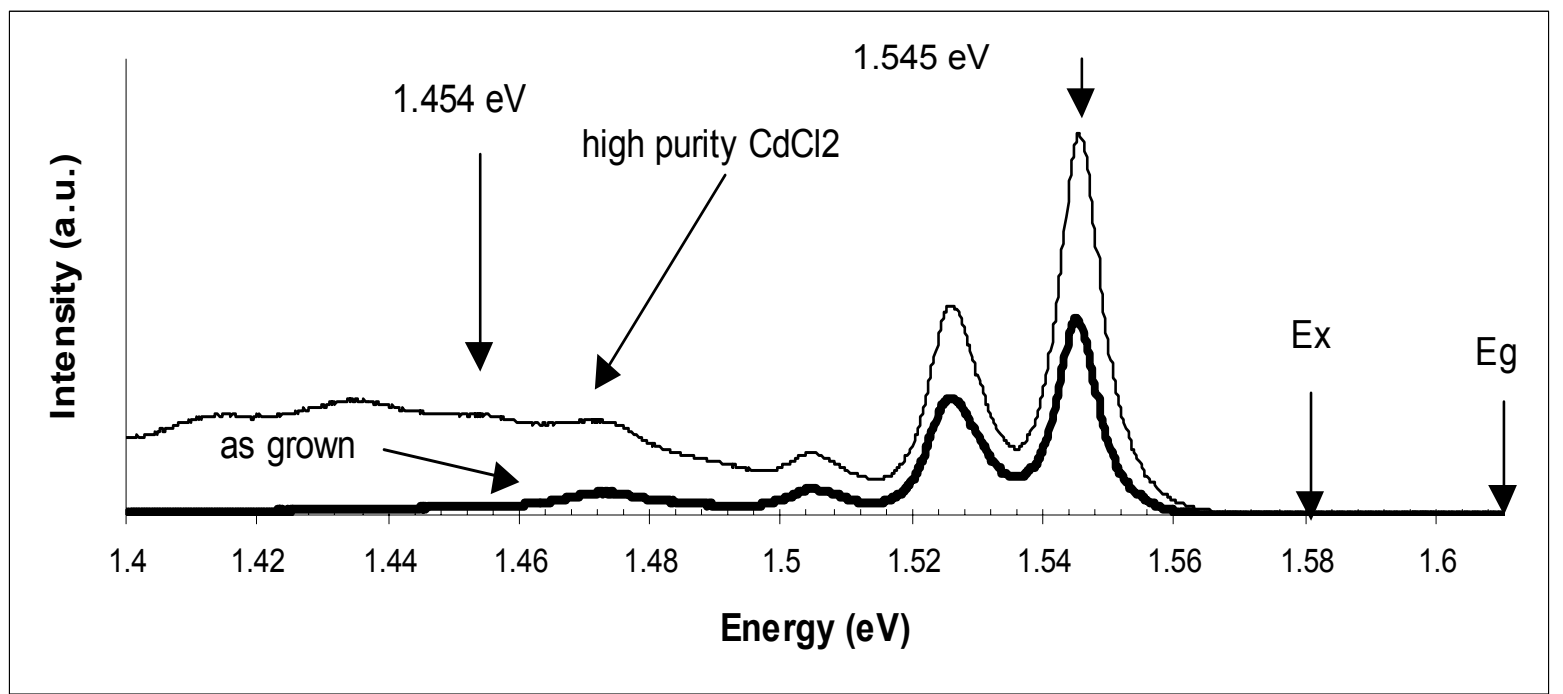

Figure 3-14. 10K, $1.581 \mathrm{eV}$ excited PL spectrum of CdTe as grown, and annealed in high purity $\mathrm{CdCl}_{2}$. Arrows indicate the CdTe band gap energy $\mathrm{E}_{\mathrm{g}}$ at $10 \mathrm{~K}$, the laser excitation energy $E_{x}$, and the energy of prominent emission lines.

High Purity $\mathrm{CdCl}_{2} 1.4$ - $1.5 \mathrm{eV} \mathrm{PL--After}$ annealing in high-purity $\mathrm{CdCl}_{2}$, both in a sealed tube and using the vapor $\mathrm{CdCl}_{2}$ system, a line appears at $1.454 \mathrm{eV}$, with two phonon replicas, that is not present in the as-grown sample. This line is also observed in the low-purity $\mathrm{CdCl}_{2}$ treated sample and the $\mathrm{CdTe}: \mathrm{Cu}$ sample, and is discussed in detail below. Also present in both samples is a feature at $1.47 \mathrm{eV}$. This line is often present in as-grown $\mathrm{CdTe}$, and its origin is not fully understood. 


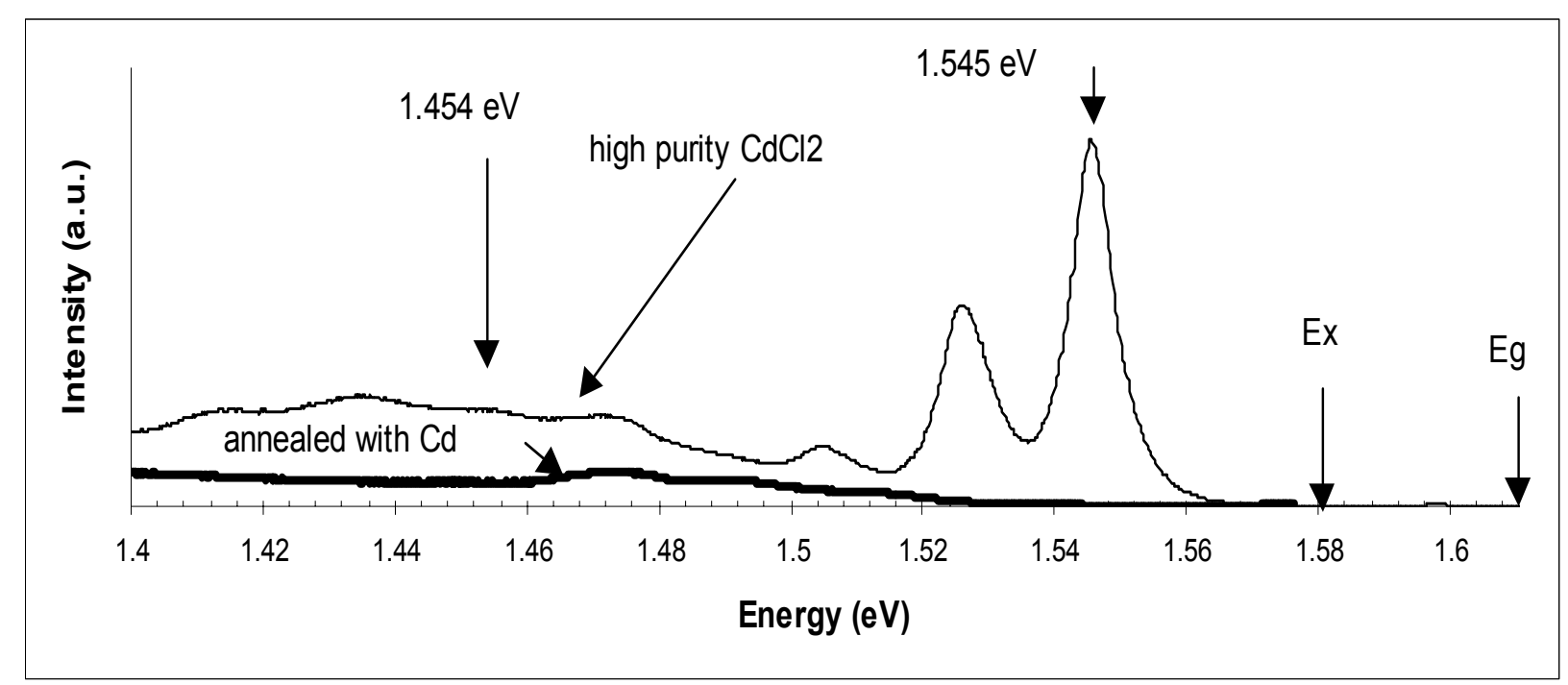

Figure 3-15. PL (at $10 \mathrm{~K}$, excited at $1.581 \mathrm{eV}$ ) from $\mathrm{CdTe}$ annealed in high purity $\mathrm{CdCl}_{2}$, and excess $\mathrm{Cd}$. Note the absence of the $1.545 \mathrm{eV} \mathrm{V} \mathrm{V}_{\mathrm{Cd}}$ vacancy peak in the latter sample.

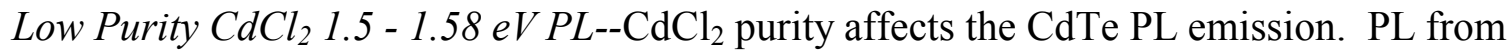
CdTe annealed with low-purity $\mathrm{CdCl}_{2}$ in a evacuated, sealed tube is compared to that from asgrown CdTe and CdTe:Cu in Figure 3-16. The $1.545 \mathrm{eV} \mathrm{V}$ Cd line in the as-grown sample is replaced by a higher-energy line, at $1.555 \mathrm{eV}$, and its phonon replicas in the low-purity $\mathrm{CdCl}_{2}$ annealed sample and the CdTe:Cu sample. This line has previously been observed only in $\mathrm{CdTe}: \mathrm{Cu}$ samples. Grecu has shown that this line is quenched in the presence of excess $\mathrm{Cd}$, and enhanced by the presence of excess Te. The line is therefore attributed to an intersitial $\mathrm{Cu} /$ Cadmium vacancy $\left(\mathrm{Cu}_{\mathrm{i}}-\mathrm{V}_{\mathrm{Cd}}\right)$ complex [14]. We note that the low-purity $\mathrm{CdCl}_{2}$ used in this work has a measured $\mathrm{Cu}$ concentration of $2 \mathrm{ppm}$.

Low Purity $\mathrm{CdCl}_{2} 1.4$ - $1.5 \mathrm{eV} \mathrm{PL--In} \mathrm{both} \mathrm{the} \mathrm{low-purity} \mathrm{CdCl}_{2}$ and $\mathrm{CdTe}: \mathrm{Cu}$ samples, the same $1.454 \mathrm{eV}$ band with two phonon replicas, present after high-purity $\mathrm{CdCl}_{2}$ treatment, is observed, although the peaks are better resolved in the $\mathrm{CdCl}_{2}$ sample. A similar $1.454 \mathrm{eV}$ transition and phonon replicas are observed by several groups in $\mathrm{Cu}$-doped CdTe: Chamonal [16] and Grecu [14] in diffusion-doped $\mathrm{CdTe}: \mathrm{Cu}$, James [17] in ion-implanted $\mathrm{CdTe:Cu}$, and Laurenti [18] in CdTe:Cu doped during growth. Each of these groups attributes the emission to a DAP transition with a $\mathrm{Cu}$ acceptor and unknown donor. The $1.454 \mathrm{eV}$ line also has been observed by at least two groups in $\mathrm{Cl}$-doped $\mathrm{CdTe}$ obtained by adding $\mathrm{CdCl}_{2}$ powder during crystal growth $[19,20]$. Each of these groups attributes the emission to a DAP transition involving a $\mathrm{Cl}$ donor, and suggest $\mathrm{Cu}$ as the acceptor involved. Comparison of the PL spectra from this work with each of the above references, it is clear that the emission energy, and number and relative intensity of the phonon replicas is the same in each case, indicating that the center responsible for the emission is the same in all of the aforementioned works. Therefore, it is possible that the center responsible for the $1.454 \mathrm{eV}$ emission is the $\mathrm{Cl}$ donor- $\mathrm{Cu}$ acceptor center. However, this emission is seen by several groups after doping with $\mathrm{Cu}$ but without introducing any intentional $\mathrm{Cl}$. Since $\mathrm{Cl}$ is not likely to be an impurity in elemental $\mathrm{Cu}$, the donor responsible for this center is evidently present in the CdTe as-grown. Furthermore, note that all of the groups that report an association of this line with $\mathrm{Cl}$ doping use $\mathrm{CdCl}_{2}$ as the $\mathrm{Cl}$ source. None of these groups disclose the purity of the $\mathrm{CdCl}_{2}$ used in the study. If, as is suggested by this work, $\mathrm{CdCl}_{2}$ results in $\mathrm{Cu}$ incorporation into the $\mathrm{CdTe}$, it is possible that the 
donor responsible for the $1.454 \mathrm{eV}$ line is not $\mathrm{Cl}$. The donor may be $\mathrm{Cl}$, but in our view, $\mathrm{Cl}-$ doping experiments involving $\mathrm{Cu}$-free $\mathrm{Cl}$ sources would strengthen the assignment of $\mathrm{Cl}$ as the responsible donor.

A similar $1.454 \mathrm{eV}$ PL emission and phonon replicas has been observed by Mouthino, et al [7] in polycrystalline $\mathrm{CdTe} / \mathrm{CdS}$ solar cells after $\mathrm{CdCl}_{2}$ treatment. While the authors do not speculate on the specific center responsible for the emission, they do note that it is a result of the $\mathrm{CdCl}_{2}$ treatment process.

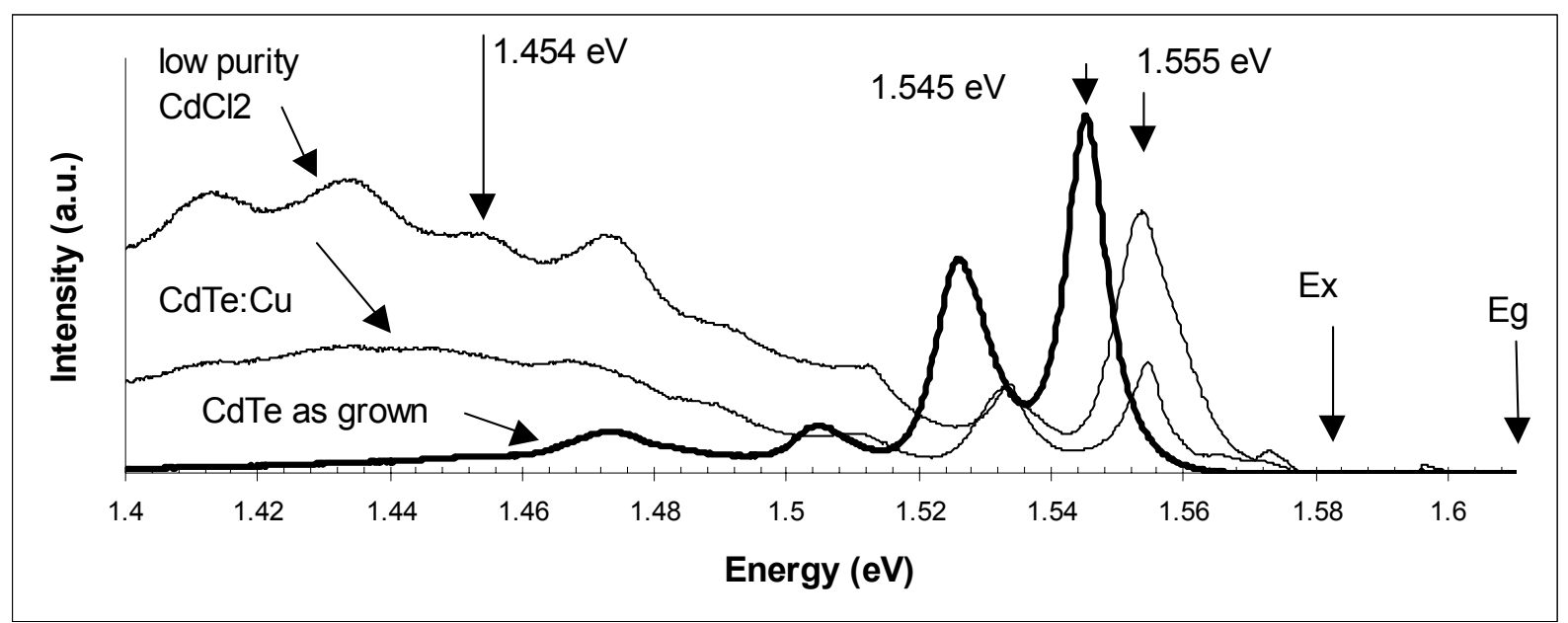

Figure 3-16. PL from as-grown CdTe, CdTe:Cu (10 nm diffused into $1 \mathrm{~mm} \mathrm{CdTe})$, and CdTe annealed in low purity $\mathrm{CdCl}_{2}$.

Electrical Measurements--The above results demonstrate that $\mathrm{CdCl}_{2}$ treatment causes the formation of additional states within the energy gap. To determine whether the $\mathrm{CdCl}_{2}$ treatment affects the electrical properties of $\mathrm{CdTe}$, we measured the bulk resistivity of as-grown and highpurity $\mathrm{CdCl}_{2}$ treated crystals. The as-grown sample had bulk resistivity of approximately $1 \times 10^{6}$ ohm-cm, while the treated crystal had a resistivity of $1 \times 10^{4} \mathrm{ohm}-\mathrm{cm}$. Clearly, the treatment affects the bulk electrical properties of the crystal as well.

Conclusions--It is well-established that $\mathrm{CdCl}_{2}$ treatment of polycrystalline $\mathrm{CdTe} / \mathrm{CdS}$ solar cells results in grain growth and passivation, and interdiffusion between the CdTe and CdS layers. These resonantly excited PL measurements suggest that the treatment also has an important effect on the interior of the CdTe grains. In particular, the annealing stabilizes cadmium vacancy centers and can result in the formation of Cu-related centers, probably associated with $\mathrm{Cl}$. The latter result is consistent with the recent SIMS work at NREL demonstrating the incorporation of $\mathrm{Cu}$ into the device during $\mathrm{CdCl}_{2}$ treatment [13]. While SIMS cannot differentiate between $\mathrm{Cu}$ in grain boundaries and $\mathrm{Cu}$ within the grains, this experiment suggests at least some of the $\mathrm{Cu}$ is incorporated into the grains. We have also shown that the purity of the $\mathrm{CdCl}_{2}$ used for the annealing may affect the $\mathrm{Cu}$ incorporation into the grains. It is important to recall that donor-acceptor pair (DAP) luminescence requires the donor and acceptor to be relatively near neighbors (with separation typically of the donor radius in CdTe, $2.5 \mathrm{~nm}$ ) and would not normally be a good measure of the density of $\mathrm{Cu}$ impurities in general or $\mathrm{Cu}$ donors in particular, or for that matter, of the $\mathrm{Cl}$ donors. Complementary experiments are needed to complete our understanding of these states. 


\subsection{Substrate configuration CdTe cells on molybdenum sheet}

This work is motivated by the interest in examining an inverted structure $\mathrm{CdS} / \mathrm{CdTe}$ cell in which the junction is formed at the top, or as one of the final layers of the structure. Almost all existing $\mathrm{CdS} / \mathrm{CdTe}$ cells are fabricated in the superstrate structure in which the junction is formed near the glass superstrate. This limits the flexibility in processing the cell and in exploring other materials options for the window/emitter layer. In addition, deposition of the $\mathrm{CdS}$, or other heterojunction partner, after the CdTe grains are formed, may change the interdiffusion characteristics, since, in the normal superstrate structure the interdiffusion is probably enhanced by the dense grain boundary structure at the $\mathrm{CdS} / \mathrm{CdTe}$ interface.

The description below is extracted in large part from a paper in the Spring 2001 Materials Research Society Symposium Proceedings: "Cadmium Telluride Solar Cells on Molybdenum Substrates," by Ilvydas Matulionis, Sijin Han, Jennifer A. Drayton, Kent J. Price, and Alvin D. Compaan.[21]

Introduction--Conventional cadmium telluride solar cells are fabricated in the superstrate configuration, glass $/ \mathrm{SnO}_{2} / \mathrm{CdS} / \mathrm{CdTe} /$ contact. These glass superstrate cells have achieved superior performance with efficiencies exceeding $16 \%$ on borosilicate glass.[22] For terrestrial power applications, ordinary soda-lime glass provides a convenient and inexpensive growth substrate. In addition, it can be heat-strengthened; it facilitates laser scribing for monolithic cell integration; and with a back lamination it facilitates fabrication into frameless modules.[23] However, the glass superstrate has two important limitations. Its large mass per unit area, in a 2$3 \mathrm{~mm}$ sheet, precludes consideration for space applications, and from a more fundamental viewpoint, the cell structure buries the electrically active junction under the 2-10 $\mu \mathrm{m}$ thick CdTe absorber layer and contact.

In the present work we have used magnetron sputtering [24] to fabricate substrate structures on $100 \mu \mathrm{m}$ Mo sheet substrates. Several aspects are similar to recent work of Singh, et al.[25], although we have used magnetron sputtering for the deposition of the CdTe, CdS, and ITO layers. Furthermore, we find that the use of a nitrogen-doped ZnTe interfacial layer between the Mo and the CdTe yields somewhat improved performance. The fact that this inverted structure (for CdS/CdTe cells) makes the $\mathrm{CdS}$ and ITO emitter the final deposited layers appears to lead to some qualitatively different $\mathrm{S} / \mathrm{Te}$ interdiffusion behavior at the $\mathrm{CdTe} / \mathrm{CdS}$ junction.

Experimental--The Mo/CdTe/CdS/indium tin oxide (ITO) cells and $\mathrm{Mo} / \mathrm{ZnTe} / \mathrm{CdTe} / \mathrm{CdS} / \mathrm{ITO}$ cells were fabricated on Mo sheet substrates $100 \mu \mathrm{m}$ thick. See the cell structure sketched in Fig. 3-17. Cadmium telluride has a relatively high work function of 5.7 eV. [26] This, together with a thermal expansion coefficient close to that of Mo, were considerations in the choice of Mo foil for substrate material. The polycrystalline CdTe, CdS, ITO, and ZnTe films were grown using planar magnetron RF sputtering.

The sputter deposition conditions were similar to those we have used for superstrate cells on glass. The Mo temperature during growth was $250^{\circ} \mathrm{C} ; 18 \mathrm{mTorr}$ of argon sputter gas flowing at a rate of $27 \mathrm{sccm}$ and 36 to $38 \mathrm{~W}$ of RF power were used for both $\mathrm{CdS}$ and CdTe growth. The cells received a standard $30 \mathrm{~min}$ annealing at $390^{\circ} \mathrm{C}$ in a vapor $\mathrm{CdCl}_{2}$ atmosphere and then a 100 $\mathrm{nm}$ thick ITO top electrode sputtered through a mask to define typically 16 cells on one substrate. 


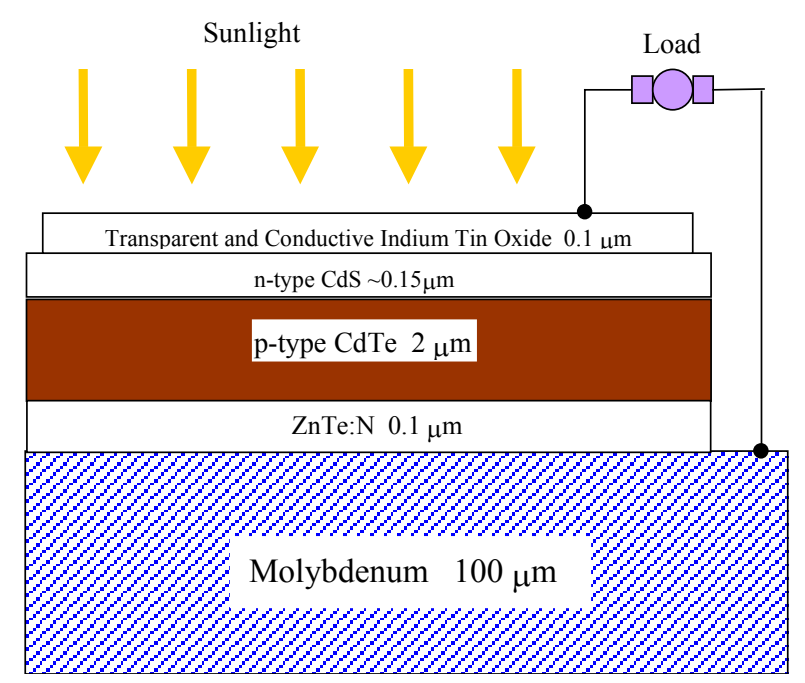

Fig. 3-17. The structure of our best substrate solar cell.

Because the substrate cells showed evidence of difficulties at the CdTe/Mo interface, for a few cells we fabricated a reactively sputtered ZnTe interfacial layer between the Mo and CdTe. This nitrogen-doped $\mathrm{p}-\mathrm{ZnTe},[27]$ has a resistivity of about $5 \Omega$-cm and carrier concentration of about $5 \times 10^{18} \mathrm{~cm}^{-3}[28]$. The use of a $\sim 150 \mathrm{~nm} \mathrm{ZnTe:N} \mathrm{layer} \mathrm{resulted} \mathrm{in} \mathrm{some} \mathrm{improvement} \mathrm{in}$ the device performance.

Quantum efficiency--The spectral quantum efficiency of a Mo substrate cell is compared with a glass superstrate cell in Fig. 3-18. Both cells were fabricated by magnetron sputtering with essentially identical sputter conditions and vapor $\mathrm{CdCl}_{2}$ treatment. The contact to the $\mathrm{CdTe}$ was evaporated $\mathrm{Cu} / \mathrm{Au}$ for the superstrate cells and Mo/ZnTe: $\mathrm{N}$ for the substrate cell. The superstrate cell was fabricated with $130 \mathrm{~nm}$ of CdS although the QE indicates that some CdS is "consumed" by interdiffusion into the CdTe. The 38\% QE at $450 \mathrm{~nm}$ is consistent with absorption in $75 \mathrm{~nm}$ of CdS. In addition this cell shows a gradual "turn-on" of the QE from 520 to 580 $\mathrm{nm}$ which probably results from a S-rich CdSTe alloy layer[5] formed during the $\mathrm{CdCl}_{2}$ processing. By contrast, the QE of the substrate cell, which was fabricated with $150 \mathrm{~nm}$ of CdS, shows little evidence of consumption of CdS (that is, the QE in the blue is consistent with the asdeposited thickness of CdS). The substrate cell also has a much sharper turn-on of the QE near $530 \mathrm{~nm}$, consistent with little alloying. (Vapor $\mathrm{CdCl}_{2}$ treatment was done after $\mathrm{CdS}$ deposition.)

At the near infrared end of the QE, there is some evidence again that less alloying occurs. It is known that formation of a Te-rich CdSTe alloy leads to reddening of the solar cell response. This is a consequence of the strong band-bowing in the CdSTe alloy system. (A little S alloyed into CdTe lowers the band gap.[5,29]) The Mo substrate cell shows a response cut-off at about $10 \mathrm{~nm}$ less than for the glass superstrate cell.

We interpret these differences between superstrate and substrate cells as arising from different behavior during the $\mathrm{CdCl}_{2}$ treatment. One possibility is that for the superstrate cell, both the $\mathrm{CdS}$ and CdTe are very small grained at their metallurgical interface, whereas for the substrate cell, the CdTe will have fully developed grains before the $\mathrm{CdS}$ is deposited. This is consistent with some observations that a $\mathrm{CdCl}_{2}$ treatment of the $\mathrm{CdS}$ (which enhances the $\mathrm{CdS}$ grain growth) before deposition of CdTe in a superstrate cell can inhibit interdiffusion. 


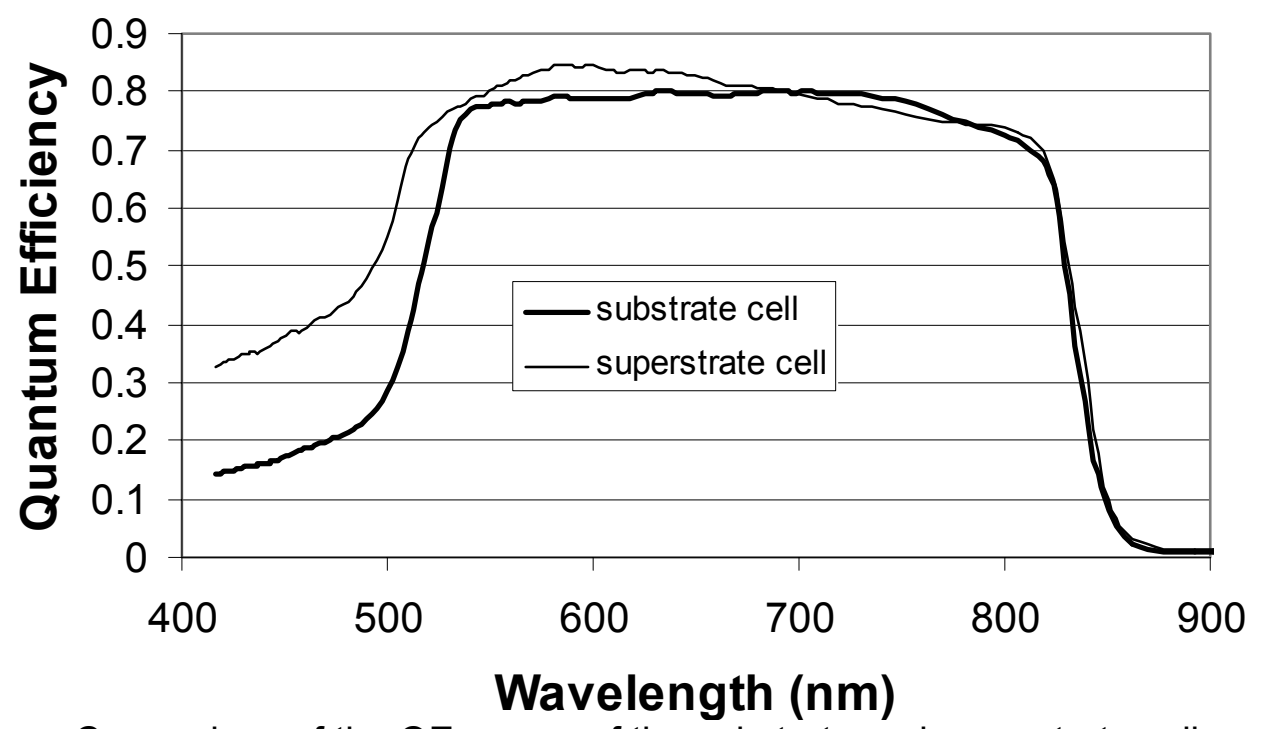

Fig. 3-18. Comparison of the QE curves of the substrate and superstrate cells.

Three plates were fabricated with different thicknesses of sputtered $\mathrm{CdS}$. The QE of the best cells from each deposition run are shown in Fig. 3-19. Comparison of these curves in the blue shows the expected differences with increasing CdS thickness leading to lower QE response. Remarkably, the QE response from 550 to $800 \mathrm{~nm}$ is much poorer for the thicker CdS $(200 \mathrm{~nm})$ than for the intermediate thickness $(150 \mathrm{~nm})$. Furthermore, the negative slope of the QE toward the red is quite high, indicating poor collection of carriers deep in the CdTe. We think that this indicates incomplete treatment of the CdTe layer during the vapor $\mathrm{CdCl}_{2}$ treatment. The top layer of CdS may be inhibiting the treatment of the underlying CdTe. The data suggest that adjustments may be needed in our $\mathrm{CdCl}_{2}$ process step for these superstrate cells and that it may need to be optimized for the thickness of the CdS emitter layer. [The QE of the cell with the thinnest CdS has intermediate behavior and seems to indicate that some alloying is occuring to produce the soft turn-on between 500 and $600 \mathrm{~nm}$. This could be consistent with thinner $\mathrm{CdS}$ inhibiting the $\mathrm{CdCl}_{2}$ processing less, but much more work is needed to confirm these effects.]
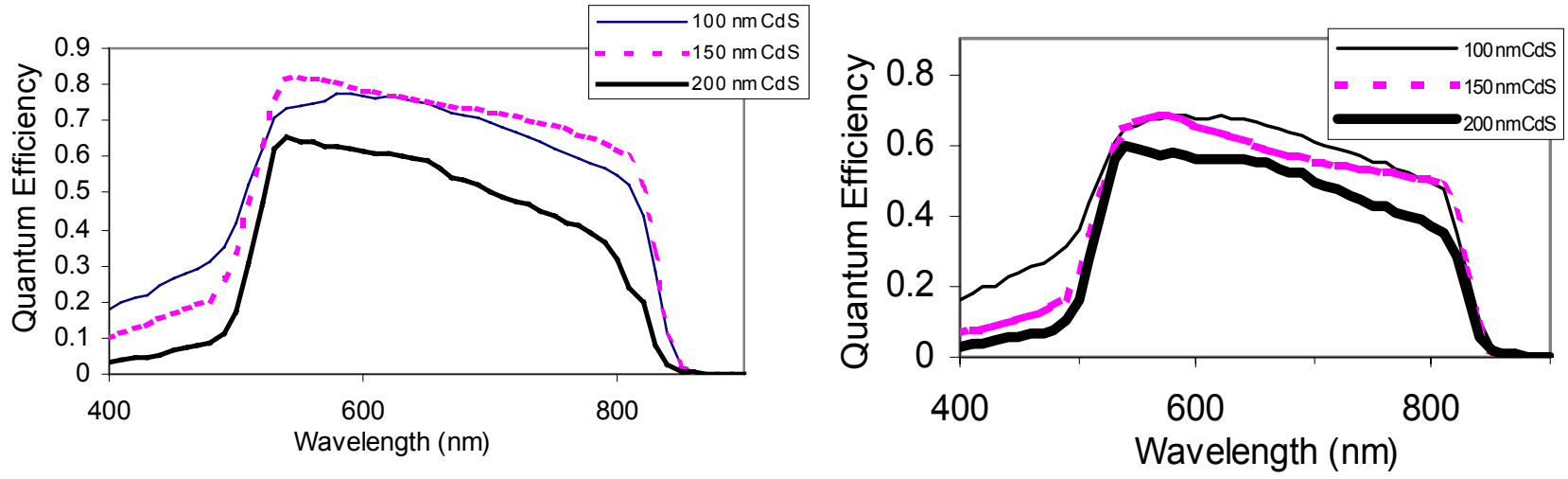

Fig. 3-19. QE curves of substrate cells with different CdS thicknesses. The two panels are for independent sets of cells confirming that the thin CdS appears to yield a "softer" turn on of the QE above $\sim 550 \mathrm{~nm}$. 
The conversion efficiency of our best cells so far is $7.8 \%$, for a cell area of $0.05 \mathrm{~cm}^{2}$. This is a significant increase over the earlier reported value from the University of Texas El Paso group of 5.3\% for CdTe cells on Mo.[25]

Fig. 3-20 shows a current-voltage curve of a substrate cell. The very severe roll-over in the first quadrant, with effects extending into the power quadrant, indicate the presence of a reverse diode or blocking diode. We believe that this is most likely to be occurring at the interface between the CdTe and the Mo layers (or ZnTe:N and Mo layers), rather than at the interface between the CdS and ITO layers. It is for this reason that we have utilized our heavily doped ZnTe:N as an interfacial layer between the Mo and CdTe. Further improvements to this interface are likely to yield the most enhancement in the cell performance.

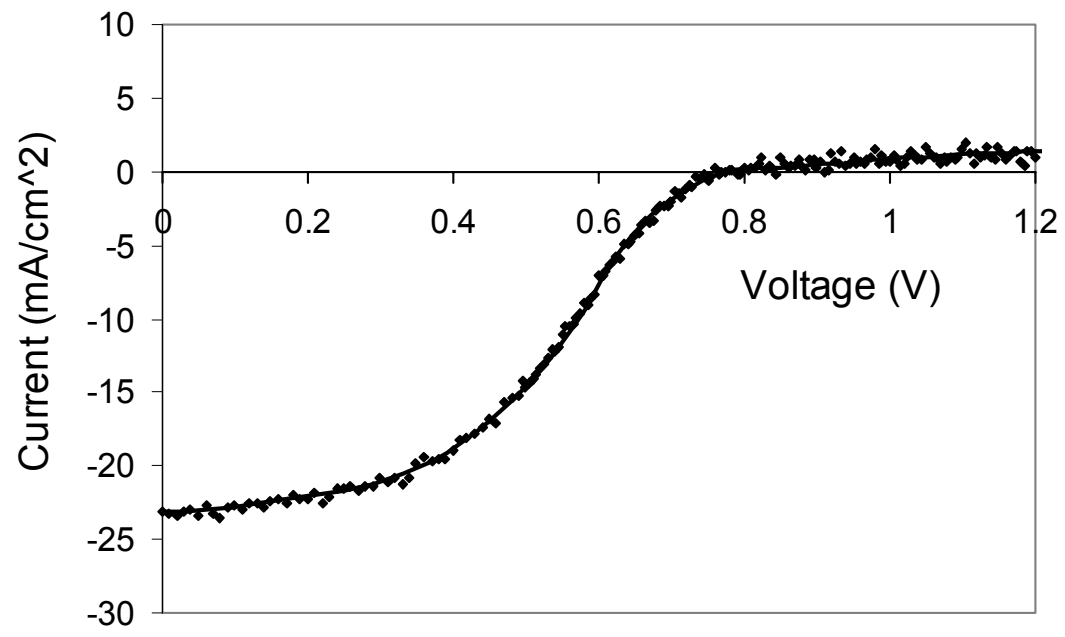

Fig. 3-20. IV curve of our best substrate cell $\left(\mathrm{V}_{\mathrm{oc}}=757 \mathrm{mV}, \mathrm{FF}=45 \%\right)$.

Other improvements might result from the use of smoother substrates. The roughness of our Mo substrates was about $400 \mathrm{~nm}$ peak-to-valley. As mentioned above, there is some indication that the $\mathrm{CdCl}_{2}$ treatment is not optimum. Furthermore, the drop in QE in the red suggests that thinner CdTe layers might be advantageous. Also no attempt has been made to adjust the properties of the ITO to optimize cell performance. We have utilized the conditions which have worked well for ITO top contacts to a-Si:H-based cells of the PV group of Xunming Deng at the University of Toledo which has recently achieved 11.6\% (active area) AM1.5 efficient triplejunction cells on $100 \mu \mathrm{m}$ stainless steel foil.[30,31]

\section{Conclusions}

Magnetron sputtering readily lends itself to the fabrication of reasonably efficient substrate $\mathrm{CdTe} / \mathrm{CdS}$ cells. This provides some attractive opportunities to study the emitter layers of this cell structure and also to examine effects which might be related to the grain morphology, since the $\mathrm{CdS}$ is deposited on fully formed CdTe grains. In this study there is clear evidence that much less interdiffusion occurs between the CdTe and $\mathrm{CdS}$ layers. There is also some evidence that the $\mathrm{CdCl}_{2}$ treatment process may need to be adjusted for this inverted structure. (Limited tests of chloride treatment of the CdTe before CdS deposition yielded poorer cells.) We believe that further study of this configuration can lead to new insights into the physics of the polycrystalline $\mathrm{CdS} / \mathrm{CdTe}$ thin-film solar cell. 


\subsection{Effect of CdTe thickness on efficiency and stability of CdS/CdTe cells}

In another paper at the MRS spring meeting, we presented a study of the efficiency and stability of sputtered cells with CdTe thicknesses ranging from 0.5 to $3.0 \mu \mathrm{m}$. This paper was titled: "Effect of CdTe thickness reduction in high efficiency CdS/CdTe solar cells," by Akhlesh Gupta, I. Matulionis, J. Drayton and A.D. Compaan.[32] The following is largely excerpted from that paper.

Introduction--CdS/CdTe solar cells prepared by high-temperature processes such as vapor transport deposition[33] or closed-space sublimation,[34,35] typically are fabricated with CdTe thicknesses ranging from 3 to $15 \mu \mathrm{m}$. By contrast, cells fabricated by low temperature processes such as magnetron sputtering[24] or electrodeposition,[36] are typically fabricated with CdTe thicknesses from 1.5 to $2.5 \mu \mathrm{m}$. It is well-known that the optical absorption coefficient in CdTe is high enough that nearly full absorption of light below $\sim 800 \mathrm{~nm}$ should occur for thicknesses of about $1 \mu \mathrm{m}$ and above. Low-temperature-fabricated cells have smaller grain sizes $(\sim 0.5-1 \mu \mathrm{m})$ than the thicker, high-temperature films $(\sim 1-5 \mu \mathrm{m})$. Cells fabricated with the thicker CdTe films are often prepared with the use of more aggressive chemical etching prior to the application of the back contact. It has been suggested that grain boundary properties may be sufficiently different for the large grain film to explain the apparent need to have thicker films to avoid shunts.

In order to determine some of the factors which affect the thickness dependence of cell performance, we have fabricated a series of $\mathrm{CdS} / \mathrm{CdTe}$ cells by magnetron sputtering with all the fabrication parameters held constant except for the CdTe thickness. Thus, we have prepared cells with CdTe layer thickness from $0.5 \mu \mathrm{m}$ to $3.0 \mu \mathrm{m}$.

Recently, considerable attention has also focused on the possible role of CdTe thickness in the long-term stability of CdTe cells prepared with contacts having copper which can diffuse deep into the CdTe and even reach the CdS/CdTe junction.[37] Thus, in addition to studies of the performance immediately after fabrication, we have also performed some limited stressing of the cells to test whether the thin CdTe cells have poorer stability under one-sun light soaking at open-circuit voltage.

Experimental--The magnetron sputtered cells were prepared as described in detail previously.[24] Essential features included the use of $8 \Omega / \square \mathrm{SnO}_{2}:$ F-coated soda-lime glass superstrates from Pilkington, Plc, rf magnetron sputtering of $0.13 \mu \mathrm{m} \mathrm{CdS}$ followed by magnetron sputtering of the CdTe layer with seven different thicknesses from $0.5 \mu \mathrm{m}$ to $3.0 \mu \mathrm{m}$. Sputtering was done at $250{ }^{\circ} \mathrm{C}$. After vapor $\mathrm{CdCl}_{2}$ treatment at $387{ }^{\circ} \mathrm{C}$ and back-contact evaporation of $3 \mathrm{~nm} \mathrm{Cu}$ and $20 \mathrm{~nm} \mathrm{Au}$, the cells were annealed at $150{ }^{\circ} \mathrm{C}$ for 45 minutes in air to diffused the $\mathrm{Cu}$. The back-contact metals were evaporated through a mask which defined typically nine cells of area $0.116 \mathrm{~cm}^{2}$ on each superstrate. No further wet processing (etching or Te layer deposition) was done after the initial superstrate cleaning in hot water with an alkaline soap. No adjustments were made in either the $\mathrm{CdCl}_{2}$ treatment or the back-contact processing to accommodate the thinner CdTe. Thus it is possible that, since these steps were optimized for cells with $2.3 \mu \mathrm{m} \mathrm{CdTe}$, some adjustment of these steps might result in higher efficiency for either thicker or thinner cells.

Double-beam optical transmission measurements were performed on the structures before contacting. The optical transmission is shown in Fig. 3-21. From the known optical absorption coefficient of crystalline CdTe, and the measured reflection losses at $752 \mathrm{~nm}$, we can calculate 
the CdTe thickness of the finished cells. The comparison between the nominal deposited thickness and a profilometer measurement of final thickness is shown in Table 3-2. Note that actual thicknesses are about $10 \%$ less than the nominal.

Table 3.2 CdTe thickness

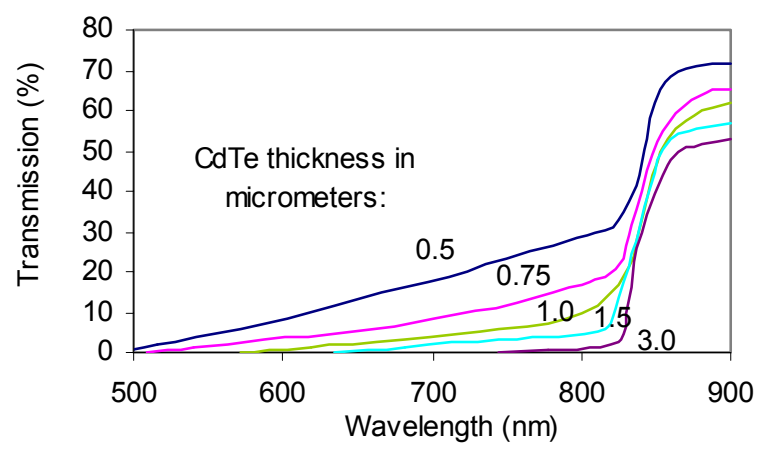

\begin{tabular}{|l|l|l|}
\hline $\begin{array}{l}\text { nominal } \\
(\mu \mathrm{m})\end{array}$ & $\begin{array}{l}\text { as- } \\
\text { depos. }\end{array}$ & $\begin{array}{l}\mathrm{CdCl} 2 \\
\text { treated }\end{array}$ \\
\hline 0.50 & 0.39 & 0.39 \\
\hline 0.75 & 0.56 & 0.60 \\
\hline 1.0 & 0.85 & 0.90 \\
\hline 1.5 & 1.30 & 1.30 \\
\hline 2.0 & 1.75 & 1.80 \\
\hline 2.5 & 2.25 & 2.30 \\
\hline 3.0 & 2.8 & 2.8 \\
\hline
\end{tabular}

Fig. 3-21. Optical transmission through uncontacted cell structure. Listed thicknesses are nominal.

X-ray diffraction from the film side near $2 \theta=90^{\circ}$ shows the presence of a $\mathrm{CdS}_{\mathrm{x}} \mathrm{Te}_{1-\mathrm{x}}$ alloy, which is expected to be formed at the CdS/CdTe interface. (See Fig. 3-22.) McCandless, et al, [38] and Mao, et al, [39] have shown that alloying can be studied conveniently at the higher order reflections. We have chosen to use the $<531>$ near $90^{\circ}$. The $\mathrm{K}_{\alpha}$ peak for pure CdTe occurs at $89.25^{\circ}$. However, alloying with $\mathrm{S}$ produces material with a smaller lattice constant depending on the amount of S present in the alloy. Fig. 3-22 shows clearly the strong peak from CdTe at $89.25^{\circ}$ and also a broader band due to the alloy which appears to be centered near $89.8^{\circ}$, especially evident for the $0.5 \mu \mathrm{m}$ thick CdTe cell. The cell used for the $2.5 \mu \mathrm{m}$ of CdTe was a control sample fabricated without the CdS layer. This trace shows, therefore, no CdSTe alloy band. Some penetration of the x-rays to the junction region occurs so the corresponding trace shows a weak peak at $90.2^{\circ}$ which is from the $\mathrm{SnO}_{2}: \mathrm{F}$-coated glass substrate. However for samples with thinner CdTe layers, the alloy band increases in intensity, due to the greater penetration of the x-rays into the interface (junction) region. It is remarkable that for $0.75 \mu \mathrm{m}$ of

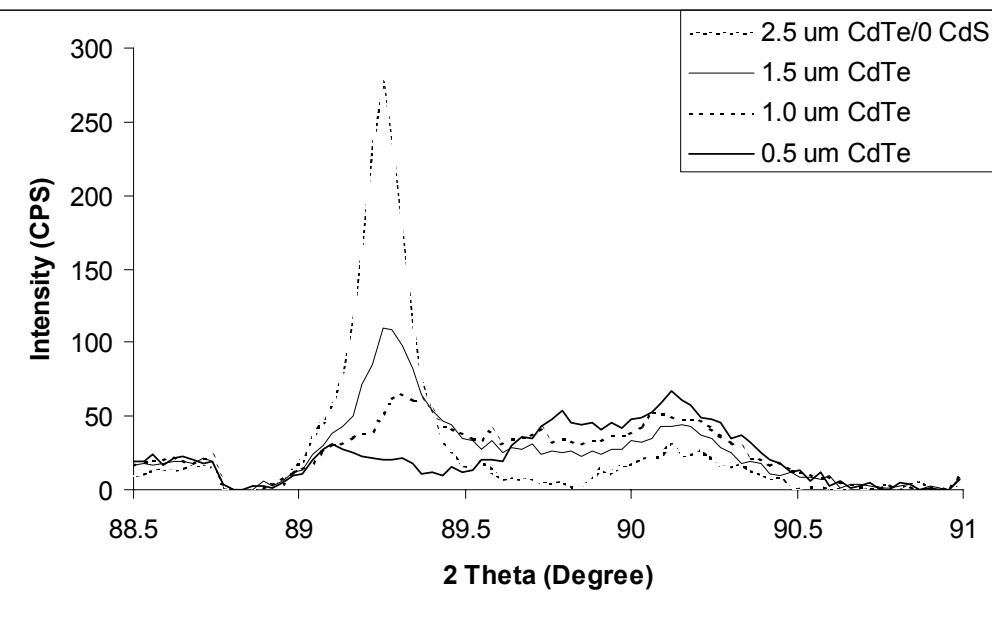

Fig. 3-22. X-ray diffractogram of complete cell structures except for back contact. Peak at $2 \theta=89.25^{\circ}$ is pure $\mathrm{CdTe}$, at $90.2^{\circ}$ is $\mathrm{SnO}_{2}$ and the CdSTe alloy extends between. 
CdTe the pure CdTe $<531>$ peak is very weak and shifted slightly by about $0.1^{\circ}$. It is essentially gone for the samples prepared with $0.5 \mu \mathrm{m}$ CdTe. Instead the alloy band centered near $89.8^{\circ}$ is the strongest for the thinnest CdTe indicating that essentially all of the original CdTe layer has been consumed in the process of alloying.

An x-ray peak at $89.8^{\circ}$ is representative of $\mathrm{CdS}_{\mathrm{x}} \mathrm{Te}_{1-\mathrm{x}}$ with $\mathrm{x}=0.06$. As shown in Refs. 40 and 41 , the alloy peak in CdS/CdTe cells is relatively broad indicating that there is a range of alloy compositions formed. The width of the band is consistent with alloy $\mathrm{x}$-values in the range $0 \leq \mathrm{x} \leq 0.06$. The presence of this Te-rich alloy is confirmed in the quantum efficiency measurements on these cells. (See below.) In addition, there is evidence from QE measurements of a S-rich alloy as well, although we have not seen it clearly in x-ray diffraction.

Cells were measured initially within one day after back-contact diffusion. Some cells of each thickness were stressed at open circuit under a metal-halide stadium lamp at approximately $55{ }^{\circ} \mathrm{C}$ in air. After stressing, the cells happened to be stored in room light at ambient for several weeks before the second I-V measurements. Current-voltage measurements were obtained with a Keithley model 2400 Source Meter and illumination with a 1000 watt Oriel solar simulator filtered for air mass 1.5 illumination. Spectral-quantum-efficiency measurements were performed with no light bias using an ELH tungsten-halogen lamp and a monochromator. Optical transmission was measured through the cells between the copper/gold contacts using a Varian model 300 double beam spectrometer.

Quantum efficiency--The external quantum efficiencies of the different thickness cells are quite similar, as seen from Fig. 3-23. All show the characteristic shift of the QE edge deeper into the near infrared which results from slight alloying of the CdTe with $\mathrm{S}$. Large band bowing in the alloy $\mathrm{CdS}_{\mathrm{x}} \mathrm{Te}_{1-\mathrm{x}}$ leads to decreasing band gap up to $\mathrm{x}=0.2$.[29] The rounded shape of the $\mathrm{QE}$ in the region from 520 to $590 \mathrm{~nm}$ is characteristic of the formation of the $\mathrm{S}$-rich alloy $\mathrm{CdS}_{\mathrm{x}} \mathrm{Te}_{1-\mathrm{x}}$ with $\mathrm{x} \leq 0.97$. Presumably the S-rich alloy exhibits very poor carrier collection, similar to the pure CdS, so that the QE is decreased by the amount of the absorption in this alloyed layer. With this assumption we can estimate the thickness of this S-rich alloy to be no more than $0.05 \mu \mathrm{m}$. Finally, the QE in the range from 420 to $500 \mathrm{~nm}$ permits an estimate the thickness of the pure $\mathrm{CdS}$ remaining in these cells. The residual CdS thickness is quite constant in these cells at $\sim 0.09$ $\mu \mathrm{m}$.

Essentially the only dependence on CdTe thickness down to $0.75 \mu \mathrm{m}(0.60$ actual $)$ evident from the quantum efficiency is a gradual decrease in collection across the spectrum (400$900 \mathrm{~nm}$ ). This could be evidence for gradually decreasing junction quality and might be improved by adjustments to the $\mathrm{CdCl}_{2}$ annealing step. For $0.5 \mu \mathrm{m}(0.39$ actual $)$ the red QE droop clearly reflects incomplete absorption and a spectrum-wide drop in current indicates that the junction is degraded for this thinnest CdTe cell. From the x-ray diffraction evidence, this thinnest cell also has essentially no pure CdTe remaining and this could play a significant role in the poor performance. Methods to reduce interdiffusion, such as preannealing the CdS before deposition of $\mathrm{CdTe}$, or the use of a high resistivity transparent conductor between the heavily doped $\mathrm{SnO}_{2}: \mathrm{F}$ and the $\mathrm{CdS}$ or CdTe, might improve the performance of the thin CdTe cells significantly. 


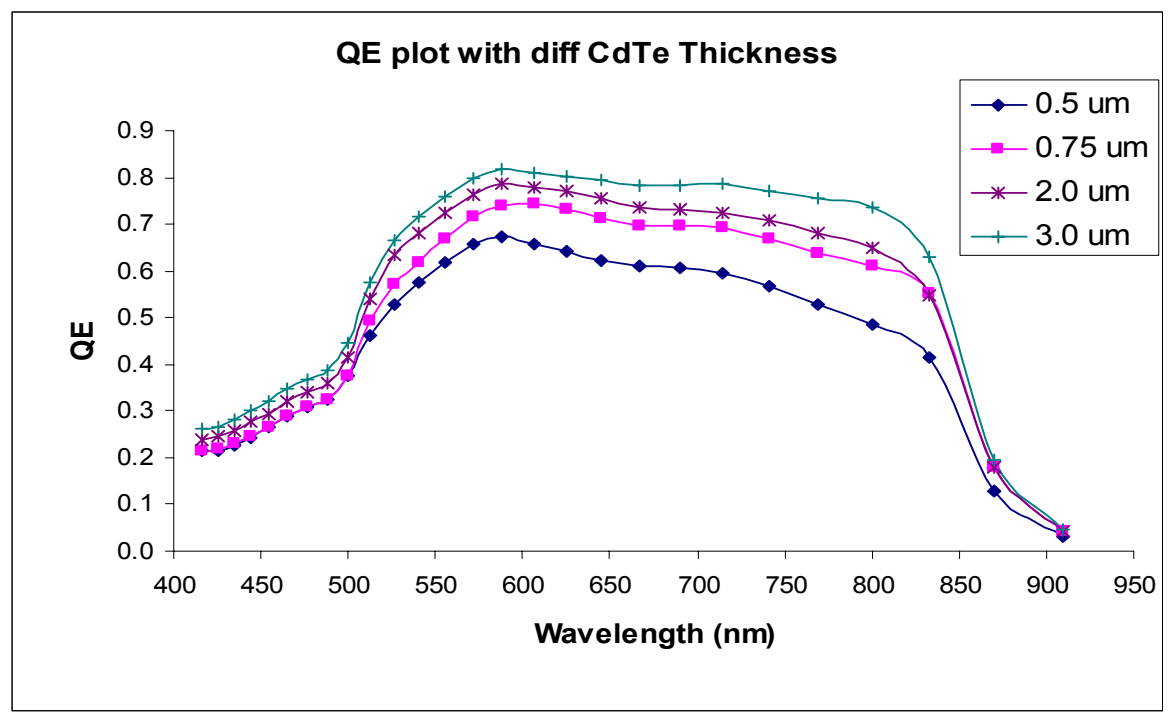

Fig. 3-23. QEs for cells with four different nominal CdTe thicknesses as shown in legend.

Cell efficiency and stability--Similar to the behavior of the QE, the electrical parameters of the cells exhibited only a gradual decrease in performance as the CdTe thickness decreased to $0.75 \mu \mathrm{m}$, but then a substantial decrease occurs for $0.5 \mu \mathrm{m}$ CdTe. The data for the average of the three best cells of each plate are collected in the six panels of Fig. 3-24. Initial values and values after seven days of stress in air at $\sim 55^{\circ} \mathrm{C}$, one-sun illumination, and open-circuit voltage are shown. The initial $\mathrm{V}_{\mathrm{OC}}$ remains above $730 \mathrm{mV}$ even for $0.75 \mu \mathrm{m}$ of CdTe. $\mathrm{J}_{\mathrm{SC}}$ values remain high down to $1.5 \mu \mathrm{m}$. Initial fill factors remain well above $60 \%$ even for $0.75 \mu \mathrm{m}$. Similarly these factors combine to yield efficiencies which trend lower but remain above $9 \%$ for $0.75 \mu \mathrm{m}$. Only the cells with the thinnest CdTe $(0.5 \mu \mathrm{m})$ exhibit significantly lower initial efficiency of $\sim 5 \%$, mostly due to the poor fill factor of $\sim 40 \%$. Above $2 \mu \mathrm{m}$, some roll-over occurs above $\sim 0.9$ $\mathrm{V}$ with little change after stress. The J-V curves for $0.75,1.0$, and $1.5 \mu \mathrm{m}$ CdTe show no rollover initially but develop after stressing a slight roll-over for forward voltages well above $\mathrm{V}_{\text {OC. }}$

The evaporated $\mathrm{Cu} / \mathrm{Au}$ contact structure used in these cells is known to lead to degraded performance under light soak at open circuit. Diffusion of copper is one mechanism proposed to lead to deterioration of cell performance and the evaporated copper of these contacts might be expected to show this deterioration most quickly. However, we wanted to test how the CdTe thickness might impact the stability of this contact. The data on stability, shown in Fig. 3-24 as the open squares, again shows little dependence on CdTe thickness except for the thinnest CdTe $(0.5 \mu \mathrm{m})$. For these thinnest CdTe structures, the cell efficiency drops to about $50 \%$ of its initial value after seven days of stress. The open-circuit voltage and the fill factor make the largest contributions to performance deterioration.

After seven days of one-sun light soak at $55^{\circ} \mathrm{C}$, the cells were stored under ambient light at room temperature for an additional 30 days. The open circles of Fig. 3-24 (not included in the MRS manuscript) show that there is a slight recovery in the current and fill factor after room temperature storage for cells with CdTe thickness of $1.5 \mu \mathrm{m}$ and above. However, the thinner CdTe cells appear to exhibit some continued deterioration in all cell parameters with room temperature storage after stressing. Fig. 3-24 also includes data on the series and shunt resistance changes with time. We have used $R_{O C}$ and $R_{S H}$, respectively as the slopes, $d V / d J$, at $\mathrm{V}_{\mathrm{OC}}$ and $\mathrm{V}_{\mathrm{SC}}$. 

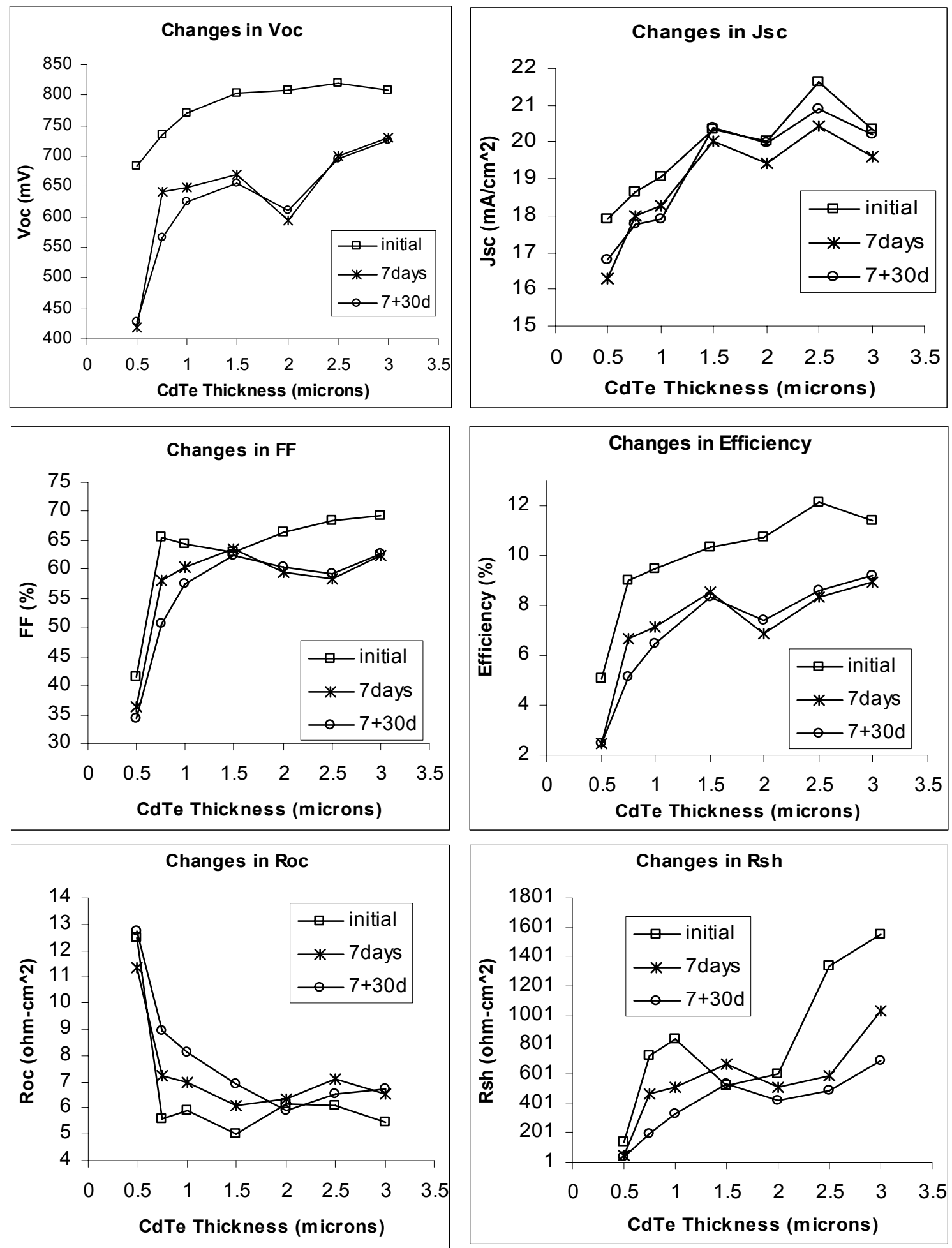

Fig. 3-24. Changes in cell performance parameters as a function of CdTe thickness. Each data point represents the average of three cells. Symbols are: $x=$ initial values; $\square=$ after light soak at $55^{\circ} \mathrm{C}$ for seven days; o= after further storage at $300 \mathrm{~K}$ in the dark. 


\section{Conclusions}

By fabricating a series of $\mathrm{CdS} / \mathrm{CdTe}$ cells with CdTe thickness from $3.0 \mu \mathrm{m}$ down to 0.5 $\mu \mathrm{m}$ we have found that the fractional change in cell parameters $\left(\mathrm{V}_{\mathrm{OC}}, \mathrm{J}_{\mathrm{SC}}, \mathrm{FF}\right)$ with stress is independent of thickness down to $0.75 \mu \mathrm{m}$. We have kept all the processing conditions constant, as optimized for $2.3 \mu \mathrm{m}$ CdTe, except for the CdTe thickness and have not made attempts to optimize other processing parameters independently with each CdTe thickness. Therefore we believe that these results could be improved with independent optimization. In particular, were the $\mathrm{CdCl}_{2}$ treatment and the back contact process independently optimized, and were an HRT layer used between the tin oxide and the $\mathrm{CdS} / \mathrm{CdTe}$, these results would almost certainly improve. We also note that no special care was taken to control $\mathrm{Na}$ diffusion although the commercial substrates normally incorporate some diffusion barrier.

Even though these cells used a simple evaporated $\mathrm{Cu} / \mathrm{Au}$ back contact with no pre- or post-etching, there is little evidence of reduced stability except for $0.5 \mu \mathrm{m}$ of CdTe. It should be noted that these cells were stressed in wintertime indoor air in Toledo with plenty of available oxygen and significant amounts of water vapor. As reported by Dobson, et al, [40] it is possible that these contribute to performance deterioration at all values of CdTe thickness with larger effects at $0.5 \mu \mathrm{m}$ of CdTe.

From this work, therefore, we judge that there should be no fundamental limit to reducing the CdTe thickness to as little at $\sim 0.75 \mu \mathrm{m}$ in high efficiency CdTe-based cells. The use of a back reflector could reduce the required CdTe thickness further. This would impact positively on CdTe utilization, potential environmental issues, and fabrication speed. 


\subsection{Nitrogen-doped $\mathrm{ZnTe}$ by reactive magnetron sputtering}

This section is based on reports given at the $28^{\text {th }}$ IEEE Photovoltaics Specialist Conference,[41] the spring 2001 Materials Research Society Symposium,[27] and the 2001 NCPV Program Review Meeting.[42]

CdTe is a high work-function semiconductor and the p-type material is difficult to contact. Most commonly used contacts to polycrystalline thin-film CdTe utilize copper in some way either as part of the contact itself or to achieve $\mathrm{p}+$ doping of the CdTe adjacent to the contact. Meyers [43], however, has shown that ZnTe can be used to fabricate high efficiency polycrystalline thin-film solar cells by electrodeposition. Also, Gessert, et al [44] have successfully used ZnTe doped with copper as part of a back contact to CdTe cells. However, Asher, et al, [45] have also shown that there is considerable diffusion of $\mathrm{Cu}$ from the $\mathrm{ZnTe}: \mathrm{Cu}$ into both the CdTe and CdS layers, which occurs during the $\sim 400{ }^{\circ} \mathrm{C}$ deposition of the $\mathrm{ZnTe}$. There is concern that this copper may be responsible for some of the stability problems observed in some $\mathrm{CdS} / \mathrm{CdTe}$ devices.

Recently atomic nitrogen has been used quite successfully to dope ZnSe and ZnTe during MBE growth.[46,47] Although electron-cyclotron-resonance plasma sources of atomic nitrogen have proven very successful for doping of epitaxial films, $[48,49]$ it is challenging to achieve effective doping in a sputtering environment with abundant gas collisions and in polycrystalline thin films with the ever-present grain boundary traps. However, we have made progress with reactive magnetron sputtering. In this section we report on the properties of thin films of reactively sputtered ZnTe:N on glass;[50] on the successful use of this ZnTe:N for back contacts to polycrystalline CdTe thin-film cells; [51,52] and on preliminary light soak tests of these contacts.

The reactive sputtering process--The reactive $\mathrm{RF}$ sputtering was carried out using a $\mathrm{ZnTe}$ target in a chamber assembled from a six-way stainless steel, copper-gasketed cross with a twoinch planar magnetron mounted in one horizontal arm. The magnetron utilized an unbalanced magnetic field configuration.[24] The substrate was suspended at the center of the cross about 2.5 inches from the sputter target in a heater assembly which provided radiant heating of the glass or $\mathrm{SnO}_{2}$-coated glass substrates. Deposition temperatures up to $400 \mathrm{C}$ were explored.[52] For our first studies the gas flow, controlled by two parallel mass flow controllers, entered from another arm of the cross approximately in the plane of the substrate. Our recent studies have utilized gas injection at the magnetron between the ground shroud and the target. This latter gas injection scheme gave slightly $(\sim 30 \%)$ lower resistivity films.

The influence of several deposition parameters on the quality of the ZnTe:N films was investigated. Growth temperatures below $200 \mathrm{C}$ lead to films of poor stoichiometry, whereas growth temperatures from $\sim 250 \mathrm{C}$ to $\sim 400 \mathrm{C}$ yielded transparent and specular films. All films discussed in the following have been deposited at $360^{\circ} \mathrm{C}$, with $\mathrm{RF}$ power of $40 \mathrm{~W}$, and total gas pressure of 18 mtorr using a flow rate of $62 \mathrm{sccm}$. Doping was controlled by the ratio of nitrogen in the sputtering gas. We prepared a series of samples with $\mathrm{N}_{2} /\left(\mathrm{N}_{2}+\mathrm{Ar}\right)$ fractions of $1 \%$, $2 \%, 3 \%$ and $5 \%$.

We have optimized the growth process while monitoring the plasma optical emission for excited state species of $\mathrm{N}$ and $\mathrm{N}_{2}$. Fig. 3-25 shows a typical emission spectrum, near the target surface, of the first positive band [53] of $\mathrm{N}_{2}\left(\mathrm{~B}^{3} \Pi_{\mathrm{g}} \rightarrow \mathrm{A}^{3} \Sigma_{\mathrm{u}}\right)$. The strongest vibrational transition in Fig. $3-25$ is for $v^{\prime}=9 \rightarrow v^{\prime \prime}=5$ at $590.6 \mathrm{~nm}$. The $v^{\prime \prime}=5$ vibrational state of the A state 


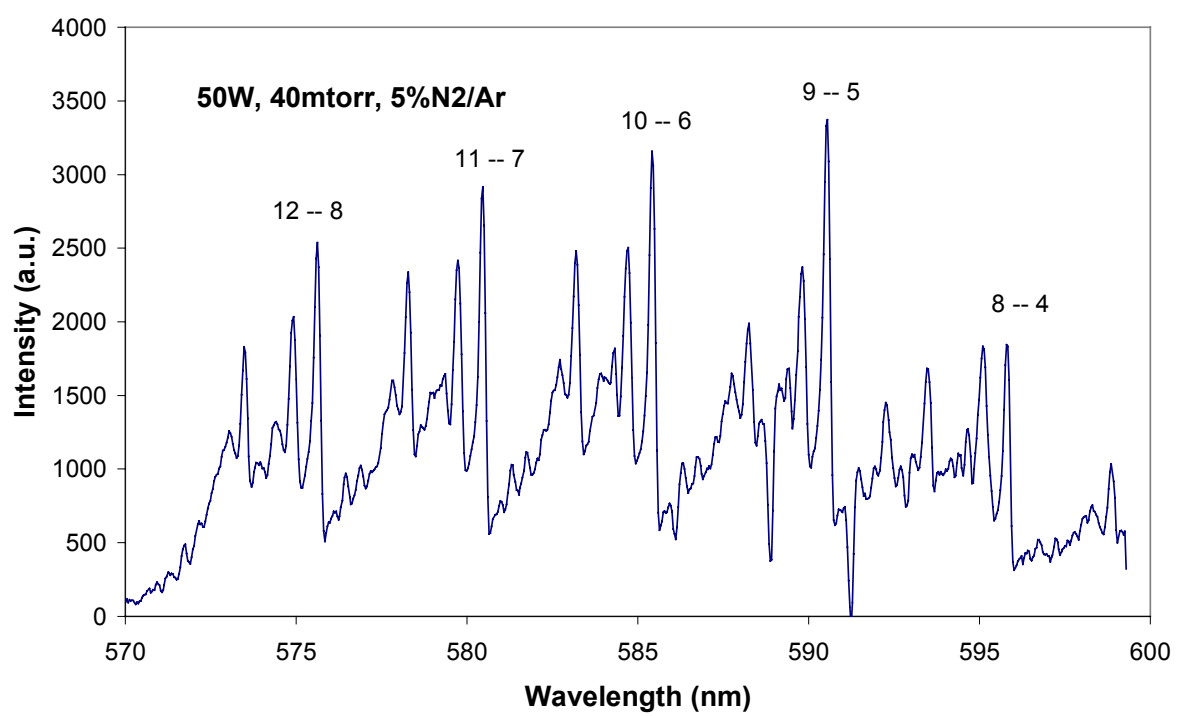

Fig. 3-25. Optical emission spectrum from the first positive band of $\mathrm{N}_{2}$ during reactive sputtering. Ar lines were subtracted; numbers indicate vibrational transitions.

lies only $\sim 2.8 \mathrm{eV}$ below the $\sim 10 \mathrm{eV}$ dissociation energy of $\mathrm{N}_{2}$. Since the ${ }^{3} \Sigma_{\mathrm{u}}$ state is metastable, significant density should impact the growth surface. Due to its low dissociation energy we expect better incorporation of atomic $\mathrm{N}$ from the metastable $\mathrm{N}_{2}$ than from ground state $\mathrm{N}_{2}$. In similar plasma nitrogen-assisted growth, Jordan, et al, [54] have provided evidence that this molecular state is advantageous for MBE growth of $\mathrm{GaN}$ using a plasma nitrogen source. They argue that the metastable molecule can much more easily release the binding energy of $\mathrm{N}$ in GaN than can atomic $\mathrm{N}$, because the second atom can carry away excess energy from the growth interface.

We have also observed optical emission from the second positive band of $\mathrm{N}_{2}$ which is in the deep blue and near uv.[53] The emission from the target region is shown in Fig. 3-26. This band originates from the $\mathrm{C}^{3} \Pi_{\mathrm{u}}$ upper state at $\sim 11.3 \mathrm{eV}$ (for $\mathrm{v}^{\prime \prime}=1$ ) and terminates on the $\mathrm{B}^{3} \Pi_{\mathrm{g}}$ lower state at $\sim 8.2 \mathrm{eV}$ (for $\mathrm{v}^{\prime \prime}=4$ ), both states being lower than the ${ }^{4} \mathrm{~S}^{0}$ (ground state $\mathrm{N}$ ) $+{ }^{2} \mathrm{D}^{0}$ (first excited state $\mathrm{N}$ ) of their precursors, and therefore metastable (even though the states are well above the dissociation energy of two ground state $\mathrm{N}$ atoms).

Fig. 3-26 also shows emission from the nitrogen molecular ion, $\mathrm{N}_{2}^{+}$. The peaks identified with the "**" at $391.4 \mathrm{~nm}$ and $388.6 \mathrm{~nm}$ are from the first negative band of $\mathrm{N}_{2}{ }^{+}$with vibrational transitions $\mathrm{v}^{\prime}=0 \rightarrow \mathrm{v}^{\prime \prime}=0$ and $\mathrm{v}^{\prime}=1 \rightarrow \mathrm{v}^{\prime \prime}=1$, respectively, from the electronic transition: $\mathrm{B}^{2} \Sigma_{\mathrm{u}} \rightarrow$ $\mathrm{X}^{2} \Sigma_{\mathrm{g}}$. The upper state of this transition lies about $18.7 \mathrm{eV}$ above the ground state of the neutral molecule. From the shape of the bands we estimate a rotational temperature of $\sim 300 \mathrm{~K}$.

The spectra show the existence of large numbers of excited state $\mathrm{N}_{2}$ molecules with a small fraction of molecular ions present near the target. However, as we image the region farther away from the sputter target, the molecular ion emission disappears and intensities of the neutral bands also change. Fig. 3-27 shows the intensity dependence on distance from the sputter target for this unbalanced magnetron. Note that the $\mathrm{N}_{2}$ lines from the first and second positive bands decrease much less rapidly than the argon lines, confirming that they are long lived and that significant numbers of excited molecules can reach the growing film surface. However, the molecular ion intensity is undetectable at the substrate even though Fig. 3-26 shows it to be nearly as strong as the second positive emission near the target. 


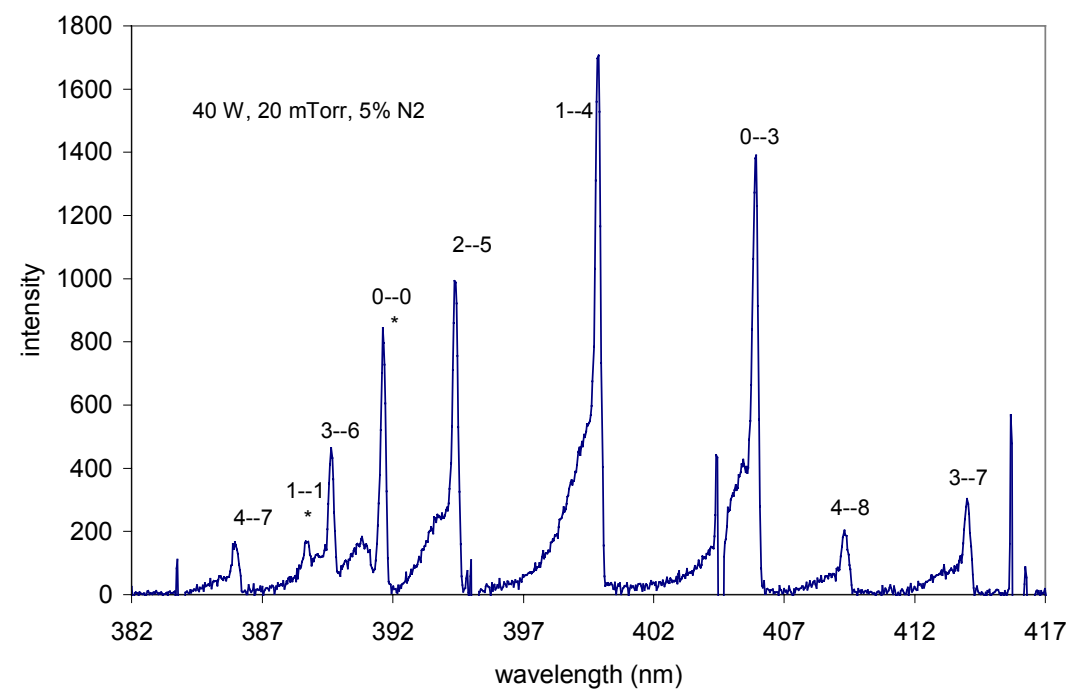

Fig. 3-26. Optical emission spectrum from the second positive band of $\mathrm{N}_{2}$ during reactive sputtering. ${ }^{*}$ indicates emission from the $\mathrm{N}_{2}{ }^{+}$molecular ion. Ar lines were subtracted; numbers indicate vibrational transitions.

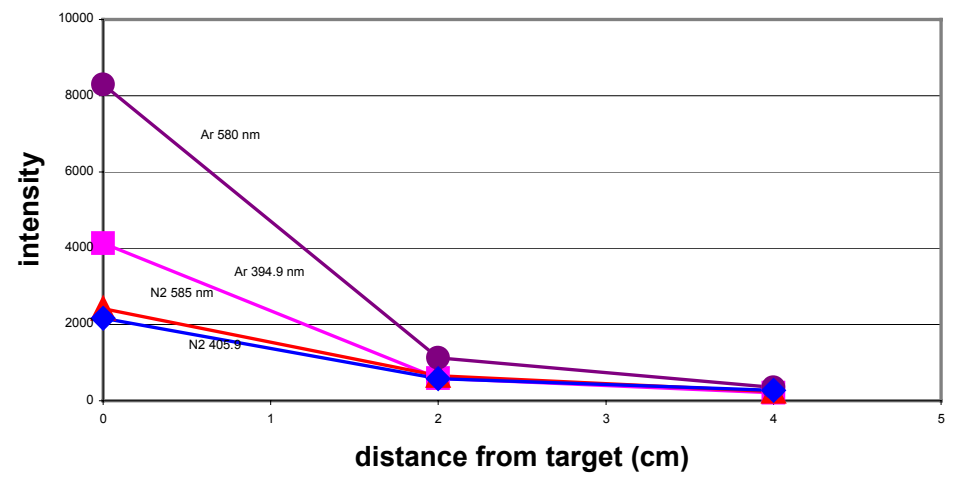

Fig. 3-27. Intensities of two Ar and two $\mathrm{N}_{2}$ emission lines vs. distance from the sputter target. (Substrate position is at $\sim 5 \mathrm{~cm} ; 5 \% \mathrm{~N}_{2}$ fraction.)

The detailed band shapes of the $\mathrm{N}_{2}$ molecular bands can be used to extract a rotational temperature. We have found the rotational temperature to be $\sim 300 \mathrm{~K}$, relatively independent of sputter parameters such $\mathrm{rf}$ power, gas pressure, and substrate temperature. We are continuing to utilize these on-line diagnostics to optimize the doping and film quality.

ZnTe:N film microstructure--The evolution of the microstructure of the ZnTe:N films with increasing $\mathrm{N}_{2}$ gas fraction was studied by Raman scattering also. In collaboration with B.E. McCandless and P.D. Paulson of IEC detailed studies were made with atomic force microscopy and $x$-ray diffraction. The AFM was done with a Digital Instruments Nanoscope III in tapping mode using a Si tip with $9 \mathrm{~nm}$ radius. Samples were rinsed in methanol and dried in argon prior to measurement. Images were analyzed for mean grain size and r.m.s. surface texture. The film microstructure is illustrated by the two AFM images of Fig. 3-28 for $0 \%$ and $3 \% \mathrm{~N}_{2}$. Analyses show mean grain diameters of $134 \mathrm{~nm}$ and $38 \mathrm{~nm}$, respectively. 

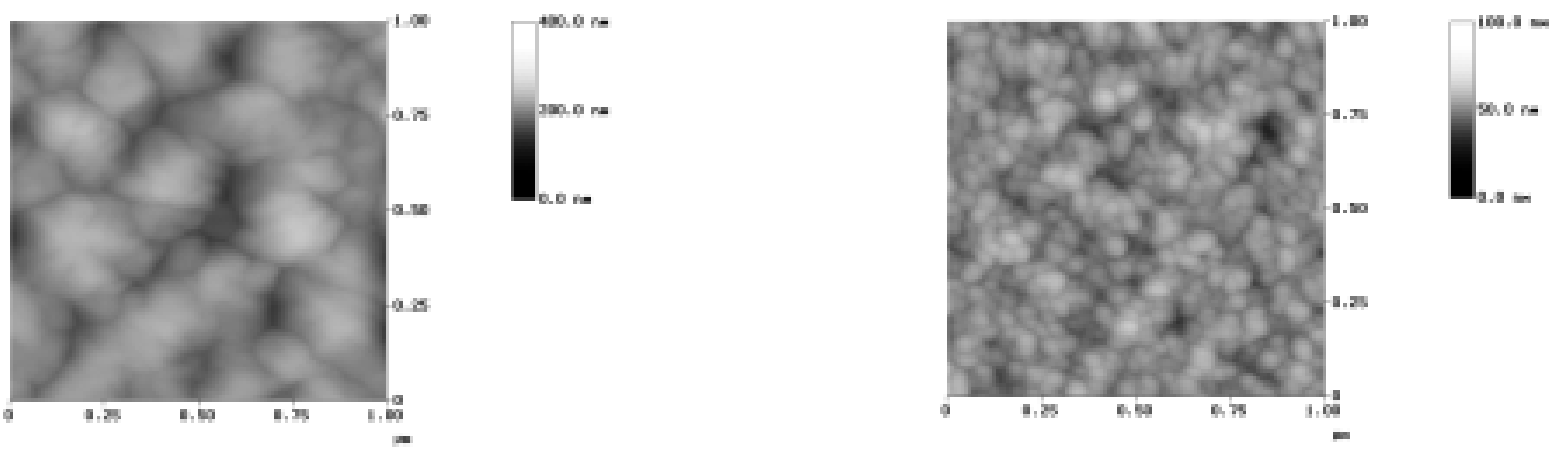

Fig. 3-28. AFM images of $0.5 \mu \mathrm{m}$ thick films of ZnTe (left) and ZnTe:N (right) grown with 3\% $\mathrm{N}_{2}$ in the sputter gas.

The crystallographic texture (See Fig. 3-29.) was studied at IEC by symmetric $\theta / 2 \theta$ x-ray diffraction with a Philips/Norelco system PW1710 with $\mathrm{Cu}-\mathrm{k}_{\alpha}$ radiation at $35 \mathrm{kV}$ and $25 \mathrm{~mA}$. The Bragg-Brentano parafocusing geometry was used with $\theta$-compensating slit to maintain constant sampling area $=12 \mathrm{~cm} \mathrm{x} 12 \mathrm{~cm}$. The focusing circle radius $=17 \mathrm{~cm}$, with $0.2 \mathrm{~mm}$ receiving slit. An evaporated gold strip $1 \mathrm{~mm}$ wide and $2 \mathrm{~cm}$ long at sample center was used for internal $2 \theta$ axis calibration. Scans were acquired over $2 \theta$ range $10^{\circ}$ to $100^{\circ}$ in $0.02^{\circ}$ steps with dwell time of 5 seconds per step. Data were smoothed and the alpha- 2 component stripped using the Rachinger method.

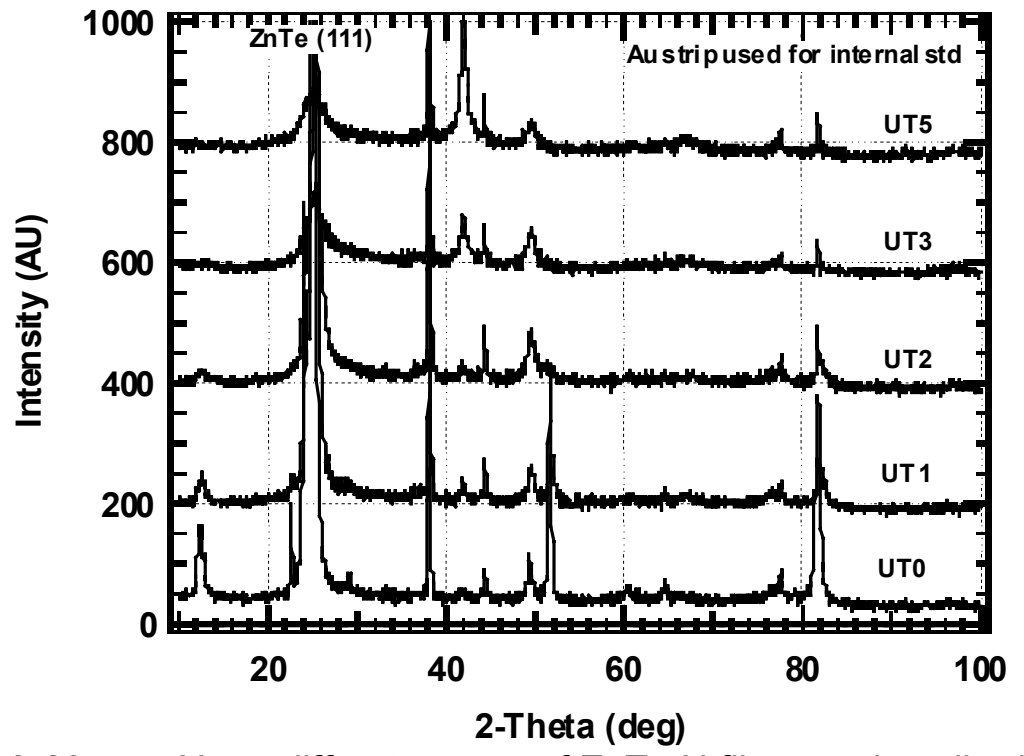

Fig. 3-29. X-ray diffractograms of ZnTe:N films as described in the text.

After indexing peaks for phase identification, a precision lattice parameter was determined by extrapolation of Nelson-Riley-Sinclair-Taylor (NRST) fit on $a_{\mathrm{hkl}}$ versus $\mathrm{F}_{\mathrm{NRST}}$ plot. Least-squares analyses of these data yield a precision of $\pm 0.0009 \AA$. Film orientation was determined by the Harris method, which normalizes the film intensity rank to the random powder standard, yielding a figure of merit called the texture coefficient, $\mathrm{p}_{\mathrm{hkl}}$. For $\mathrm{N}$ hkl reflections, $\mathrm{p}_{\mathrm{hkl}}$ $=\mathrm{N}$ indicates a preferred orientation along that $<\mathrm{hkl}>$ axis, $\mathrm{p}_{\mathrm{hkl}}=1$ indicates random orientation, 
and $\mathrm{p}_{\mathrm{hkl}}<1$ indicates orientation along a different $<\mathrm{hkl}>$ axis. Particle size estimation was performed by determination of the FWHM of the (111) reflection, deconvolution of instrument function, and application of the Scherrer formula to residual broadening. Note that increasing $\mathrm{N}_{2}$ in the sputter gas decreases the grain size as seen both by AFM and XRD, but also decreases the strong $<111>$ crystallographic texture of these films and shifts toward $<220>$.

Table 3-3. XRD analyses (UT0...5 indicate $\mathrm{N}_{2}$ fraction)

\begin{tabular}{|l|l|l|l|}
\hline Sample & $\begin{array}{l}\text { Orientation } \\
\text { Parameter } \\
\mathrm{p}_{111}(\mathrm{~N})\end{array}$ & $\begin{array}{l}\Delta \mathrm{a}_{\mathrm{o}} \\
\pm 0.0009 \\
(\AA)\end{array}$ & $\begin{array}{l}\text { XRD } \\
\text { Particle } \\
\text { Size }(\mathrm{nm})\end{array}$ \\
\hline UT0a & $7.0(9)$ & +0.0146 & 125 \\
\hline UT1a & $5.4(9)$ & +0.0217 & 35 \\
\hline UT2a & $0.4(4)$ & +0.0211 & 14 \\
\hline UT3a & $0.4(5)$ & +0.0204 & 10 \\
\hline UT5a & $0.3(5)$ & +0.0181 & 8 \\
\hline
\end{tabular}

Raman scattering, Fig. 3-30, shows a strong $205 \mathrm{~cm}^{-1}$ LO peak and its overtone and a small feature at the $170 \mathrm{~cm}^{-1}$ position of the TO mode. Consistent with heavy doping, the TO mode appears to be increasingly screened and shifted toward the TO mode with $1 \%$ and $3 \% \mathrm{~N}_{2}$ in the sputter gas. However, the broad peaks near 170 and $240 \mathrm{~cm}^{-1}$ also could indicate a transition to an amorphous or nanocrystalline phase. It is possible that the $\mathrm{N}_{2}$ is inhibiting the film nucleation on the glass substrates and we are presently trying to improve the grain size and mobility of these films as well as obtain further increases in doping density.

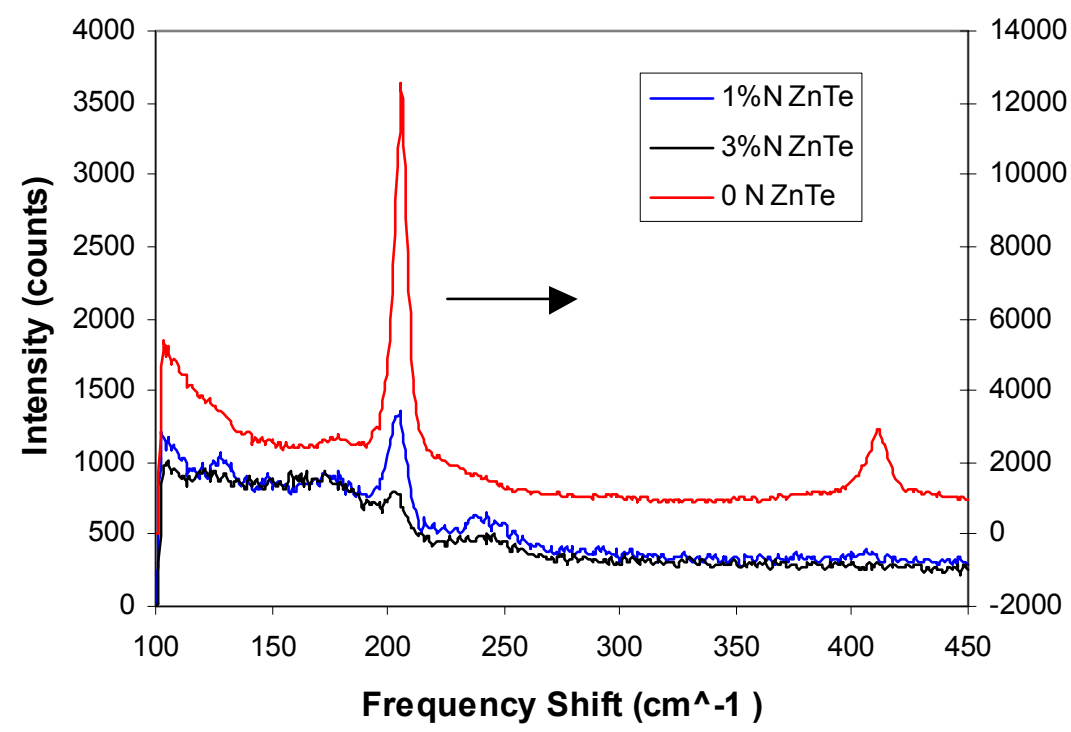

Fig. 3-30. Room temperature Raman spectra of films of ZnTe:N, using $514 \mathrm{~nm}$ excitation. Percent $\mathrm{N}$ is the fraction in the sputter gas. 
Optical and electronic properties--The optical transmission curves of intrinsic and nitrogen-doped films grown at $360 \mathrm{C}$ are shown in Fig. 3-31. Strong interference fringes indicate smooth films. The ZnTe:N film shows the onset of strong absorption at $600 \mathrm{~nm}$ vs. 560 $\mathrm{nm}$ for the intrinsic ZnTe film but otherwise equivalent transparency for $\lambda>700 \mathrm{~nm}$.

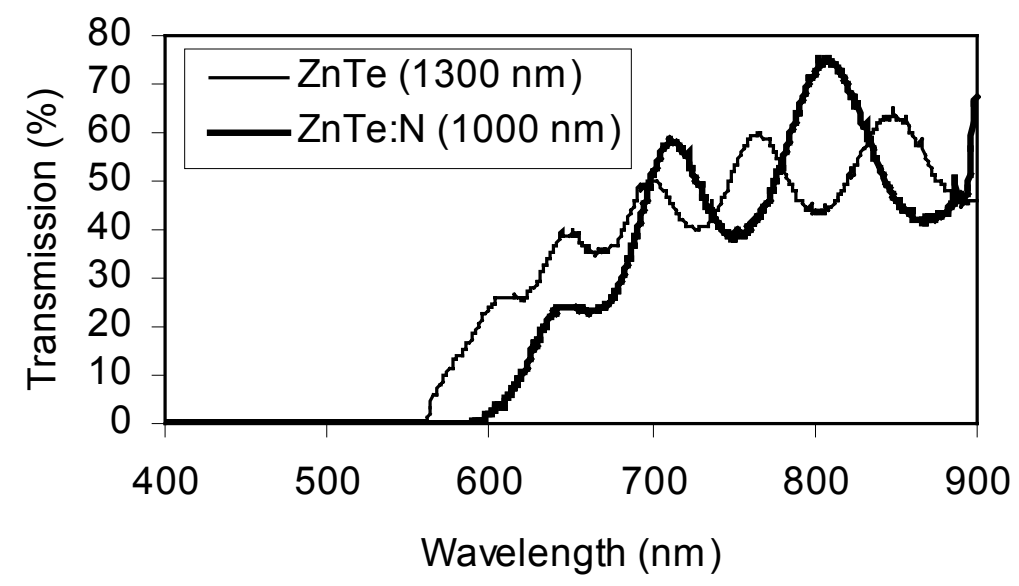

Fig. 3-31. Optical transmission of pure $\mathrm{ZnTe}$ film and $\mathrm{ZnTe}: \mathrm{N}$ film sputtered with $2 \%$ $\mathrm{N}_{2} /\left(\mathrm{N}_{2}+\mathrm{Ar}\right)$.

The electrical properties of the film depend on the location relative to the center of the sputter target. Our Phase II Annual Report described the variation of resistivity, carrier concentration, and mobility from the film center to the edge. The resistivity changes with $\mathrm{N}_{2}$ concentration in the sputter gas are shown in Fig. 3-32 as well as the variation from center to edge. In addition, Fig. 3-32 shows the effect of a $200{ }^{\circ} \mathrm{C}$ air anneal on the film resistivity. We

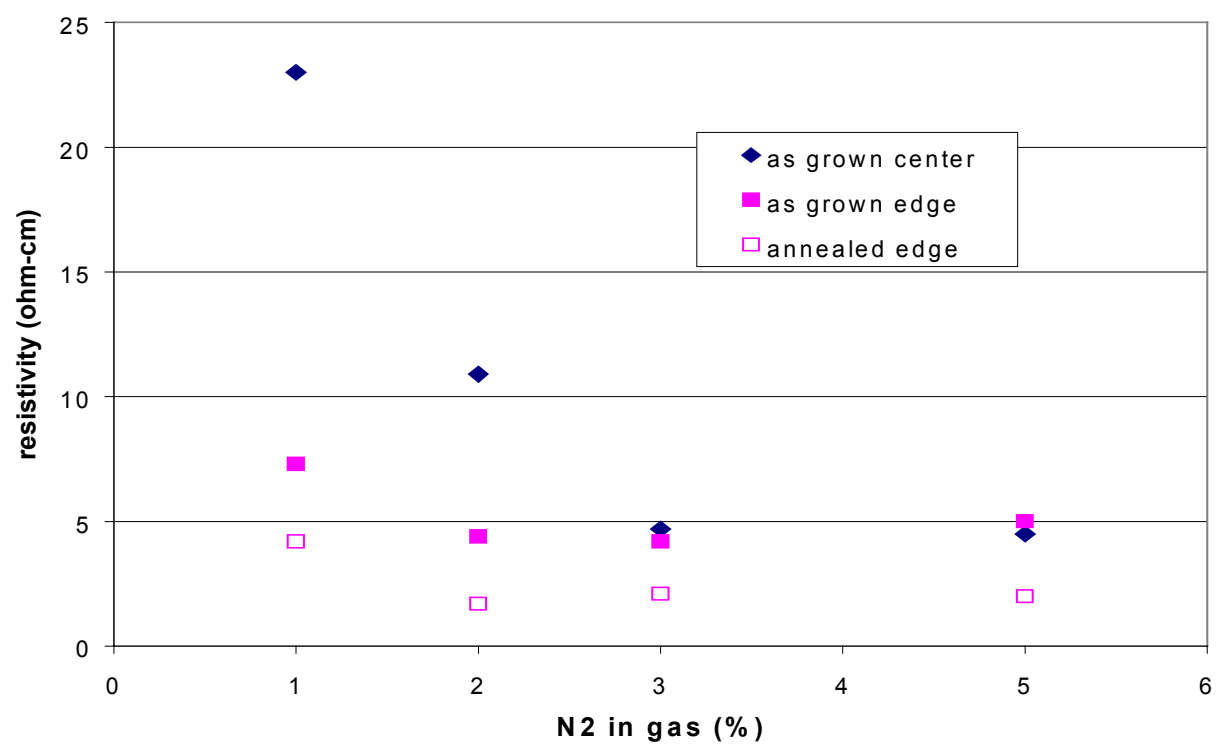

Fig. 3-32. Resistivity of ZnTe:N films vs. $\mathrm{N}_{2} /\left(\mathrm{Ar}+\mathrm{N}_{2}\right)$ fraction, with total flow of $70 \mathrm{sccm}$. 
find that an air anneal significantly lowers the resistivity and also reduces most of the variation from center to edge. We believe that this is due to a reduction in grain boundary barrier height during the anneal. (Annealing in pure $\mathrm{N}_{2}$ does not change the resistivity significantly.) A summary of Hall data before and after annealing and for four concentrations of $\mathrm{N}_{2}$ in the sputter gas is given in Table 3-4.

Table 3-4. Mobility and carrier concentration of ZnTe:N films.

\begin{tabular}{|c|c|c|c|c|}
\hline $\begin{array}{l}\text { \% of } \mathrm{N}_{2} \text { in } \\
\text { sputter } \\
\text { gases }\end{array}$ & $\begin{array}{l}\text { Mobility as } \\
\text { grown } \\
\left(\mathrm{cm}^{2} / \mathrm{V}-\mathrm{s}\right)\end{array}$ & $\begin{array}{l}\text { Mobility after } \\
\text { anneal } \\
\left(\mathrm{cm}^{2} / \mathrm{V}-\mathrm{s}\right)\end{array}$ & $\begin{array}{l}\text { Carrier } \\
\text { concentration as } \\
\text { grown }\left(/ \mathrm{cm}^{3}\right)\end{array}$ & $\begin{array}{l}\text { Carrier } \\
\text { concentration after } \\
\text { anneal }\left(/ \mathrm{cm}^{3}\right)\end{array}$ \\
\hline 1 & $2.83 \pm 0.42$ & $1.62 \pm 0.45$ & $9.04 \mathrm{E}+16$ & $2.23 \mathrm{E}+17$ \\
\hline 2 & $1.91 \pm 0.42$ & $2.08 \pm 1.2$ & $2.50 \mathrm{E}+17$ & $5.26 \mathrm{E}+17$ \\
\hline 3 & $1.1 \pm 0.25$ & $0.92 \pm 0.49$ & $1.27 \mathrm{E}+18$ & $2.92 \mathrm{E}+18$ \\
\hline 5 & $0.55 \pm 0.1$ & $1.93 \pm 0.43$ & $2.68 \mathrm{E}+18$ & $1.57 \mathrm{E}+18$ \\
\hline
\end{tabular}

We have obtained activation energies for the conductivity through Van der Pauw measurements taken at $20 \mathrm{~K}$ increments from $85 \mathrm{~K}$ to $345 \mathrm{~K}$. The results are shown in Table 3-5. For the as-grown films (AG), the data fit a sum of two exponentials with one activation energy $\mathrm{E}_{1}=\sim 125 \mathrm{meV}$ and the second $\mathrm{E}_{2}=\sim 40 \mathrm{meV}$, although the $5 \%$ sample appears anomalous, possibly related to a large amorphous component. There are substantial changes after the $200{ }^{\circ} \mathrm{C}$ heat treatment $(\mathrm{H})$ in air. We suggest that $\mathrm{E}_{2}$ may be due to grain boundary barriers that respond to the low temperature annealing in air. The 2 and $3 \%$ samples show a large reduction in $\mathrm{E}_{2}$ with air annealing. It should be noted that Grun, et al,[55] found the zero-doping limit for the $\mathrm{N}$ acceptor energy in epitaxial $\mathrm{ZnTe}$ films to be $53 \mathrm{meV}$ and neither the as-grown nor heat-treated polycrystalline films exhibit an activation energy very close to this.

Measurements of a $0.15 \mu \mathrm{m}$ layer of $\mathrm{ZnTe}: \mathrm{N}$ on a $2 \mu \mathrm{m}$ layer of as-grown CdTe result in a resistivity of $50 \mathrm{ohm}-\mathrm{cm}$ with a mobility of about $0.1 \mathrm{~cm}^{2} / \mathrm{Vs}$ and a carrier density of about $2 \mathrm{x}$ $10^{18} / \mathrm{cm}^{3}$. Depositing the ZnTe: $\mathrm{N}$ on cadmium-chloride-treated CdTe, however, produces a film with a resistivity of almost $1000 \mathrm{ohm}-\mathrm{cm}$ with a mobility of about $0.2 \mathrm{~cm}^{2} / \mathrm{V}$-s and a carrier density of about $3 \times 10^{16} / \mathrm{cm}^{3}$. But low resistivity can be regained after an $\mathrm{HCl}$ etch, to about 4 $\mathrm{ohm}-\mathrm{cm}$ with a mobility of about $4 \mathrm{~cm}^{2} / \mathrm{Vs}$ and a carrier density of about $2 \times 10^{17} / \mathrm{cm}^{3}$.

Table 3-5. Conductivity activation energies for ZnTe:N films

\begin{tabular}{|l|r|l|r|r|}
\hline Sample Name & $\%$ Nitrogen & AG or H & E1 (meV) & E2 (meV) \\
\hline \hline $3 Z T-59$ & $1 \%$ & AG & 130 & 44 \\
\hline $3 Z T-58$ & $2 \%$ & AG & 120 & 40 \\
\hline $3 Z T-60$ & $5 \%$ & AG & 45 & 6.4 \\
\hline $3 Z T-58$ & $2 \%$ & $\mathrm{H}$ & 95 & 22 \\
\hline $4 Z T-27$ & $3 \%$ & $\mathrm{H}$ & 81 & 17 \\
\hline $4 Z T$ (av. of 5) & $3 \%$ & $\mathrm{H}$ & 80 & 17 \\
\hline
\end{tabular}

ZnTe-based contacts to CdS/CdTe cells--Similar reactively sputtered zinc telluride films were used to contact solar cells on glass substrates with $\mathrm{SnO}_{2}: \mathrm{F} / \mathrm{CdS} / \mathrm{CdTe}$ layers. We have applied these contacts both to substrate structures from First Solar, LLC, and to our rf sputtered structures, with slightly better results obtained from the vapor transport deposited (VTD) 
material of First Solar. The ZnTe contacts were applied to the VTD layers directly after the standard wet $\mathrm{CdCl}_{2}$ treatment. Although initially we have found that better performance could be obtained with a bilayer contact structure involving a buffer layer of intrinsic ZnTe $30 \mathrm{~nm}$ thick followed by the doped ZnTe:N layer of $\sim 80 \mathrm{~nm}$, more recently we find the undoped layer to be unnecessary. This change may be related to lower impurity levels of $\mathrm{H}_{2} \mathrm{O}$ and $\mathrm{O}_{2}$ in the chamber in more recent depositions. For cell contacts, the ZnTe:N layer was covered by Ni dc sputtered through a mask to define the $0.18 \mathrm{~cm}^{2}$ cells. After Ni deposition, the cells were heat treated in air at $200 \mathrm{C}$ for 45 minutes. A typical I-V curve is shown in Fig. 3-33. Several of the cells with ZnTe:N/Ni, however, show significant roll-over near $\mathrm{V}_{\mathrm{OC}}$ indicating the presence of some back-diode effect.

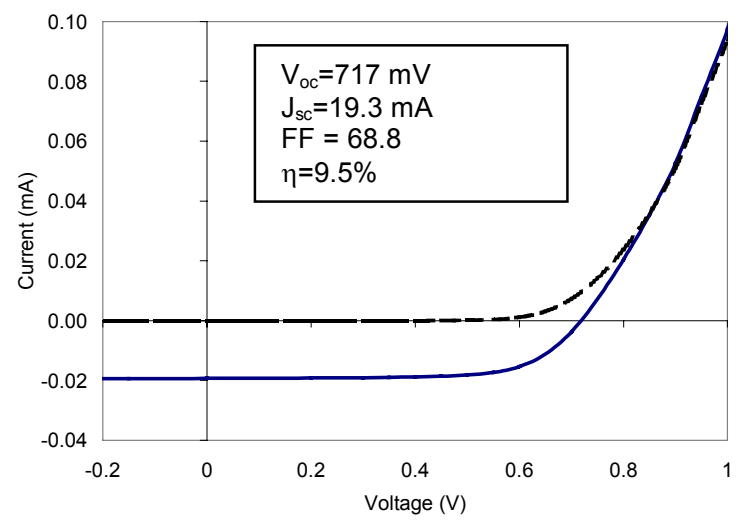

Fig. 3-33. I- I $\quad$ at one sun for cells with ZnTe:N/Ni back contact (8FS-5/16).

Stress tests of ZnTe-based contacts--Intermediate-term stability tests were performed on cells with ZnTe:N/Ni contacts. We compared side-by-side the performance of the ZnTe-based contacts with cells which received our standard evaporated copper (4 $\mathrm{nm})$ / evaporated gold (20 $\mathrm{nm}$ ) contacts followed by $150{ }^{\circ} \mathrm{C}$ diffusion for 45 minutes in air. Three types of stressing were used: one-sun light soak at either (1) open circuit or (2) resistive load near the maximum power point, and (3) hot/dark stress $\left(100{ }^{\circ} \mathrm{C}\right)$ in air.

Under the two light-soak conditions, the cells with ZnTe-based contacts performed quite similarly to those with our standard $\mathrm{Cu} / \mathrm{Au}$ contacts as shown in Fig. 3-34. Both showed an overall efficiency deterioration from about $10 \%$ to about $8 \%$. The ZnTe-based contacts exhibited quite stable fill factors and some drop in $\mathrm{V}_{\mathrm{OC}}$, whereas the $\mathrm{Cu}$-based contacts showed relatively stable $\mathrm{V}_{\mathrm{OC}}$ but larger drops in fill factors. Our tests were all made with tungstenhalogen light and the lamp variability prevented unambiguous conclusions regarding $\mathrm{I}_{\mathrm{SC}}$.

In the hot/dark stress at $100{ }^{\circ} \mathrm{C}$, there were large differences between the contact types. The ZnTe-based contacts showed superior stability compared to $\mathrm{Cu} / \mathrm{Au}$ ones, although the initial performances were similar. The stability results for 3000 -hour testing cycle at $100{ }^{\circ} \mathrm{C}$ are shown in Fig. 3-35. Although the $\mathrm{Cu} / \mathrm{Au}$ contacts initially showed little evidence of "roll-over" in forward current, after stressing above about 500 hours, they developed severe roll-over effects in the forward current. The ZnTe-based contacts exhibited a slight roll-over initially but, up to 3000 hours this back-diode effect did not develop much further. 


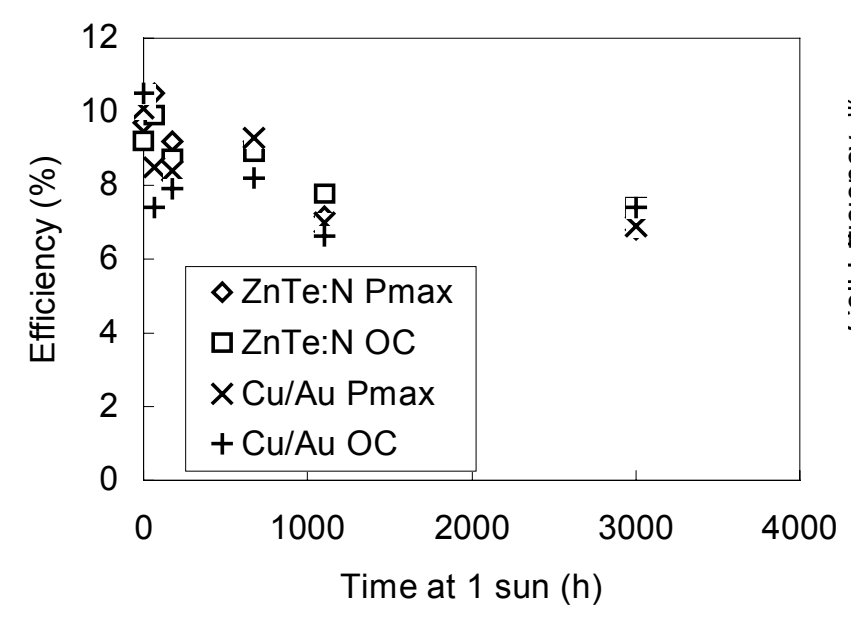

Fig. 3-34. Stability test results for two types of contacts under one-sun light soak at $\sim 60 \mathrm{C}$ in air. Cells held at either $\mathrm{V}_{\mathrm{OC}}$ or resistive load near $P_{\max }$.

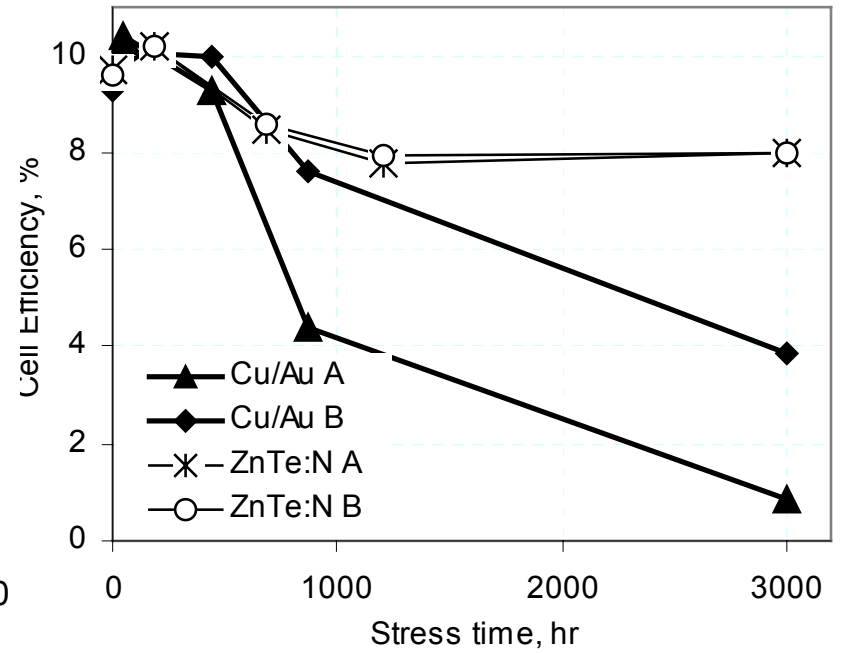

Fig. 3-35. Stability test results for two cells each with $\mathrm{Cu} / \mathrm{Au}$ and $\mathrm{ZnTe}: \mathrm{N}$ based contacts. Stress conditions: $100^{\circ} \mathrm{C}$, air, no light.

Additional stress studies of these reactively sputtered, ZnTe-based contacts have been done as part of cadmium telluride teaming activity at First Solar, LLC, under light soak conditions for $\sim 1300$ hours at $65 \mathrm{C}$ and $100 \mathrm{C}$ in air and in $\mathrm{N}_{2}$. The conditions included light soak at open circuit, resistive load, and short circuit, as well as dark/hot. The results were generally similar to the data we show here.

Since the stress data of Fig. 3-35, we have continued to monitor the performance of these and similarly prepared contacts. Additional data are shown in Fig. 3-36. 


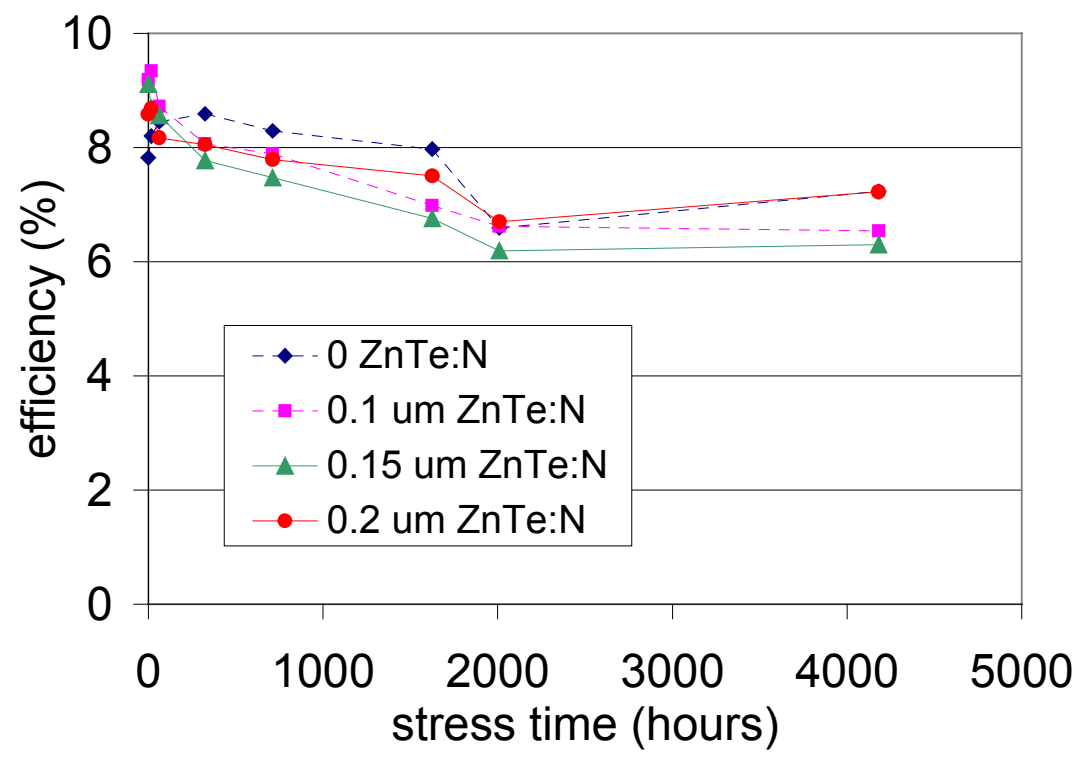

Fig. 3-36. Efficiency of several cells contacts with different thicknesses of ZnTe:N. Cells were light soaked at $\mathrm{V}_{\mathrm{OC}}$ in air at $\sim 55^{\circ} \mathrm{C}$ for the time indicated.

Conclusions on the use of ZnTe:N for back contacts--This work demonstrates that reactive sputtering of $\mathrm{ZnTe}$ with $\mathrm{N}_{2}$ can be used to achieve carrier concentrations at least up to the mid- $10^{18} \mathrm{~cm}^{-3}$ range in polycrystalline thin films. Our Hall-effect measurements, obtained in a lateral geometry, show low mobility, presumably due to grain boundary barriers. We have recently observed that post-deposition mild heat treatment in the presence of molecular oxygen can reduce the resistivity somewhat. This suggests that the oxygen may be helping to passivate the grain boundaries.

We have demonstrated also that this material appears to be suitable for back contact structures to CdTe. To date, we have not achieved open circuit voltages higher than $750 \mathrm{mV}$ however; we believe that this limitation may be related to the absence of any heavily doped region in the CdTe under the contact. This is clearly an issue requiring further study, which has the potential for further improving the results.

Finally, we note that these films exhibit good transparency for wavelengths above $\sim 700 \mathrm{~nm}$. This suggests that ZnTe: $\mathrm{N}$ would be an excellent candidate for transparent tunnel junctions in tandem solar cells [56] with a top cell of CdTe or a wider-band-gap alloy such as CdZnTe.

The effort on reactively sputtered $\mathrm{ZnTe}: \mathrm{N}$ is being continued under support from the High Performance Photovoltaics Program of NREL. 


\subsection{Studies of HRT layers}

In our Annual Report for Phase I of this project we reported on a teaming study of magnetron sputtered cells on high resistivity transition (HRT) layers of intrinsic $\mathrm{SnO}_{2}$ (TO), Cddoped TO, and Zn-doped TO coated on highly conductive $\mathrm{SnO}_{2}: \mathrm{F}(\sim 10 \Omega /$ square). The results suggest the encouraging possibility that the HRT layer might allow the CdS to be thinned below $130 \mathrm{~nm}$ while still retaining most of the $\mathrm{V}_{\mathrm{OC}}$. But, the very limited availability of such substrates with suitable HRT layers has constrained further studies. However, during Phase III we did obtain a small supply of substrates with HRT layers from First Solar through Dean Giolando. In this section we present results of that more extensive study with particular attention on differences (including stress effects) between substrates with standard TEC-8 (Pilkington) and TEC-8 coated with the HRT (with proprietary composition).

In Figs. 3-37 and 3-38 we show the quantum efficiencies for typical magnetron sputtered cells with $\mathrm{CdCl}_{2}$ treatment and with $3 \mathrm{~nm} \mathrm{Cu} / 20 \mathrm{~nm} \mathrm{Au}$ contacts. (As usual for our processing, no etch or deionized water rinse is used after initial substrate cleaning.) Five plates were sputtered with different CdS thicknesses of 0, 25, 50, 80, and $130 \mathrm{~nm}$. In most cases nine cells were defined during the $\mathrm{Cu} / \mathrm{Au}$ evaporation on each plate. For each sputter deposition, a TEC plate and a TEC/HRT plate $(\sim 1.5 \times 3$ inch) were mounted side-by-side in the sputter chamber. The plates also received identical vapor $\mathrm{CdCl}_{2}$ treatments at $387^{\circ} \mathrm{C}$, contact evaporation, and $150^{\circ} \mathrm{C}$ diffusion for $45 \mathrm{~min}$.

Quantum efficiency comparisons--The quantum efficiencies are very similar for the two sets of superstrates and clearly show the reduced blue absorption with the thinner CdS layers. (Note that we showed in Phase I that $30-50 \mathrm{~nm}$ of CdS is typically consumed during the $\mathrm{CdCl}_{2}$ treatment with the larger consumption for the thicker $\mathrm{CdS}$. This is consistent with the QE for 25 nm CdS which shows almost no loss of blue performance.)

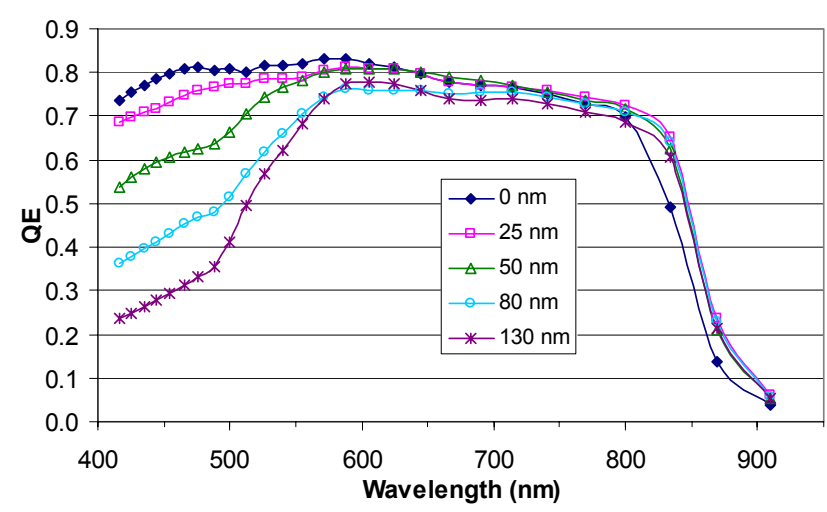

Fig. 3-37. QE for cells on TEC-8 with CdS thicknesses indicated.

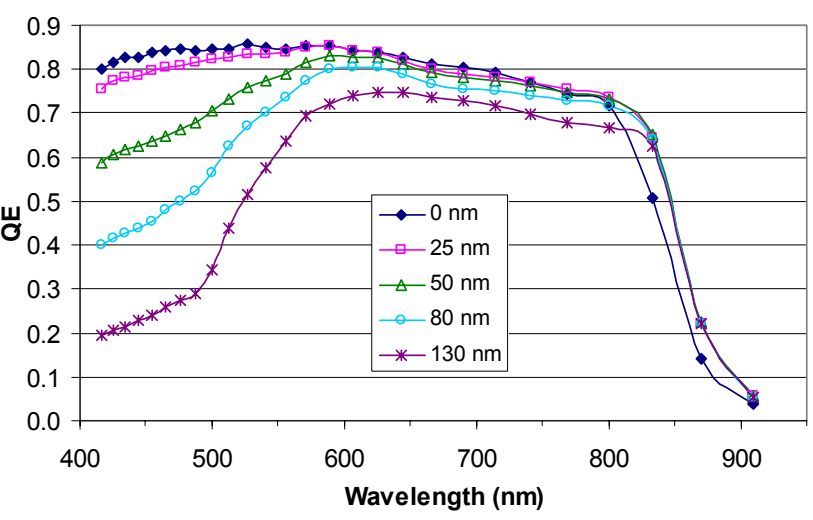

Fig. 3-38. QE for cells onTEC-8/HRT with CdS thicknesses indicated.

I-V comparisons--The I-V parameters for the cells on each plate are summarized in Tables 3-6, 7 that show, respectively, the results for TEC-8 and TEC-8/HRT substrates. In each case the tables show the average of all functioning cells and the best cell for each CdS thickness. The last column lists the fraction of surviving cells. Note that, except for zero CdS, the HRT substrates gave high performance on all nine cells whereas the TEC-8 substrates had somewhat more shorted cells. More dramatic differences showed up after stressing as discussed later. 
Table 3-6. Average and best cell I-V parameters for sputtered cells with different CdS thicknesses on Tec-8 substrates Substrate: TEC, Average Data

\begin{tabular}{|c|c|c|c|c|c|c|c|c|}
\hline \hline Sample & CdS & Voc & Jsc & FF & Eff. & Roc & Rsh & Cells \\
\hline 920B & 0 & 456 & 23.71 & 59.2 & 6.49 & 5.53 & 169 & $9 / 12$ \\
\hline T925A & $25 \mathrm{~nm}$ & 513 & 24.95 & 61.25 & 7.84 & 5.35 & 400 & $7 / 9$ \\
\hline T926A & $50 \mathrm{~nm}$ & 586 & 23.9 & 65.21 & 9.14 & 6.35 & 492 & $9 / 9$ \\
\hline T927A & $80 \mathrm{~nm}$ & 700 & 21.77 & 67.28 & 10.25 & 6.31 & 895 & $9 / 9$ \\
\hline T928A & $130 \mathrm{~nm}$ & 810 & 20.15 & 68.21 & 11.13 & 7.97 & 1556 & $7 / 9$ \\
\hline
\end{tabular}

Substrate: TEC, Best Cell Data
\begin{tabular}{|c|c|c|c|c|c|c|c|}
\hline \hline CdS & Voc & Jsc & FF & Eff. & Roc & Rsh & Cell\# \\
\hline 0 & 502 & 25.63 & 62.34 & 8.02 & 4.51 & 266 & 6 \\
\hline $25 \mathrm{~nm}$ & 524 & 25.92 & 63.39 & 8.62 & 4.55 & 428 & 9 \\
\hline $50 \mathrm{~nm}$ & 605 & 24.51 & 66.14 & 9.8 & 4.6 & 529 & 9 \\
\hline $80 \mathrm{~nm}$ & 722 & 22.23 & 68.12 & 10.93 & 5.04 & 940 & 9 \\
\hline $130 \mathrm{~nm}$ & 814 & 20.41 & 69.78 & 11.59 & 7.4 & 1315 & 4 \\
\hline
\end{tabular}

Table 3-7. Average and best cell I-V parameters for sputtered cells with different CdS thicknesses on Tec-8/HRT substrates

Substrate: HRT, Average Data

Substrate: HRT, Average Data
\begin{tabular}{|c|c|c|c|c|c|c|c|c|}
\hline Sample & CdS & Voc & Jsc & FF & Eff. & Roc & Rsh & Cells \\
\hline H920B & 0 & 592 & 25.29 & 60.57 & 9.08 & 5.91 & 264 & $7 / 9$ \\
\hline H921A & $25 \mathrm{~nm}$ & 716 & 25.31 & 61.37 & 11.11 & 6.04 & 518 & $9 / 9$ \\
\hline H922A & $50 \mathrm{~nm}$ & 708 & 23.99 & 65.72 & 11.17 & 6.16 & 792 & $9 / 9$ \\
\hline H923A & $80 \mathrm{~nm}$ & 782 & 22.71 & 68.46 & 12.16 & 6.3 & 728 & $9 / 9$ \\
\hline H924B & $130 \mathrm{~nm}$ & 827 & 20.75 & 70.07 & 12.01 & 5.23 & 1085 & $9 / 9$ \\
\hline
\end{tabular}

Substrate: HRT, Best Cell Data

\begin{tabular}{|c|c|c|c|c|c|c|c|}
\hline \hline CdS & Voc & Jsc & FF & Eff. & Roc & Rsh & Cell\# \\
\hline 0 & 607 & 25.93 & 63.16 & 9.94 & 5.41 & 379 & 5 \\
\hline $25 \mathrm{~nm}$ & 727 & 25.46 & 62.22 & 11.51 & 6.25 & 584 & 5 \\
\hline $50 \mathrm{~nm}$ & 716 & 24.99 & 66.4 & 11.88 & 4.94 & 833 & 9 \\
\hline $80 \mathrm{~nm}$ & 801 & 24.2 & 69.49 & 13.46 & 5.26 & 837 & 6 \\
\hline $130 \mathrm{~nm}$ & 824 & 21.14 & 71.08 & 12.39 & 4.85 & 1014 & 9 \\
\hline
\end{tabular}

The data of Tables 3-6 and 3-7 show that the most striking effect of the HRT is higher $\mathrm{V}_{\mathrm{OC}}$ when the as-deposited CdS thickness is $80 \mathrm{~nm}$ or less - as much as $200 \mathrm{mV}$ higher for $25 \mathrm{~nm} \mathrm{CdS}$. The HRT yields only marginally higher currents and fill factors. The HRT layer also significantly improves (raises) the shunt resistance for CdS thicknesses of $50 \mathrm{~nm}$ and below.

The comparisons of dark I-V and light I-V between the two types of substrates are shown in Fig. 3-39. The dark I-Vs show almost no diode turn-on behavior for zero CdS. $25 \mathrm{~nm}$ of CdS for HRT substrates, or $50 \mathrm{~nm}$ of CdS for Tec- 8 substrates, greatly improve the dark diode characteristics. But $130 \mathrm{~nm}$ of CdS again yields relatively poor dark turn-on characteristics. Furthermore, 50 $\mathrm{nm}$ and $80 \mathrm{~nm}$ of CdS show a dark turn-on but then show significant rollover in the forward direction for voltage above $\sim 0.8 \mathrm{~V}$.

One interesting conclusion from these changes in I-V with CdS thickness is that roll-over in the forward current quadrant of CdTe cells can arise from junction properties (i.e., CdS thickness) as well as the more commonly discussed dependence on backcontact properties. 

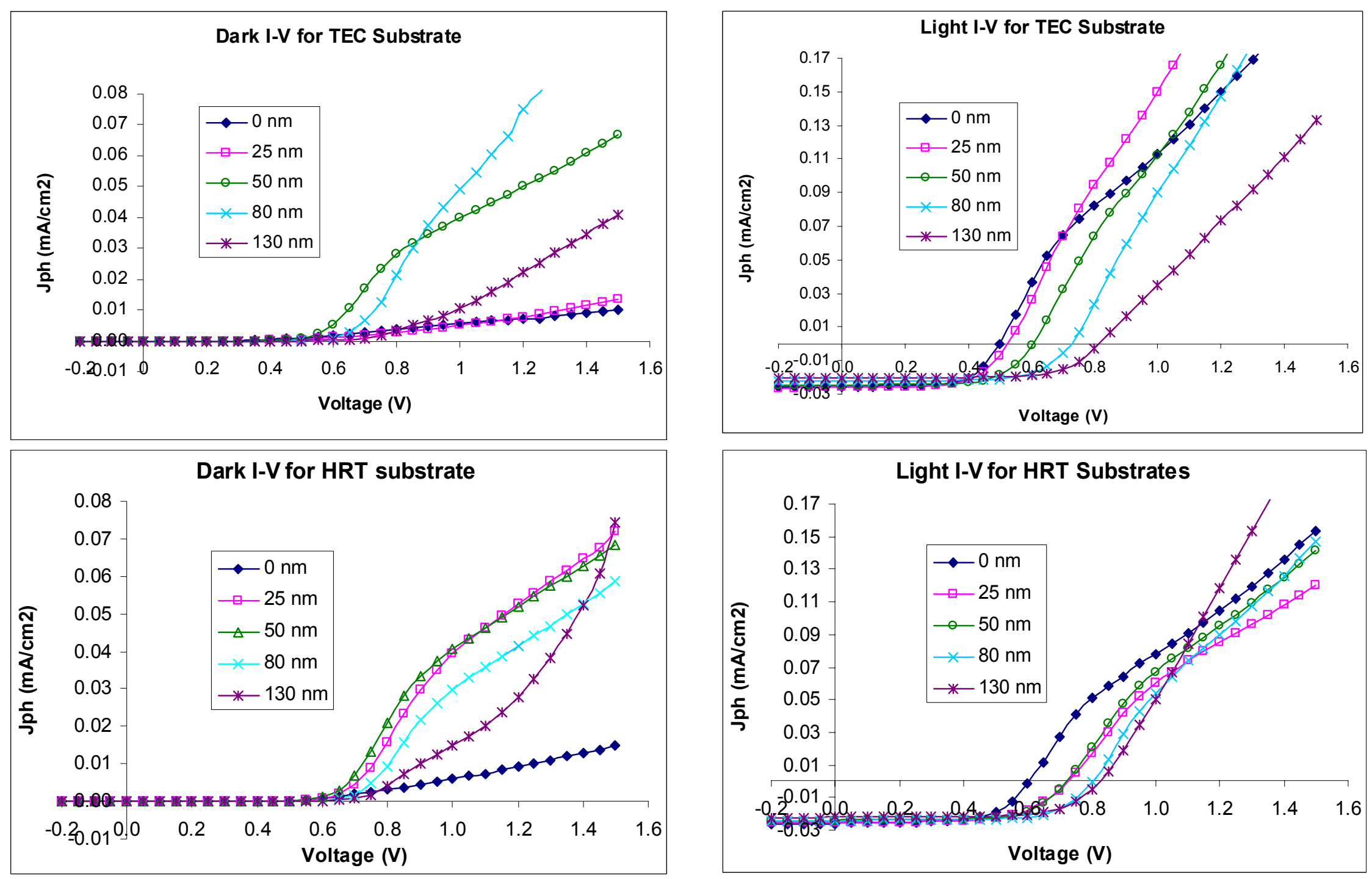

Fig. 3-39. Dark and light I-V curves for cells with different thicknesses of CdS on Tec-8 and Tec-8/HRT substrates. 

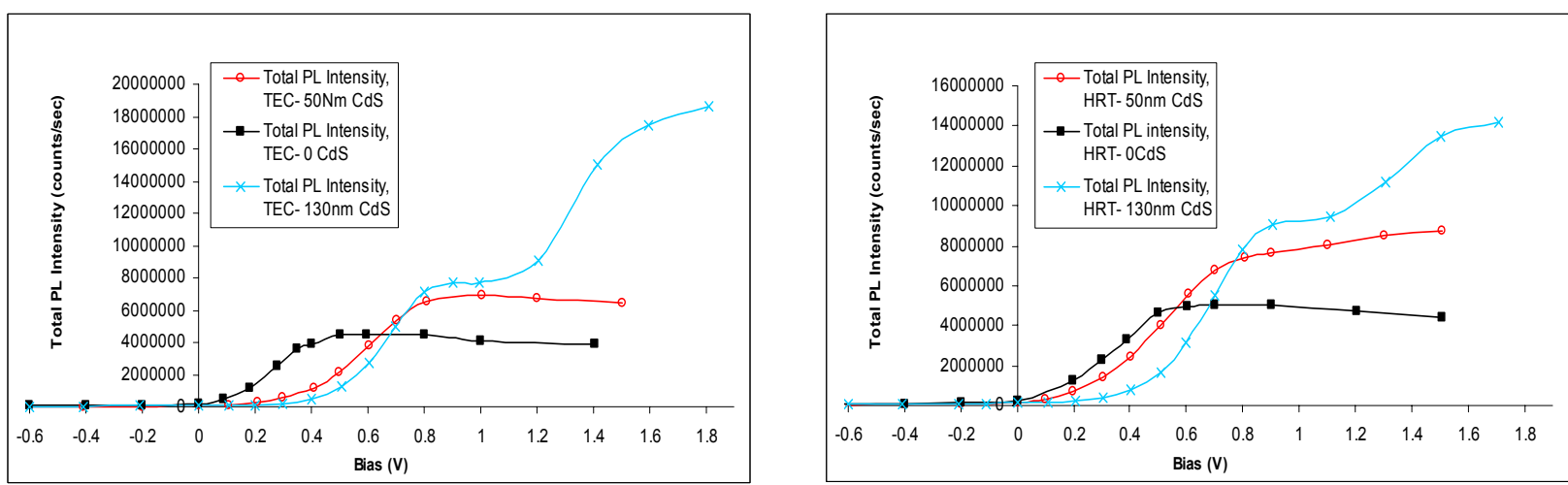

Fig. 3-40. Bias-dependent photoluminescence from sputtered cells on TEC-8 (left panel) and TEC-8/HRT substrates (right panel) for three CdS thicknesses.

Bias $P L$--Although there are some quantitative differences in the bias-PL response between the cells on the two types of substrates, the basic features are not strongly dependent on the substrate buffer layer. However, there are dramatic differences in the behavior as a function of the thickness of the CdS. The bias PL is controlled by the strength of the electric field at the junction. Thus these data indicate that the cells with no CdS have a small built-in field so that an external bias of $400 \mathrm{mV}$ brings the bias PL to saturation. This is consistent with the small $\mathrm{V}_{\mathrm{OC}}$ measured in these cells. (See Tables 3-6, 7.) $50 \mathrm{~nm}$ or more of CdS raises this saturation point to $\geq 700 \mathrm{mV}$. The data also show, however, that the PL intensity above the saturation voltage rises as the amount of CdS increases. This higher intensity of bias PL (above $\sim 0.8 \mathrm{~V}$ ) with thicker $\mathrm{CdS}$ is not fully understood. It may indicate improved carrier lifetime in the CdTe region near the junction when thicker CdS is used. Finally, for $130 \mathrm{~nm}$ of CdS there is a strong increase in bias PL above $1.2 \mathrm{~V}$, which is not seen with thinner CdS. This may be due to field-induced carrier injection (electroluminescence). Further studies are in progress, in our continuing project, including the behavior of the bias PL with stress and its dependence on CdS thickness.

Comparative stress studies--In addition to the set of comparison cells described above, we prepared an earlier set of cells with $0,50,80$, and $130 \mathrm{~nm}$ of CdS on both Tec- 8 and Tec15/HRT. (The performance of our standard cells on Tec- 8 and Tec-15 is equivalent.) The performance of these cells was tracked over time during storage at room temperature and during light soak under one-sun illumination at $60-65{ }^{\circ} \mathrm{C}$. The yield of good initial cells was not as high as for the second set described above. (The yield on the second set had been improved with more aggressive cleaning of the substrates before starting the sputter deposition.) Nevertheless, several interesting results can be found from comparisons between substrate types and the functional dependence of stability on the CdS thickness. The cells were measured 1) the same day after the $150{ }^{\circ} \mathrm{C}$ diffusion of the $\mathrm{Cu} / \mathrm{Au}$ contacts. Then they were measured 2) after 7 days of storage at room temperature, 3) after $4 \mathrm{hrs}$ of light soak at $\mathrm{V}_{\mathrm{OC}}$, 4) $71 \mathrm{hrs}$ of light soak, 5) 18 days, total, of light soak, and finally 6) after storage for 57 days at room temperature.

All cells with no CdS on Tec-8 substrates were found to be shorted at the initial measurement. This could plausibly be interpreted as resulting from micro-nonuniformities and the absence of any high resistivity layer, whether HRT or CdS. The plate with no CdS, only HRT yielded only two good cells, and these two cells, remarkably, deteriorated much more 
Table 3-8. I-V parameters on stressed cells with different CdS layers.

CdS: $0 \mathrm{~nm} \quad$ TEC Sample: $917 \mathrm{~A}$ (all cells shorted)

CdS: $\mathbf{0} \mathbf{n m}$

HRT Sample: H917A (only 2 cells good, averaged)

\begin{tabular}{|c|c|c|c|c|c|c|}
\hline Time & Voc & Jsc & FF & Eff. & Roc & Rsh \\
\hline 0 & 436 & 23.12 & 60.2 & 6.03 & 7.8 & 93 \\
\hline 7d @ RT, dark & 340 & 21.83 & 41.07 & 3.15 & 9.6 & 35 \\
\hline +4 hr LS, OC & 619 & 25 & 52.2 & 8.14 & 7.28 & 190 \\
\hline +67 hr LS, OC & 644 & 24.12 & 50.19 & 7.83 & 7.13 & 158 \\
\hline +15 d LS, OC* & $645^{*}$ & $23.13^{*}$ & $46.31^{*}$ & $6.91^{*}$ & $8.16^{*}$ & $123^{*}$ \\
\hline +57d RT, dark* & $413^{*}$ & $20.76^{*}$ & $34.89^{*}$ & $2.99^{*}$ & $9.22^{*}$ & $38^{*}$ \\
\hline
\end{tabular}

\begin{tabular}{|} 
CdS: $\mathbf{5 0} \mathbf{~ n m ~}$ \\
\begin{tabular}{|c|c|c|c|c|c|c|}
\hline Time & Voc & Jsc & FF & Eff. & Roc & Rsh \\
\hline 0 & 639 & 24.75 & 65.49 & 10.37 & 5.74 & 441 \\
\hline 7d @ RT, dark & 569 & 24.52 & 62.8 & 8.78 & 5.68 & 347 \\
\hline +4 hr LS, OC & 659 & 24.25 & 60.55 & 9.68 & 5.06 & 498 \\
\hline +67 hr LS, OC & 617 & 22.86 & 54.16 & 7.83 & 6.28 & 232 \\
\hline +15 d LS, OC & 481 & 18.69 & 45.64 & 4.13 & 6.8 & 75 \\
\hline +57d RT, dark & 503 & 19.52 & 44.68 & 4.39 & 7.17 & 85 \\
\hline
\end{tabular}
\end{tabular}

CdS: $\mathbf{5 0} \mathrm{nm}$

HRT Sample: H915A (average of 9 cells)

\begin{tabular}{|l|c|c|c|c|c|c|}
\hline \multicolumn{1}{|c|}{ Time } & Voc & Jsc & FF & Eff. & Roc & Rsh \\
\hline 0 & 746 & 23.82 & 65.77 & 11.68 & 6.77 & 615 \\
\hline 7d @ RT, dark & 706 & 24.08 & 62.43 & 10.62 & 6.77 & 465 \\
\hline +4 hr LS, OC & 723 & 23.33 & 62.89 & 10.64 & 5.97 & 1054 \\
\hline +67 hr LS, OC & 589 & 21.25 & 51.29 & 6.43 & 6.62 & 134 \\
\hline +15 d LS, OC & 570 & 19.83 & 50.7 & 5.74 & 6.55 & 129 \\
\hline +57d RT, dark & 557 & 20.12 & 47.84 & 5.37 & 6.43 & 116 \\
\hline
\end{tabular}

CdS: $130 \mathrm{~nm}$

TEC Sample: $918 \mathrm{~A}$ (average of 2 cells)

\begin{tabular}{|c|r|r|r|r|r|r|}
\hline Time & Voc & Jsc & FF & Eff. & Roc & Rsh \\
\hline 0 & 813 & 20.77 & 71.09 & 12 & 6.15 & 1270 \\
\hline 7d @ RT, dark & 805 & 20.9 & 69.92 & 11.77 & 5.61 & 967 \\
\hline +4 hr LS, OC & 783 & 19.85 & 69.89 & 10.85 & 5.5 & 1437 \\
\hline +67 hr LS, OC & 740 & 19.53 & 66.52 & 9.59 & 6.08 & 871 \\
\hline +15 d LS, OC & 638 & 19.98 & 59.28 & 7.56 & 5.5 & 287 \\
\hline +57d RT, dark & 655 & 19.28 & 58.65 & 7.4 & 4.77 & 396 \\
\hline
\end{tabular}

CdS: $130 \mathrm{~nm}$

HRT Sample: H918A (average of 5 cells)

\begin{tabular}{|c|r|r|r|r|r|r|}
\hline Time & Voc & Jsc & FF & Eff. & Roc & Rsh \\
\hline 0 & 811 & 21.86 & 70.87 & 12.56 & 5.76 & 1512 \\
\hline 7d @ RT, dark & 801 & 22.09 & 69.33 & 12.26 & 5.39 & 1296 \\
\hline +4 hr LS, OC & 787 & 20.25 & 69.06 & 10.98 & 5.94 & 1252 \\
\hline +67 hr LS, OC & 768 & 20.54 & 65.27 & 10.27 & 6.24 & 815 \\
\hline +15 d LS, OC & 682 & 21.26 & 60.18 & 8.74 & 6.06 & 457 \\
\hline +57d RT, dark & 670 & 20.84 & 57.23 & 8 & 5.52 & 309 \\
\hline
\end{tabular}


strongly during room temperature storage than during light soak. Actually one of these two initially functional cells died during the 15 day light soak so that the last two rows of the first panel (indicated by *) show data for only one cell. [For the surviving cell, the six measurements of efficiency were 5.44, 4.32, 9.46, 8.77, 6.91, 2.99\% with most of the drop for the second and sixth data points due to a drop in fill factor during the dark, room temperature storage.] These cells without $\mathrm{CdS}$ appear to benefit from light soaking and, correspondingly, decay considerably in the dark even at room temperature. We suggest this is probably related to some response of the HRT to light soaking and perhaps a reduction in its dark resistivity. However, this is difficult to check until we have access to a more consistent source of the HRT material.

In the set of cells with $50 \mathrm{~nm}$ of CdS ("thin CdS" cells) the effect of the HRT is to increase the voltage by about $100 \mathrm{mV}$ and maintain that difference through most of the light soaking. The HRT used with thin CdS causes a minor loss of current ( $\sim 0.5 \mathrm{~mA})$, some increase in resistance at open circuit and very significant increase in shunt resistance as expected. In general, the devices with thin CdS degraded much faster than those with thick CdS (see next paragraph) in all parameters, but especially in $\mathrm{J}_{\mathrm{sc}}$ and $\mathrm{FF}$.

With our standard thickness of CdS $(130 \mathrm{~nm})$, the use of the HRT layer has little effect on the initial $\mathrm{V}_{\mathrm{OC}}$ but does appear to reduce the loss of $\mathrm{V}_{\mathrm{OC}}$ during long light soak. In this case the data appear to show increased currents (by about $1 \mathrm{~mA}$ ) but this may be an artifact of this particular set of samples. The efficiencies of the thick CdS devices do not change very much on storage at room temperature, and hence also are not improved during initial hours of stressing but rather decrease. The devices with HRT layers showed less degradation in comparison to their counterparts on TEC-7. This effect is more pronounced with thin CdS due to slower degradation in $\mathrm{J}_{\mathrm{sc}}$ and FF. But overall, the devices made on HRT with thick CdS are the most stable and efficient.

In this study, as in previous studies by us and others, the use of an appropriate HRT layer between the $\mathrm{SnO}_{2}: \mathrm{F}$ and the sputtered $\mathrm{CdS}$ allows the use of thinner $\mathrm{CdS}$ while maintaining better $\mathrm{V}_{\mathrm{OC}}$ and fill factors. In addition, there is a very substantial increase in the yield both initially, for very thin or no CdS and over long-term light soak stress. However, there is a strong indication in these data that the characteristics of this particular HRT may be changing during light soak perhaps because of light-induced metastable states that increase the conductivity.

Further studies of these HRT layers and thin CdS layers will continue under our new Thin Film Partnership Program award. 


\subsection{Effects of sodium on PL from CdTe}

Two recent studies have used photoluminescence to monitor the CdTe film properties in distinctly different ways. In the first study, a summer 2001 undergraduate student, Kathleen Hinko, who was participating in the NSF-sponsored Research Experiences for Undergraduates program, used PL to study CdTe films deposited on soda-lime glass (SLG) and on borosilicate glass (BSG) from three different sputter source targets. She found interesting differences among the films from different targets and also a dependence on substrate material. In the second study, graduate student Xiangxin Liu used the departmental accelerator to implant $\mathrm{Ar}, \mathrm{Cu}$, and $\mathrm{Te}$ into single crystal CdTe. He was able to use PL to monitor the progress of successive anneals in removing the ion-implantation-induced damage and then identify particular features in the PL spectra.

Effects of sodium diffusion--For her summer study, Katie Hinko worked with Akhlesh Gupta and with technician Matt Fritts to sputter deposit several films of CdTe from three different targets. Two were commercial targets from Cerac and from Plasmaterials and one was prepared by Akhlesh from a cold-pressed powder followed by sintering at $300{ }^{\circ} \mathrm{C}$. Katie then performed $\mathrm{CdCl}_{2}$ treatments on parts of the films. One treatment was done in our standard vapor $\mathrm{CdCl}_{2}$ system using dry air ambient and another piece was treated equivalently except that pure $\mathrm{N}_{2}$ ambient was used. (For the $\mathrm{N}_{2}$ ambient, a nitrogen flow of $90 \mathrm{sccm}$ was used and the films were placed face down $1 \mathrm{~mm}$ above a glass plate coated with $\mathrm{CdCl}_{2}$.)

For the untreated films, weak PL was observed from the films prepared from Plasmaterials and homemade targets on both types of substrates. No PL was observed from the film sputtered from the Cerac target. After vapor $\mathrm{CdCl}_{2}$ treatment in $\mathrm{N}_{2}$, little change in PL was observed from any of the films. However, the standard treatment in dry air yielded large increases in the PL signals. Figs. 3-41 and 3-42 show the PL signals of treated films from the three different targets. Fig. 3-41 is for films deposited on borosilicate glass and Fig. 3-42 for films on soda-lime glass. Note that the PL is much stronger, for all target cases, for the films on SLG.

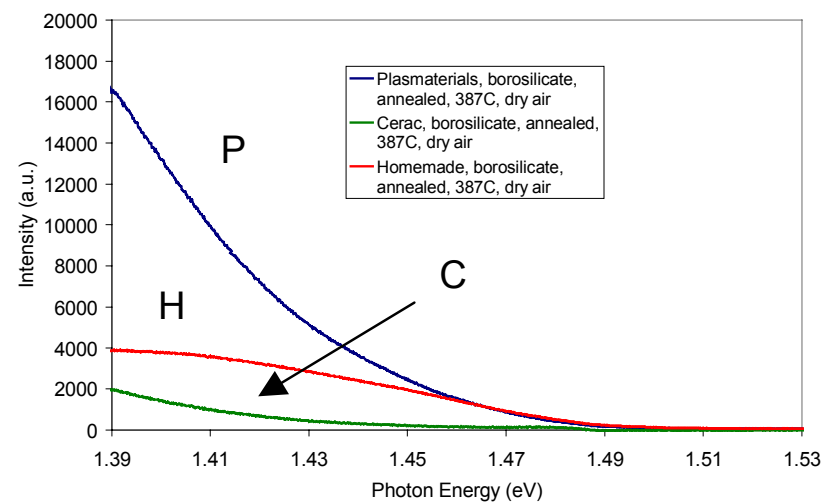

Fig. 3-41 PL from films on borosilicate glass substrates, sputtered from Plasmaterials $(P)$, Cerac $(C)$, and homemade $(\mathrm{H})$ targets.

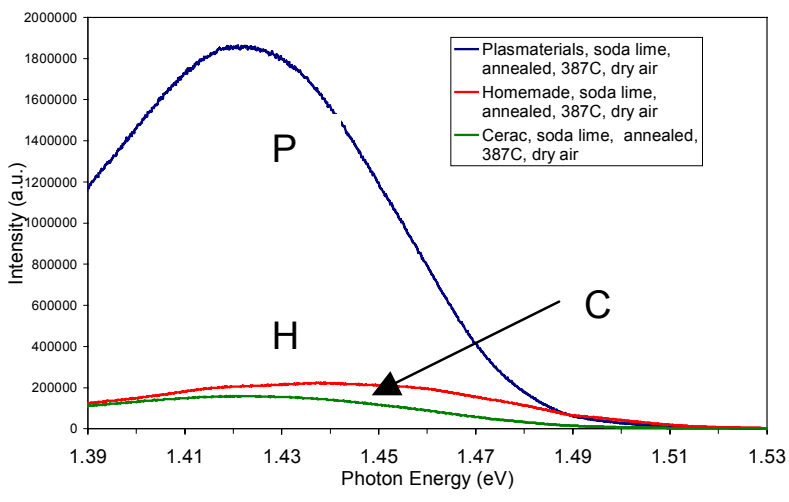

Fig. 3-42. PL from films on soda-lime glass substrates, sputtered from Plasmaterials $(\mathrm{P})$, Cerac $(\mathrm{C})$, and homemade $(\mathrm{H})$ targets.

We believe that this difference may be due to the diffusion of $\mathrm{Na}$ into the film from the SLG substrate. In order to check for the influence of sodium, Katie then modified several films 
on BSG by evaporating a methanol solution of $\mathrm{NaCl}$ on the surface and diffusing in air at $387{ }^{\circ} \mathrm{C}$ for 45 minutes. The resulting spectra are shown in Fig. 3-43. Note that the PL intensity of the $\mathrm{CdCl}_{2}$-treated CdTe film on BSG exhibits a strong increase after the $\mathrm{NaCl}$ diffusion at $387{ }^{\circ} \mathrm{C}$. (The CdTe film on SLG showed little further increase.) Although elemental analysis of $\mathrm{Na}$ content in the films has not yet been done, these data suggest that $\mathrm{Na}$ can play a significant role in activating photoluminescence in CdTe films. In preliminary tests, we found little change in the electrical conductivity of these films but this is being more thoroughly examined. We are presently testing whether small quantities of $\mathrm{Na}$ may play a role in solar-cell performance.

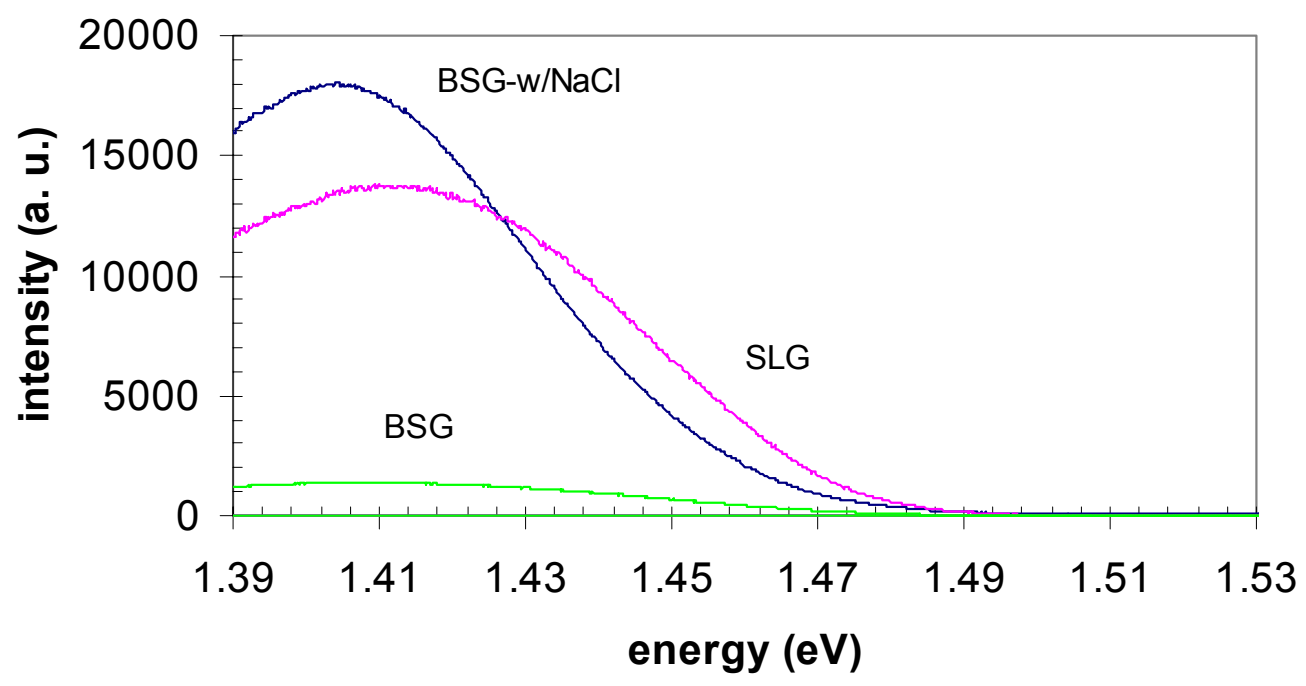

Fig. 3-43. PL spectra of CdTe films on borosilicate or soda-lime glass after vapor $\mathrm{CdCl}_{2}$ treatment (BSG and SLG) and the BSG after a subsequent diffusion from an $\mathrm{NaCl}$ film.

We tentatively interpret these effects as indicating that $\mathrm{Na}$, whether diffused from the $\mathrm{SLG}$ or from the $\mathrm{NaCl}$ at the surface, introduces large numbers of shallow donors in the $\mathrm{CdTe}$ which can pair with deeper acceptors such as $\mathrm{Cu}$ to yield donor-acceptor pair luminescence. Although the acceptor density is unlikely to have increased, the presence of the Na could increase the DAP radiative probability. Although interstitial $\mathrm{Na}$ is expected to be a donor in $\mathrm{CdTe}$, it is possible that this enhancement of PL signals in the films may be related to a secondary influence of the sodium, such as through enhanced annealing effects. Further studies are in progress under the continuing Thin Film Partnership Program support. 


\subsection{Preliminary results on PL from ion-implanted CdTe}

It is well known that ion implantation of impurities into semiconductors is an excellent method for controlled introduction of dopants into shallow surface layers. Holloway, et al, [57] have reported PL studies of implanted CdTe and have identified PL features from a variety of species. They did not use any post-implantation anneal to remove damage from the ion beam which is known to be present for room-temperature implantations. Graduate student Xiangxin Liu together with Matt Fritts prepared several samples of single-crystal CdTe implanted with Ar as well as with $\mathrm{Cu}$ and $\mathrm{Te}$ at a variety of doses. Fig. 3-44 shows how the PL spectrum of crystalline CdTe is killed as the implanted dose of Te increases from $1.3 \times 10^{11}$ to $1.3 \times 10^{12}$ to $1.3 \times 10^{13}$ ions $/ \mathrm{cm}^{2}$. Note that the $488 \mathrm{~nm}$ line of the argon laser was used to approximately match the light penetration depth to the ion projected range, $\sim 0.23 \mu \mathrm{m}$. Note that if the implanted ions are averaged over a depth equal to the projected range plus the range straggling $(0.23+0.09 \mu \mathrm{m})$ the above fluences yield ion densities of $4.1 \times 10^{15} \mathrm{~cm}^{-3}, 4.1 \times 10^{16} \mathrm{~cm}^{-3}, 4.1 \mathrm{x}$ $10^{17} \mathrm{~cm}^{-3}$. The lightest implant shows the beginning of two peaks at 1.538 and $\sim 1.51 \mathrm{eV}$, however, as the dose is increased further, the implantation-induced damage greatly attenuates the PL signal. This is due to decreased carrier lifetime in the implanted region. Annealing is required to remove this damage.

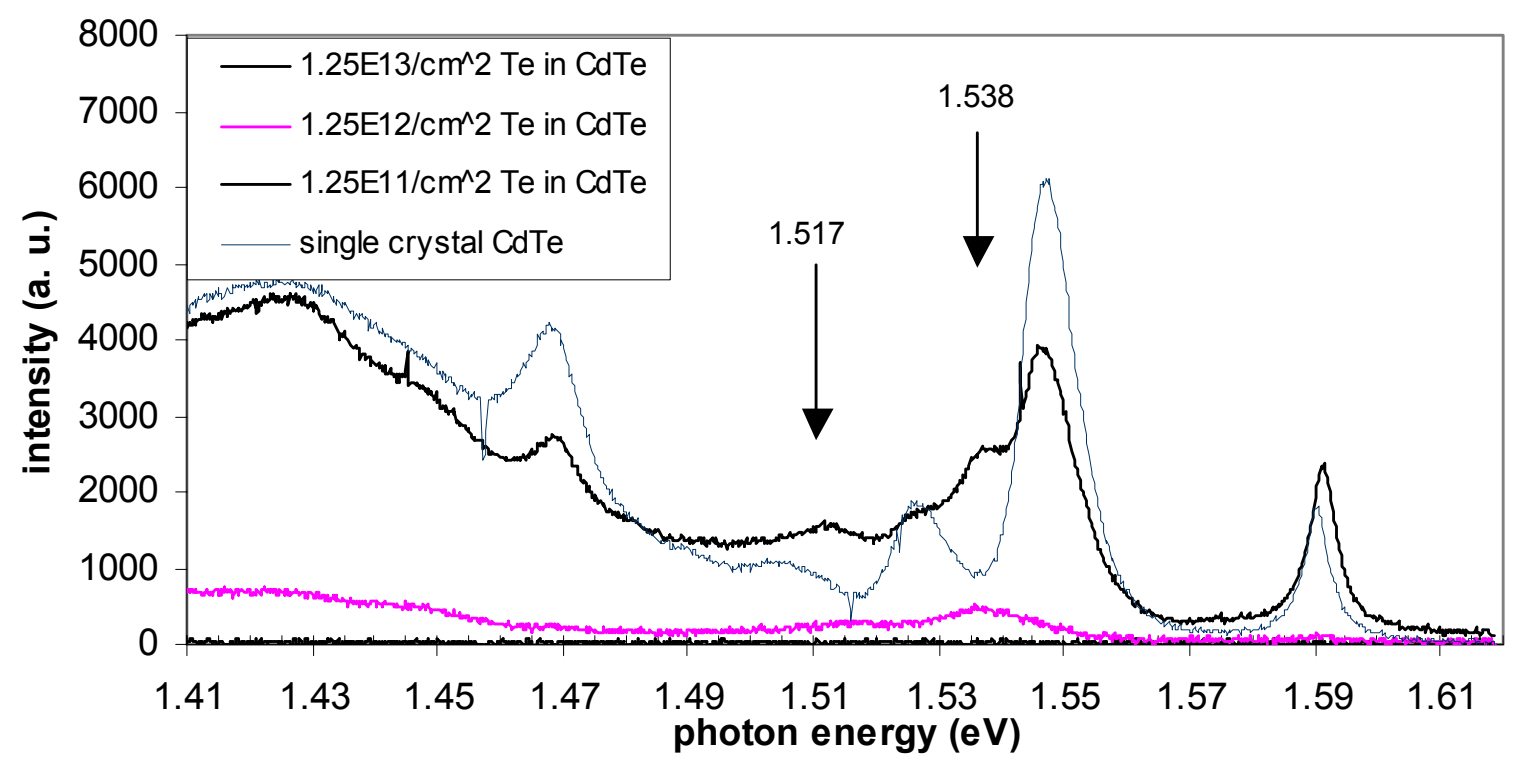

Fig. 3-44. PL obtained with $0.8 \mathrm{~mW}$ at $488 \mathrm{~nm}$ from unimplanted, crystalline $\mathrm{CdTe}$ and from regions implanted with $880 \mathrm{keV} \mathrm{Te} e^{4+}$ to the doses indicated.

For the annealing, the small, single-crystal samples were placed face down on a sputtered film of CdTe to serve as a proximity cap. The PL was then obtained after successive 30-minute anneals in $\mathrm{N}_{2}$ at $350,375,400$ and $425^{\circ} \mathrm{C}$. The results of these anneals for the sample implanted with $1.3 \times 10^{13} / \mathrm{cm}^{3} \mathrm{Te}$ are shown in Fig. 3-45. The lowest trace shows the absence of any PL signal for the as-implanted sample. Other traces show the recovery of the PL after annealing at $350{ }^{\circ} \mathrm{C}$ (“aimp"), $375^{\circ} \mathrm{C}$ ("aaimp"), and $400{ }^{\circ} \mathrm{C}$ (“1E18...").

The results discussed above indicate that ion implantation can be used to introduce controlled densities and depth distributions of impurities into CdS, and that the implantationinduced damage can successfully be annealed out through moderate temperature anneals in $\mathrm{N}_{2}$ 
with the use of a proximity cap to avoid surface deterioration. These studies of defect chemistry will continue under the continuing Thin Film Partnership Program contract.

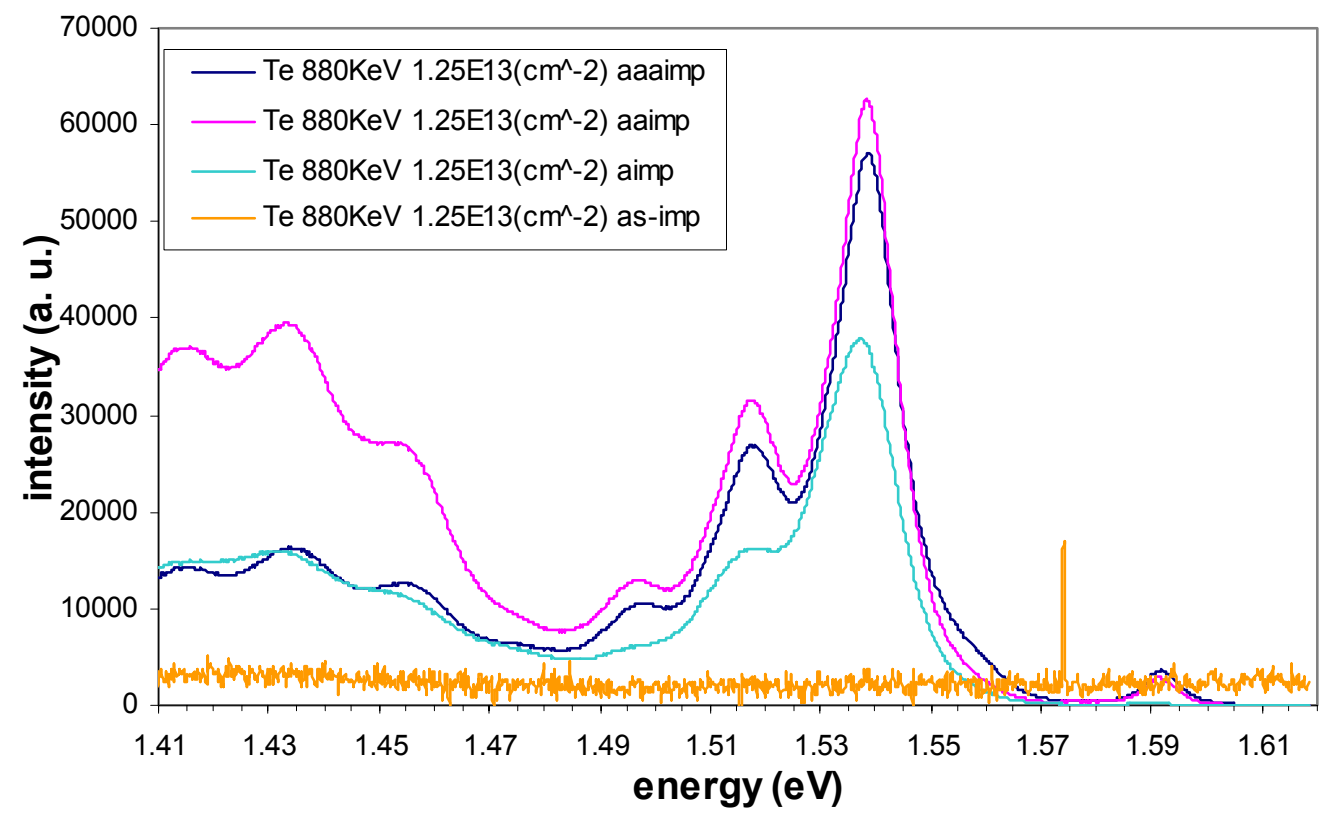

Fig. 3-45. $\quad \mathrm{PL}$ obtained with $1.2 \mathrm{~mW}$ at $488 \mathrm{~nm}$ from crystalline CdTe and from regions implanted with $880 \mathrm{keV} \mathrm{Te} e^{4+}$ to $10^{13}$ ions $/ \mathrm{cm}^{2}$ and annealed successively at 350 and $400{ }^{\circ} \mathrm{C}$. For visibility, data have been multiplied by 50 for the lowest trace. 


\subsection{Studies of sputtered $\mathrm{Ni}_{\mathbf{x}} \mathrm{P}$ as a $\mathrm{Cu}$ free back contact for $\mathrm{CdTe}$ cells}

We have investigated the use of magnetron sputtered $\mathrm{Ni}_{2} \mathrm{P}$ as a $\mathrm{Cu}$-free back contact to $\mathrm{CdS} / \mathrm{CdTe}$ cells. In this study Brian Sunderland (who was an NSF Research Experiences for Undergraduates student at UT during the summer of 2001) and Akhlesh Gupta deposited $\mathrm{Ni}_{\mathrm{x}} \mathrm{P}$ on cell structures from First Solar, LLC, by pulsed dc magnetron sputtering. Depositions were done at room temperature and with substrate heating at temperatures up to $275^{\circ} \mathrm{C}$. A variety of surface preparations were used as well as post-deposition heat treatments. Brian and Akhlesh also made extensive stress measurements on these contacts. Details are summarized below.

NiP film properties - EDS measurements of the sputtered films on glass revealed that the average film stoichiometry was $\mathrm{Ni}_{\mathrm{x}} \mathrm{P}$ with $\mathrm{x} \cong 2.5$. Electrical measurements gave typical resistivities of $\sim 10^{-3} \Omega / \square$.

Contact preparation-These studies were done on VTD CdTe from First Solar. For reference, we contacted some cells with our standard evaporated $\mathrm{Cu} / \mathrm{Au}$ contacts and typically obtained best cell parameters of: $\mathrm{V}_{\mathrm{OC}}=812 \mathrm{mV} ; \mathrm{J}_{\mathrm{SC}}=20.59 \mathrm{~mA} / \mathrm{cm}^{2} ; \mathrm{FF}=72.06 \%$; and $\eta=$ $12.05 \%$. Generally a mild etch with $0.05 \% \mathrm{Br}$ :methanol was used to prepare the CdTe surface for the $\mathrm{Cu} / \mathrm{Au}$ evaporation and a $200{ }^{\circ} \mathrm{C}$ diffusion for 45 minutes was used after deposition. For the NiP deposition, the samples were loaded into the diffusion-pumped sputter chamber where the NiP was sputtered in Ar from a 2-inch magnetron by pulsed de sputtering at $100 \mathrm{~W}$ of power, to a thickness of $0.4 \mu \mathrm{m}$. For some depositions the plates were radiantly heated as high as 275 ${ }^{\circ} \mathrm{C}$. A mask defined contacts of area $0.18 \mathrm{~cm}^{2}$.

Etching: We found a surface etch pretreatment before deposition of $\mathrm{Ni}_{\mathrm{x}} \mathrm{P}$ to be essential for good initial device performance. We studied both bromine-methanol $\left(\mathrm{Br}_{2} / \mathrm{MeOH}\right)$ and nitricphosphoric (NP) acid solutions and found that the NP etch was better (Table 3-9). This could be due to the NP etch giving a thicker layer of interfacial Te which seems to yield better back contact formation.

Table 3-9. Performance of NiP-contacted cells vs. etch and vs. deposition temperature

\begin{tabular}{|c|c|c|c|c|c|c|c|c|}
\hline Etch solutio & $\begin{array}{l}\text { NiP dep } \\
\text { temp }\end{array}$ & Diffusion & $\begin{array}{l}\text { Voc } \\
(\mathrm{mV})\end{array}$ & $\begin{array}{l}\text { Jsc } \\
(\mathrm{mA})\end{array}$ & FF & $\begin{array}{l}\text { Eff. } \\
(\%)\end{array}$ & $\begin{array}{l}\text { Roc } \\
(\Omega)\end{array}$ & $\begin{array}{l}\text { Rsh } \\
(\Omega)\end{array}$ \\
\hline $\mathrm{Br} 2 / \mathrm{MeOH}$ & room temp & as dep & 613 & 20.03 & 53.11 & 6.52 & 12.13 & 381 \\
\hline \multirow{2}{*}{ NP etch } & \multirow{2}{*}{ room temp } & as dep & 633 & 20.12 & 56.12 & 7.15 & 8.81 & 379 \\
\hline & & $250 \mathrm{C}$ & 732 & 20.45 & 60.8 & 9.1 & 12.25 & 684 \\
\hline \multirow{2}{*}{ etch } & \multirow{2}{*}{$\begin{array}{c}(\mathrm{C} / \mathrm{NiP}) \\
\text { room temp }\end{array}$} & as dep & 685 & 20.68 & 54.01 & 7.65 & 11.36 & 451 \\
\hline & & $250 C$ & 704 & 21.09 & 58.19 & 8.64 & 11.54 & 703 \\
\hline \multirow{2}{*}{ NP etch } & \multirow{2}{*}{$200 C$} & as dep & 724 & 17.28 & 35.23 & 4.41 & 70.6 & 127 \\
\hline & & $250 C$ & 719 & 17.74 & 37.52 & 4.79 & 60.26 & 162 \\
\hline \multirow{2}{*}{ NP etch } & \multirow{2}{*}{$250 \mathrm{C}$} & as dep & 732 & 19.11 & 57.65 & 8.06 & 18.71 & 617 \\
\hline & & $250 \mathrm{C}$ & 741 & 19.02 & 57.49 & 8.1 & 19.6 & 548 \\
\hline NP etch & $275 C$ & as dep & 682 & 18.28 & 51.55 & 6.43 & 22.86 & 400 \\
\hline
\end{tabular}

Substrate Temperature: We deposited $\mathrm{Ni}_{\mathrm{x}} \mathrm{P}$ at substrate temperatures of room temperature, $200^{\circ} \mathrm{C}, 250^{\circ} \mathrm{C}$ and $275^{\circ} \mathrm{C}$, and studied its effect on the initial device performance and stability under stress. (See Table 3-9.) Of the elevated temperature depositions, the initial performance of devices with $\mathrm{Ni}_{\mathrm{x}} \mathrm{P}$ deposited at $250^{\circ} \mathrm{C}$ was best but still lower than that of the room-temperature-deposited and subsequently diffused $\mathrm{Ni}_{x} \mathrm{P}$. In addition we found that the 
further diffusion of high-temperature-deposited $\mathrm{Ni}_{\mathrm{x}} \mathrm{P}$ did not improve the performance, and in many samples decreased the performance. It is unusual that the cell performance for $\mathrm{Ni}_{\mathrm{x}} \mathrm{P}$ deposited at $200^{\circ} \mathrm{C}$ is poorer than either that of $\mathrm{Ni}_{\mathrm{x}} \mathrm{P}$ deposited at room temperature or at $250^{\circ} \mathrm{C}$. At this point we hesitate to draw any conclusions about this since a variety of process steps might have influenced the Te-rich interface after etching such as the duration of the pre-heat cycle prior to starting $\mathrm{Ni}_{\mathrm{x}} \mathrm{P}$ sputtering.
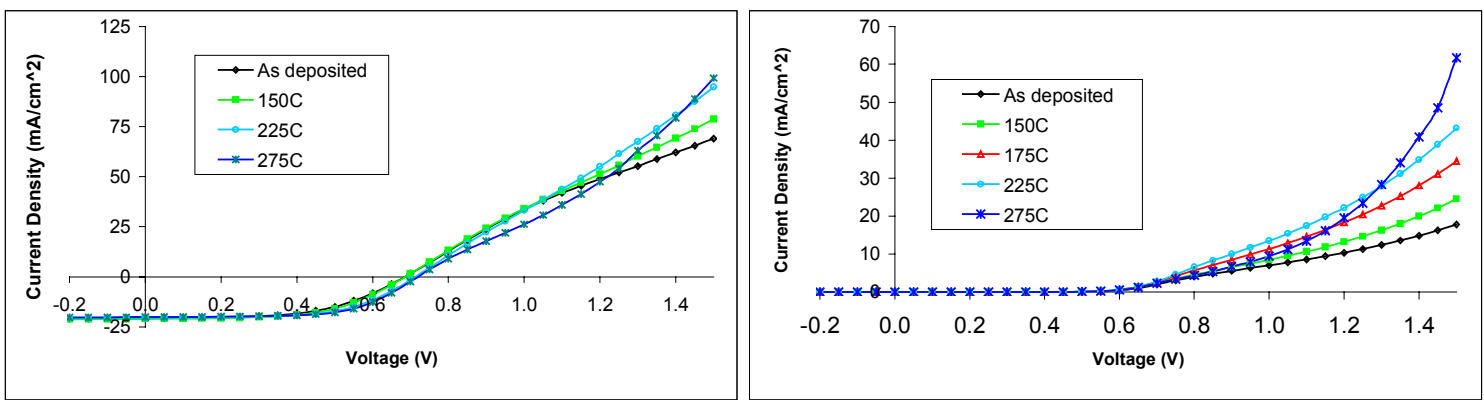

Fig. 3-46. I-V curves of NiP-contacted cells. Left: one-sun I-V; right: dark I-V. Temperatures are for the 30 minute post-deposition anneal.

Post-deposition diffusion treatment: The initial cell efficiency of devices with asdeposited back contacts was limited to about $7.5 \%$ due to low Voc and FF. The devices also show some roll-over around $\mathrm{V}_{\mathrm{oc}}$ and poor diode turn-on behavior. We studied post-deposition annealing to try to induce some diffusion of $\mathrm{P}$ into CdTe to improve the device performance. These annealings were carried out in air and $\mathrm{N}_{2}$ atmosphere in the temperature range of $175^{\circ} \mathrm{C}$ $300^{\circ} \mathrm{C}$. The $\mathrm{N}_{2}$ environment and temperature of $250-275^{\circ} \mathrm{C}$ was found best for annealing which increased the efficiency by $15-20 \%$ due to increased Voc and FF. Table 3-10 shows detailed device parameters for one such annealing study on an NP etched VTD CdTe surface with $\sim 50$ $\mathrm{nm}$ of sputtered carbon and room-temperature-deposited NiP (sample 7FS6B). (The postdeposition diffusion results for cells without the carbon layer were similar. Fig. 3-46 shows the full light and dark I-V characteristics. The I-V traces show evidence of roll-over in the forward quadrant suggesting problems with the interface between the CdTe and NiP. The post-deposition heat treatment improves the I-V characteristics but only slightly.

Table 3-10. Effect of post-deposition diffusion on NP etched/graphite/NiP contact.

\begin{tabular}{|c|c|c|c|c|c|c|}
\hline temp $(\mathrm{C})$ & $\begin{array}{c}\text { Voc } \\
(\mathrm{mV})\end{array}$ & $\begin{array}{c}\text { Jsc } \\
(\mathrm{mA})\end{array}$ & $\mathrm{FF}$ & $\begin{array}{c}\text { Eff. } \\
(\%)\end{array}$ & $\begin{array}{c}\text { Roc } \\
(\Omega)\end{array}$ & $\begin{array}{c}\text { Rsh } \\
(\Omega)\end{array}$ \\
\hline Initial & 685 & 20.68 & 54.01 & 7.65 & 11.36 & 451 \\
\hline 150C & 685 & 21 & 55.97 & 8.06 & 10.94 & 521 \\
\hline 175C & 693 & 21.42 & 56.8 & 8.42 & 10.61 & 557 \\
\hline 200C & 694 & 21.64 & 57.2 & 8.59 & 10.66 & 601 \\
\hline 225C & 712 & 20.47 & 59.16 & 8.63 & 10.15 & 779 \\
\hline 250C & 704 & 21.09 & 58.19 & 8.64 & 11.54 & 703 \\
\hline 275C & 720 & 20.09 & 61.41 & 8.88 & 11.24 & 956 \\
\hline 300C & 694 & 18.6 & 54.45 & 7.01 & 14.41 & 260 \\
\hline
\end{tabular}

Sputtered carbon as an interfacial layer and stress measurements-During the stress stability study, with its repeated measurements, a large fraction of the $\mathrm{Ni}_{\mathrm{x}} \mathrm{P}$ contacted cells 
shorted. Therefore, some cells were prepared with an interfacial layer of about $50 \mathrm{~nm}$ of dc sputtered carbon before the NiP deposition. This carbon deposition was done with a separate 2inch magnetron in the same sputter chamber as the NiP. The initial results indicate little difference with or without the carbon layer, but the stress measurements suggest that there may be some improvement in stability with the carbon. The contacts without carbon are averaged over three cells whereas the contacts with the carbon interfacial layer are averaged over six. (Fewer of the NiP contacts survived as compared with the $\mathrm{C} / \mathrm{NiP}$ for which almost all survived.) Cells were stressed at $60-65^{\circ} \mathrm{C}$, one-sun illumination and open-circuit condition for several months. The initial I-V parameters and the changes with light-soak stress are given in Tables 311 and 3-12, respectively, for NiP contacts without and with an interfacial layer of carbon. Both types of contacts show a degradation of about $10 \%$ in efficiency after a continuous exposure for $231 \& 285$ days which would translate into $693 \& 855$ normal day \& night outdoor exposure for $\mathrm{Ni}_{\mathrm{X}} \mathrm{P}$ and $\mathrm{C} / \mathrm{Ni}_{\mathrm{X}} \mathrm{P}$ back contacts respectively. Moreover, generally the devices have the tendency to recover if kept in dark after stress degradation, which could slow even further the degradation in actual day $\&$ night exposure. High-temperature-deposited $\mathrm{Ni}_{x} \mathrm{P}$ degraded faster than roomtemperature-deposited $\mathrm{Ni}_{\mathrm{x}} \mathrm{P}$ irrespective of anneal temperature.

Table 3-11. Stress data for NP etched, NiP contacts (diffused at $275^{\circ} \mathrm{C}$, \#7FS4A)

Average data of 3 cells

\begin{tabular}{|c|c|c|c|c|c|c|c|c|c|c|c|c|}
\hline Stress Time & $\begin{array}{c}\mathrm{Voc} \\
(\mathrm{mV})\end{array}$ & $\begin{array}{c}\text { Jsc } \\
(\mathrm{mA})\end{array}$ & $\mathrm{FF}$ & $\begin{array}{l}\text { Eff } \\
(\%)\end{array}$ & $\begin{array}{l}\text { Roc } \\
(\Omega)\end{array}$ & $\begin{array}{l}\text { Rsh } \\
(\Omega)\end{array}$ & $\begin{array}{l}\text { Voc } \\
(\mathrm{mV})\end{array}$ & $\begin{array}{c}\text { Jsc } \\
(\mathrm{mA})\end{array}$ & $F F$ & $\begin{array}{l}\text { Eff } \\
(\%)\end{array}$ & \begin{tabular}{|l} 
Roc \\
$(\Omega)$
\end{tabular} & $\begin{array}{l}\text { Rsh } \\
(\Omega)\end{array}$ \\
\hline Initial & 631 & 19.61 & 58.47 & 7.24 & 8.35 & 637 & 628 & 19.79 & 56.96 & 7.07 & 8.68 & 572 \\
\hline ostdiffusion & 729 & 19.46 & 59.12 & 8.39 & 18.18 & 785 & 743 & 19.73 & 58.94 & 8.63 & 19.56 & 1008 \\
\hline $28 \mathrm{hrs}$ & 737 & 19.48 & 60.46 & 8.68 & 17.76 & 807 & 743 & 19.63 & 59.49 & 8.68 & 19.38 & 910 \\
\hline 17 days & 733 & 19.23 & 57.92 & 8.16 & 21.95 & 680 & 743 & 19.42 & 57.42 & 8.28 & 22.58 & 720 \\
\hline 64 days & 712 & 19.36 & 55.74 & 7.68 & 23 & 681 & 731 & 19.56 & 55.08 & 7.88 & 24.22 & 763 \\
\hline 127 days & 716 & 19.4 & 55.23 & 7.68 & 23.52 & 619 & 734 & 19.56 & 54.1 & 7.77 & 24.48 & 655 \\
\hline 231 days & 720 & 18.65 & 56.07 & 7.52 & 23.81 & 657 & 738 & 18.83 & 55.62 & 7.73 & 24.18 & 705 \\
\hline $\mathrm{ige}$ & 1.23 & -4.16 & -5.16 & 0.37 & 30.97 & 6.31 & -0.6 & 4.56 & 5.6 & 102 & 23.6 & 30. \\
\hline
\end{tabular}

Table 3-12. Stress data for NP etched, C/NiP contacts (diffused at $275^{\circ} \mathrm{C}$, \#7FS6B)

Average data of 6 cells Best stable device

\begin{tabular}{|c|c|c|c|c|c|c||c|c|c|c|c|c|}
\hline Stress time & $\left.\begin{array}{c}\text { Voc } \\
(\mathrm{mV})\end{array}\right) \begin{array}{c}\text { Jsc } \\
(\mathrm{mA})\end{array}$ & FF & $\begin{array}{c}\text { Eff } \\
(\%)\end{array}$ & $\begin{array}{c}\text { Roc } \\
(\Omega)\end{array}$ & $\begin{array}{c}\text { Rsh } \\
(\Omega)\end{array}$ & $\begin{array}{c}\text { Voc } \\
(\mathrm{mV})\end{array}$ & $\begin{array}{c}\text { Jsc } \\
(\mathrm{mA})\end{array}$ & FF & $\begin{array}{c}\text { Eff } \\
(\%)\end{array}$ & $\begin{array}{c}\text { Roc } \\
(\Omega)\end{array}$ & $\begin{array}{c}\text { Rsh } \\
(\Omega)\end{array}$ \\
\hline Initial & 686 & 20.89 & 52.12 & 7.46 & 11.91 & 398 & 689 & 20.7 & 49.81 & 7.11 & 13.12 & 336 \\
\hline postdiffusion & 708 & 18.79 & 56.6 & 7.57 & 13.17 & 585 & 737 & 19.33 & 61.09 & 8.7 & 13.39 & 985 \\
\hline 8 days & 729 & 19.69 & 57.46 & 8.25 & 11.94 & 527 & 741 & 20.19 & 60.59 & 9.06 & 11.7 & 777 \\
\hline 25 days & 722 & 19.47 & 55.91 & 7.87 & 14.11 & 484 & 736 & 20.06 & 58.2 & 8.59 & 13.99 & 646 \\
\hline 71 days & 722 & 19.4 & 53.84 & 7.55 & 17.85 & 445 & 740 & 19.97 & 55.42 & 8.2 & 18.16 & 600 \\
\hline 118 days & 697 & 19.54 & 51.56 & 7.03 & 18.33 & 374 & 717 & 19.9 & 52.31 & 7.46 & 19.76 & 489 \\
\hline 181 days & 704 & 19.36 & 52.09 & 7.11 & 17.76 & 382 & 721 & 19.96 & 52.65 & 7.57 & 18.38 & 484 \\
\hline 285 days & 700 & 18.81 & 51.95 & 6.85 & 18.82 & 380 & 718 & 19.43 & 52.68 & 7.35 & 19.44 & 477 \\
\hline \% change & -1.13 & 0.11 & -8.22 & -9.51 & 42.90 & -35.04 & -2.58 & 0.52 & -13.77 & -15.52 & 45.18 & -51.57
\end{tabular}


The light I-V curve comparison of the sputtered $\mathrm{C} / \mathrm{NiP}$ contacts immediately after fabrication, after diffusion, after 8 days of light-soak stress at $\mathrm{V}_{\mathrm{OC}}$, and after 285 days stress is shown in Fig. 3-47. The addition of a sputtered $\mathrm{C}$ interfacial layer appears to improve the stability considerably, especially in reducing the number of shorted cells.

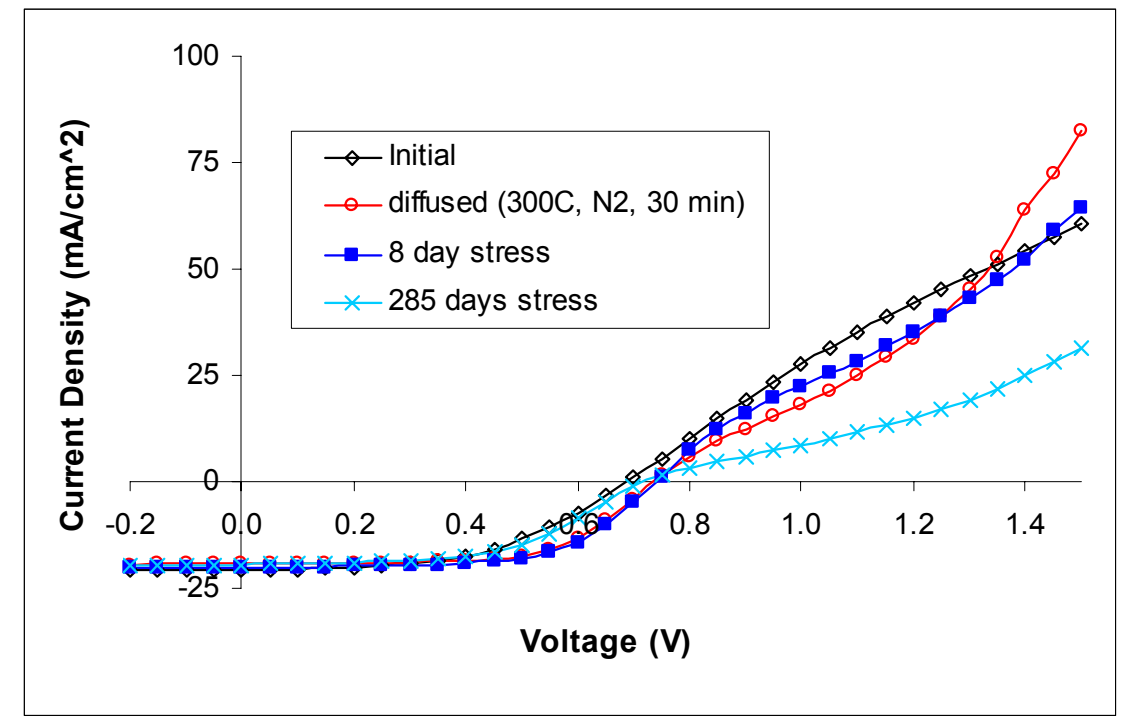

Fig. 3-47. I-V curves at one-sun illumination for C/NiP contacts, as deposited, after diffusion, after 8 days of stress and after 285 days of continuous stress.

In conclusion, the sputtered NiP contacts, as a copper-free back contact to CdTe, appear to show some promise, especially in terms of reasonably good stability. However, even with the use of an NP etch to create a Te-rich interfacial layer, we have been unable to avoid roll-over in the forward current, the best fill factors are only slightly above $60 \%$, and the open circuit voltage is limited to about $740 \mathrm{mV}$. (Perhaps the optimum process sequence or interfacial layer is yet to be found; however, it may be that we have reached the limitations of this material combination.) By contrast, our nitrogen-doped ZnTe back contacts (also Cu-free) have achieved fill factors of almost $69 \%$ although the voltage is even somewhat lower than for $\mathrm{NiP}\left(\mathrm{V}_{\mathrm{OC}} \leq 717 \mathrm{mV}\right)$. 


\subsection{REFERENCES}

[1] P.V. Meyers and H.S. Ullal, National CdTe R\&D Team Meeting Minutes, Thin-Film Photovoltaics Partnership Program, Golden, CO, January 25-26, 2001 (unpublished).

[2] J.R. Sites, Colorado State Univ. NREL subcontract report, Jan. 2000.

[3] AMPS-1D has been developed by the Penn State University and aimed at simulating semiconductor multilayer devices. It is available at http://www.psu.edu/dept/AMPS.

[4] Potter, M. D. G., D. P. Halliday, M. Cousins, K. Durose, Thin Solid Films, 361-362, 248 (2000).

[5] Diana Shvydka, K.J. Price, A.D. Compaan, "Absorption and photoluminescence studies of lightly alloyed $\mathrm{CdTe}(\mathrm{S})$ and $\mathrm{CdS}(\mathrm{Te})$, II-VI Compound Semiconductor Photovoltaic

Materials edited by R. Noufi, D. Lincot, and H.W. Schock [Mat. Res. Soc. Symp. Proc. 668, H6.2.1 (2001)]

[6] K. Price, "Effect of $\mathrm{CdCl}_{2}$ treatment on the interior of CdTe crystals," II-VI Compound Semiconductor Photovoltaic Materials edited by R. Noufi, D. Lincot, and H.W. Schock [Mat. Res. Soc. Symp. Proc. 668, H1.7.1 (2001)]

[7] Moutinho, H. R., M. M. Al-Jassim, D. H. Levi, P. C. Dippo, L. L. Kazmerski, J. Vac. Sci. Tech. A. 16, 1251 (1998).

[8] Moutinho, H. R., R. G. Dhere, M. M. Al-Jassim, D. H. Levi, L. L. Kazmerski J. Vac. Sci. Tech. A. 17, 1793 (1999).

[9] D. Grecu and A. D. Compaan, J. Appl. Phys. 87, 1722 (2000).

[10] T. Okamoto, Y. Matsuzaki, N. Amin, A. Yamada, M. Konagai, Jpn. J. Appl. Phys. 37, 3894 (1998).

[11] P. R. Edwards, S. A. Gallaway, K. Durose, Thin Solid Films, 361-362, 364 (2000).

[12] L. M. Woods, G. Y. Robinson, D. H. Levi, $28^{\text {th }}$ IEEE PVSC-2000, (IEEE Piscataway, N.J.) pp. 603-6.

[13] T. A. Gessert, A. Duda, S. E. Asher, C. Narayanswamy, D. Rose, Proc. $28^{\text {th }}$ IEEE Photovoltaic Specialists Conference-2000 (IEEE Piscataway, NJ.) pp. 654-7.

[14] D. Grecu, A. D. Compaan, D. Young, U. Jayamaha, D. H. Rose, J. Appl. Phys. 88, 2490 (2000).

[15] S. H. Wei, presentation at the National CdTe Team Meeting Minutes, Golden, CO, January 25-26, 2001.

[16] J. P. Chamonal, E. Molva, J. L. Pautrat, Solid State Comm, 43, 801 (1982).

[17] K. M. James , J. L. Merz, J. Vac. Sci. Tech. A, 6, 2664 (1988).

[18] J. P. Laurenti, G. Bastide, M. Rouzeyre, Solid State Comm, 67, 1127 (1988).

[19] B. K. Meyer, W. Stadler, D. M. Hofmann, P. Omling, D. Sinerius, K. W. Benz, J. Cryst. Growth 117, 656, (1992).

[20] S. Seto, A. Tanaka, Y. Masa, M. Kawashima, J. Cryst. Growth 117, p. 271, (1992)

[21] I. Matulionis, S. Han, J.A. Drayton, K.J. Price, and A.D. Compaan, "CdTe Solar Cells on Molybdenum Substrates," Mat. Res. Soc. Symp. Proc. 668, 2001

[22] X. Wu, J.C. Keane, R.G. Dhere, C. DeHart, D.S. Albin, A. Duda, T.A. Gessert, S. Asher, D.H. Levi, and P. Sheldon, $17^{\text {th }}$ European PVSEC, Munich, 22-26 Oct. 2001.

[23] R.C. Powell, R. Sasala, G. Rich, M. Steele, K. Bihn, N. Reiter, S. Cox, and G. Dorer, "Stability testing of CdTe/CdS thin-film photovoltaic modules", $25^{\text {th }}$ IEEE PVSC; p.785. 
[24] M. Shao, A. Fischer, D. Grecu, U. Jayamaha, E. Bykov, G. Contreras-Puente, R.G. Bohn, and A.D. Compaan, "Radio-frequency-magnetron-sputtered CdS/CdTe solar cells on sodalime glass," Appl. Phys. Lett. $\underline{69}$, 3045-3047 (1996).

[25] V.P.Singh, J.C.McClure, G.B.Lush, W.Wang, X.Wang, G.W.Thompson, and E.Clark. Solar Energy Materials and Solar Cells 59 (1999) 145-161.

[26] R.H. Bube, "Photovoltaic Materials", Imperial College Press, 1999.

[27] Jennifer Drayton, Akhlesh Gupta, Konstantin Makhrachev, Kent Price, Randy G. Bohn, and Alvin D. Compaan, "Properties of RF sputtered ZnTe:N films for back contact to CdS/CdTe solar cells", II-VI Compound Semiconductor Photovoltaic Materials edited by R. Noufi, D. Lincot, and H.W. Schock [Mat. Res. Soc. Symp. Proc. 668, H5.9.1 (2001)

[28] K. Makhratchev, K.J. Price, X. Ma, D.A. Simmons, J. Drayton, and A.D. Compaan, Proc. NCPV Program Review Meeting, April 16-19, 2000.

[29] A.D. Compaan, Z. Feng, G. Contreras-Puente, C. Narayanswamy, and A. Fischer, Mat. Res. Soc. Symp. Proc. 426, 367 (1996); A.D. Compaan, Z. Feng, G. Contreras-Puente, C. Narayanswamy, and A. Fischer, Mat. Res. Soc. Symp. Proc. 426, 367 (1996); A. Fischer, X. Deng, D. Grecu, K. Makhratchev, X. Ma, R. Wendt, D. Zuo, A.D. Compaan and R.G. Bohn, "Properties of $\mathrm{CdS}_{\mathrm{x}} \mathrm{Te}_{1-\mathrm{x}}$ Alloy Films," 26th IEEE Photovoltaic Specialists Conference-1997, pp. 447-450.

[30] A.D. Compaan, X. Deng, R.G. Bohn, "High Efficiency Thin Film CdTe and a-Si Based Solar Cells", Annual Report, 2000 [http://www.nrel.gov/publications/]

[31] X. Deng, official NREL test results: http://www.physics.utoledo.edu/ dengx/11point8.gif

[32] A. Gupta, I Matulionis, J. Drayton, and A.D. Compaan, "Effect of CdTe thickness reduction in high efficiency CdS/CdTe solar cells," II-VI Compound Semiconductor Photovoltaic Materials edited by R. Noufi, D. Lincot, and H.W. Schock [Mat. Res. Soc. Symp. Proc. 668, H6.4.1 (2001)]

[33] D. Rose, R. Powell, U. Jayamaha, M. Maltby, D. Giolando, A. McMaster, K. Kormanyos, G. Faykosh, J. Klopping and G. Dorer, Proc. $28^{\text {th }}$ IEEE Photovoltaic Specialists Conference-2000 (IEEE Piscataway, NJ.) pp. 428-31.

[34] C. Ferekides, J. Britt, Y. Ma, and L. Killian, Proc. $23^{\text {rd }}$ IEEE Photovoltaic Specialists Conf.-1993 (IEEE Piscataway, NJ.) p. 389.

[35] X. Wu, R. Ribelin, T.G. Dhere, D.S. Albin, T.A. Gessert, S. Asher, D.H. Levi, A. Mason, H.R. Moutinho and P. Sheldon, Proc. $28^{\text {th }}$ IEEE Photovoltaic Specialists Conference-2000 (IEEE Piscataway, NJ.) pp. 470-4

[36] D.W. Cunningham and D.E. Skinner, Apollo ${ }^{(\mathrm{R})}$ Thin Film Process Development: Phase 2 Technical Report, May 1999-April 2000. 36 pp.; NICH Report No. SR-520-28710 (available at www.nrel.gov).

[37] T.A. Gessert, A. Dude, S.E. Asher, C. Narayanswamy, and D. Rose, Proc. $28^{\text {th }}$ IEEE Photovoltaic Specialists Conference-2000 (IEEE Piscataway, NJ.) pp. 654-7.

[38] B.E. McCandless, R.W. Birkmire, D.G. Jensen, J.E. Phillips, and I. Youm, $14^{\text {th }}$ NREL/SNL Photovoltaics Progam Review, ed. by Witt, Al-Jassim, and Gee, p. 647 (1997) (AIP CP394).

[39] D. Mao, L.H. Feng, Y. Zhu, J. Tang, W. Song, R. Collins, D.L. Williamson, and J.U. Trefny, $13^{\text {th }}$ NREL Photovoltaics Program Review Meeting, AIP Conf. Proc. 353, p. 352 (1996).

[40] K.D. Dobson, I. Visoly-Fisher, R. Jayakrishnan, K. Gartsman, G. Hodes, \& D. Cahen, Mat. Res. Soc. Symp. Proc. 668, H8.24.1-6 (2001). 
[41] K. Makhratchev, K.J. Price, X. Ma, D.A. Simmons, J. Drayton, K. Ludwig, A. Gupta, R.G. Bohn, \& A.D. Compaan, "ZnTe:N Back Contacts to CdS/CdTe Solar Cells," $28^{\text {th }}$ IEEE Photovoltaic Specialists Conference-2000, pp. 475-478 (IEEE, Piscataway, N.J.)

[42] Proceedings of the 2001 NCPV Program Review Meeting, 14-17 October 2001, Lakewood, Colorado (CD-ROM). (2001). [http://pix.nrel.gov:8020/BASIS/nich/www/public/SDF]

[43] P.V. Meyers, $7^{\text {th }}$ European Photovoltaics Conference, October, 1986.

[44] C. Narayanswamy, T.A. Gessert, and S.E. Asher, NCPV Photovoltaics Program Review, ed. by M. Al-Jassim, J.P. Thornton, and J.M. Gee (AIP Conference Proceedings CP462), 1999, p. 248.

[45] S.E. Asher, F.S. Hasoon, T.A. Gessert, M.R. Young, P. Sheldon, J. Hiltner, J. Sites, "Determination of $\mathrm{Cu}$ in $\mathrm{CdTe} / \mathrm{CdS}$ Devices Before and After Accelerated Stress Testing," 28th IEEE Photovoltaic Specialists Conference--2000, IEEE, Piscataway, NJ; pp. 479-482.

[46] H. Haase, J. Qiu, J.M. DePuydt, and H. Cheng, Appl. Phys. Lett. 59, 1272 (1991).

[47] Y. Fan, J. Han, L. He, J. Saraie, R.L. Gunshor, M. Hagerott, H. Jeon, A.V. Nurmikko, G.C. Hua, and N. Otsuka, Appl. Phys. Lett 61, 3160 (1992); S. Kajima, H. Okuyama, Y. Sanaka, T. Kobayashi, S. Tomiya, and A. Ishibashi, Appl. Phys. Lett. 73, 235 (1998).

[48] D.B. Ingerly, Y. Chen, R.S. William, T. Takeuchi, and Y.A. Chang, Appl. Phys. Lett. 77, $382(2000)$ and references therein.

[49] T. Baron, K. Saminadyar, and N. Magnea, Appl. Phys. Lett. 83, 1354 (1998)

[50] R.G. Bohn, C.N. Tabory, C.Deak, M. Shao, A.D. Compaan, and N. Reiter, Proc. 24th IEEE Photovoltaic Specialists Conference 1994, pp. 354-356 (1995).

[51] Xianda Ma, MS Thesis, May, 1999 The University of Toledo (unpublished).

[52] A.D. Compaan, X. Deng, R.G. Bohn, "High Efficiency Thin Film CdTe and a-Si Based Solar Cells", Annual Technical Report, 1999. NREL Contract No. ZAF-8-17619-14.

[53] R.W.B. Pearse and A.G. Gaydon, The Identification of Molecular Spectra, $4^{\text {th }}$ ed, Chapman and Hall (London) pp. 217-229.

[54] D.C. Jordan, I.S.T. Tsong, D.J. Smith, B.J. Wilkins, and R.B. Doak, Appl. Phys. Lett. 77, 3030 (2000).

[55] M. Grun, A. Haury, J. Cibert, and A. Wasiela, J. Appl. Phys. 79, 7386 (1996).

[56] M.W. Wanlass, K.A. Emery, T.A. Gessert, G.S. Horner, C.R. Osterwald, and T.J. Coutts, Solar Cells 27, 191 (1989).

[57] D. Halliday, M.D.G. Potter, D.S. Boyle, and K. Durose, Mat. Res. Soc. Symp. Proc. 668, H1.8.1-6, 2001. 


\subsection{Publications}

\subsection{Refereed papers published or in press $(3 / 4 / 98-10 / 15 / 01)$ :}

1. A. Fischer, L. Anthony and A.D. Compaan, "Raman Analysis of Short-Range Clustering in Laser-Deposited $\mathrm{CdS}_{\mathrm{x}} \mathrm{Te}_{1-\mathrm{x}}$ Films," Appl. Phys. Lett. 72, 2559, (1998).

2. Y.L. Soo, S. Huang, Y.H. Kao, and A.D. Compaan, "Investigation of interface morphology and composition mixing in $\mathrm{CdTe} / \mathrm{CdS}$ heterojunction photovoltaic materials using synchrotron radiation," J. Appl. Phys. 83, 4173 (1998).

3. M. Tufino-Velazquez, G. Contreras-Puente, M.L. Albor-Aguilera, M.A. GonzalezTrujillo, and A.D. Compaan, "Thin Film Solar Cell Heterojunctions Deposited by rf Planar Magnetron Sputtering and HW-CVST," Proc. of the 14th Photovoltaic Solar Energy Conference of Europe (Barcelona, Spain-1997).

4. R. Wendt, A. Fischer, D. Grecu and A.D. Compaan, "Improvement of CdTe solar cell performance with discharge control during film deposition by magnetron sputtering," J. Appl. Phys. 84, 2920-2925 (1998).

5. R. Wendt, A.D. Compaan, D. Grecu, K. Makhratchev, X. Ma, and R.G. Bohn, "CdTe Cell Performance vs. Plasma Parameters during Magnetron Sputter Deposition," 2nd World Conference and Exhibition on Photovoltaic Solar Energy Conversion--proceedings (Vienna, Austria, 6-10 July 1998, paper VD5.13, [report EUR 18656 EN by the Joint Research Centre European Commission, Luxembourg, 1998], pp. 1059-62.

6. X. Deng, G. Miller, R. Wang, L. Xu, and A.D. Compaan, "Study of Sputter Deposition of ITO Films for a-Si:H n-i-p Solar Cells," 2nd World Conference and Exhibition on Photovoltaic Solar Energy Conversion--proceedings (Vienna, Austria, 6-10 July, 1998, paper VB5.22).[report EUR 18656 EN by the Joint Research Centre European Commission, Luxembourg, 1998], pp. 700-703

7. S. Huang, Y.L. Soo, Y.H. Kao, and A.D. Compaan, "Annealing effects and Te mixing in CdTe/CdS heterojunctions," Appl. Phys. Lett., 74, 218-220 (1999).

8. K. Wei, F.H. Pollak, J.L. Freeouf, D. Shvydka, and A.D. Compaan, "Optical Properties of $\mathrm{CdTe}_{1-\mathrm{x}} \mathrm{S}_{\mathrm{x}}(0 \leq \mathrm{x} \leq 1)$ : Experiment and Modeling," J. Appl. Phys. 85, 7418-7425 (1999)

9. A.D. Compaan, I Matulionis, and S. Nakade, "Lasers and Beam Delivery Options for Polycrystalline Thin-Film Scribing," NCPV Photovoltaics Program Review (AIP Conference Proceedings No. 462, 1999 ed. by M. Al-Jassim, J.P.Thornton, and J.M. Gee), pp. 42-47.

10. D. Grecu and A.D. Compaan, "Photoluminescence Study of Cu Diffusion in CdTe," NCPV Photovoltaics Program Review (AIP Conference Proceedings No. 462, 1999 ed. by M. Al-Jassim, J.P. Thornton, and J.M. Gee), pp. 224-229.

11. X. Deng, "Study of Triple-Junction Amorphous Silicon Alloy Solar Cells", NCPV Photovoltaics Program Review (AIP Conference Proceedings No. 462, 1999 ed. by M. Al-Jassim, J.P. Thornton, and J.M. Gee), pp. 297-302.

12. D. Grecu and A.D. Compaan, "Photoluminescence Study of Cu Diffusion and Electromigration in CdTe, Appl. Phys. Lett. 75, 361-3 (1999).

13. A.D. Compaan, J.R. Sites, R.W. Birkmire, C.S. Ferekides, and A.L. Fahrenbruch, "Critical Issues and Research Needs for CdTe-Based Solar Cells," Electrochemical Society Symposium Proceedings, ECS99-11, edited by V.J. Kapur, R.D. McConnell, D. 
Carlson, G.P. Ceasar, and A. Rohatgi (1999) pp.241-251."Photovoltaics for the $21^{\text {st }}$ Century" Seattle, WA, May, 1999.

14. X.B. Liao, J. Walker, and X. Deng, "Effect of buffer layers in narrow bandgap a-SiGe solar cells," in Amorphous and Heterogeneous Silicon Thin Fims-Fundamentals to Devices, MRS Symp. Proc. 557, 779 (1999).

15. Y.L. Soo, S. Huang, S. Kim, G. Kioseoglou, Y.H. Kao, A.D. Compaan, D. Grecu, and D. Albin, "Effects of heat treatment on diffusion of $\mathrm{Cu}$ atoms into CdTe single crystals," Appl. Phys. Letts. 76, 3729 (2000).

16. D. Grecu, A.D. Compaan, D. Young, U. Jayamaha, and D.H. Rose, "Photoluminescence of Cu-doped CdTe and related stability issues in CdS/CdTe solar cells," J. Appl. Phys. 88, 2490 (2000).

17. A.D. Compaan, I Matulionis, and S. Nakade, "Laser scribing of polycrystalline thin films," Optics and Lasers in Engineering 34 15-45 (2000).

18. K. Makhratchev, K.J. Price, X. Ma, D.A. Simmons, J. Drayton, K. Ludwig, A. Gupta, R.G. Bohn, \& A.D. Compaan, "ZnTe:N Back Contacts to CdS/CdTe Solar Cells," $28^{\text {th }}$ IEEE Photovoltaic Specialists Conference-2000, pp. 475-478 (IEEE, Piscataway, N.J.)

19. K.J. Price, D. Grecu, D. Shvydka, \& A.D. Compaan, "Photoluminescence of CdTe:Cu and CdS/Cu," $28^{\text {th }}$ IEEE Photovoltaic Specialists Conference-2000, pp. 658-661 (IEEE, Piscataway, N.J.).

20. J. Drayton, A. Gupta, K. Makhratchev, K.J. Price, R.G. Bohn, and A.D. Compaan, "Properties of RF Sputtered ZnTe:N for Back Contact to CdS/CdTe Solar Cells," Mat. Res. Soc. Symp. Proc. 668, H5.9.1, 2001

21. I. Matulionis, S. Han, J.A. Drayton, K.J. Price, and A.D. Compaan, "CdTe Solar Cells on Molybdenum Substrates," Mat. Res. Soc. Symp. Proc. 668, H8.23.1, 2001

22. D. Shvydka, A.D. Compaan, and K. J. Price, "Absorption and photoluminescence studies of lightly alloyed $\mathrm{CdTe}(\mathrm{S})$ and $\mathrm{CdS}(\mathrm{Te})$," Mat. Res. Soc. Symp. Proc. 668, H6.2.1, 2001

23. A. Gupta, I Matulionis, J. Drayton, and A.D. Compaan, "Effect of CdTe thickness reduction in high efficiency CdS/CdTe solar cells," II-VI Compound Semiconductor Photovoltaic Materials edited by R. Noufi, D. Lincot, and H.W. Schock [Mat. Res. Soc. Symp. Proc. 668, H6.4.1, (2001)].

24. A.D. Compaan, D. Shvydka, K.J. Price, A. Vasko, V.G. Karpov, "Bias-dependent luminescence in CdS/CdTe cells", National Center for Photovoltaics Program Review Meeting, Oct. 14-17, 2001 (Lakewood, CO.)

25. J. Drayton, C. Taylor, A. Gupta, R.G. Bohn, A.D. Compaan, B.E. McCandless, and D. Rose, "Optical, structural and transport properties of reactively sputtered ZnTe:N," National Center for Photovoltaics Program Review Meeting, Oct. 14-17, 2001 (Lakewood, CO)

26. Diana Shvydka, A. D. Compaan, and V. G. Karpov, "Nonlocal optical response in CdTe Photovoltaics", National Center for Photovoltaics Program Review Meeting, Oct. 14-17, 2001 (Lakewood, CO)

27. X. Deng and X.B. Liao, S. Han, H. Povolny and P. Agarwal, "Amorphous silicon and silicon germanium materials for high efficiency triple-junction solar cells", Solar Energy Materials \& Solar Cells, 62, 89 (2000).

28. H. Povolny, P. Agarwal, S. Han and X. Deng, "Comparison study of a-SiGe solar cells and materials deposited using different hydrogen dilution", in Amorphous and 
Heterogenous Silicon Thin Films-2000, ed. by H. Branz, R. Collins, S. Guha, H. Okamoto and M. Stuztzmann, 2000.

29. X. Deng, H. Povolny, S. Han and P. Agarwal, "Ultra-lightweight amorphous silicon solar cells deposited on $7.5 \mu \mathrm{m}$ thick stainless steel substrates", in Proceedings of $28^{\text {th }}$ IEEE Photovoltaic Specialist Conf. (2000).

30. P. Agarwal, H. Povolny, S. Han and X. Deng, "Study of a-SiGe:H films and n-i-p devices used in high-efficiency triple-junction solar cells", J. of Non-Cryst. Solids, 2001.

31. E.L. Miller, R.E. Rocheleau and X. Deng, "Design considerations for a hybrid amorphous silicon / photoelectrochemical multijunction cell for hydrogen production", to be submitted to Proc. of International Symposium on Solar Hydrogen Fuel Cells- 2001, August 26-30, 2001, Cancun, Mexico.

32. X. Deng, W. Wang, X. Liao, S. Han, H Povolny, X. Xiang, and W. Du, Proc. of NREL NCPV Program Review Meeting, 2001.

33. W. Wang, H. Povolny, W. Du, X.B. Liao and X. Deng, "Improved Triple-Junction a-Si Solar Cells with Heavily Doped Thin Interface Layers at the Tunnel Junctions", Proc. of IEEE $29^{\text {th }}$ Photovoltaic Specialist Conference, 2002.

34. X. Liao, H. Povolny, P. Agarwal and X. Deng, "Raman and IR Study of Narrow Bandgap a-SiGe and $\mu \mathrm{c}-\mathrm{SiGe}$ Films Deposited Using Different Hydrogen Dilution”, to be published in Proc. of IEEE 29 $9^{\text {th }}$ Photovoltaic Specialist Conference, 2002.

35. X.B. Liao, W. Wang and X. Deng, "AMPS Modeling of Nanocrystalline Si p-Layer in aSi NIP Solar Cells", to be published in Proc. of IEEE $29^{\text {th }}$ Photovoltaic Specialist Conference, 2002.

36. T. Smith, B. Friedmann, A. N. Witt, R. Wang, X. Deng and D. Furton, "Photoluminescence of carbonaceous grain mantle materials with silicon impurities", Proceedings of Laboratory Space Science Workshop, Harvard-Smithsonian Center for Astrophysics, April 1-3, 1998, p245.

37. S. Huang, Y.L. Soo, Y.H. Kao, W.A. Anderson, and X. Deng, "Interfacial roughness in thin film silicon photovoltaic materials", American Physical Society March Meeting, Atlanta, Georgia, March, 1999.

38. X. Deng, P. Agarwal, H. Povolny and S. Han, "Amorphous silicon germanium solar cells and thin films deposited using different hydrogen dilution”, in Proceedings of NCPV Program Review Meeting_-2000, A13 (2000).

\subsection{Annual Subcontract Reports:}

1. Compaan, A. D.; Deng, X.; Bohn, R. G. (1999). High Efficiency Thin Film CdTe and aSi Based Solar Cells: Annual Technical Report, March 4, 1998 - March 3, 1999. 68 pp.; NICH Report No. SR-520-27666. [Full manuscript available at http://www.nrel.gov/docs/fy00osti/27666.pdf]

2. Compaan, A. D.; Deng, X.; Bohn, R. G. (2001). High Efficiency Thin Film CdTe and aSi Based Solar Cells: Annual Technical Report, 4 March 1999 - 3 March 2000. 77 pp.; NICH Report No. SR-520-30739. [Full manuscript available at: http://www.nrel.gov/docs/fy01osti/30739.pdf] 


\subsection{Annual Contract Summary published in U.S. Dept. of Energy Photovoltaic}

Energy Program Contract Summary, FY 1999 [DOE/GO-102000-0976]:

1. Alvin D. Compaan, Xunming Deng, Randy G. Bohn, Xianbo Liao, Kent Price, Ronghua Wang, Greg Miller, James Walker, Dan Grecu, Ilvydas Matulionis, Xianda Ma, Diana Shvydka, Konstantin Makhratchev, Chitra Narayanswamy, "High Efficiency Thin-Film Cadmium Telluride and Amorphous Silicon Based Photovoltaic Cells," edited by McConnell, R. D.; Hansen, A. (1999). NCPV FY 1998 Annual Report. 572 pp.; NICH Report No. BK-210-25626 [Full text available at: http://www.nrel.gov/docs/fy99osti/25626.pdf]

2. A.D. Compaan and X. Deng, "High Efficiency Thin-Film Cadmium Telluride and Amorphous Silicon-Based Solar Cells," (Thin Film PV Partnership), p. 144 


\subsection{Project Personnel}

\subsection{Research professor/scientists}

Akhlesh Gupta (Ph.D. Indian Institute of Technology, Delhi)

Xianbo Liao (Institute of Semiconductors, Chinese Academy of Sciences) (5/98--)

\subsection{Postdoctoral Associates:}

Wenjing Wang (Ph.D. Chinese Academy of Sciences, 1994) (5/00-6/02)

WooGeun Lee (Ph.D., Pusan National Univ. Korea, 2000) (4/00-10/01)

Kent Price $\quad$ (Ph.D., U. of North Carolina, physics, 1998) (10/98-6/01)

Sijin Han (Ph.D., U. of Science and Technology of China, 1998) (12/98-12/00)

Pratima Aggarwal (Ph.D. Indian Institute of Technology, 1996) (2/99-6/00)

\subsection{Graduate Students:}

Ronghua Wang

M.S. completed May 1998: "Study of single-junction and triple-junction amorphous silicon based solar cells"

Greg Miller

M.S. completed August 1999: "Study of transparent conductive oxides in amorphous silicon based solar cells"

Shogo Nakade

M.S. completed Feb. 1999: "Time-Resolved Reflectivity Measurements on ThinFilm Photovoltaic Materials"

Chitra Narayanswamy

M.S. completed May 1999: "SIMS Analysis of Cu in ZnTe-Based Back Contacts for CdTe/CdS Solar Cells"

Xianda Ma

M.S. completed May 1999: "ZnTe:N Film as a Back Contact Material for Solar Cells"

Dan Grecu

M.S. completed 1998 (non thesis)

Ph.D. 1999: "Photoluminescence Study of Cu-doped CdTe and Related Stability Issues for CdS/CdTe Solar-Cell Devices" 
Ilvydas Matulionis

M.S. completed 1997 (non thesis)

Ph.D. spring 2002 "Superstrate and Substrate Type CdTe Solar Cells and Monolithic Integration of Photovoltaic Modules"

Diana Shvydka

M.S. completed 1999 (non thesis)

Ph.D. spring 2002 "Physical Characterization of CdTe/CdS Photovoltaics:

Defects, Fields, and Micrononuniformities"

Henry Povolny

M.S. spring 99, "Effects of Early Transition Metal Solutes on the DO3-B2

Critical Temperature of $\mathrm{Se}_{74} \mathrm{Al}_{14} \mathrm{Si}_{12}$ "

Ph.D. expected fall 2002

Wenhui Du

M.S. and Ph.D. in progress

Konstantin Makhratchev

M.S. June, 2000 "Optimization of CdS/CdTe Solar Cells"

Jennifer Drayton

M.S. and Ph.D. in progress

Catherine Taylor

M.S. in progress

Xiangxin Liu

M.S. and Ph.D. in progress

\section{$5.4 \quad$ Undergraduate and high school students}

\subsubsection{NSF Research Experiences for Undergraduates (REU)}

Summer 1998:

Jennifer Drayton, Univ. of Toledo "Quantum Efficiency Studies of CdTe Solar Cells"

Ray Kallaher "Study of Indium Tin Oxide as the Top Contact in Hydrogenated Amorphous Silicon Based Solar Cells"

\section{Summer 1999:}

Adam Smith, Michigan State Univ.

Catherine Taylor, Westminster College, New Wilmington, PA

Dave Simmons, (Research Experiences for Teachers), St. Johns Jesuit High

School, Toledo, $\mathrm{OH}$ 
Summer 2000:

Keith Ludwig, Univ. of St. Thomas, Minneapolis, MN

Summer 2001:

Brian Sunderland, Colorado College

Kathleen Hinko, Ohio State University

\subsubsection{Undergraduate summer 2001 assistant (hourly):}

Anthony Vasko (summer 2001)

Jonathan Smith "Cell Efficiency vs. CdTe thickness" (summer 1998)

\subsection{Technical Assistants}

Robert Burmeister (4/96- ) (25\% time)

Matt Fritts (10/01--) (50\% time) 


\section{REPORT DOCUMENTATION PAGE}

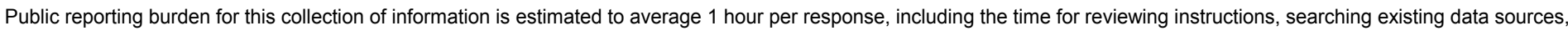

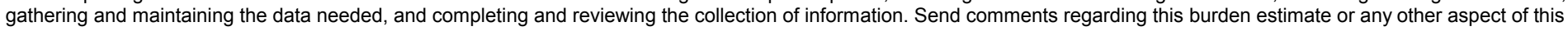

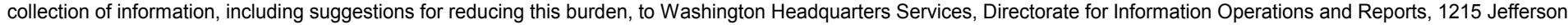

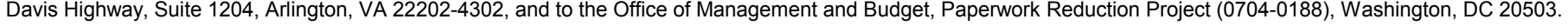

\begin{tabular}{|l|l|l|}
\hline 1. AGENCY USE ONLY (Leave blank) & $\begin{array}{l}\text { 2. REPORT DATE } \\
\text { October 2003 }\end{array}$ & $\begin{array}{l}\text { 3. REPORT TYPE AND DATES COVERED } \\
\text { Subcontract Report } \\
\text { 4 March 1998-15 October 2001 }\end{array}$ \\
\hline
\end{tabular}

4. TITLE AND SUBTITLE High Efficiency Thin Film CdTe and a-Si Based Solar Cells: Final Technical Report, 4 March 1998-15 October 2001

6. $\operatorname{AUTHOR}(\mathrm{S})$

A.D. Compaan, X. Deng, and R.G. Bohn

7. PERFORMING ORGANIZATION NAME(S) AND ADDRESS(ES)

Department of Physics and Astronomy

The University of Toledo

Toledo, Ohio 43606

9. SPONSORING/MONITORING AGENCY NAME(S) AND ADDRESS(ES)

National Renewable Energy Laboratory

1617 Cole Blvd.

Golden, CO 80401-3393

5. FUNDING NUMBERS

PVP35001

ZAF-8-17619-14

8. PERFORMING ORGANIZATION REPORT NUMBER

10. SPONSORING/MONITORING AGENCY REPORT NUMBER

NREL/SR-520-34822

11. SUPPLEMENTARY NOTES

NREL Technical Monitor: Bolko von Roedern

12a. DISTRIBUTION/AVAILABILITY STATEMENT National Technical Information Service

12b. DISTRIBUTION CODE

U.S. Department of Commerce

5285 Port Royal Road

Springfield, VA 22161

13. ABSTRACT (Maximum 200 words): This is the final report covering about 42 months of this subcontract for research on highefficiency CdTe-based thin-film solar cells and on high-efficiency a-Si-based thin-film solar cells. Phases I and II have been extensively covered in two Annual Reports. For this Final Report, highlights of the first two Phases will be provided and then detail will be given on the last year and a half of Phase III. The effort on CdTe-based materials is led by Prof. Compaan and emphasizes the use of sputter deposition of the semiconductor layers in the fabrication of CdS/CdTe cells. The effort on highefficiency a-Si materials is led by Prof. Deng and emphasizes plasma-enhanced chemical vapor deposition for cell fabrication with major efforts on triple-junction devices.

14. SUBJECT TERMS: PV; a-Si; solar cells; thin films; sputter deposition; plasma-enhanced; chemical vapor deposition (CVD); CdS/CdTe; laser scribing; triple-junction devices;

15. NUMBER OF PAGES

16. PRICE CODE

17. SECURITY CLASSIFICATION OF REPORT Unclassified
18. SECURITY CLASSIFICATION OF THIS PAGE Unclassified
19. SECURITY CLASSIFICATION OF ABSTRACT Unclassified
20. LIMITATION OF ABSTRACT

UL 